\title{
NUAULU SETTLEMENT AND ECOLOGY
}


The publication of this book was subsidized with a subvention from THE BRITISH ACADEMY 


\section{VER H A N D E L I N G E N}

VAN HET KONINKLIJK INSTITUUT

VOOR TAAL-, LAND- EN VOLKENKUNDE

\section{3}

ROY F. ELLEN

\section{NUAULU SETTLEMENT AND ECOLOGY}

AN APPROACH TO THE ENVIRONMENTAL RELATIONS OF AN EASTERN INDONESIAN COMMUNITY

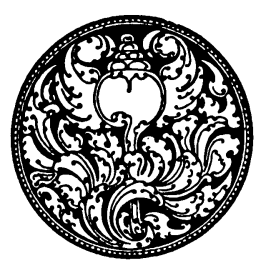


I.S.B.N. 90.247.2163.6 


\section{PREFACE}

This book originated as a thesis submitted for the degree of Doctor of Philosophy in the University of London. The fieldwork among the Nuaulu of Seram on which it is based was undertaken between December 1969 and May 1971, and again for three months in 1973, under the auspices of the Indonesian Academy of Sciences. During these periods I was supported by grants in aid from the Social Science Research Council, the Hayter Travel Awards scheme and the LondonCornell Project for East and Southeast Asian Studies, the Central Research Fund of the University of London, the Galton Foundation and the Department of Geography, Kings College London. The British Academy made a generous grant towards the cost of publication. To all these bodies I am most grateful.

Gratitude may be shown in many ways, but it is least served by lists which resemble telephone directories. Therefore, while my acknowledgements are not exhaustive, this does not indicate a lack of appreciation for the assistance kindly given me by many persons at various times, before, during and subsequent to fieldwork.

For identification of botanical specimens I am indebted to Mr. L. L. Forman of the Herbarium, the Royal Botanic Gardens, Kew, and Dr. Chang Kiaw Lan of the Botanic Gardens, Singapore. Dr. D. Brunsden of Kings College London kindly undertook the analysis of soil specimens. At various stages in the preparation of the manuscript I have benefited from the valuable help, criticism and advice of many people. I would like to single out for particular mention Biki Wilson and the staff of the London School of Economics drawing office, and James Woodburn for sustained support and careful assistance over five years. Stephen Morris, Paul Stirling and Peter Loizos have contributed in various ways to make this book a little better than it otherwise might have been. To Juliet Merrifield I am thankful for tolerance, hospitality and commonsense in the latter days. 
I am also appreciative of the assistance and kindness shown to me while undertaking fieldwork. In particular I would like to thank Mr. and Mrs. A. Myers Sahetapy-Warella and M. Resmol in Ambon; J. B. Letsoin (Kepala Kecamatan), Om Piet Tutuarima and his family in Amahai; Father Van der Bijl of the Pastoran Katolik, Masohi; and in Sepa, Bapak Raja, Oei Tjan Sun and Adam and Ali Tehurua. My degree of debt to the Nuaulu themselves is, of course, immense. Their hospitality and kindheartedness was very much more than I deserved. Because of this I am only too aware of the enormous responsibility which I have undertaken in claiming to have interpreted certain aspects of their way of life. I hope, therefore, that they will be my final critics.

Finally, a note on the content and structure of this book. It is an attempt at a systematic analysis of the settlement pattern of a small community in both sociological and ecological terms. While it claims to be sociological, it represents neither a study of a particular economic system nor a general ethnography. While it claims to be ecological, it suffers from the absence of the relevant detailed support studies in botanical ecology, dietary composition and energy expenditure. As such studies are at present unavailable for eastern Indonesia, I have been forced to rely on comparable research undertaken in these fields in Papua New Guinea. I have felt justified in doing this on account of the close ecological, subsistence economic and population biological similarities between the two areas. Furthermore, my concern in this work is not so much with precise nutritional and input-output calculations (although in the circumstances I have aimed at a high degree of accuracy), but rather with broad ratios. The practical difficulties in measuring energy flow for human communities under field conditions are considerable and often underestimated in studies of this kind, but I am satisfied that those errors which remain in my own measurements do not substantially affect the critical ratios I discuss.

\author{
R. F. E. \\ Eliot College, \\ University of Kent at Canterbury.
}




\section{CONTENTS}

Preface V

List of Tables $\quad$ VIII

List of Figures $\quad X$

List of Maps XI

Chapter I. Ecology, Generative Analysis and

Settlement Patterns 1

Chapter II. Nuaulu Ethnography and Environment 4

Chapter III. The Location and Structure of Nuaulu Villages 27

Chapter IV. Non-domesticated Resources and the Ecology of Settlement 61

Chapter V. Sources and Social Organization of Cultivated Land $\quad 81$

Chapter VI. Site Selection and Garden Preparation 108

Chapter VII. Garden Development and Ecological Succession 161

Chapter VIII. Analyzing Settlement: The Wider Relevance of the Nuaulu Case 190

Appendices

A. Local Climatic Data and Nuaulu Ecology 212

B. Local Minerals and Soils 215

C. A Note on Data Collection Relating to Land Holdings 220

D. Measurement of Consumption and Energy Expenditure 222

Orthography and Glossary $\quad 229$

List of Works Cited 234

Notes 243

$\begin{array}{ll}\text { Index } & 258\end{array}$ 


\section{TABLES}

1. Population densities for the central Moluccan region 4

2. Population of Seram by administrative districts 10

3. Population of Nuaulu villages 12

4. Distribution of Nuaulu clans according to villages 13

5. Basic Nuaulu land use categories 24

6. Density of population and dwellings in Nuaulu villages 44

7. Numerical composition of the household 48

8. Genealogical composition of the household 48

9. Mode of recruitment to household 49

10. Relationship category and type of marriage contracted 50

11. Residence pattern for all extant Nuaulu marriages 53

12. Differential exploitation of the non-domesticated environment 63

13. Catalogue of major sources of animal protein 70

14. Major non-domesticated plant resources of food energy and protein

15. Energy expenditure of males involved in exploitation of non-domesticated resources

16. Annual percentage of all new gardens cut from primary forest: some comparative Malayo-Oceanic data

17. Some numerical aspects of the relationship between wasi and nisi

18. Mode of acquisition of wasi, held in Ruhuwa in late 1970

19. Implications of various types of land transfer for vegetational cover

20. Vegetative status of land alienated to affines at time of transfer

21. Data on gardens cleared in Ruhuwa, 1969-70 and 1970-71 109

22. Areas of cultivation according to local categories of topography

23. Land within a four kilometre radius of Ruhuwa, classified to show relative accessibility 
24. Distribution of Ruhuwa land according to clan

25. Distribution of Ruhuwa land according to household

26. Movement of land between clans in Ruhuwa

27. Distribution of wasi with respect to distance from village

28. Distribution of wasi according to fifty-metre contourintervals

29. Household composition, size and number of garden huts

30. Main stages of the Nuaulu horticultural cycle

31. Sample crop-inventory for a single nisi honwe

32. Developmental history of a typical nisi honwe

33. The contribution of major domesticated plant resources to Nuaulu diet

34. Energy expenditure of males involved in the exploitation of domesticated resources

35. Total labour and energy expenditure of males involved in subsistence activities

36. Nisi honwe locations selected by one individual over a ten year period

37. Values for Ruhuwa carrying capacity under various conditions 183

38. Ruhuwa cultivated area in terms of garden types

39. Meteorological data recorded at Ruhuwa, 1970-71

40. Mean monthly rainfall over 25 years

41. Nuaulu mineral categories

42. Chemical analysis of Nuaulu soil samples

43. Composition of principal foodstuffs per 100 grams

44. Number of man-days devoted to various activities by mature males 


\section{FIGURES}

1. Possible permutations of Nuaulu clan segmentation 17

2. Interrelatedness of basic Nuaulu land-use categories 25

3. The arrangement of structures in four Nuaulu villages 35

4. Diagrammatic summary of the cosmological referents of village structure $\quad 40$

5. Exchange relationships and marital alliance 54

6. Processual sequence for land cleared from primary forest $\quad 89$

7. Distribution of wasi in terms of distance from Ruhuwa for each clan

8. Flow diagram illustrating the recent movement of land between clans

9. Time devoted to Ruhuwa garden activities in relation to rainfall

10. Generative processes resulting in the clustering of cultivated land around village

11. Summary flow diagram illustrating the principal possibilities for artificial vegetative successions

12. Succession possibilities in terms of Nuaulu vegetational categories

13. Amahai: mean monthly rainfall

14. Age and sex structure of Ruhuwa population 


\section{MAPS}

1. Seram and adjacent islands

2. Central Seram: present distribution of settlements and traditional ethnic groupings

3. Approximate distribution of Nuaulu clans and villages prior to their movement to the coast in the vicinity of Sepa

4. Nuaulu villages: their present location and immediate environs

5. Distances travelled by Ruhuwa Nuaulu

6. Ruhuwa: the village-plan and environs

7. The geographical limits of the Ruhuwa Nuaulu exploitative environment

8. Land holdings in the vicinity of Ruhuwa

9. The vicinity of Ruhuwa, showing all wasi for which ownership was recognized during 1970-71

10. Distribution of Ruhuwa wasi superimposed on land classified in terms of Nuaulu categories of topography

1. Distribution of Ruhuwa wasi according to clan

12. Some examples from the clan Nepane-tomoien of individual garden hut complexes

13. Distribution of Ruhuwa wasi in terms of the principal local categories of land use

14. Basic geological composition of the Ruhuwa Nuaulu exploitative environment 



\title{
CHAPTER I
}

\section{ECOLOGY, GENERATIVE ANALYSIS AND SETTLEMENT PATTERNS}

\begin{abstract}
Theories and models are invented by men because they are logically necessary for explanation. And the need for explanation results from the discovery of problems or of things to be explained. But problems do not usually arise unless those who discover them already have certain theories which lead them to problems. Thus, the nature of theories and models is intimately linked with the nature of the problems to which they give rise and give rise to them. (Cohen 1968: 15-16)
\end{abstract}

This book is about the pattern of settlement and ecology of the Nuaulu, a group of sedentary swidden ${ }^{1}$ cultivators and hunters of south central Seram. I hope, however, that it will have relevance for certain general problems. It has three interrelated aims: to describe and account for Nuaulu patterns of settlement; to attempt to outline and exemplify a suitable method of assessing the fine interaction of cultural and ecological variables in small-scale communities, and to explore the usefulness of a generative form of analysis in this respect. It makes no claims to be an exhaustive treatment of ecology and should be understood more as a systematic analytical account of settlement within a general ecological context. The conceptual framework is that of the ecosystem and all processes are seen in terms of their system-wide repercussions. There is no need to explain in detail this particular approach even if, as Vayda suggests (1968: xii), there has been a general reluctance to adopt such techniques. This has been done quite adequately elsewhere (e.g. Geertz 1963; Vayda 1965; Vayda and Rappaport 1968; Harris 1969), while I hope that its justification will become apparent in relation to the problems treated here.

One of the difficulties of a systems approach, in which the principal variables of interest represent the behaviour of men, is to recognise and adequately deal with what has become known as their 'duality' (Langton 1973: 132). All such systems can be seen as containing both 'things' and their images. The former are linked and articulated around flows of matter and energy, and the latter are linked by flows of information 
(Buckley 1967; Langton 1973: 132). It is the proximity and interrelatedness of these two fundamental processes in a human ecosystem which is my central concern here (c.f. Brookfield 1969: 62); and while the difficulties of incorporating the environment as it is perceived into an interpretative methodology are not to be underestimated, the problem should not be insuperable (Langton 1973: 133). While no claim is made here to resolve it, an attempt is made to tackle it and perhaps reduce the practical difficulties through the exploration of an example.

The theoretical roots of the approach adopted are to be found partly in the suggestions of Frederik Barth (1966) concerning the use of models of process rather than models of form, ${ }^{2}$ and partly in certain propositions made by Goodenough $(1956 ; 1957)$ and Frake (1962a). However, I am not suggesting that my own analysis corresponds either to Barth's particular conception of a generative model, or to the explicit kind of formalism displayed in the work of those who maintain that ethnographic description should resemble linguistic description. I have severe doubts about both the desirability and the possibility of such a programme of research (c.f. Keesing 1972). Rather it is the utility of focussing analysis on ecological and socio-ecological processes with which I am principally concerned, and both these recent attempts to formulate processual modes of analysis can be useful in the description and interpretation of Nuaulu settlement and ecology. On the other hand, these represent but particular variants and reformulations of existing processual and generative theories (Buckley 1967: 17-23). Thus, taking the Nuaulu settlement pattern - an artifact of a human-dominated ecosystem - as a unit of analysis, an attempt is made to explain the observed pattern in terms of the processes which generate it, and how these are influenced by both culturally ordered information, and noncultural matter and energy.

A critical factor which this form of analysis forces the investigator to consider is the role of indigenous decision-making behaviour, the rationale of resource evaluation and the available categories of choice. To some extent it must entail an ethno-ecological approach (Conklin 1957: 20) 1969: 221-31). A generative perspective enables the interaction of socio-ecological processes and the decision-making sequences in numerous cultural contexts to be evaluated, an interaction which generates the overall pattern of settlement.

It is argued that emphasis on process not only adds an analytical dimension to description but also allows for a more integrated approach. Seen in the context of earlier ecological analysis, it might also assist in 
rejecting the treatment of culture and environment as belonging to different and quite separate spheres and constructively integrate ecological variables with other socio-cultural variables. It is not the gross categories of environment and technology per se that are often critical in ecological enquiry, but rather the significant reticulation composed from them. 'To such gross questions', remarks Vayda, 'only gross answers can be given.' (1965: 3).

After the presentation of some basic introductory information, the Nuaulu analysis proceeds by first examining the residential component of the settlement pattern in terms of the processes which determine its location, form and composition. From this point of departure, the analysis then systematically investigates the role of non-domesticated resources in local ecology and the processes of settlement generation in the domesticated component of the Nuaulu environment. In the final section the general theoretical and methodological issues raised in the introduction are examined in the light of the preceeding analysis. At this juncture I feel it is more fitting to move directly to the substantive ethnography and then examine the merits of the mode of exposition, rather than begin with abstract theoretical discussion not rooted in the data. 
CHAPTER II

\section{NUAULU ETHNOGRAPHY AND ENVIRONMENT}

\section{Introduction}

The ethnographic study of Seram has had a long history - but the available data are still inadequate by the standards of present-day anthropology. European influence is usually reckoned as beginning around 1511-12 (Boxer 1965: 217-218; Cooley 1971: 178) with the first Portuguese voyages to the Indies. Further contacts were made particularly by the Dutch - resulting in settlements along the south coast in conjunction with the trade in cloves. ${ }^{1}$ Though the Dutch themselves became increasingly active, through the East India Company, the missions and latterly the government of the Netherlands East Indies, in general the most important contributions to our anthropological knowledge of the island were made by Germans. This tradition began with Bastian's Die Molukken (1884), but the first work of major importance came in 1918 with the publication of Tauern's Patasiwa und Patalima, which first drew attention to the two aspects of Seramese cultural organization which have continued to prove of interest and fascination to more recent students: the division of the island into the NINE and FIVE groups, Patasiwa and Patalima respectively, and the kakian initiation ceremonies. Duyvendak (1926) returned to the same themes and offered interpretations of a Durkheimian kind. His work is scholarly and useful, especially in view of the fact that the entire analysis was based upon literary sources. Duyvendak also offers a comprehensive review of the literature on Seram up until the time he was writing (1926: 1-9). However, by far the most careful and important researches to date have been those undertaken in west and central Seram by the Frobenius expedition of 1937-38, which include Jensen's account of Wemale religion (1948), Jensen and Niggemeyer's documentation of Seramese myths (1939) and Röder's work on the religious organization of the peoples of the Manusela region (1948). ${ }^{2}$

It is disappointing that very little attention has been paid to economic organization among the various peoples of the island. Martin, as long ago as 1894 , had described subsistence activities and their associated 
technologies to a limited extent. Recent writers have tended to pay only scant attention to the subject and sometimes avoided it altogether, devoting their attention to more elevated matters. ${ }^{3}$ But all this merely reflects a much more general neglect of the anthropological analysis of the economies of those communities dependent upon systems of swidden agriculture throughout Indonesia (Koentjaraningrat 1965: 316). While excellent field reports exist for certain other parts of Southeast Asia, for example Freeman's work on Iban agriculture (1955; 1970) and Conklin's (1957) on the Hanunoo, outer Indonesia, in which about $90 \%$ of the area under cultivation is worked by such methods (Geertz 1963: 13), is not represented by a single monograph. Almost $89 \%$ of the total area of Indonesia, approximately one-third of a population of some $122,663,000^{4}$ has been neglected in this way (Koentjaraningrat 1967: 387; also Dobby 1969: 349). The material presented here may begin to rectify this unsatisfactory situation.

\section{Seram: its environment and population}

Seram (MAP 1) is located in the central administrative division (Maluku Tengah) of the eastern Indonesian province of the Moluccas only three degrees south of the equator. It comes within the Southeast Asian monsoon area with a rainy season from May to August (Appendix A) and ecologically is part of the permanently humid tropics, though towards their southern limits (Fosberg, Garnier and Küchler 1961: 333-347). The vegetation is characteristic of the climate, reflecting the immense variety of the Southeast Asian region (Vavilov 1951: 29,44; Merrill 1954: 238). The greatest part of the island is covered in mature rain forest, largely of the Agathis type, with man-induced secondary forest and a limited amount of dry field and swidden cultivation located along the coast and around the numerous inland highland communities. Zoogeographically the area is important on account of its transitional and heterogenous nature, though the animal life can be said to be basically Melanesian (Brookfield with Hart 1971: 54). The low density of population (TABLE 1) has meant that there has been little succession to grasslands, the principal exceptions being the southeast corner of Seram together with the adjacent island of Geser. Almost all grassland that does exist appears to be the result of human impact (Fosberg 1962, Conklin 1959). The offshore islands of Ambon, Saparua, Haruku and Nusalaut, where the population densities are considerably greater, have extensive tracts of grassland and little rain forest. 


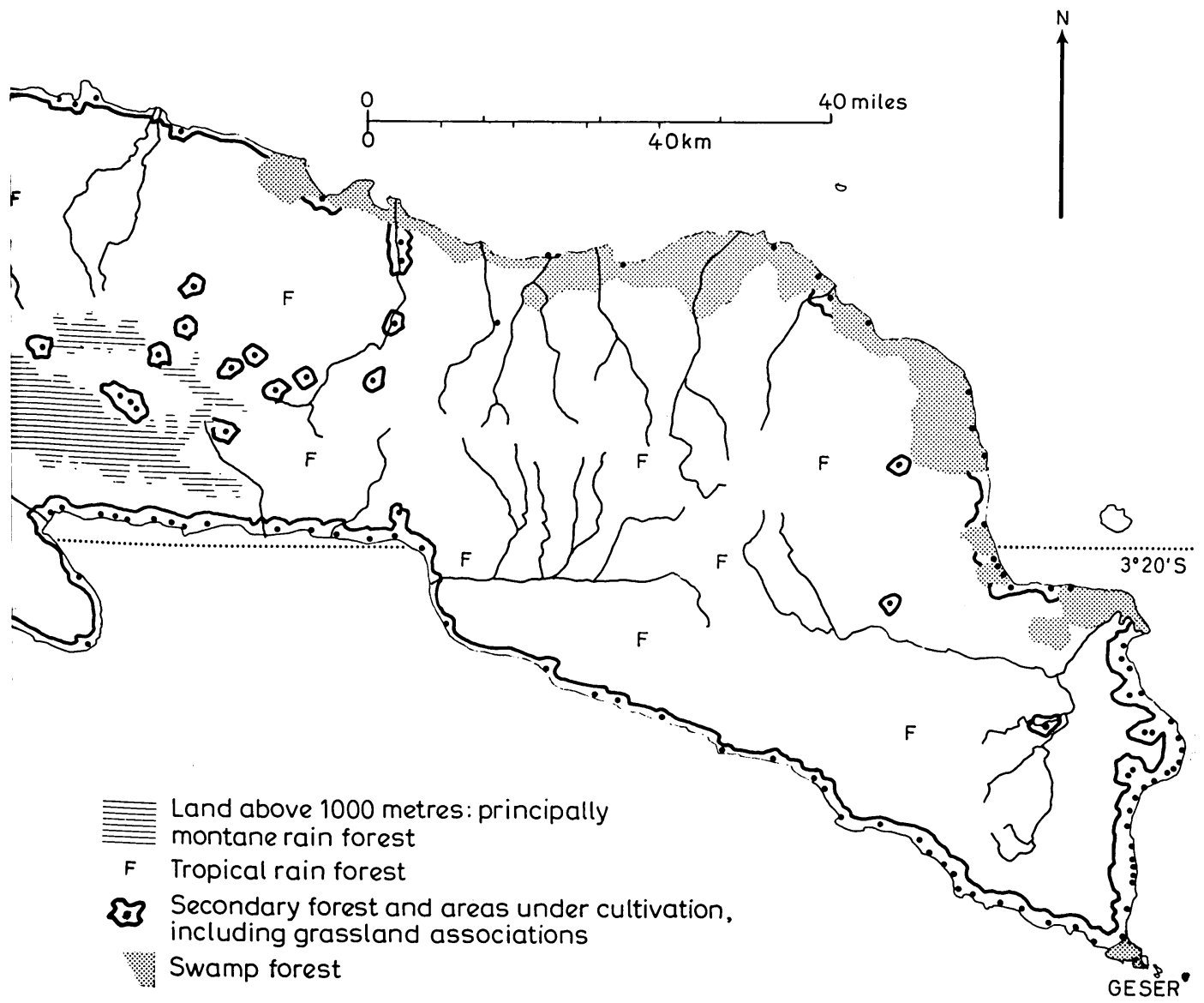

TABLE 1. Population densities for the central Moluccan region

\begin{tabular}{lcccc}
\hline & $\begin{array}{c}\text { Area } \\
\text { (in hectares) }\end{array}$ & Population & \multicolumn{2}{c}{$\begin{array}{c}\text { Population per hectare } \\
\text { (hectares per person in } \\
\text { brackets) }\end{array}$} \\
\hline Seram & $2,478,000$ & 164,626 & 0.07 & $(15,05)$ \\
Ambon & 80,000 & 193,729 & 2.42 & $(0.41)$ \\
Haruku & 19,000 & 19,805 & 0.96 & $(1.04)$ \\
Saparua & $16,000)$ & 40,450 & 0.47 & $(2.13)$ \\
Nusalaut & 3,000 I & 418,610 & 0.16 & $(6.18)$ \\
\hline Totals & 586,000 & & &
\end{tabular}




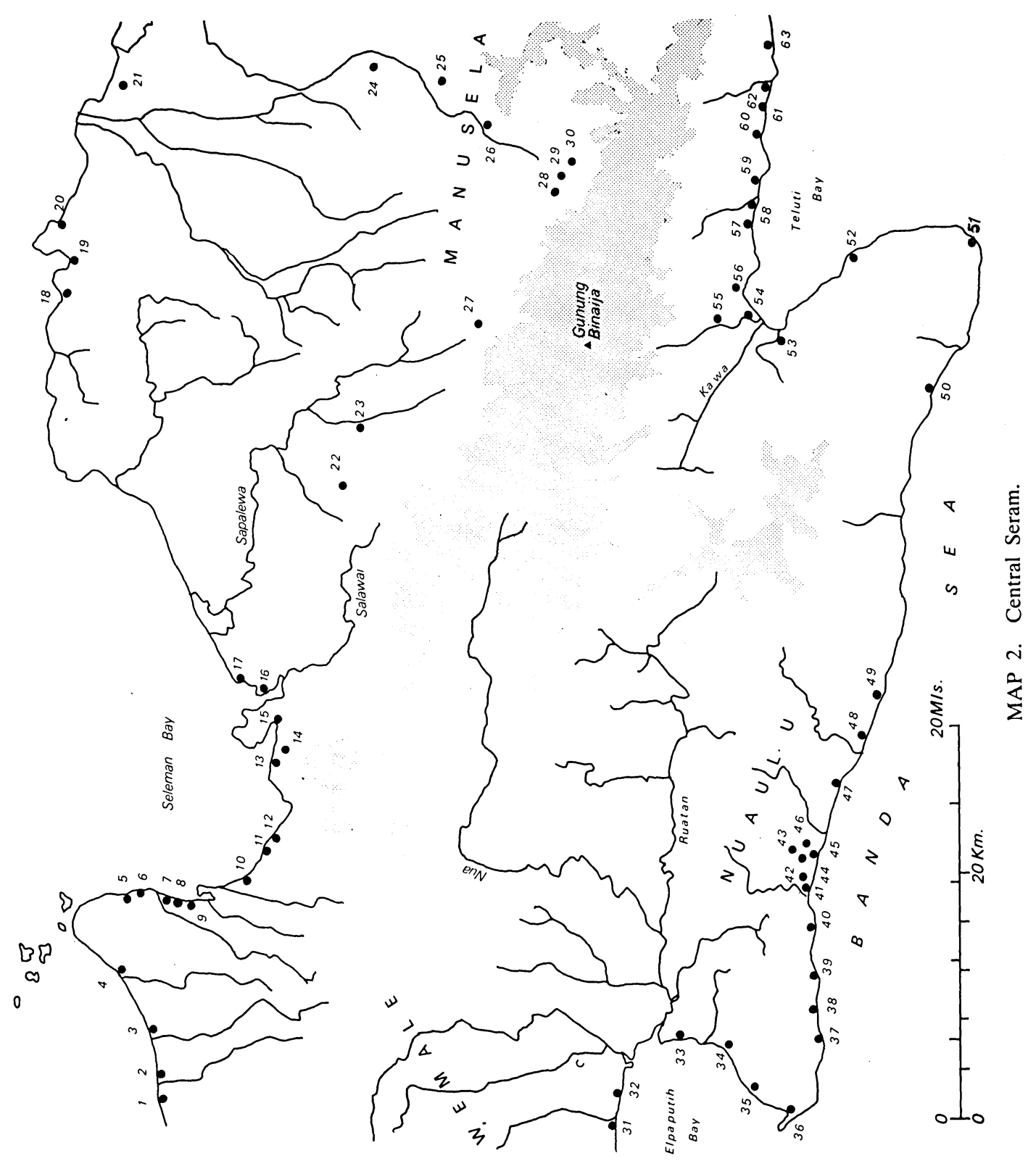


MAP 2. Central Seram: present distribution of settlements and traditional ethnic groupings. (Adapted from Topographische Dienst 1921, Eiland Seran en omliggende eilanden (Scale 1: 500000), Netherlands.)*

* The shaded areas represent land above the 1000 metre contour. The major settlements (numbered) are as follows:*
1. Lisabeta
2. Loon
3. Marehunu
4. Lisiela
5. Kalutu Kara
6. Paa
7. Pauni
8. Herelau
9. Wailulu
10. Iralerumah Real
11. Horale Kolalinje
12. Seleman
13. Rumah Sokal
14. Sawai
15. Rumah Olat
16. Besi
17. Opin
18. Wahai
19. Hatuola
20. Labuhan
21. Pasahari
22. Huaulu
23. Roho
24. Kaloa
25. Makualaina
26. Hatuila
27. Kanikeh
28. Mariana
29. Ilela
30. Manusela
31. Waija
32. Waraka
33. Makariki
34. Haruru
35. Masohi
36. Amahai
37. Ruta
38. Hururu
39. Jainwelo
40. Hatuheno
41. Nuelitetu
42. Bunara
43. Aihisuru
44. Watane
45. Sepa
46. Hahuwalan
47. Ruhuwa
48. Tamilau
49. Jalahatan
50. Suhulu
51. Haja
52. Tehoru
53. Ekano
54. Sahunulu
55. Peliana
56. Japutih
57. Hatu
58. Hatumetan
59. Mosso
60. Negriangus
61. Wolu
62. Lafa
63. Tehua

* Nuaulu villages are those italicized.

The population of Seram is mainly concentrated in the large Christian and Muslim settlements along the coast and is greater in the east (MAP 1 and TABLE 2). The communities of the interior tend to be smaller and the population very thinly spread, the most densely inhabited inland region at the present time being west Seram. Level coastal land is heavily cultivated with a considerable proportion devoted to coconut and cloves. The land rapidly steepens away from the shore line and even coastal communities are forced to cultivate gardens on the steep valley walls of the short rivers descending to the sea. In some localities there are more extensive areas of low-lying land, around the mouths of the rivers Kawa and Eti and in the vicinity of Kairatu in west Seram, around the mouth of the Ruatan on Elpaputih Bay, along the lower course of the river Bobot and for much of the north coast from Seleman Bay as far as the river Masiwang (MAPS 1 and 2). Some of this has been exploited for garden land and has succeeded to grassland. Other areas are too swampy and remain largely uncultivated, but a valuable source of naturally pro- 
pagated sago palms. Large parts of the highlands, particularly in the central part of the island, have been depopulated during the last 100 years, the inhabitants having resettled along the coast. This is dealt with more fully below and the problems surrounding demographic pressures on land and other scarce resources are treated in detail in subsequent chapters.

TABLE 2. Population of Seram by administrative districts

\begin{tabular}{lccc}
\hline & $\begin{array}{c}\text { No. of } \\
\text { settlements* }\end{array}$ & Population & $\begin{array}{c}\text { Mean pop. } \\
\text { per settlement }\end{array}$ \\
\hline East Seram & 37 & 41,218 & 1,114 \\
North Seram & 21 & 12,045 & 573 \\
Taniwel & 34 & 8,271 & 243 \\
Werinama & 34 & 6,165 & 181 \\
Amahai & 20 & 18,538 & 927 \\
West Seram & 64 & 39,300 & 614 \\
Kairatu & 29 & 19,208 & 662 \\
Tehoru & 20 & 15,282 & 764 \\
Bula & 20 & 4,599 & 230 \\
\hline Totals & 279 & 164,626 & 590 \\
\hline
\end{tabular}

* Each settlement corresponds to the Indonesian administrative unit of desa. Often, as in the Nuaulu case, a desa is composed of a number of quite separate hamlets.

Ethnic classification poses considerable difficulties and I have no intention of wrestling with the problems here (see, for example, Duyvendak 1926: 10-24). It has been usual in the past to distinguish between the so-called Malays (either Protestant Christian or Muslim) of the coast and the offshore islands, and the tribal Alifuru peoples, traditionally inhabiting the interior and consisting of a number of clearly and not-so-clearly identifiable tribal groupings. This is in many ways unsatisfactory as the coastal peoples possess a considerable cultural heritage in common with the Alifuru. Nevertheless, there are also significant differences in social and economic organization and here I will adopt the convention of using the term Ambonese to refer to the coastal peoples - particularly those found in the west and central parts of the island - in contrast to the Alifuru (ibid 10-11).

The ethnic designations for the Alifuru of central Seram given in MAP 2 accord approximately with the linguistic areas distinguished by Stresemann (1927), although village movement has somewhat obscured the picture over the past century. Indigenous Seramese languages are 
classed by Esser (1938) in an Ambon-Timor group of Austronesian languages and by Dyen (1965) in the Ambic sub-family of his Moluccan linkage. Ambonese Malay has long been the lingua franca and in some localities the local language is present in remnant form only.

\section{The Nuaulu: identification and internal organization}

Settlement and man-environment relations among the Nuaulu can only be understood in relation to the various groups and social relations which exist. In this section I begin by examining some general aspects of Nuaulu external relations in their historical context and make some preliminary remarks on internal groups and their structure, with particular emphasis on the ipan or clan.

The Nuaulu, together with a number of villages (such as Opin and Rumah Olat) on Seleman Bay on the north coast, have a population of in the region of 1,000 . They appear to represent a small but distinct cultural aggregate referred to in the literature as the Patakai. ${ }^{5}$ The Nuaulu themselves are one of only a few remaining Alifuru groups in which the local Malay dialect is not widely understood among adults. However, many individuals are competent in the indigenous languages of adjacent communities, such as Sepa and Nuelitetu (see MAP 2). The ethnographic record for these peoples is poor and fragmentary (e.g. Tichelman 1925).

At the present time there is little direct contact between the two Patakai groups (MAP 2). They are separated by the mountainous spine which runs for much of the length of the island, reaching its highest in the central region around Manusela and Gunung Binaija (3055 metres). Rumah Olat and Opin lie to the north in the Wahai (North Seram) administrative district, and the Nuaulu to the south in the administrative district of Amahai (Tichelman 1925). Formerly, the Nuaulu were located around the headwaters of the river Nua, hence their name - Nua (name of river), ulu (head) - although some clans were not actually in the drainage basin of the Nua. The approximate distribution of clans and their territories is given in MAP 3, as they existed prior to re-settlement. Both groups come within the hitherto imperfectly described Patalima division of the island.

The present pattern of village distribution is largely a result of Dutch colonial attempts to pacify and bring under greater governmental control the mountain peoples of central Seram at the time when the first formal administrative districts were established in 1882 (Sachse 1907: 
33). Pacification itself had been more or less achieved by 1910 , such that in 1914 the Dutch considered it possible to withdraw the garrison they held at Wahai (Naval Staff Intelligence Department 1918: 212, Seran 1922: 244). Through the intervention of the local rajas of the influencial Muslim settlements along the coast, and under some pressure, many Alifuru clans moved to areas nearer the coast. Nevertheless, this was only after visits to the coast for the purpose of trade had become commonplace and general hostilities had effectively ceased. Tichelman (1925: 659-661) reports that by 1925 no permanent mountain villages existed in the Amahai district, although some clans periodically occupied highland village sites in a clandestine fashion.

The new coastal villages were within relatively short distances of the settlements which theoretically exercised authority over them. Thus, the Nuaulu now constitute five settlements under the overlordship of the raja of the large Muslim village of Sepa: Bunura, Watane (Nuaulu lama), Aihisuru, Hahuwalan and Ruhuwa, with a total population of 496 individuals at the time of my census in 1970 (TABLE 3). The villages lie in the narrow coastal region, approximately where longitude $129^{\circ} 5^{\prime}$ east meets the south coast of the island. Since occupying these present locations, some Nuaulu have been absorbed into other coastal communities, through conversion to Christianity and Islam or by marriage. The most important villages in this respect are the large Muslim settlement of Sepa, the Christian villages of Hatuheno and Nuelitetu and the tribal village of Jalahatan, which, although related to the Nuaulu, are culturally and linguistically distinct (MAPS 2 and 4).

TABLE 3. Total population of Nuaulu villages, January 1971

\begin{tabular}{lclr}
\hline \multicolumn{2}{c}{ Administrative Unit } & & \multicolumn{2}{c}{ Local Group } \\
\hline Bunara & 150 & Bunara & 150 \\
Niamonai (Nuaulu lama) & 166 & Watane & 61 \\
& & Aihisuru & 44 \\
Ruhuwa & 180 & Hahuwalan & 61 \\
Total & 496 & Ruhuwa & 180 \\
\hline
\end{tabular}

In terms of the local Indonesian authority structure, the Nuaulu villages are part of the desa of Sepa, which in turn is part of the Amahai administrative district (kecamatan). Each Nuaulu administrative unit (TABLE 3 ) is customarily designated by the authorities a soa, with a 
headman (kepala soa) and one or two assistants, whose main prerogatives generally concern liaison with government officials, the raja of Sepa and the supervision of guests. The position, known by the Nuaulu as jonate aia, although hereditary, is not a traditional one, and the headman's authority - as far as the Nuaulu are concerned - is limited only to those affairs which they consider to come within his sphere of reference. Important ritual and other politico-jural authority is vested in clan chiefs and elders. The power of the raja of Sepa largely relates to the organization of such tasks as path-clearing, the arrangement of mutually beneficial measures of conservation (sasi), mediating in serious (usually intervillage) disputes and generally acting as an intermediary between the district administration and the Nuaulu.

TABLE 4. Distribution of Nuaulu clans according to villages

\begin{tabular}{|c|c|c|c|c|c|}
\hline & Bunara & Watane & Aihisuru & Hahuwalan & Ruhuwa \\
\hline Sonawe-aipura & + & & & & \\
\hline Sonawe-ainakahata & & + & + & & + \\
\hline Numanaita & + & & & & \\
\hline Pia & + & & & & \\
\hline Huri & + & & & & \\
\hline Somori & + & & & & + \\
\hline Sopanan & + & & & & \\
\hline Kamama & + & + & & & \\
\hline Penisa & + & + & & & + \\
\hline Matoke & & & + & & + \\
\hline Nepane-nesinopu & & & & + & \\
\hline Nepane-tomoien & + & + & & & + \\
\hline
\end{tabular}

Traditionally, the Nuaulu comprised geographically and politically autonomous patriclans or ipan, associated mythologically with a traditional place of origin; though during the last 100 years they have, on the whole, lost any geographical autonomy they once had (c.f. Tauern 1918: 127). Most villages now consist of a number of different clans, though each still retains considerable ritual and political autonomy. The continuing independence of the clan is expressed in the Nuaulu proverb - ipane osa nene, mansia panesi (literally: 'one clan has many/sufficient people'). It is said to correspond to the Malay proverb satu suku, satu bangsa (one clan, one people). Both signify the economic and political self-sufficiency of the clan unit. Each clan, which is exogamous and totemic, possesses extensive knowledge and legends concerning its own history and traditional territories in the mountains and localities of former villages are still known (MAP 3). 


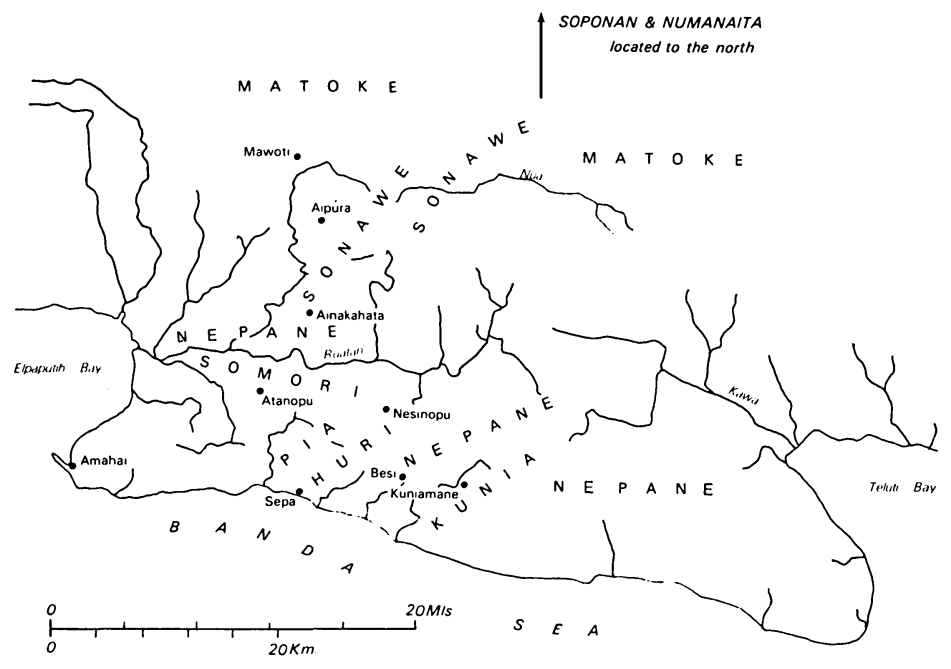

MAP 3. Approximate distribution of Nuaulu clans and villages prior to their movement to the coast in the vicinity of Sepa. (Based on information given by informants.)

TABLE 4 gives the distribution of Nuaulu clans according to village. The settlements of Watane, Aihisuru and Hahuwalan, as well as combining to form a single administrative unit, also form a common ritual community for certain festivals, largely those concerned with the village ritual house or suane. Consequently, though the clan Nepane-nesinopu is geographically distinct at Hahuwalan it has no more effective autonomy than any other. This larger entity, of which Hahuwalan forms part, is known as Niamonai (the old village), to distinguish it from the much more recent settlements of Ruhuwa and Bunara.

The Nuaulu use the term ipan for any one of the entries given in TABLE 4; each has a clan chief (jonate ipan), descended - at least theoretically - in the most senior genealogical line from the founding ancestor, and who is regarded as the custodian for the resources of the whole clan. As such, it is his duty to perform the necessary rituals, inaugurate sasi (ritualised measures of conservation) and the like, concerning the exploitation of these resources at the appropriate season. Also each ipan has a kapitane, traditionally the war leader. Each of these persons is head of one of two clan divisions: descent groups with certain ritual responsibilities to their own and the complementary division. The ipan therefore has a dual structure, each half being focussed on a ritual 
house (numa mone), either numa onate or numa kapitane, in which are kept sacred valuables and in which reside the spirits of the ancestors. Each numa mone has a sacred name. The jonate ipan or kapitane are not interchangeable in terms of either.status or role; both are equally necessary for the well-being of the clan.

All clans and their chiefs are theoretically of equal status, with the exception of the chief of the Matoke clan, who has particular status and duties by virtue of his patrilineal ancestor being the first mortal. In him is vested ritual guardianship of all land and the sacred suane. The translation of the Malay term tuan tanah, by which this office is generally known in the central Moluccas, is 'Lord of the Land'. Although this is not the literal meaning of the equivalent Nuaulu term and perhaps 'more grandiose than real' (Ter Haar 1948: 92), it does summarily indicate his role, and is therefore used interchangeable with jonate Matoke. In Bunara, where Matoke was not originally to be found, the chief of the Sonawe-aipura clan is invested with the title jonate Matoke Sonawe and performs the role of Lord of the Land in the village. However, the list given in TABLE 4 demands still further explanation, relating to the question of clan structure and segmentation (c.f. Tauern 1918: 127).

From what has already been said it is apparent that, for example, the ipan Somore in Bunara is a political entity distinct from the ipan Somore in Ruhuwa, though in the sense of having the same esoteric knowledge, taboos, totems and ritual practices the two are identical. They are genealogically related at a depth of only a few generations, and are consequently, in effect, unnamed subclans. A second kind of ipan that can be distinguished is the named subclan, such as Nepane-nesinopu or Sonawe-aipura. These represent separate ritual as well as political entities, though there may be certain ritual similarities between named subclans of a single clan, and their ultimate genealogical unity is acknowledged. The second part of the name usually refers to the locality of their ancestral village in the mountains (MAP 3). Named subclans may be divided into two or more unnamed subclan units. Thirdly, some clans remain unsegmented. In short, genealogical descent from a common male ancestor can be traced in the cases of unnamed subclans, all of relatively recent origin. Otherwise, individual clans or named subclan members claim descent with reference to a common village of origin. However, knowledge of individual ancestors usually only extends back three or four generations.

Binary fission of genealogical units usually occurs when one clan division - numa kapitane or numa onate - sets up residence in a different 
location, when it effectively becomes an unnamed subclan in its own right, ultimately forming the basis of two more clan divisions. The sacred name of its ritual house is retained, serving to distinguish it from its fraternal segment. The situation is exemplified by the segmentation of the clan Penisa, on the basis of clan divisions which existed until about 1930 , when one numa mone and his adherents shifted to the then new village of Ruhuwa:

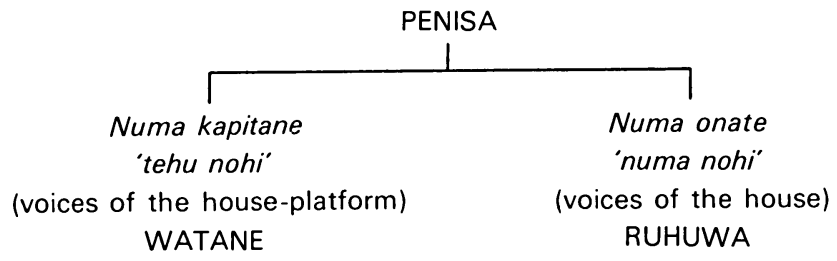

These in turn segmented to give four new clan divisions.

All possible permutations of Nuaulu clan segmentation, representing phases in developmental cycles, are shown in FIGURE 1. It is because of the variety of different forms taken by a clan in the course of its development that I have generally found it easier to use the terms 'clan' and ipan to cover all stages, rather than to talk of named and unnamed subclans. The latter have no basis in Nuaulu interpretation of their own clan organization and their use would only lead to confusion. Fission of genealogical units is discussed further in Chapter III in relation to village formation.

Clan members address one another by kinship terms, and clansmen in the same settlement often work together. To a considerable extent the localised clan regulates marriage, corporately approving or disapproving certain unions and negotiating bridewealth. Formerly, as well as being associated with a traditional place of origin, it controlled access to cleared land and secondary forest growth, fishing locations and hunting territory, as well as village land and numa mone with their associated valuables.

Every clan division contains one or more households (numa), usually an extended family unit, often with the husband of a married daughter resident. Such affines are subject to the immediate authority of the household head and may assist in certain ways in the ceremonial activities of their wives' clans, but in no real sense do they become ritually incorporated into that clan. All affinal alliances are important in Nuaulu social and economic organization, marriages being ideally 
contracted between bilateral cross-cousins, but more usually between persons not in a specified genealogical relationship.

FIGURE 1. Possible permutations of Nuaulu clan segmentation.

1.

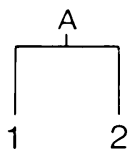

2.

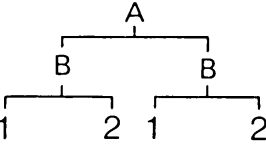

3.

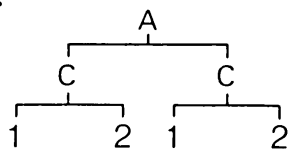

4.

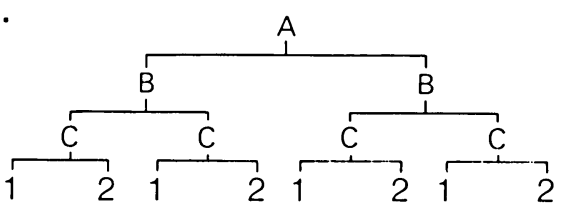

5.

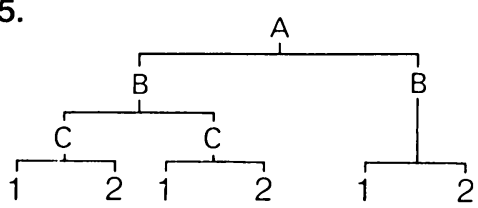

\section{A - named clan \\ B - named subclan ipan \\ C - un-named subclan \\ $1 \& 2$ - paired divisions - numa mone}

Despite the pattern of re-settlement and changes in local organization which have already been discussed briefly, the structure of Nuaulu subsistence remains essentially highland-oriented, in contrast to the partial trade and fishing economies of the Christian and Muslim communities along the coast. ${ }^{6}$ This may partly explain the retention and apparent dominance of clan organization and an essentially domestic mode of production. The tripartite highland subsistence pattern of swidden cultivation, hunting and collecting (especially naturally propagated sago and Canarium nuts) remains intact, with the addition of a few cash crops, principally in the form of coconut palms and clove trees. Nuaulu coconut and clove groves are very small compared with those of their Muslim neighbours. Their starch staple crops include sago, yams, manioc, taro, sweet potato and bananas, but the total number of types planted is considerable (Ellen 1973: 460-4).7 Game animals are principally wild pig, deer, cassowaries and cuscus, but a wide variety of other flesh is also consumed. The consumption of fish is of increasing significance. Permanent animal domestication is limited to dogs and chickens, though occasionally a wild piglet or small cassowary will be tamed and fattened. None of these are of great ecological significance except as very marginal consumers and scavengers. 


\section{External relationships}

In order to understand fully Nuaulu social and ecological organization at the present time it is important to consider those relationships existing between the Nuaulu and the longer established Muslim and Christian communities of the coast (c.f. Barth 1956; 1969: 9-38). MAP 4 illustrates the relative distribution for the Nuaulu and non-Nuaulu villages in the vicinity of Sepa.

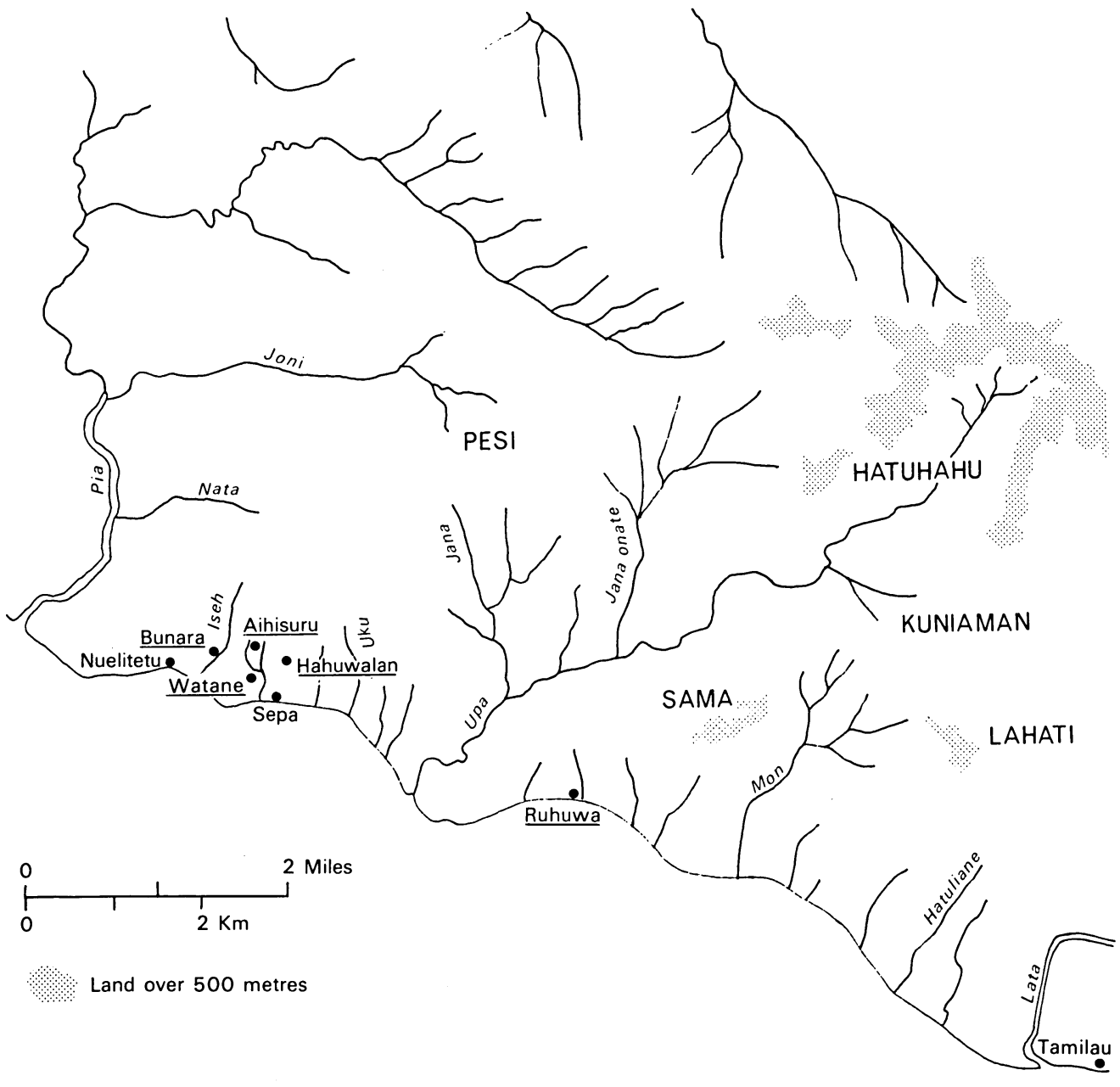

MAP 4. Nuaulu villages: their present location and immedicate environs. Names in upper case lettering indicate specific topographically-distinctive areas of forest distinguished andexploited by the Ruhuwa Nuaulu. Nuaulu villages are those underlined. 
Prior to the movement to the coast, the Nuaulu and coastal peoples occupied rather different ecological niches. At the present time there is an overlap in these due to the adoption by the Nuaulu of certain cash cropping practices and by virtue of competition for garden land and the resources of the forest. Land availability is important, for possession of land by the Muslim village of Sepa represents one of the most crucial factors determining land choice in any given year. The position with respect to land availability in the village of Ruhuwa is shown in MAP 7. All this means that in an analysis primarily concerned with the factors generating the Nuaulu pattern of settlement, some attention must also be paid to the exploitative processes and land use pattern of their neighbours. As with almost any other community, it is impossible to understand Nuaulu ecology in isolation - and not only ecology, for the essential 'opposition' between Nuaulu and Sepa is central to their whole way of life. The life-styles and communities are distinguished in terms of a wide variety of structural oppositions in Nuaulu thought and there are conflicts of interest and competition in numerous socio-economic spheres. Nevertheless, there are important respects in which the two communities rely on each other. From the Nuaulu point of view, Sepa is the focus of activities directed towards the outside world. Here copra and cloves can be exchanged for cloth, bush knife blades, soap and other trade goods. From the point of view of Sepa, the Nuaulu are (among other things) a source of land, forest and garden products, occasional labour and a market for some of their own surpluses.

The accepted ways in which Nuaulu may interact with members of other ethnic groups are through trade, restricted marriage, formerly in hostilities, nowadays through administrative politics and pela alliances between villages. Clearly, the significance of these various forms of contact is not simply dependent on frequency, but some approximate measure of the degree of interaction with other communities can be obtained by examining data on work scheduling (Appendix D). Of the 1,538 man-days for which information is available for Ruhuwa, 162 $(10.86 \%)$ were devoted to a variety of activities broadly classified as 'visiting'. While this term may conceal some quite specific subsistence activities (such as labour for kinsmen and pela partners) and visiting may also take place in connection with other activities, a few figures are worth presenting, if only to focus the discussion. The data, presented in terms of journeys to other villages, are set out graphically in MAP 5.

The figure for Amahai (and Masohi) is strikingly high, because Amahai is the sub-district government post and Masohi the capital of the 


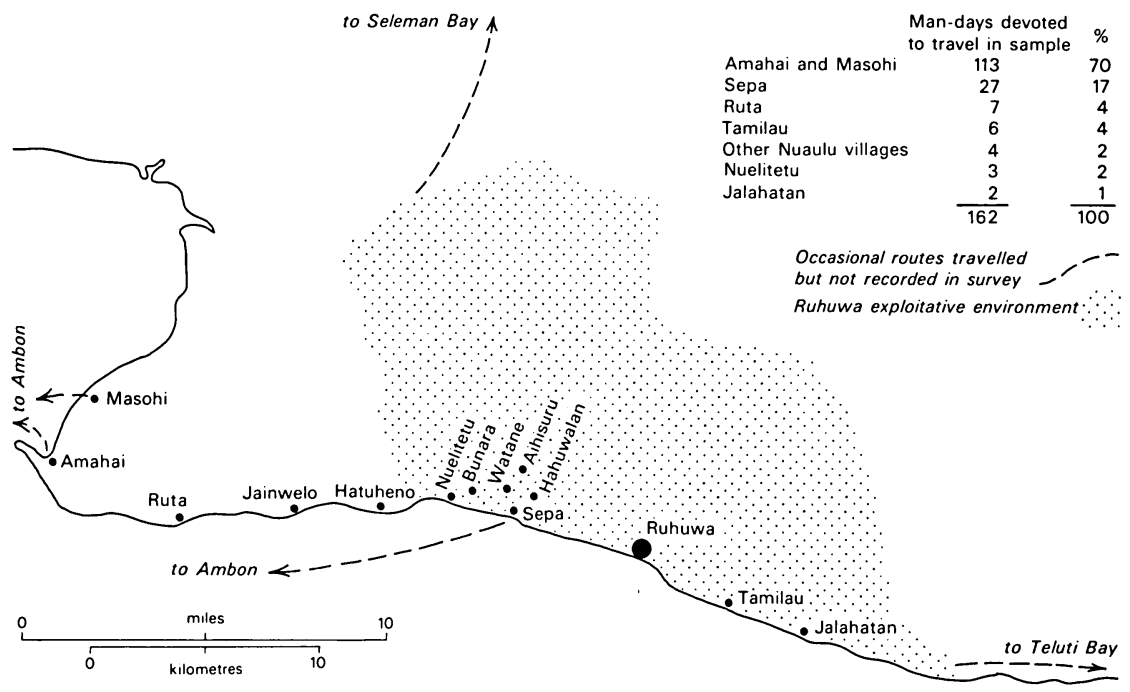

MAP 5. Distances travelled by Ruhuwa Nuaulu on other than purely subsistence activities. For an explanation of the sample used see page.

district (daerah) of the Central Moluccas. Most visits in the sample concerned attendance at national and local celebrations organised by the administration, visits in connection with other government, military or police matters and the occasional seeking of refuge from home disputes. Rarely is trade the proximate reason for going to Amahai, although visits may be exploited for this purpose. Occasionally there are visits from government officials, military or police patrols, but over and above this the amount of through traffic in Ruhuwa is still quite high, mainly because it is located on a major coastal path.

The figure for Sepa, in view of its proximity and strategic importance for the Nuaulu, is surprisingly low. However, it refers only to journeys specifically to this Muslim settlement, and conceals the quite high volume of interaction which takes place on visits to more distant locations, both those to other villages and while en route to or from hunting and collecting localities. This point is equally true for other places within the Ruhuwa exploitative environment - other Nuaulu villages and to a lesser extent Nuelitetu, Tamilau and Jalahatan. Even so there is less reason for Ruhuwa Nuaulu to frequent other Nuaulu villages (except of kinsmen) than to visit some non-Nuaulu villages which are important market and administrative centres. A further fact which the sample figure does not indicate is the location of Ruhuwa in an area with 
many Sepa gardens and groves, providing daily opportunities for trading and other contact. In contrast to interaction with Amahai, most relations with Sepa concern trade - the selling of copra and cloves in exchange for manufactured goods, and to a lesser extent administrative business such as dispute resolution and communal work.

Most interactions between Ruhuwa Nuaulu and other Nuaulu, and most with non-Nuaulu take place within their own exploitative environment. These include those based on affinal ties. Of the 28 extant marriages in Ruhuwa recorded in my 1970 census, 16 were with women from outside the village, 14 of which were from other Nuaulu villages and 2 of which were from Jalahatan. Only 1 male, a Kei Islander, had married into the village. Only one living person was known to have married out of the village, a widow who remarried a man of Jalahatan. There are 3 living converts to Islam from Ruhuwa, a single male now living in Sepa and a married couple in Ruta. An adopted youth from another Nuaulu village now living in Ruhuwa completes the list of permanent movements of personnel that I observed between Ruhuwa and the outside world in 1970. While inter-village kinship ties are important, in terms of the overall volume of interaction (as well as in terms of significant productive and exchange relationships) they may amount to very little.

All the external relationships so far discussed are within the Amahai administrative sub-district, but while contact with people outside this area may be infrequent, what does exist is both spatially extensive and historically important. The pela alliances between villages which have already been mentioned are just one aspect of this. These involve a kind of blood-brotherhood between villages, frequently far apart and ethnically distinct. Pela partners may seek assistance from each other in economic and political activities, but marriage between the communities is expressly forbidden. In addition to pela there are traditional relationships with other 'Patakai' speakers to the north of the island which involve occasional visiting, while some individual Nuaulu have travelled beyond Seram to Ambon and other places, usually to trade but sometimes simply for pleasure. In fact, while such long distance travel is probably quite recent in origin, there is a long history of contact between different ethnic groups, so that Nuaulu culture is both dependent on the acknowledgement of the existence of other groups and has been directly affected materially and ideologically by contact. Porcelain and other material items have been obtained through trading contacts (direct or indirect) with Chinese; contact with European culture and that of the 
Christian Ambonese since the seventeenth century resulted in the acquisition of other trade goods (such as firearms) and an acquaintance with Christianity and conversion; while contact with Muslim Malays, Bugis, Javanese and others was responsible for the Islamization of the surrounding area, the introduction of certain crops and animals, iron tools and so on. At the present time the principal trade goods in demand are valuables such as ornamented batik and kain timor textiles, a variety of luxuries including pottery, calico, clothing, crockery, jewellery and salt. Such things are obtained largely by the sale or exchange of copra and cloves.

\section{Cognitive approaches to Nuauı environmental relations}

The information on Nuaulu social relations presented above provides a necessary background to the analysis of settlement. It remains to augment this description with some general remarks on the Nuaulu conception of their relations with the total environment, the entire web of social, supernatural and biological relations in which an individual finds himself involved. This is a preliminary to the understanding of indigenous decision making as it relates to appropriational, locational and other economic questions involved in generating the local pattern of settlement. Having already mentioned something of external relationships, I shall begin with a model concerning Nuaulu behaviour with non-Nuaulu.

Although the Nuaulu are separate geographically and are culturally different in certain respects from northern speakers of the same language, they are united with them in contrast to all other peoples. Travel between them is not frequent but contact is maintained and as guests they are in a special position. They regard having the same language and many traditions and practices as being important unifying features. The grouping has no political significance, the traditional political unit being the clan. Nuaulu clans still maintain bonds with their fellows in some of the northern villages (e.g. Rumah Olat) and visiting clan-mates are accorded a special position as fellow kinsmen, addressing each other by using relationship terms. These attitudes transcend religious differences and it is said that the relationship between those still adhering to the tribal religion on the one hand and Christians and Muslims on the other is as the relationship between elder and younger brother.

In common with all other Alifuru, both sets of Patakai speakers, as members of the Patalima division of the island, see themselves in oppo- 
sition to those of the Patasiwa division. Many of the villages of Seram can be either ascribed to Patalima (F i v e D i v i s i o n) or to Patasiwa ( $\mathrm{N}$ in e Division), the former towards the east and the latter towards the west. They do not appear to represent tribal entities but rather communities within each division have quantifiable parts of ritual activities in terms of fives, nines or multiples of these numbers (Tauern 1918; Duyvendak 1926; Cooley 1962: 13-18). However, all Alifuru consider themselves as a single group in opposition to the coastal Ambonese, and at a higher level still, the Nuaulu identify themselves with the Ambonese vis-à-vis all peoples not obviously Seramese in origin.

This model of social interaction with non-Nuaulu is particularly interesting in that it exemplifies the familiar concentric conscious model, a community identifying itself with successively larger groups (Ward 1966: 206), combined with one built up by ascending oppositions between groups. These successive binary oppositions ultimately culminate in Nunusaku, the mythical waringin tree at the headwaters of the rivers Eti, Sapalewa and Tala in west Seram, in which all peoples who have ever lived are believed to have their origin.

The same two sets of principles which appear in the model of ethnic relations - concentrism and binary opposition - appear repeatedly in local classifications of social and natural space. They will be met with again when considering the ideological referents of village structure. Indeed, the model discussed above represents only one of a large number of similar interlinking devices which help explain environmental relations: models of genealogical relations, geographical orientation, overall cosmology, flora, fauna and so on. In most of these the mix of ideational, social and material elements is variable, although Nuaulu classifications of topography and vegetational associations are relatively distinct. $^{8}$ Various aspects of these systems will be considered in detail in what follows. Here the discussion is restricted to some brief generalities, but with particular attention to the classification of vegetational associations since this is highly relevant to the development of the analysis.

At the highest level, vegetation is classified by the Nuaulu simply into two contrasting categories, on the basis of whether or not it has been affected by man; thus there is forest (wesie), specifically 'empty forest' (wasi huje), in which no land rights are held, and land that is or has once been cultivated and in which certain rights are vested (wasi). The term wasi is polysemous, representing all cultivated land in opposition to wesie as well as individual social units of land: 


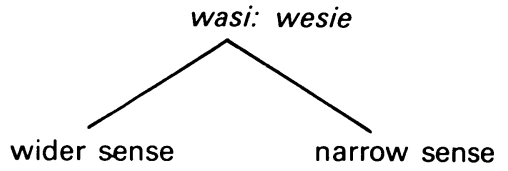

Wasi, therefore, is a general and jural term; individual areas of cultivation being known as nisi, which are in turn divided into three basic types:

(1) nisi honwe, a recently cleared garden plot up until the end of the first year;

(2) nisi monai, a garden after the first year, including sago, clove and coconut groves - each representing a separate sub-category and which may (as in the case of coconut) be up to 60 years old;

(3) nisi ahue, secondary growth of various kinds.

Definition of these categories is based in part on the state and content of the plot, and in part on the time period since it was first cleared. Thus, although the Nuaulu recognise many sub-varieties of terrain, their immediate environmental classification is constructed, with the addition of residential areas (niane), from a set of five contrasting categories which cover all culturally significant major vegetational and horticultural land surface types (TABLE 5). ${ }^{9}$

TABLE 5. Basic Nuaulu land use categories*

\begin{tabular}{|c|c|c|c|c|}
\hline Category & Gloss & $\begin{array}{c}\text { Estimated land area } \\
\text { (in hectares) within } \\
4 \mathrm{~km} \text { radius of } \\
\text { Ruhuwa (includes } \\
\text { Nuaulu and non- } \\
\text { Nuaulu land) }\end{array}$ & $\begin{array}{l}\text { Percentage } \\
\text { land area }\end{array}$ & $\begin{array}{c}\text { Chapter in } \\
\text { which cate- } \\
\text { gory is } \\
\text { analysed }\end{array}$ \\
\hline 1. nisi honwe & $\begin{array}{l}\text { newly cleared } \\
\text { garden land }\end{array}$ & 70 & 3 & 5,6 \\
\hline 2. nisi monai & $\begin{array}{l}\text { garden land, } \\
\text { after first year }\end{array}$ & 410 & 17 & 6,7 \\
\hline 3. nisi ahue & $\begin{array}{l}\text { discarded gardens, } \\
\text { secondary growth }\end{array}$ & 360 & 15 & 7 \\
\hline 4. wesie & $\begin{array}{l}\text { primary forest, } \\
\text { advanced second- } \\
\text { ary forest }\end{array}$ & 1410 & 58 & 4,5 \\
\hline \multirow[t]{2}{*}{ 5. niane } & village area & 180 & 7 & 3 \\
\hline & & 2430 & 100 & \\
\hline
\end{tabular}

* This table does not include the littoral: the area between high and low tides and the upper beach area, largely covered in kasitena nuai (Thespesia populnea). No individual or group rights are exercised with respect to this area. 
While contrast is emphasised in the ways in which the Nuaulu conceive land-man relationships, this does not mean that the dynamic successional relationships between the categories are ignored or not understood. It is the very fluidity of the boundaries of the categories and the concept of continua which a static model or classification fails to illustrate. This dynamic relationship between categories is shown in FIGURE 2. Thus the derivative nature of wasi from wesie, and both niane and nisi from wasi, and the ultimately cyclical nature of the system whereby wasi returns to wesie are recognised within a basic set of oppositions, in terms of land surface categories, but which also reflect oppositions of wider and more general cosmological and cognitive significance.

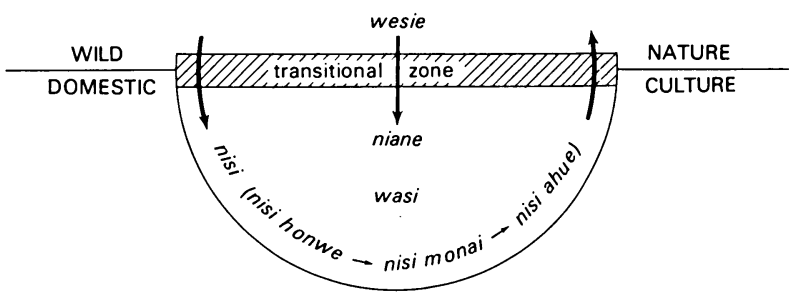

FIGURE 2. Interrelatedness of basic Nuaulu land-use categories.

Further, such an approach emphasises the extent to which culture is capable of altering natural processes. The Nuaulu environment can be manipulated both physically - with a sophisticated use of a limited technology - and ritually. While the efficacy of labour to this effect with purely human resources is recognised, only by magical participation can the effectiveness of the techniques employed be maximized.

Invocation to the ancestors and spirits is the main medium of magical manipulation, though a wide variety of different types of taboo signs and charms are an important subsidiary means of assistance, in preventing spirits and mortals from intervening harmfully in man-environment relations. Great care is also taken not to provoke supernatural interference, by performing rituals correctly, and avoiding damaging or felling trees or using land or materials believed to be the haunt of particularly vicious spirits. Augury does not modify the environment, but does add an extra dimension to the natural senses, so that an individual is better equipped to take individual decisions - a valuable addition to his assemblage of techniques for exploiting and regulating the environment around him.

A note might usefully be added at this stage on the value of using indigenous terms. It is true, as Conklin has adequately demonstrated (1957: 30 and passim), that the swidden cycle can only be precisely and 
succinctly described and analysed by the use of vernacular terms for garden and vegetation types, as these are very rarely translatable simply as brief glosses. On the other hand, it should be recognised that the adoption of this procedure is accompanied by certain problems, in particular the question of translatability of terms and the fact that over-use of such terms leads to confusion and stultification (Stauder 1971: 36). These matters are not discussed any further here, but each individual category will be explored later in some depth in relation to subsistence activities, succession and the generative processes of settlement. Some problems in the use of indigenous classifications are returned to in Chapter VIII.

Most of the material presented in this analysis relates specifically to the village of Ruhuwa, but the principles of organization elicited apply equally to other Nuaulu villages. Thus, if a settlement pattern is defined as the function of that environmental space in which a given population habitually interacts, then the Nuaulu area as a whole may be seen as a series of overlapping settlement patterns of individual villages. At another level it would be legitimate to discuss under the rubric of 'settlement pattern' the spatial dispersion of villages, say, on the entire island of Seram. This level of analysis is common to much work in economic geography. The present analysis concentrates on the more local level, although it is clear that the relation between the two cannot be entirely avoided.

As it stands, the definition of the Ruhuwa Nuaulu settlement pattern is very general, but it does contain within itself the first important analytical distinction which can be drawn. This is the distinction between residence and resource, where resources may take the form of energy, matter or information. For the purposes of analysis, Ruhuwa is taken as a single ecological population, a group constituting a unit in the energy exchanges with other populations and different species within its exploitative environment (c.f. Rappaport 1968: 32). Moreover, it is useful to see this area as composed of three concentric spaces of increasing size, the residential area, an inner area dominated by the exploitation of domesticated resources, and an outer area where man-environment interaction is more diffuse and dominated by hunting and collecting activities. Ruhuwa Nuaulu relations with groups outside their exploitative environment have already been briefly discussed. In the two chapters which follow the residential area and the outer area are dealt with successively. The remaining portion of the analysis is largely devoted to the examination of interactions in the inner sector. 
CHAPTER III

\section{THE LOCATION AND STRUCTURE OF NUAULU VILLAGES}

\section{Residence and resources}

The location of residential areas concerns the relationship between productive resources and units of consumption. In view of this, the ideal settlement layout should involve a minimization of the distance between the totality of all residences and the totality of all resources. In practice the degree to which this can be achieved is limited since resources are generally scattered and communities split up into discrete residential units, typically households. The spatial deployment of these units is very heavily dependent on political and other sociological factors.

In the Nuaulu case the minimal residential unit is the household (numa) and the basic localized resource the garden (nisi). The ideal relationship between the two might appear to be to locate the garden as near as possible to the household, or vice versa. Indeed, there are considerable pressures for the Nuaulu to do this. The sum total of these might be expressed formally as a minimum house-field distance rule. Frake (1962a) has shown for the Subanan of Mindanao a case where the pressures in favour of this rule, in terms of culturally specified priorities, outweigh those against it, such that the residence unit is actually located at an absolute minimum distance from the dry rice plots currently in use - inside them. This is consistent with the kind of social organization the Subanan display, focused as it is on the independence of the household within a system of bilateral descent. Among the Nuaulu the patriclan basis of social structure does not readily adapt itself to this formulation of the relationship between resources and residences. On the contrary, there are considerable pressures (commitment to corporate ritual, patriclan-structured kinship obligations, economic and other exchange relationships, and indeed the cosmological connotations of village arrangement itself), which are consistent with the placing of clan residential units together. The pressures for different clans to reside together are of relatively recent origin and the autonomy a clan possesses is still quite substantial. Indeed, for social relationships 
between members of the same clan and members of different ones the boundaries between villages become almost meaningless. That is, membership of a particular village does not necessarily determine behaviour between members of different Nuaulu formal groups. Nevertheless, it is only to be expected that bonds of cooperation between members of different formal groups, as members of a single local group, will increase as they become more politically and economically integrated into wider central Moluccan society. Consequently, there are traditional pressures agglomerating households into clan units and more recent pressures agglomerating clans into villages (niane), which might be expressed formally as a minimum residence-residence rule.

If it is not possible to fragment residential groupings in the interest of overall economy, then it might be expected that the village should represent the actual 'central point' of the entire pattern of settlement. This, after all, is in accordance with the axiomatic statement with which this chapter began. In the case of Ruhuwa the village probably does represent the centre point of the exploited environment as a whole, although in terms of the distribution of gardens this is far from being the case. By using principal access paths to gardens (MAP 8) as 'links' in a network I have calculated by means of a simple matrix (Hagget 1969: 634-8) that the actual central point of the area under cultivation lies in the vicinity of wasi 115 , at the point where the coastal path fords the Samna-ukuna river. This is some 0.6 kilometres east of the village. This very common situation whereby there is considerable divergence between the village and the actual centre of the settlement pattern has been discussed by Brookfield (1968: 427), and in the Nuaulu case provides some measure of the strength of the principle of minimum residence-residence distance (i.e. the maintenance of village centralism as opposed to dispersed households). This becomes even more striking when the mean centres and mean distances of the garden distributions for each clan are computed (MAP 10 and FIGURE 7). Such indices give some idea of the differential pressures acting against minimum residence-garden distance, although it should be borne in mind that the calculation of central points represents a measurement of distance only, and, as I hope to demonstrate, actual 'accessibility' is considerably more than a crude measure of linear proximity.

The reasons for this are explored in subsequent chapters, but it does throw into relief a basic problem for Nuaulu horticulturalists - the desire to utilize land as near as possible to the village and the difficulties involved in achieving it. In a sense, much of this monograph can be seen 
as an attempt to describe methods by which the Nuaulu resolve the conflict inherent between the two rules outlined above.

Given the village as the principal local group in Nuaulu settlement organization, however, it should not be forgotten that the very site chosen for a village must inevitably affect the total pattern of settlement, the land available for exploitation and the direction it takes. For instance, in siting villages directly on the coast (whatever other advantages may or may not accrue) the shape of the settlement pattern narrowly represented by the distribution of gardens - is immediately moulded to accord with the geographical situation presented. The same, of course, is true for the effect of any physical barrier to exploitative expansion.

In dealing with the location and structure of the Nuaulu village it is necessary to understand the pressures, environmental, ideological and organizational, which go to determine the form which Nuaulu patterns of residence take. But to begin with it is of some importance to consider the historical factors which affect the present location of Nuaulu settlement.

\section{Nuaulu villages prior to re-settlement}

It is not the intention here to consider in detail the factors affecting village location before Nuaulu re-settlement, but a cursory glance serves as a useful and necessary introduction to the present pattern of village distribution. Some of the more important villages and clan territories are shown in MAP 3, for the southern side of the central mountainous divide. ${ }^{1}$

It seems that location was primarily dictated by the elementary requirements of subsistence and convenience, with a certain regard for the requirements of social relations between mutually belligerent but intermarrying clan-hamlets. No villages, either formerly or at the present time, appear to have been located above 1000 metres (MAP 2), and all were therefore below the fringes of the montane rain forest. Villages were ideally situated on prominent well-drained land that might be conveniently defended, (though there is no evidence that any kind of fortifications were erected), but near to water, invariably on the right bank of the fast flowing tributaries to the major rivers, such as the Nua and Ruatan. The siting of villages on the right bank of a river is still the case and is due to the propitiousness of the right hand in Nuaulu thought. It seems that villages were never directly located on the banks of these larger rivers, which are often swampy malarial areas. The distance 
between villages was considerable, often as much as 15 kilometres, measured orthographically. Each clan-hamlet claimed certain rights over cleared land and secondary growth forest, fishing locations and hunting territory.

Settlement distribution may also have been in some way related to the groupings of Patalima and Patasiwa. At the present time migration and admixture has meant that there are considerable irregularities in the distribution of villages claiming allegiance to one or other of these groupings, but, as has been suggested, there appears to have been a territorial basis for these divisions, though what little evidence we have suggests that these were of little indigenous political significance (see above pp. 22-23). If this is correct then Patalima Nuaulu would have been restricted in their movements westwards. This may also have some bearing, together with the historical data available, on more recent Nuaulu clan movements, which appear to have been essentially southwards and eastwards. ${ }^{2}$

\section{Historical origins of village distribution}

Any consideration of the situation as it exists at present must begin with the political and environmental conditions which prevailed along the south coastal region, in the vicinity of Sepa, during the period when the Nuaulu were descending from the highlands. This probably relates to the period of the formation of the first administrative districts, around 1882 (Sachse 1907: 32), or possibly even earlier. For the first clear historical documentation for permanent Nuaulu villages in the highlands it is necessary to go back to a map in the Atlas van Oost-Indiën (published between 1735 and 1747), which shows a number of localities in the central highlands labelled as Nuaulu. Unfortunately, and as far as I am aware, there are very few written records providing detailed information on the re-settlement of tribal peoples in Seram as a whole, let alone for the Nuaulu in particular. I have therefore had to rely heavily on the statements of living informants.

There can be no doubt that the Nuaulu were subject to a certain degree of pressure (for administrative reasons and in order to facilitate trade) to site villages relatively near the communities that had putative authority over them. The absence of relevant historical documents makes it impossible to judge the exact form which this took. There was probably a mutual desire to have the re-settled villages not too close to existing settlements, through mutual fear, the continuance of hostilities and head-hunting on a reduced scale and, certainly in the case of 
Muslims, a fear of ritual contamination. Moreover, the retention of a minimum distance between the Nuaulu and other villages was related to the availability of suitable lands, although it is known that as late as the 1930s areas of mature forest still stretched as far as the shoreline. This is reflected, to a certain extent, in the distribution of landholdings in some Nuaulu villages. ${ }^{3}$

Since the movement from the highlands there has been an increase in population leading to the establishment of new villages. This process is at least partly related to the population/cultivable land ratio, though also to inter-clan and clan-segment conflict. The permanence and size of villages, as is general throughout much of Seram, is closely related to the extensive and elaborate use of garden huts. This is explored in depth in Chapter VI.

\section{The present location of Nuaulu villages 4}

Some attention has already been paid to the general pressures leading to the movement of the Nuaulu in toto to the coastal area around Sepa, and some indication given as to the kind of social pressures which were contingent to the siting of Nuaulu villages in their present localities. But what were the particular factors generating the location of extant Nuaulu villages (MAP 4)?

The first Nuaulu coastal settlements appear to have been simultaneously at Aihisuru (literally, 'the tree of Hisuru') and Watane ('flat place'). These two hamlets, together with Hahuwalan ('the pig of Walan') it will be recalled, constitute Niamonai, the 'old village' or, in Malay, 'kampong lama'. Naurita, the Lord of the Land in Aihisuru and the recognized ritual senior of all Nuaulu, explained to me that the splitting of the settlement into two parts, one mountain-ward (Aihisuru) and one seaward (Watane), was a conscious decision of compromise. Apparently, there was considerable fear of government authority, the missions, police and enforced schooling; and with an arrangement of this kind they were able to retain a certain degree of independence, isolation and protection. While bowing reluctantly to the authority of Sepa, ${ }^{5}$ they were careful that the mountainward villages should be sited on precipitous terrain some distance above the host village, hoping that it would thus obtain something of the autonomy isolation brings, and secure the protection which the location offered. Later, the same reasoning seems to have been applied in the location of Hahuwalan, ${ }^{6}$ and the principle appears to have been also adopted in other similar cases of re-settlement of tribal peoples from the interior. ${ }^{?}$ 
The movement of Nuaulu clans to the coast was a gradual and irregular operation, the first to arrive and settle being the clans Somori from Atanupa and Sonawe-aipura. Among the last to arrive were Sopanan and Nepane-tomoien, which, as has been noted elsewhere, had already spent a period of time further east. By the time all clans had descended, the area of Nuaulu settlement was said to have been considerable, occupying a large triangular area between the present locations of Aihisuru, Watane and Bunara.

Ruhuwa, some 3.5 kilometres east of Sepa, appears to have come into existence around 1930, when Nauhua, the father of Tapone (the present head of the Sonawe-ainakahata clan) was forced to leave Niamonai on account of a disapproved marriage. ${ }^{8}$ Subsequently, and for a diversity of reasons, segments of other clans - typically based on a single numa mone - joined the Sonawe settlement. With the movement of a segment of the Matoke clan to Ruhuwa an important structural problem arose, in that there now existed two separate but unnamed subclans of the senior clan, each of whose chiefs was a Lord of the Land. Previously there had been only one among the entire Nuaulu. The problem was in part resolved by recognizing the jurisdiction of each one with respect to his own village, but nevertheless retaining the overall ritual hegemony of the Lord of the Land in Aihisuru. The Aihisuru clan became known as Matoke hanaie (MALE) and that of Ruhuwa Matoke pina (FEMALE); the former the elder and the superior, the latter the younger and inferior, in possession of a somewhat different esoteric knowledge and body of ritual prohibitions and powers.

The most recent Nuaulu village, Bunara, has effectively come into being during the last decade. The manifest cause, according to many of the present inhabitants, was that the clans which made the move were concerned with the high death-rate and incidence of sickness among their members. This they attributed to malice shown towards them by members of other clans, expressed through sorcery. Evidently, this was also connected with social tension between clans. Maybe even the general close proximity of many of the inhabitants had the effect of promoting unhealthy conditions. ${ }^{9}$

In summary, the present location of Nuaulu villages has been largely determined by two basic outside pressures, (a) the political hegemony of the raja of Sepa in conjunction with Dutch colonial government requirements for pacification and administration and (b) the actual area of land available for re-settlement along the coast. The former has led to the establishment of new political/administrative units, as in the imposition 
of the concept of soa, the use of census units and the creation of village officials. This has tended to obscure traditional socio-political complexity. On the part of the Nuaulu there was a tendency to conform to what was absolutely minimally necessary in these respects, while precise location was effectively tempered by ideological and physical factors. The most important changes affecting the shape of the Nuaulu settlement pattern, apart from the external factors mentioned, but a direct result of them, were the agglomeration of different clans into multi-clan villages; the location on or near important paths and the proximity of large trading settlements providing the stimulus to plant cash crops and participate in the coastal economy; and finally the fact that the Pax Neerlandica meant that defence was no longer a significant consideration.

At the present time the expansion of old village sites or the establishment of new ones is still hampered by land availability and political constraints. In fact, conditions are much more difficult now than they must have been earlier. Nowadays, expansion is prevented by the presence of extensive grovelands of coconut, while, except during periods of political instability, such as the Republik Maluku Selatan period (see footnote 4), the re-occupation of mountain villages would be prohibited by the district authorities and not altogether welcomed by the Nuaulu themselves who are now increasingly being incorporated into the wider central Moluccan society and economy.

\section{Environmental determinants of village location}

The factors involved in the disposition of villages so far examined are broadly 'social'. This does not necessarily imply any historical or analytical priority, but rather stresses the importance of viewing environmental constraints in the context of recent history and contemporary social relations.

With environmental factors the material is familiar: villages must be built in areas within certain environmental and physical limits, dependent on the technological repertoire available to exploit that environment. In the Nuaulu case such limits are wide, only the most extreme terrains being completely avoided, such as swampland, land subject to periodic flooding, exceptionally steep land, rock outcrops and locations without reasonable access to water. Villages are located both on the narrow coastal strip (Watane, Bunara, Ruhuwa), and in the rocky hinterland between 150 and 200 metres above sea-level (Aihisuru and Hahuwalan). The respective terrains are as follows: the latter limited by 
a rocky and uneven surface with a thin soil, characterized by an irregular village layout; and the former, sandy and level with relatively abundant space, allowing for a regular layout (MAP 6 and FIG. 3).

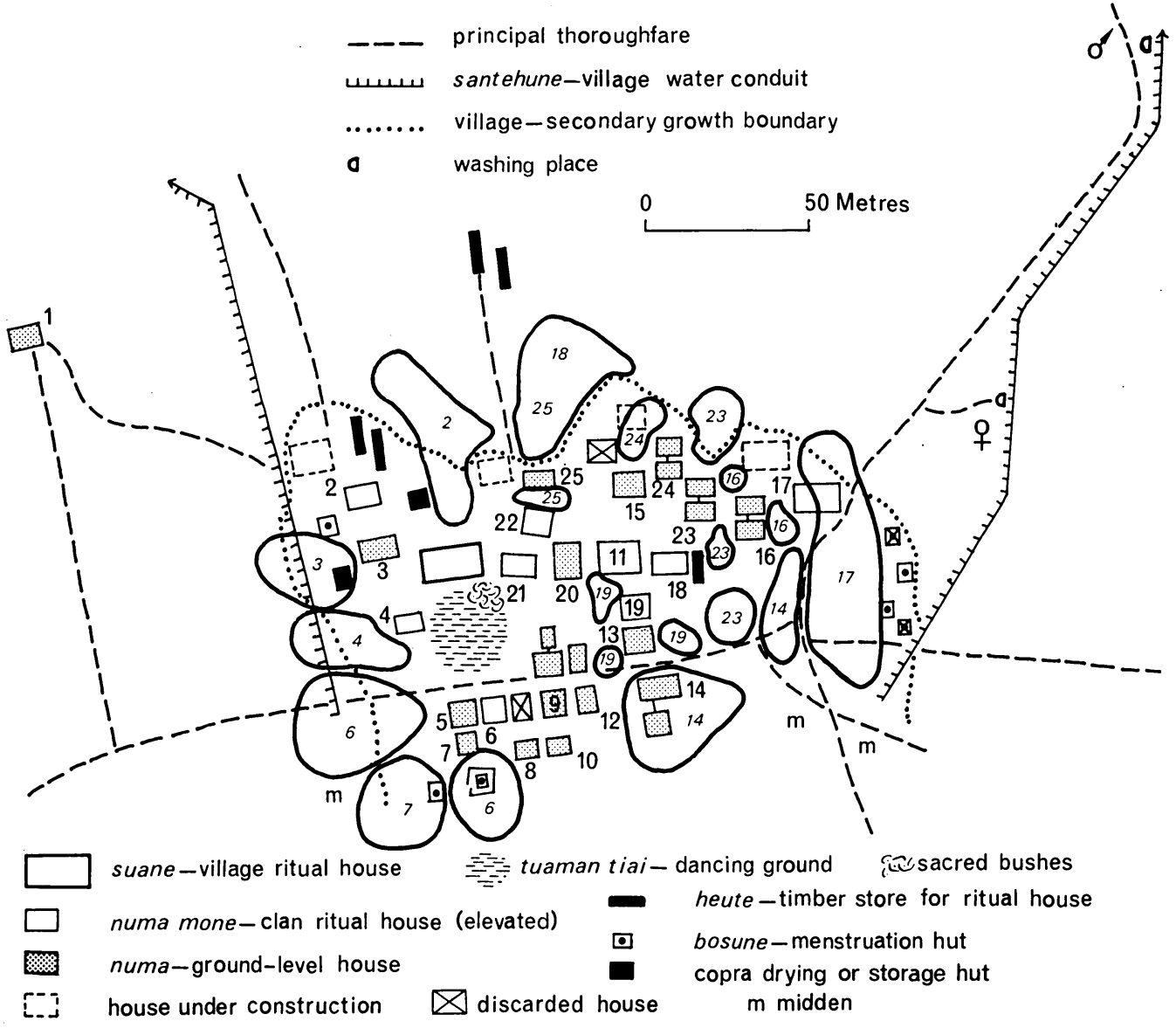

MAP 6. Ruhuwa: the village plan and environs. The enclosed spaces indicate the distribution and ownership pattern (by household) of fruit trees within the limits of the village area.
1. Teliam (Paulus)
10. Patioka
18. Konane
2. Tapone
11. Hotena
19. Tuisa
3. Numapena
12. Tuale
4. Komisi
13. Paikole
20. Sau'ute
5. Nepinama
14. Sorita
6. Hatarai
15. Sanakamura
21. Wairisa
7. Lohia (clan Sonawe)
16. Inane
22. Lohia (clan Penisa)
8. Retau'une
17. Iako
23. Menai
24. Sahunete
9. Mainjo
25. Naunepe 


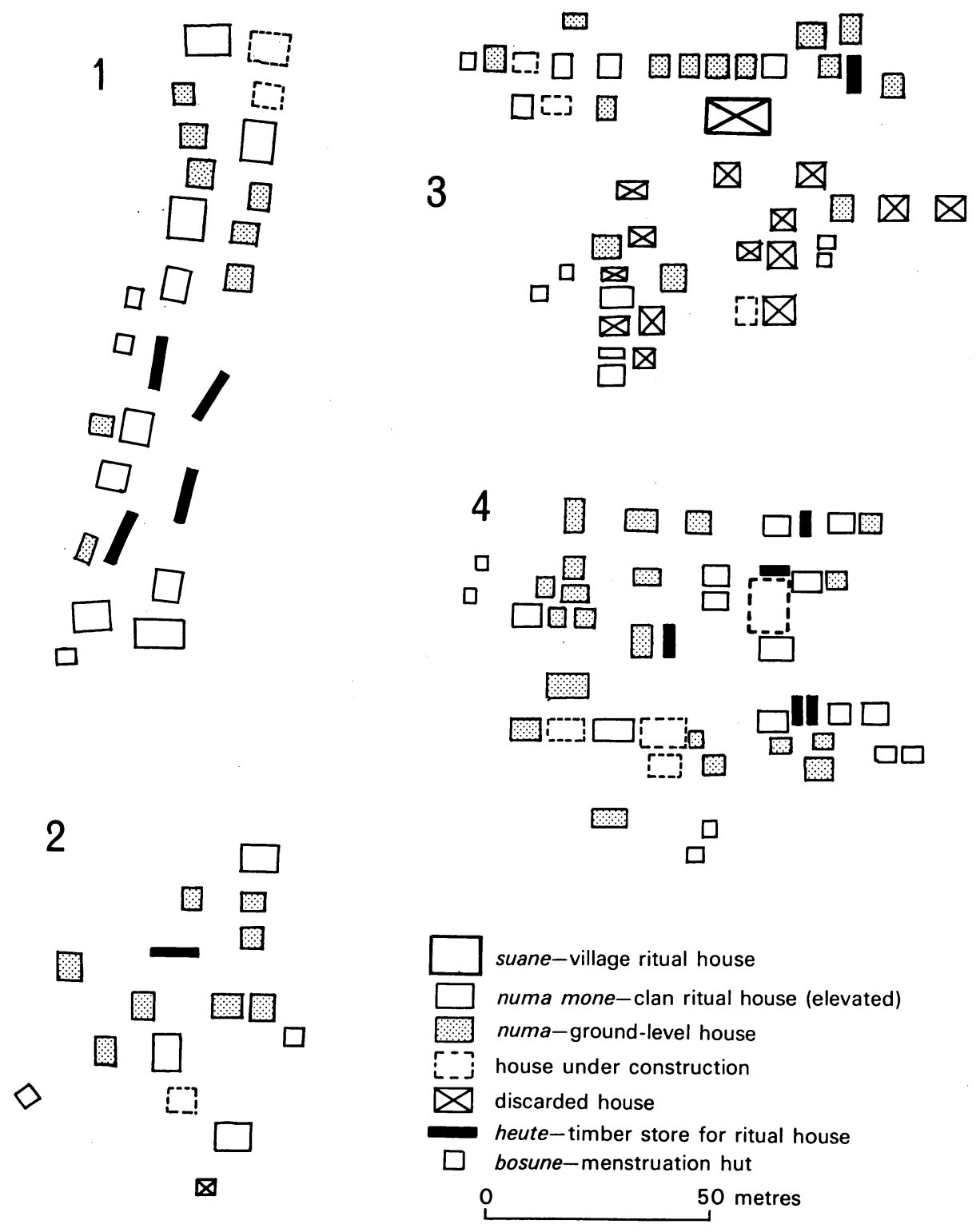

FIGURE 3. The arrangement of structures in four Nuaulu villages:

(1) Aihisuru, (2) Hahuwalan, (3) Watane, (4) Bunara. 
Conduits and the proximity of water

One of the most fundamental factors affecting the siting of all settlements is the accessibility of water. In the Nuaulu area, villages are always situated on the right bank of the rivers or large streams which are flowing during the wet season, and are frequently named after them (as in the case of Ruhuwa and Bunara). However, permanently flowing fresh water is usually found only in places which are otherwise unsuitable for habitation, that is high up in the hinterland where there are rocky and steep gully sides.

The Nuaulu overcome this by an elaborate system of conduits (santehune) constructed from split bamboo haulms, averaging 735 centimetres in length, coupled with wooden supports and secured with rope made from the fibres of the aren-palm (Arenga pinnata). In this way relatively unpolluted and fresh water is brought right within the village area. Conduits vary between 400 and 1400 metres in length and may be composed of over 180 separate lengths of bamboo..$^{10}$

Not only does the conduit system, which operates continuously, irrespective of the season, ensure a year-round supply of readily accessible water, but it also reduces contamination by tapping water as high as possible above the village and transporting it under relatively hygienic conditions. This sometimes involves completely enclosed lengths of piping. Construction of a santehune is undertaken by the entire village, and upkeep is the responsibility of individuals who discover breakages or leaks.

\section{Ideological factors in village structure}

In common with many other communities in the Indonesian region (van Ossenbruggen 1918), the individual Nuaulu village is considerably more than a merely haphazardly evolved conglomeration of houses, more even than a carefully planned entity designed to meet the needs of economy of movement and land usage. The village is part of a carefully ordered universe, and for the constellation of village elements to be out of order is for the whole to be out of order with the cosmos. Consequently, it is regarded as being of the utmost importance that every Nuaulu village should attempt to conform to the same basic structural ideal. In short, village layout must be seen as a visible paradigm of some very important aspects of the social system. ${ }^{11}$

The focal point of each village is the suane ${ }^{12}$ (Ellen 1973: 87, figure 5), or village ritual house, and consequently lies in the very centre where it is visible and accessible. Not only is the suane the location for dances and 
traditionally the meeting place of elders, it is also the focus of ritual activity in its own right. The Nuaulu maintain a distinction between religious activity which is performed for and on behalf of man, and that which is performed by man but - as they say - 'belongs to the Suane and is the domain of the ancestors'. The former consists of the familiar life crisis rituals, together with certain other festivals, including a great dance festival, and the latter, of the specific rituals concerned with various stages in the life-cycle of the suane or of individual clan ritual houses and sacred objects.

In construction and basic plan the suane, in which there is little variation from village to village, resembles the ordinary traditional Nuaulu house: built on piles off the ground, it has the same conspicuous swallow-tailed gable, the numerous solid hardwood supporting posts and roof of sago-palm thatch. But in several respects the two structures are rather different. Not only is it much larger ${ }^{13}$ and without walls, but its orientation is different, and this is crucial. While, in common with all Nuaulu houses, the roof ridge runs parallel to the coast, along an eastwest axis, two entrances are not, as in all other Nuaulu houses, oriented along a mountain-sea axis, but run at right angles to it. This is so that they are in alignment with the diurnal path of the sun. ${ }^{14} \mathrm{~A}$ further entrance, set in the middle of the side nearest the sea, is used only on the occasion of important festivals. The suane, which is under the guardianship of the Matoke clan, also differs in certain other respects from the ordinary traditional houses: the presence of a central upright with important ritual connotations, the large drum on the right hand side of the entrance on the seaward aspect, and greater attention to decorative carving. In referring to the suane emphasis is laid on its sacredness and, almost equally, its maleness. Women only enter to take part in dances, and then only at the express invitation of men. The suane is undoubtedly the most salient feature not just of the Nuaulu village but its entire social and ritual organization.

To the seaward side of the suane is the tuaman tiai, a piece of ground measuring approximately the area of the suane itself - about 200 square metres - and used principally for dancing. Building on it is strictly prohibited, except for a structure known as the sabua, erected in conjunction with certain festivals. Similarly, the sone (Cordyline fruticosa), wainite (Languas speciosa), kokine (Musa sp.) and other bushes planted on it for use in religious ceremonies may never be uprooted or tampered with outside a ritual context, on pain of death.

Surrounding the suane on every side is the general living area of the 
village, the principal features of which are the houses, or numa; but also within this area are situated a variety of other structures, including drying platforms, timber stores (heute), storage huts for coconuts, nurseries for clove seedlings and copra drying huts. As such, it constitutes the mundane sector of the village in which all the normal business of village life takes place; and yet, even here are found structural features imposing some degree of cosmological order.

While the precise location of houses within the area is not determined by such cosmological injunction so much as by kinship affiliation or marriage rules, houses themselves are bound by very definite rules relating to their orientation, structure, construction and behaviour with respect to them. ${ }^{15}$ Entrances, as has been mentioned, are oriented along the mountain-sea axis. ${ }^{16}$

The traditional house or numa mone at once mirrors and contrasts with the suane. Each house ${ }^{17}$ is owned and occupied by a particular extended family group or household (also termed numa), units which form the minimal corporate groups of Nuaulu society.

The principal divisions of the house to be noted here are:

(a) the hunisone, or principal interior central space, composed of split bamboo flooring (lante hunisone),

(b) the rini, the shelf or loft in the roof space,

(c) the pantetane, outside platform,

(d) the kakarane, elevated platform along north and east sides.

Of all parts of the house, the most important for practical purposes is the hunisone, which comprises the basic living area. To the west FEMALE end is, appropriately, the fireplace, the spaces at the sides and the back of which are used for storing a wide variety of domestic objects. Directly over the fireplace is a shelf for curing meat and drying other foodstuffs. The hunisone is the normal location for cooking, eating, sleeping and participation in innumerable minor domestic tasks.

At both ends of the lante hunisone in the roof space are situated the large lofts or rini, stretching the width of the house. The rini at the west end is largely used for storing mundane articles, such as baskets, but it is here also that are to be found large quantities of pig and deer jawbones and cassowary breastbones, of which it is forbidden to dispose.

The rini at the opposite east (MALE) end is also used for mundane objects, typically male paraphernalia such as spears and bows, but the half towards the mountain side is devoted entirely to storing valuables: porcelain, brass objects, red cloths, baskets containing woven kain timor, 
'beads, bracelets and so on. Further objects are actually placed in the roof thatch, or on the mountainward wall of the house, together with objects of ceremonial attire. Often, hanging directly under the rini at the MALE end is a basket containing certain valuables in which the spirits of the immediate ancestors are said to reside.

The kakarane, a shallowly elevated platform confined to the north and east sides of the house, is primarily a sitting and sleeping place for males, but it is also used for storing valuables, as well as more mundane clothing, baskets of root tubers for planting or other food.

On the seaward aspect of every numa mone is the pantetane, a platform of constant width (around 180 centimetres) but of varying length. Much of the daytime relaxation takes place here. It is also the site where numerous male and female domestic tasks are performed. Here also the men, particularly elders, meet to discuss important matters away from midday heat.

For most of the time women are confined to their parts of the house and men to theirs. In addition to this there is a finer and more complex pattern of ritual seating arrangements for the various rites held within the house. However, the symbolism of the Nuaulu house is too rich and complex to pursue fully here (but see Cunningham 1964).

Although the basic pattern of orientation is common to all houses, and behaviour patterns with respect to them are also identical on ritual occasions, there is a tendency to reserve strict adherence to many of these formalities for numa mone. At the present time many of the houses in a Nuaulu village, about 60 to 70 per cent, are built at ground level, and non-traditional houses are felt not to require the meticulous ritual attitudes for the traditional houses containing sacred valuables.

If the SACRED and MUNDANE sectors of the village area can be seen as being circumscribed by two concentric circles, then a third, PROFANE sector, can be added by inscribing yet another. This sector occupies the liminal area between the village (niane) and the forest (wesie), and appropriately concerns activities with polluting connotations. It is here that the bosune, menstruation huts, are located in which women are confined for the length of each menstrual period, where young girls are confined for up to six months on attaining puberty and where mothers give birth to their children. ${ }^{18}$ Here also are erected huts for the very sick, who must be kept apart from the healthy. Here are to be found middens, the washing places at the end of the conduits, and the prescribed places for male and female defecation and micturition. In practice its polluting properties are concerned with both sexes, but more 
fundamentally so for females, with whom it is symbolically associated. ${ }^{19}$

The cosmological parameters of village structure are summarized in FIGURE 4, with the addition of certain other referents relevant to the discussion. What is apparent from this figure is not merely the symmetry of these two cosmological models, but the opposed principles on which it is based: on the one hand there is a concentric symmetry (FIGURE 4a), such that the contrast between central and peripheral is congruent with the contrast SACRED: $P R O F A N E,{ }^{20}$ and on the other, sets of oppositions based on directional qualities of village layout (FIGURE 4b) (c.f. Lévi-Strauss 1965: 135). The second diagram could be expanded to include further oppositions involving Nuaulu concepts of orientation. For example, wind (ihute) is referred to by its source, according to whether from the mountains (ihute suara), from the sea (ihute taranunu), or from either direction along the coast (from the east, ihute ihate, from the west, ihute hanate). Though specifically relating to wind direction, these terms are used in other orientational contexts, such as in relation to the village, so that MOUNTAIN, MALE and suaru all have associated connotations in Nuaulu thought. The same is true regarding the use of prepositions of place. These sets of binary oppositions are not isolated, but are merely the manifestation in terms of the physical entity of the village of the prevailing dyadic symbolism in Nuaulu ritual and belief, which is so typical of eastern Indonesia (Van Wouden 1935), and made manifest in dualism with reference to descent groups, natural species, cosmography and the like.
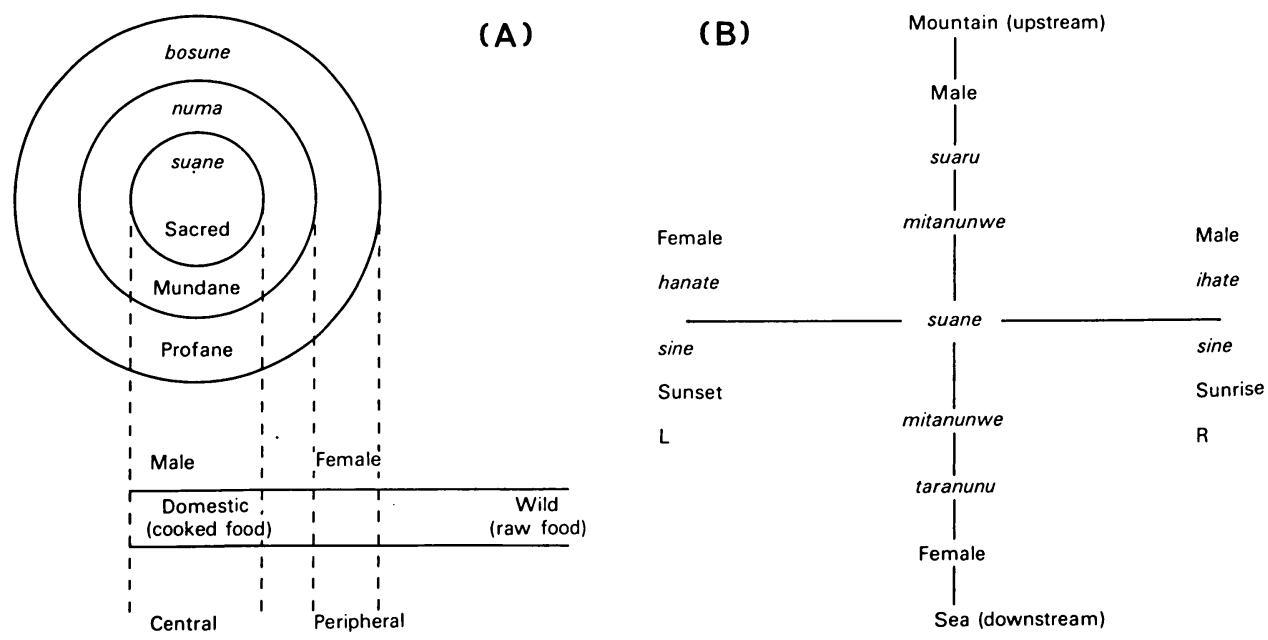

FIGURE 4. Diagrammatic summary of the cosmological referents of village structure. 
Whilst there are two principles of order involved here, they are both integrated into the total model of the village. Moreover, without an understanding of the basic principles, the symbolism of Nuaulu villages would certainly appear confusing - witness, for example, the three separate contexts in which the opposition MALE: FEMALE occurs. A further point of interest lies in the triadic concentric division of the village area, such that the SACRED and the PROFANE are mediated by the MUNDANE (Stanner 1967: 230). But while both SACRED and MUNDANE sectors fall clearly within the DOMESTIC context the PROFANE sector is ambiguously neither entirely DOMESTIC nor WILD, niane or wesie. This liminality emphasizes the dangerous and polluting qualities of this peripheral area. Again, the distinction between niane and wesie is perfectly congruent with the Nuaulu attitudes towards the categories COOKED and $R A W$ - the ideals relating to the consumption of prepared and unprepared foods, the locational appropriateness of cooked and uncooked meats. ${ }^{21}$.

Appropriately enough, the village is subject to ritual to maintain and re-emphasize its significance with respect to the rest of the cosmos. The ceremonial concerning this is known as aunenene usa kotua rerehoni niane haha, (clearing with fire to make the village pure). The similar ceremony found in Christian Ambonese villages is known as adat cuci negori, 'washing the village ceremony' (Cooley 1962: 60-4). The Nuaulu version involves the cutting and burning of all weed and grass-covered areas in the village, in which it is compared to the clearing and firing of a garden plot. All that is dead, rotting and decaying, including dead leaves and branches from still living trees, is removed. The resultant ash is symbolically washed away with water, lest the village should remain 'hot', the clan chiefs going round the village sprinkling water from a large bamboo. The bamboo is first cut out and the inside wiped round with sinsinte leaves (Codiaeum variegatum Blume.) by the chief of the Nepane-tomoien clan, on account of the fact that this clan originally occupied the territory. In this way dirt is removed, what is polluted made pure and what is disorderly made orderly. The ceremony is similar in some vital respects to the ritual washing accompanying the termination of a woman's first menses seclusion and childbirth.

What has characterized the discussion of village internal structure so far is that attention has been devoted to prescriptions regarding village shape and the orientation and location of its component parts. But the model which has emerged is not merely one of ideal structure; it is a concise statement of the actual structure of the village, so far as these 
particular prescriptions are relevant. It offers a neat illustration of what might be termed ideological rules, that is, prescriptions concerning, at face value, general (not individual) relationships in the arrangement of the various tangible components of the village or settlement pattern as a whole. The 'rules' are simply a reflection of the obvious utility (indeed, necessity) of making cosmology manifest in some concrete form. And yet, it should be emphatically pointed out (since the structural and descriptive approach used above might seem to obscure it), that ideology is not something which exists in a vacuum - it exists only in as much as it is a statement about actual behaviour, regardless of whether idealized behaviour is consistently realized or not. Nevertheless, although the form of the Nuaulu village is a central referent of social structure, its social organization is not consciously discussed in terms of the ideal village as it is in some other societies (c.f. Crocker 1969). In Nuaulu the model itself is not seen as a definite and proper guide to the relations between individuals, groups and communities, so much as a rather general framework. Clans, for instance, as one would expect from a knowledge of recent Nuaulu culture-history, do not, as in some communities, stand in a defined geographical relation to each other (LéviStrauss 1963: Fig. 9; Crocker 1969: 46).

The degree of congruity between the three separate entities of ideal model, actual village and actual behaviour can never be complete, since to some extent they are all variables in a changing system. At the physical level there is change in the component structures due to aging and new requirements, sometimes necessitating expansion. ${ }^{22}$ For example, when I arrived in the field, of the three ritual villages, Bunara had no suane, that of Niamonai was dilapidated and structurally unsound, while Ruhuwa possessed a relatively new one, for which the ritual cycle had not then been completed. Eighteen months later Bunara had begun to build a new suane, Niamonai had removed its old one and the ritual was still incomplete for that of Ruhuwa. Two years later the picture was different yet again. Also, the very fact that since re-settlement there have been five localized hamlets and only three politico-ritual units demonstrates this lack of congruity. In fact there is no reason to suggest either that in former times villages always coincided with the ideal. On the contrary, this would seem rather unlikely, on the basis of constant changes in the developmental cycle of the village, though it must be expected that failure to implement the model at all would result in certain cognitive difficulties.

In this instance then the configuration and orientation of the compo- 
nent parts of Nuaulu villages are seen as being, at least in part, generated by ideational rules illustrative of significant cosmological dimensions. Yet, within the framework which this set of prescriptions offer, there is considerable room for manoeuvre. Although the orientation and configuration of the village as described cannot be altered (at least in terms of indigenous decision-making behaviour), various pressures mould the ideological model in order to generate the total village pattern as it can be observed at any one point in time. ${ }^{23}$ Alternatively, the process might be described in terms of the ideological construction and limitation of other generative factors. Some consideration must now be given to these pressures.

\section{Environmental factors affecting village layout}

It has already been noted that there are very real environmental considerations to be taken into account in evaluating the choice of particular village sites. Though initial choice must to some extent obviate the more dire environmental disadvantages, location will always be subject to differential physical disadvantages, either (more especially) in terms of the quality of terrain and vegetation, or, over time, by being subject to periodic attack by the elements.

Unsuitable terrain, in the form of stoniness, rock, thin soil, gullies which are readily subject to flooding, and the like, can generally be avoided and this, to some degree, will be reflected in the distribution of habitations in a single village, or it may be overcome by adapting in a suitable manner the form of habitations. The traditional elevated Nuaulu house is admirably adapted for uneven and stony ground simply by restricting contact with the ground to piles, enabling a flat living surface to be constructed above it. With the simpler houses built at ground level there begin to be distinct constructional problems in adapting to the surface of the ground, even in villages (such as Ruhuwa and Bunara) where the ground is more or less level. The problems can only be remedied by such means as supporting walls in dips and gullies with rocks and stones. Erosion during the life-span of such dwellings can undermine walls and create instability. The traditional house is also free from flooding. Ground-built houses, especially if they are on low-lying ground, require trenching to redirect floodwater.

Nuaulu villages are of two types: those actually located in coastal areas at sea-level, and those in the immediate hinterland. The former are characterized overall by their regularity of form, to the point of the geometric alignment of houses with bamboo open-work fences (pakelo), 
which have no other purpose apart from decoration and the marking of paths - something which has almost certainly been adopted from coastal practice. In the hinterland villages this is not feasible and houses must be sited purely to conform to what is physically possible, thus resulting in an irregular pattern (FIGURE 4). The spacing of dwellings in such villages is largely a function of the terrain, leading to a clustering of houses on ground most suitable for building. In the coastal villages suitable terrain is at less of a premium and other factors can be taken into consideration: sufficient space for trenching (an important factor with ground built houses) and passageways, cleanliness and privacy. On one occasion I was told that six metres was the ideal space to allow between dwellings. However, this is rarely achieved and appears to be an ideal derived through contact with the rigidly geometric layout of Christian and Muslim villages such as Amahai and Ruta.

Terrain constraints, then, also affect the density of dwellings and population (TABLE 6). This is clearly the case with Aihisuru and Hahuwalan where physical expansion is limited by steep rocky declines on three sides. With Bunara, however, where terrain can in no way be argued as a relevant limiting factor, the high densities seem to be explained by the difficulty of lateral expansion due to ownership of adjacent land by non-Nuaulu coastal Muslims (see below pp. 58-59).

Within all villages, providing the ground is suitable, some land is devoted to the growing of useful trees, principally banana and sago palms, and the cultivation in dooryard gardens of a few root tubers, usually manioc. Obviously, those villages on the coastal strip provide eminently more suitable conditions for this form of minimal horticulture, but in both Aihisuru and Hahuwalan limited cultivation is possible in selected places. A census of all domesticated tree and plant species in the village area of Ruhuwa indicated a preponderance of uri (varieties of bananas and plantains; Musa paradisiaca $\mathrm{L}$. and $\mathrm{M}$. sapientum L.), claiming over half of the total number of individual

TABLE 6. Density of population and dwellings in Nuaulu villages

\begin{tabular}{lccccc}
\hline & Population & $\begin{array}{c}\text { Number of } \\
\text { households }\end{array}$ & $\begin{array}{c}\text { Approximate } \\
\text { areas in } \\
\text { hectares }\end{array}$ & $\begin{array}{c}\text { Persoms per } \\
\text { hectare }\end{array}$ & $\begin{array}{c}\text { Dwellings } \\
\text { per hectare }\end{array}$ \\
\hline Bunara & 150 & 35 & 1.00 & 150 & 33 \\
Watane & 61 & 20 & 1.25 & 48.8 & 16 \\
Aihisuru & 44 & 15 & 0.53 & 83.0 & 28.3 \\
Hahuwalan & 61 & 11 & 0.75 & 81.33 & 14.6 \\
Ruhuwa & 180 & 25 & 2.60 & 69.23 & 9.61 \\
\hline
\end{tabular}


plants. Together, hatane (Metroxylon sagu Rottb.; sago), sesene (Ananas comosus Merr.; pineapple), nusi (Citrus limon Burm.; lime) and tobako (Nicotiana tobacum L.; tobaco) constituted a further twenty per cent; while the remainder included breadfruit, papaya, kwining, betel-vine, chempedak, mango, durian and mangosteen. Species not present in the sample, but commonly found in other villages, include lemon grass, manioc and chilli (Ellen 1973: table 6, pp. 102, 460-4). In addition to plants of economic value there are also those of ritual significance already mentioned, as well as some whose value is purely decorative. The number of fruit trees a particular clan, household or individual possesses in the village area will normally be a function of how they are placed for suitable adjacent land. Though there is no fixed reason why trees should not be planted away from the house, it is regarded as difficult since present rights in such trees are susceptible to subsequent confusion of ownership. Consequently, households on the periphery of the village or those near large open spaces tend to have more trees than other households. However, a household may sometimes own trees not in its immediate vicinity through gifts from affines. Although all land in the village is corporately owned, there is a generally accepted (if not formalized) rule that a person with trees on a particular portion of land has established planting rights on that portion. Trees planted by individuals are initially reckoned as being their own property and are inherited collectively by their male offspring. Older trees, therefore, ultimately become corporate clan property. Rights in trees are dealt with in more detail in Chapter $\mathrm{V}$.

In this way the differential distribution and concentration of fruit trees and their ownership has some bearing on the evolution of the villageplan, positively in adding a further dimension for consideration, and negatively with respect to the difficulties in siting new houses on such land. The actual distribution and ownership pattern of fruit trees in Ruhuwa is shown in MAP 6. As has been pointed out by Conklin (1960: 41), tree ownership may indicate the approximate location of residences in earlier generations, making it possible (at least to a limited extent) to trace out changes in house location over a period of time.

\section{Genealogical organization of village structure}

In some instances environmental circumstances compel construction of the settlement in the idiom of the prevailing ideology to be substantially altered, such as in the face of demographic pressure. Nevertheless, even in the case of these particular situations it is difficult to ascribe departure 
from an ideologically preferred arrangement purely in terms of the pressure of land or people or of topography; other reasons must be invoked, derived from particular sets of inter-personal and inter-group relations, commonly having a genealogical basis. These might be termed inter-personal or organizational 'rules'. There is a tendency for these to be prevalent at lower levels of settlement organization, in the relationship between garden plots or the relationship between houses. On the larger scale, the most important social factors affecting Nuaulu settlement are the pressures from adjacent non-Nuaulu. I shall now explain some of the ramifications of these pressures in relation to a more general consideration of pattern generation at the level of the village-plan, with particular reference to Ruhuwa.

\section{The numa as a kinship group}

The term numa covers both the house as a physical entity and the persons who occupy it. Although certain formal behaviour is the prerogative of the numa as a group vis-à-vis other numa, it is essentially characterized as all those people living in the same house, and as such is a local group, even though recruitment is almost without exception along lines of kinship and affinity. It is primarily defined by the criterion of local residence.

The members of a household are always intimately related by ties of kinship and marriage and constitute a single domestic grouping or household, forming a single labour pool. Food is prepared and cooked for the household as a whole, and its members usually eat together. To some extent, it is also a land and property-owning unit, though to say so requires some qualification. Land ultimately belongs to the clan, but rights are also spoken of at an individual level, while land owned by all individuals of a single household may be regarded as the land of that household. In practical terms this means that all gardens (together with the domestic animals, largely chickens owned by household members) are accessible to any other member and the products from such gardens serve the common hearth. It is therefore an independent unit in the economic sense, though this does not rule out economically significant exchange relationships between different households. Each household, especially if it is a numa mone (clan ritual house), also possesses certain sacred valuables, which individuals may possess in their own right or which are held corporately on behalf of the clan. The male elder, unless he is quite senile, is regarded as household head and guardian of its contents, and those persons under his authority are collectively known as 
the wehekuka of that elder. If the house is a numa mone the clan, in theory, exercises a collective ownership and has special corporate responsibility for its upkeep and protection of its contents.

Households are small and genealogically simple. TABLE 7 shows the range in numerical composition of households for the five Nuaulu villages in south Seram. It can be seen that while the mean composition of the Nuaulu household is as low as 5.5 and the mode only 4, the range in size is considerable, though there are no single-person households. Although the household does not always act independently, its limited size appears to be of crucial importance in many economic activities.

The genealogical composition of all the households under discussion is shown in TABLE 8 . It will be seen that the most prevalent type of family group is the two-generation type, of parents and married or unmarried children, that is, the elementary family. The development of more extensive families is generally hindered by a strong tendency towards partition as soon as the unit increases in size and collateral elementary families start to emerge. As will be seen, the composition and size of households is reflected in the actual shape and dimensions of domestic structures.

At any one moment in time a Nuaulu individual is, for all intents and purposes, a member of a single household only; to be otherwise invites confusion of rights and obligations. But sometimes there is irregular shifting of residence by some young married couples between that of the groom and his bride. This form of bilocal residence is by no means common and is related to the type of marriage contracted. It is equally as rare, but by no means unknown, for a single individual to alternate between households. This usually occurs when an individual's genealogical connections with the households concerned are more or less equal in degree of relatedness.

Membership of a household may be obtained by birth, adoption, incorporation or by marriage, while birth, marriage and death regularly modify its personnel. Changes in residence may be effected by death of parents, illness, marriage, or a combination of these other factors. The relative contributions to household composition of these four modes of recruitment for the five Nuaulu villages are shown in TABLE 9.

Membership of a particular household by birth does not necessarily entitle male children to rights in the corporate property of that household and this includes rights over land and other tangible goods, valuables, titles and magical formulae. Except in most exceptional circumstances, every child born within the lifespan of a union is 
TABLE 7. Numerical composition of the household

\begin{tabular}{|c|c|c|c|c|c|c|c|c|c|c|c|c|c|c|c|c|c|c|c|c|}
\hline $\begin{array}{l}\text { Number of persons } \\
\text { per household }\end{array}$ & 2 & 3 & 4 & 5 & 6 & 7 & 8 & 9 & 10 & 11 & 12 & 13 & 14 & 15 & 16 & 17 & $\begin{array}{c}\text { Total no } \\
\text { households }\end{array}$ & $\begin{array}{c}\text { Total } \\
\text { population }\end{array}$ & $\begin{array}{c}\text { Mean } \\
\text { composition }\end{array}$ & $\begin{array}{c}\text { Modal } \\
\text { composition }\end{array}$ \\
\hline \multicolumn{21}{|l|}{ Frequency: } \\
\hline Ruhuwa & 1 & 2 & 4 & - & 3 & 5 & 3 & 2 & 2 & 1 & - & 1 & - & - & - & 1 & 25 & 180 & 7.2 & 7 \\
\hline Bunara & 1 & 5 & 8 & 4 & 3 & 3 & 4 & - & 1 & - & - & - & - & - & - & - & 29 & 150 & 4.5 & 4 \\
\hline Watane & 2 & 1 & 1 & 1 & 2 & 2 & - & 1 & 1 & - & - & - & - & - & - & - & 11 & 61 & 5.5 & $2,6,7$ \\
\hline Aihisuru & - & 2 & 2 & 2 & 1 & 2 & - & - & - & - & - & - & - & - & - & - & 9 & 44 & 4.8 & $3,4,5,7$ \\
\hline Hahuwalan & 1 & 1 & 3 & 1 & 3 & - & 1 & - & - & - & - & 1 & - & - & - & - & 11 & 61 & 5.5 & 4,6 \\
\hline TOTAL & 5 & 11 & 18 & 8 & 12 & 12 & 8 & 3 & 4 & 1 & - & 2 & - & - & - & 1 & 85 & 496 & 5.8 & 4 \\
\hline
\end{tabular}

TABLE 8. Genealogical composition of the household (including adopted kin)

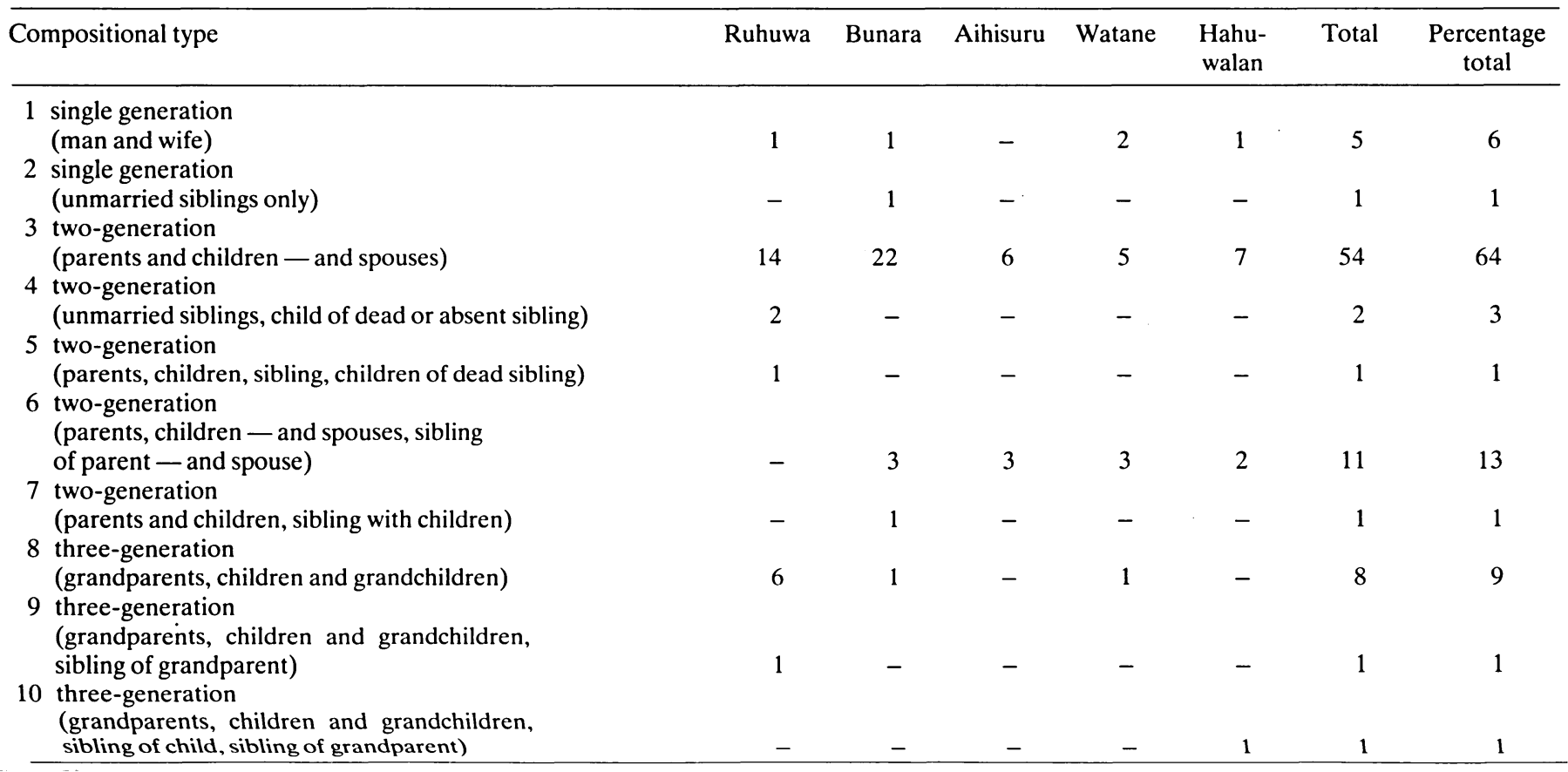


TABLE 9. Mode of recruitment to household

\begin{tabular}{lrrrrrrr}
\hline & Ruhuwa Bunara & Watane Aihisuru & $\begin{array}{c}\text { Hahu- } \\
\text { walan }\end{array}$ & Totals & $\begin{array}{c}\text { Percentage } \\
\text { total }\end{array}$ \\
\hline $\begin{array}{l}\text { Mode of } \\
\text { recruitment: }\end{array}$ & & & & & & & \\
Birth & 136 & 116 & 44 & 35 & 48 & 379 & 76 \\
Adoption & 7 & 3 & - & - & - & 10 & 2 \\
Marriage & 31 & 30 & 16 & 9 & 13 & 99 & 20 \\
Incorporation & 6 & 1 & 1 & - & - & 8 & 2 \\
\hline Totals & 180 & 150 & 61 & 44 & 61 & 496 & 100 \\
\hline
\end{tabular}

considered as a social member of the father's clan, irrespective of the clanship of the head of the household - and this is even the case if the child is illegitimate.

Adoption and incorporation among the Nuaulu (relationships covered by the term momoi), which together constitute 4 per cent of members recruited to Nuaulu households, appear to be explicitly geared to reallotting genealogically displaced persons within the kinship network. Rarely is it regarded as a means by which infertile couples can secure heirs. Nuaulu momoi relationships may occur in the following circumstances:

(1) where the father has died: in such cases, unless the child is still dependent on the mother, it is usually considered desirable that it be brought up by the relatives of the deceased father;

(2) where the father has died, but the child is still dependent on its mother, it may remain in the household where the mother is domiciled, with her parents or new husband;

(3) where occasionally a mature child may continue to reside in the household of its mother, even if she has been married, it is incorporated into that household but remains a member of the clan of its father;

(4) where both parents are dead, or a widowed mother has married, children may be adopted by near patrilateral or matrilateral kin.

\section{Marriage and residence pattern}

Marriage is a crucial determinant of household membership, though its effects are variable. The Nuaulu are now, whatever may have existed in the past, a strictly monogamous community. The household and the clan are both rigorously exogamous units, marriage being understood as essentially a contract between one clan and another, and the conjugal 
pair the pivot by which two traditionally hostile groups are linked. But, in fact, marriage almost always involves three clans, as I shall now explain.

The central figure involved in bridewealth negotiations is the groom's mother's brother (MB), while the convenor of bride service (kona upua) arrangements, involving the presentation of meat (typically cuscus), dammar resin, betel nuts and sago flour, is his sister's husband (ZH), whose importance lies in the fact that having taken his own wife from the clan of the groom, he is regarded as being in debt to his wife's clan. Once it is apparent that the critical equations of the Nuaulu system of kinship terminology are consistent with bilateral cross-cousin marriage, certain elements of behaviour become clearer. Given the equation $\mathrm{ZH}=\mathrm{WB}$ (wife's brother), the roles discussed above can be seen as a system of ideal bilateral exchange.

Marriage is preferred between bilateral cross-cousins, men in the so-called nemakai ('strong') relationship (MBS-FZS) ideally exchanging sisters. However, as TABLE 10 illustrates, such unions are rare; classificatory sisters are hardly ever exchanged symmetrically and alliances seldom persist for more than a few generations. There is some

TABLE 10. Relationship category and type of marriage contracted, for all extant marriages in five Nuaulu villages*

\begin{tabular}{lcccc}
\hline Type of marriage & $\begin{array}{c}\text { By negotiation } \\
\text { (so mai'inai) }\end{array}$ & $\begin{array}{c}\text { By entering } \\
\text { the bride's } \\
\text { household } \\
\text { (jai nisi pina) }\end{array}$ & $\begin{array}{c}\text { Elopements } \\
\text { (rumanai pina) }\end{array}$ & Totals \\
\hline
\end{tabular}

Relationship

category:

1. Bilateral

cross-cousin

marriage

$1(1)$

$5(6)$

4(5)

$10(12)$

2. Other permissible

Nuaulu of same

generation

$-\quad 11(13)$

$60(71)$

$71(84)$

3. Non-Nuaulu

(Jalahatan,

Nuelitetu, Kei)

$-\quad 1(1)$

2( 2)

$3(3)$

4. Unacceptable genealogical

\begin{tabular}{lcccc} 
connection & - & - & $1(1)$ & $1(1)$ \\
\hline Totals & $1(1)$ & $17(20)$ & $67(79)$ & $85(100)$ \\
\hline
\end{tabular}

* The figures in parenthesis refer to the percentage proportions of marriage types. 
evidence, partly demographic and partly related to the distribution and desire for stable relationships between clan-hamlets, to suggest that nemakai unions occurred to a greater extent formerly, and that alliances between bride-receiving and bride-giving clans were more regularized, clan $A$ always being in a specific wife-giving and wife-taking relationship to clan $B$. This pattern of idealized connubial relations is re-inforced by the practice of the levirate and the sororate, again consistent with certain key equations in the kinship terminology system (e.g. $\mathrm{W}=\mathrm{BW}, \mathrm{D}=\mathrm{BD}$, $\mathrm{D}=\mathrm{WZD}$. . .). The negative injunction forbidding clan endogamy, seen in the light of the above discussion, is perfectly consistent in logical terms with the prohibition on marriage with the wife's brother, since WBW $=\mathrm{Z}$.

A Nuaulu marriage may be brought into existence in any one of three ways: by negotiation (so mai' inai, literally 'big talk'), by entering into the bride's household (jai nisi pina, literally 'to eat the gardens of women') or by elopement (rumanai pina). TABLE 10 illustrates the types of union contracted for all extant marriages in the five settlements.

Marriage by elopement, as in the rest of the central Moluccas, is the most common method at the present time. The procedures involved are absolutely minimal, consisting of a pre-arranged elopement by the couple, efforts by angry kinsmen of both parties to discover them, hostility between the two clans themselves and, usually, the return of the couple after a period of time, during which tempers have been allowed to cool. In cases where the hostility of kin and clan elders can be gauged with some accuracy, it may only be necessary for the couple to make a symbolic elopement of one night to a garden hut. However, although no precise records are available for other societies, it is apparent that the number of marriages formed in this way are considerably fewer than among adjacent communities (Cooley 1962: 21). The Nuaulu, who regard it as being contrary to the wishes of the ancestors and speak with a certain degree of shame over its increase in recent years, see elopement almost purely as a device to obtain de facto recognition of otherwise disapproved-of unions. Some elopements, though, may themselves be the cause of hostility, leading to inter-clan feuding. The reason why almost 80 per cent of Nuaulu marriages are, initially at least, disapproved of by one or other, or both clans involved appears to be related to a low total population and an unequal sex ratio in favour of males (TABLE 3 , FIGURE 18), which in turn affects the effective area of choice in mate selection. It is also related to the scarcity and consequently inflated value of traditional valuables required for bridal transactions; but it is not necessarily (as is true for the Christian Ambonese) an alternative to 
bridewealth, which will often still be vociferously demanded by the clan of the bride, even if payment has been delayed. This is also the only form of marriage open (though not approved) to non-initiated men. Male initiation occurs considerably later than that of females, who become eligible for marriage as soon as they emerge from their first menses seclusion. This delay is related to the development of the skills required by the neophyte at the initiation itself and is the cause of tension between the inherent desire for marriage and the prohibition against it. There is, however, no restriction whatsoever on non-initiates having sexual relations.

Marriage where the groom leaves his own household and enters that of his spouse is a far more prestigious form of matrimony than elopement. It has the approval of the parties concerned and is secured by the requisite ceremonial and the undertaking of complex bridal transactions. Sometimes it is designed to meet certain specific contingencies, for example, in order for the male affine to act as provider in a household with no or too few active adult males. In such a case his period of residence is until other mature males become available. It is rarely a permanent arrangement, so much so, that of the eleven extant unions established in this way in Ruhuwa only two were still residing uxorilocally at the time of fieldwork. In most cases of this kind of marriage a husband tries to set up a separate household as soon as possible, though his affinal obligations will still remain intact. However, what are in one sense obligations are in another sense benefits accruing to his own clan in that in this way he is able to supply his kinsmen from the gardens of his affines-thus the name for this connubial form, 'eating the gardens of women'. It invariably happens that the bride's clan will make a gift of land, sometimes more than one wasi (see below, Chapter V), to the husband shortly after marriage, which means that in the long run the clan of the husband gains territorially. This, to some degree, must be an incentive for such a marriage, together with a reduced bridewealth payment for the clan of the groom, ${ }^{24}$ in the same way that the potential labour of the groom is an incentive for the clan of the bride. Alienation of land is, nowadays anyway, not the result of such unions only and often occurs in conjunction with the other types of marriage; I shall return to this issue later.

In some cases it is possible to come to an arrangement whereby the parents of the wife or other affinal relatives become de facto dependents of the man who originally entered in, who thus assumes household headship. There is no question, however, of the groom being incor- 
porated into the clan of his bride, though in similar circumstances this has been recorded for other Indonesian peoples. ${ }^{25}$ There are, of course, strong ideological objections to the residential aspects of such a marriage, and this may hasten the urgency of terminating that part of the transaction which involves uxorilocal residence. The bilocal shifting of residence discussed above appears as a partial solution to the strain between households in some instances of 'marrying-in' unions.

TABLE 11 shows the general pattern of residence, with respect to the type of marriage contracted for the Nuaulu area. Most elementary families either set up residence neolocally or are living with the kin of the husband. Despite substantial payments, the woman herself never becomes absorbed into her husband's clan, even with a negotiated marriage which always begins in a virilocal manner, and always retains a commitment to her natal clan, ritually and through kinship connections.

Of the 28 extant marriages in Ruhuwa at the time of my field census, 12 were with partners from within the village and 16 had one outside partner (all females). The complete absence of rules and preferences relating to village exogamy and endogamy reinforces what was said in the first section of this chapter concerning the essential relationship between Nuaulu formal groups and local groups at the present time.

Summarily, Nuaulu marriage is idealized as being essentially a transaction between clans in which a woman is exchanged for an agreed sum and/or services. This establishes or refurbishes an alliance in which bride-givers are superior to bride-receivers. The marriage transaction itself consists of a series of major and minor transactions: the bridewealth, the kona upua payments (plus payments made at a later date), the smaller nesaneu payment of minor valuables from the husband of the husband's younger married sister, and the similar sasau payments of the bride to the married brother of the groom. Logically, in a system where

TABLE 11. Residence pattern for all extant Nuaulu marriages

\begin{tabular}{lcccc}
\hline $\begin{array}{l}\text { Type of marriage } \\
\text { contracted: }\end{array}$ & $\begin{array}{c}\text { By } \\
\text { negotiation }\end{array}$ & $\begin{array}{c}\text { By entering the } \\
\text { bride's household }\end{array}$ & Elopement & Totals \\
\hline $\begin{array}{l}\text { Form of residence: } \\
\text { 1. Neolocal }\end{array}$ & $1(1)$ & $4(5)$ & $47(56)$ & $52(62)$ \\
2. Virilocal & - & $4(5)$ & $16(18)$ & $20(23)$ \\
3. Uxorilocal & - & $8(9)$ & $4(5)$ & $12(14)$ \\
4. Bilocal & - & $1(1)$ & - & $1(1)$ \\
\hline Total & $1(1)$ & $17(20)$ & $67(79)$ & $85(100)$ \\
\hline
\end{tabular}


marriage between bilateral cross-cousins is consistently practised, the exchanges surrounding a marriage are illustrated in FIGURE 5a, that is, both nesaneu and sasau payments are in a single direction (B-A). However, in Nuaulu actuality, the situation is more frequently that illustrated in FIGURE 5b, involving three clans, such that nesaneu (A-B) is from the clan of the $\mathrm{ZH}$ and sasau (C-B) from the clan of the bride to that of ego. This picture is altogether more characteristic of a system of circulating connubium. The many ramifications and implifications, logical and actual, of these complex inter-clan exchange relationships cannot be explored here, though the essential situation is suggested in the diagrams.
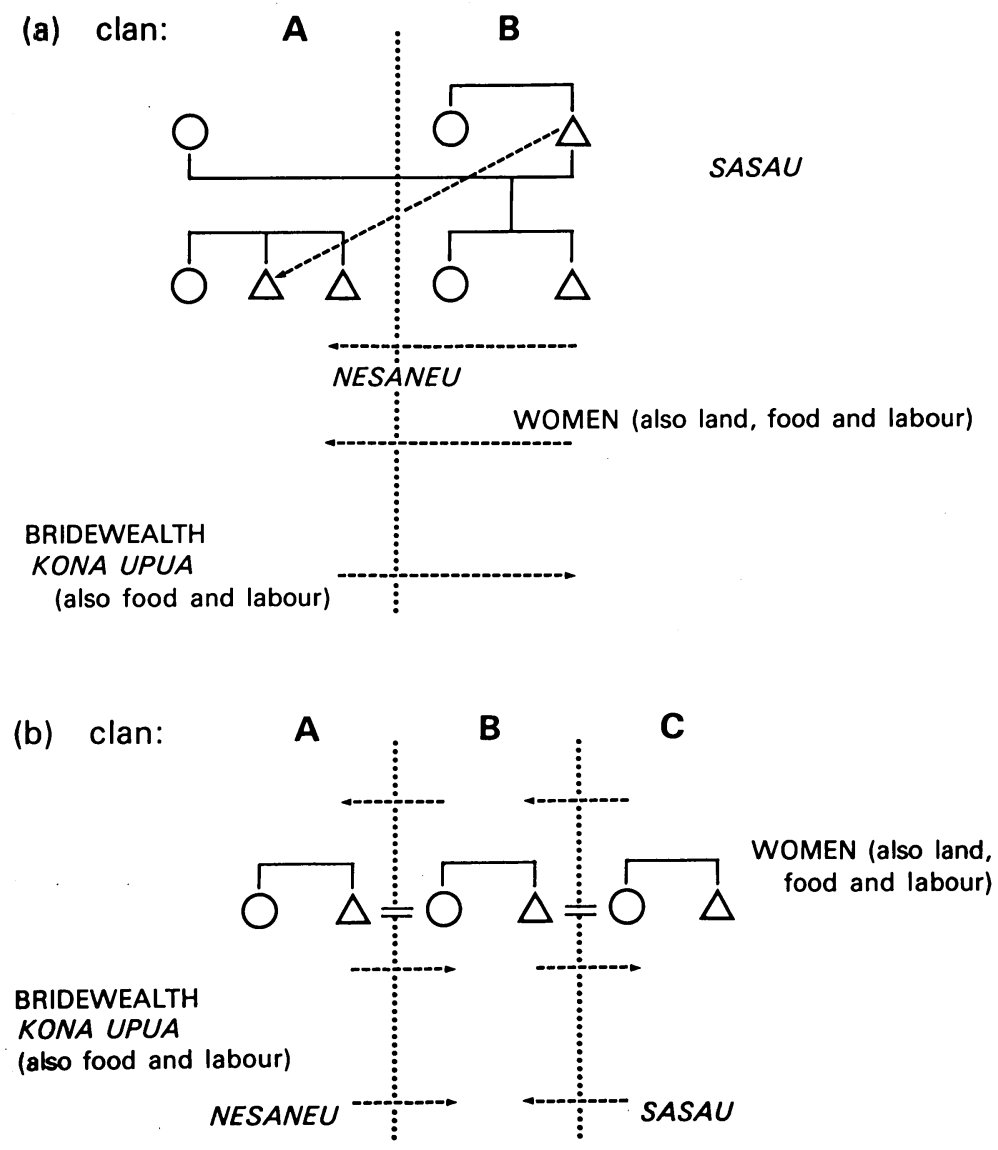

FIGURE 5. Exchange relationships and marital alliance. 
Marriage is the initiation of a new transactional relationship between two clans, or the confirmation of an existing one, after which goods and services continue to flow between clans for the life of the union. Such ties also form the foundation for common group activities and act as channels for the distribution of resources. As has been shown these economic functions sometimes affect the choice of marriage-partner. The single marital transaction, however, is recognized as just one in a wider pattern of wife-giving/wife-receiving relationships which extend through a clan universe, spreading out laterally and coming into being and terminating through time. The ideal preferential pattern of alliances is only partially obtainable, due to a number of demographic, economic and social pressures affecting the size and nature of exchange transactions, the economic and social needs of the clans involved and the finite number of possible unions.

As a means of recruitment to household membership, marriage may involve both sexes, recruiting, in the case of 'marrying-in' males, to the household of their in-laws, at least temporarily, frequently until the birth of the first child; in the case of elopement, females to the household of their husband or to a newly established household altogether, and in the rare negotiated situation, females to the household of their husband. Sometimes an elopement may be effectively transformed into that of 'marrying-in' by the couple living uxorilocally. The various possibilities for residence and succession in the residential pattern are set out below:

(1) by negotiation virilocal

virilocal $\longrightarrow$ neolocal

(2) 'marrying-in' uxorilocal

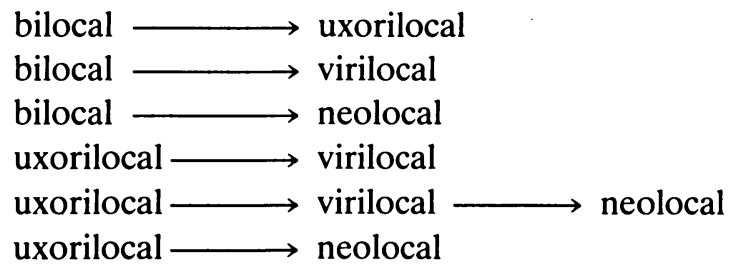

(3) elopement neolocal

virilocal

virilocal $\longrightarrow$ neolocal

virilocal $\longrightarrow$ uxorilocal 


\section{Implications of kinship relations for village-plan}

Nuaulu kinship rules and conventions concerning residence unquestionably affect the physical layout of the village - both in terms of the size and shape of individual domestic structures and in terms of their dispersion.

An obvious factor of the first kind is that the presence of an important elder (clan head, kapitane or other person of similar status) will often imply the occupation of a numa mone (clan ritual house). Thus, status is a determinant of house structure. At the same time, the size and composition of the household to some extent is a factor in the physical appearance of the house. Nevertheless, the correlation between actual size of the domestic structure and the number of persons living in it is not a high one, and this appears to be attributable to the mobility of personnel, the relatively long life of a single structure (particularly a numa mone), and the fact that numa mone are built for essentially ritual and not domestic reasons. The correlation appears somewhat better between the area of living space and the number of inhabitants past puberty, since children are seldom taken into account in the construction of a dwelling (c.f. David 1971). Households with large numbers of adults sometimes have extensions built onto the original dwelling (e.g. 20 on MAP 5), while extra space can be gained by constructing separate cooking shelters (e.g. 14, 16, 23 and 24 on MAP 5). In such households, compositional complexity may also be reflected in internal partitioning. There is a much stronger correlation between total clan population (taking men living with their wives' parents as temporary members of their host clan) and the number of separate households $(r=0.99)$, suggesting that there are few pressures exerted differentially on clans and that there is an equal availability of land resources for building.

Ideas and preferences about residence also affect the distribution of houses - their spacing with respect to each other. In general there is a desire to construct new houses close to the parental home, usually virilocally but sometimes uxorilocally. Often actual construction of the house follows some time after a couple has actually been living with one or other of the spouses' kinsfolk. It was generally agreed that the ideal situation was to have the houses of genealogically related persons, and by extension the entire clan, close together. Nevertheless, however advantageous the close proximity of houses of related households might be, the importance attached to the small independent household grouping is such that multiple occupation is a rare occurrence and is not catered for in the structural design of the dwelling, in contrast to 
Ambonese and tribal groups further east on Seram. However, restrictions within the village, of both an idealogical and physical kind, often prohibit expansion in the desired direction.

Analyses of the observable pattern of any one village must, at the very least, consider two basic rules as to the most desirable relations between houses and their occupants: the minimization of the distance between clan members, and the optimization of that between households. The advantage of the first is that in disputes members can offer ready support and also that clan identity can be expressed in the form of separate sectors of the village. The actual physical arrangement is not far off this ideal but is necessarily blurred by the fact of 'marrying-in'. Thus, in MAP 5 , the households are divided between the various clans as follows: ${ }^{26}$

$\begin{array}{ll}\text { Matoke } & 1,14,16-17,23 \\ \text { Nepane-tomoien } & 9,11-12,18-20,25 \\ \text { Penisa } & 22,24 \\ \text { Somori } & 4,8,15 \\ \text { Sonawe-ainakahata } & 2-3,5-7,10,13,21\end{array}$

Even if clans are not always geographically discrete, clan divisions invariably are. The rationale of the second is less clear. The relationship between different households is an ambiguous one for the Nuaulu; on the one hand the close cooperation between numbers of related households requires siting as closely together as possible, on the other hand ruptures in social relations based on petty jealousies and hostilities are best avoided and healed by tangible recognition of the fact by maximum distance between opponents. Domestic disputes (sometimes ending in divorce) and sorcery accusations can lead to both temporary and permanent change of residence at the household and village level. Factors such as the shortage of building land and the permanent nature of house structures tend to favour dense village layout and do not encourage flexibility in siting or re-siting of houses (see above pp. 43-45). In the event of serious ruptures those involved normally shift, via genealogical links, to households away from the foci of conflict, sometimes outside the village.

\section{Non-kinship organizational factors and village structure}

In discussing the relationships between the physical village and organizational factors I have so far concentrated only on kinship, because the great majority of such factors are expressed through the idiom of kinship. Increasingly though, other internal factors are affecting the 
shape of the village. Similarly, non-indigenous ideological factors are becoming important. Thus, in some circumstances, religious conversion puts a person outside the village community, not merely metaphorically but physically also (see footnote 22) and the consequences can be quite considerable. Various pressures come from government and administrative sources. The impact of these were already beginning to be appreciable during 1969-71 with the 'Projekt Sosial' in Bunara, an example of government 'development' aid for tribal peoples in the Moluccas (see footnote 9). By 1973 the project also involved Watane and Ruhuwa. The most important physical manifestation of this government assistance has been the construction of houses of splitbamboo walling intended to replace traditional Nuaulu elevated dwellings. On the whole, the Nuaulu have been reluctant to occupy these new houses. Another innovation brought about during the last few years is the building of a permanent government rest-house in Ruhuwa. The extent to which these things will permanently alter the pattern of the Nuaulu village is as yet uncertain but it is clear that they must have some impact. Much depends on the ability of the government to complete effectively its intended programme of work. ${ }^{27}$

\section{The developmental cycle of the village and expansion}

In considering village-plans what is rarely taken into account is that, like the social groups of which they are composed, they are constantly changing entities - from their very inception till their abandonment. Though they may be inhabited continuously for many decades the physical appearance of each site constantly changes. They are not the static creations implied by the treatment given them by Fraser (1968); houses are being demolished and rebuilt; new houses are built to accommodate expanding populations; service paths come into existence; old ones become abandoned; old water sources dry up or become useless and it becomes necessary to exploit new ones; adjacent gardens are being created; old ones neglected; trees are planted and removed and patterns of ownership change, and the physical appearance and distribution of structures changes as does the entire micro-environment of the village surface.

The Nuaulu village requiring expansion faces distinct problems in its present coastal situation. The two most important of these are the claims of outsiders to land adjacent to Nuaulu villages and the sheer physical problems resulting from terrain. In Aihisuru (FIGURE 4.1, and accompanying text) steeply falling and rocky surfaces on three sides 
prevent effective expansion. In Ruhuwa, the situation is more complex. Here, expansion of actual residential area can be brought about in two unsatisfactory ways. The coconut groves which occur along the coast, and which at this point are the property of Muslim clans from Sepa, can either be cut down with the payment of appropriate compensation, thus allowing lateral expansion, or the village can expand towards the mountains which is disadvantageous in terms of gradient, large stands of timber and the fact that the land is claimed by individual Nuaulu clans. As all land in the village is owned by the village as a whole, if land towards the mountains is required for expansion the clan and the particular household which has rights in that land is obliged to part with it for the common good, without compensation. ${ }^{28}$ In general, the result of such pressures against outward village expansion has been the inward concentration of dwellings. There is evidence that the total Nuaulu population is rising, based on a combination of field census materials (see, for example, FIGURE 14), statements by informants and other circumstantial data and head-counts from earlier literary sources (e.g. Seran 1922: 206). However, the present sites appear to be able to contain the rise without substantial expansion.

\section{Integration of factors affecting village-plan}

What has become apparent from a consideration of the factors which affect the final form the concrete village-plan will take is their number, variety and differential intensity of effect, which depends on the consensus of the community, the needs of individual groups and persons and what is possible in given environmental and social circumstances. There are 'rules' concerning the configuration of the various elements in the village and concerned with the distance between those various elements. The pattern of Nuaulu villages and their successional aspects are the product of a number of structurally relevant variables - political power, ritual authority, property, descent principles, subsistence requirements, emotional attachment and the like, and cannot be ascribed to a single formula. It is one of the failures of most studies of the Indonesian village to date (see, for example, those in Koentjaraningrat 1967) to consider, in an analytically relevant way, the multifarious factors that may affect village structure. Often it has seemed that villages have existed in an environmental and sociological vacuum.

The Nuaulu village-plan, like any other, must at the very least fulfil several minimum social and ecological requirements. But in attempting to maximize particular culturally determined ends, there is often conflict 
between opposing demands. Thus the Nuaulu are forced to make a compromise between adhering rigidly to a prescribed structural formula and arranging the village-plan merely according to kinship, capricious interpersonal relationships and the demands of physical location. There is an inherent conflict between the symmetry imposed by ideological factors and the asymmetric demands of others. In terms of villageplanning, the Nuaulu possess a basic structural schema indicative and justified in terms of the attitudes and values of the community; it is a model of certain fundamental cosmological relationships, in the Nuaulu case, purely an orientational model - a body of rules generating an ideal configuration. This basic ancestrally-ordained framework can be manipulated and skewed by environmental and social pressures, but remains valid unless a prescription as to a desirable relationship is contravened. It is therefore insufficient to say, as Fraser has done (1968: 8), that all planning solutions in tribal villages are traditional ones - 'long established solutions already approved by ancestors'. To do this is to ignore the enormous pressures which go to affect any ancestrallyordained formulation and give the village pattern in its totality. And then there are those social factors which are of external origin; the effects of government rest-house policy and 'aid' programmes, the implications of the creation of distinct administrative units for the structure and siting of villages (the imposition of the concept 'soa'), and so on.

This short investigation of the factors affecting the structure of Nuaulu villages serves as the natural focus for the description of the pattern of settlement in general. It is assumed for the purposes of analysis, though not in any arbitrary way, that the village is a fixed point, that is, a given. This permanency has already been remarked upon. Although individual sites are always changing compositionally and structurally through time, they have a finite lifespan and are closely geared to the prevailing agricultural regime, reflecting the constant changes in the location and exploitation of cultivation sites. Nevertheless, for all practical purposes, the village as a total entity may be regarded as a constant, relative to all decision-making behaviour involved in the generation of other aspects of the overall pattern of settlement. It is appropriate that the village should have this analytical priority, since the village itself lies at the very centre of the Nuaulu personal universe and their general concept of the environment. 


\section{CHAPTER IV}

\section{NON-DOMESTICATED RESOURCES AND THE ECOLOGY OF SETTLEMENT ${ }^{1}$}

\section{Parameters of settlement}

To view the settlement pattern simply as a spatial entity results in only a partial understanding of a complex situation. Nevertheless, for practical purposes and as a point of departure, a particular area exploited by a specified population may, in an approximate way, be defined cartographically. Thus the absolute limits of Nuaulu exploitation can be represented graphically, although the boundaries are irregular and changing. MAP 7 shows the entire area exploited by the Ruhuwa Nuaulu (180 persons) during the period in which fieldwork took place - some 900 square kilometres, broadly coinciding with the drainage basins of three major watercourse systems: the Ruatan, Pia and Lata-Tevi. In dynamic terms this represents the limit of the environment as it interacts with a single specified population; in anthropocentric terms it represents the Ruhuwa-Nuaulu exploitative area, which biologically can be characterized as a single man-modified ecosystem.

Having said this, the differential intensity of exploitation for various parts of this area as a whole indicate that the larger part is really of very little direct ecological or economic relevance for Ruhuwa subsistence or social organization. Field data on work scheduling for a test period of 524 man-days, illustrated in TABLE 12, show that the exploitation of non-domesticated resources occurred in 13 locally-defined localities of varying size and importance. However, the cumulative area of all localities (214 square kilometres) does not match the entire area which the Nuaulu maintain they exploit. There is a lack of congruity between ideology and statistics, although this is emphatically not a distinction between claimed territory and area actually exploited, since Nuaulu concepts of territory, except in the narrow sense of land owned and cultivated, have been largely only of historical importance since the occupation of the present settlement localities.

To some degree it must be expected that had the composition of my field sample been different and had it covered a different period of time the results would have accordingly differed. This I accept, but the 


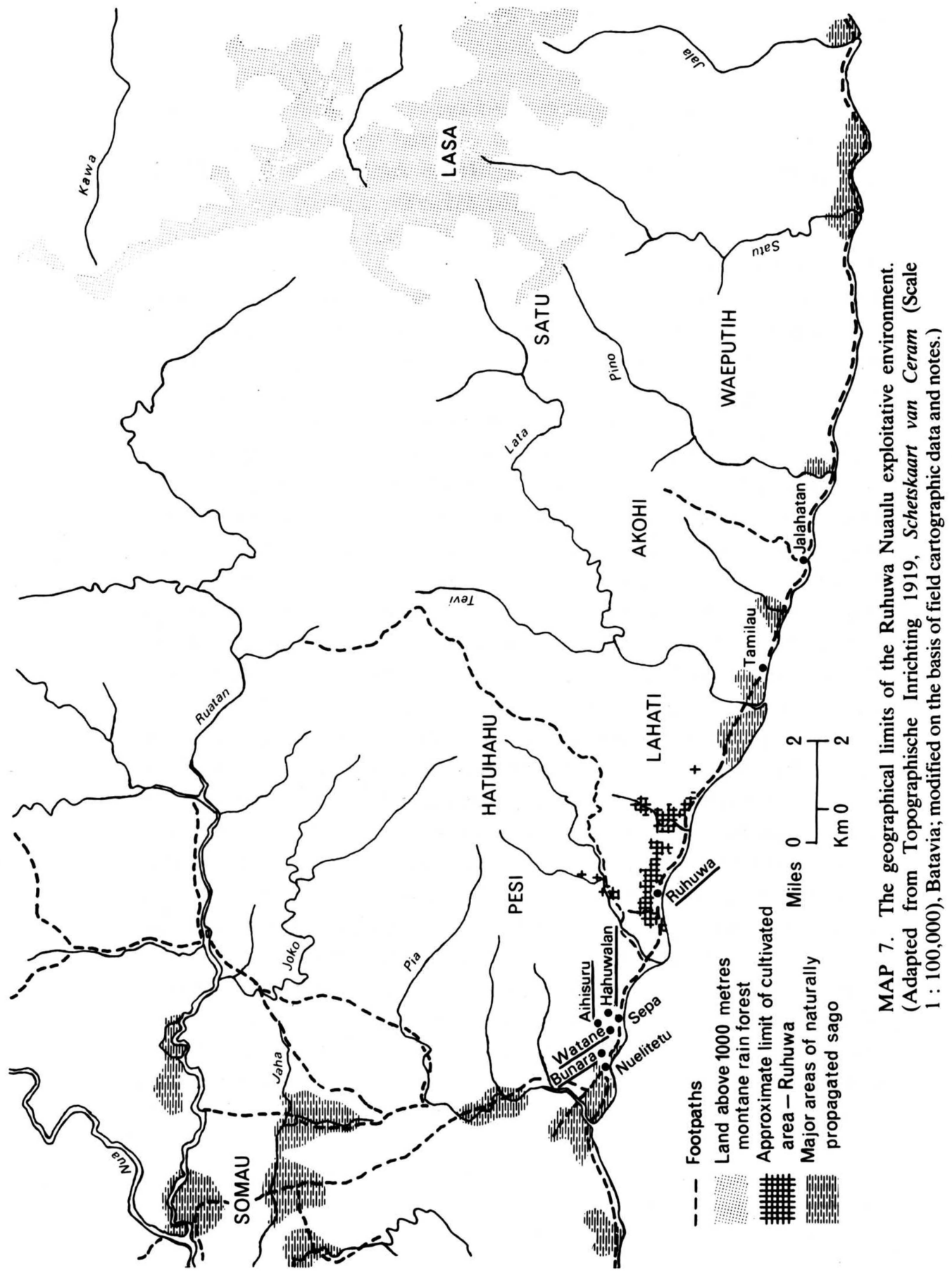


TABLE 12. Differential exploitation of the non-domesticated environment, Ruhuwa, 1970 (measured in man-days)*

\begin{tabular}{|c|c|c|c|c|c|c|c|}
\hline Locality & Reference & $\begin{array}{l}\text { Hunt- } \\
\text { ing }\end{array}$ & $\begin{array}{c}\text { Various } \\
\text { gathering } \\
\text { activities }\end{array}$ & $\begin{array}{l}\text { Extraction } \\
\text { of wild } \\
\text { sago }\end{array}$ & $\begin{array}{l}\text { Fish- } \\
\text { ing }\end{array}$ & $\begin{array}{c}\text { Total } \\
\text { no. } \\
\text { man-days }\end{array}$ & $\begin{array}{l}\text { Per- } \\
\text { centage } \\
\text { total }\end{array}$ \\
\hline $\begin{array}{l}1 \text { Upa river } \\
\text { area }\end{array}$ & MAP 4 & 81 & 56 & & & 137 & 28 \\
\hline 2 Sama & MAP 4 & 15 & 33 & & & 48 & 8 \\
\hline $\begin{array}{c}3 \text { Mon river } \\
\text { area }\end{array}$ & MAP 4 & 26 & 7 & & & 33 & 6 \\
\hline $\begin{array}{l}4 \text { Awao } \\
\text { river area }\end{array}$ & MAP 8 & 9 & 2 & & & 11 & 2 \\
\hline $\begin{array}{l}5 \text { Ruhuwa- } \\
\text { village } \\
\text { vicinity }\end{array}$ & MAP 8 & 17 & 20 & & 18 & 55 & 11 \\
\hline $\begin{array}{l}6 \text { Lihuru } \\
\text { river area }\end{array}$ & MAP 8 & 1 & & & & 1 & - \\
\hline 7 Lahati & MAP 6 & 26 & 4 & 1 & & 31 & 5 \\
\hline 8 Somau & MAP 6 & 1 & & 165 & & 166 & 34 \\
\hline $\begin{array}{c}9 \text { Lata river } \\
\text { area }\end{array}$ & MAP 6 & 30 & & & & 30 & 5 \\
\hline $\begin{array}{c}10 \text { Joko river } \\
\text { area }\end{array}$ & MAP 8 & 2 & 2 & & & 4 & - \\
\hline 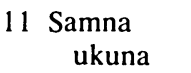 & MAP 8 & 1 & & & & 1 & - \\
\hline 12 Turiaro & MAP 8 & 5 & 1 & & & 6 & 1 \\
\hline $\begin{array}{l}13 \text { Ruatan } \\
\text { river area }\end{array}$ & MAP 6 & 1 & & & & 1 & - \\
\hline Totals & & 215 & 125 & 166 & 18 & 524 & 100 \\
\hline Percentage tot & tals & 41.5 & 23.5 & 31.5 & 3.5 & 100 & \\
\hline
\end{tabular}

\begin{tabular}{lcc}
\hline b. & & \\
Locality & Approximate area $\left(\mathrm{km}^{2}\right)$ & Man-day/area index \\
\hline 1 Upa & 14 & 10 \\
2 Sama & 8 & 6 \\
3 Mon & 8 & 4 \\
4 Awao & 0.5 & 22 \\
5 Ruhuwa & 0.5 & 36 \\
6 Lihuru & 0.75 & 1 \\
7 Lahati & 25 & 1.25 \\
8 Somau & 48 & 3.5 \\
9 Lata & 48 & 0.5 \\
10 Joko & 0.25 & 16 \\
11 Samna ukuna & 0.5 & 2 \\
12 Turiaro & 0.25 & 24 \\
13 Ruatan & 60 & 0.01 \\
\hline Total & 214.25 & \\
\hline
\end{tabular}

* For a discussion of the sample used see Appendix D. 
important point to grasp is precisely that there is this variability over time and that the boundaries of the area exploited during one period are slightly different from the boundaries for some other period. Furthermore, when the figures given in TABLE 12 are themselves analysed, the differential intensity of exploitation for each of the 13 separate localities is shown up dramatically, as is the variability from locality to locality in the type of activity undertaken. The data considered in the table will be discussed further below, their relevance here has simply been to illustrate the fact that attempts to define precise boundaries for the exploitative environment are empirically impossible in the Nuaulu case and that acceptance of such a boundary might result in inaccurate deductions concerning their ecological relations. It is much more helpful to see the threshold between the exploited and non-exploited parts of the environment as a varying point along a spatial continuum, changing through time and as a function of demand for various non-domesticated resources. Energy flow and interaction between the population of Ruhuwa and different parts of the non-domesticated environment varies over time: seasonally, annually and in terms of longer cycles as determined by factors such as periodic demand for and availability of various resources.

Given the view that the boundaries of the area exploited change, it is far less likely that the arena in which the great majority of Ruhuwa environmental interactions take place will be seen in isolation from the wider socio-ecological context. I think that failure to appreciate this has been responsible in the past for some concealment of the critical variables affecting settlement generation. It becomes quite apparent, therefore, that not only is a purely cartographic approach dangerous, but also that there are some awkward definitional problems involved, which, if not treated, tend to distort subsequent analysis. ${ }^{2}$

\section{The exploitative environment}

Within the settlement area of Ruhuwa as a whole, environmental exploitation is far from being uniform, for reasons of the differential availability of various resources, or due to natural barriers effectively limiting availability. This suggests that ecological variation within a given exploitative area may be quite considerable, determining the breadth of choice available in the selection of particular locations for residence and exploitation of resources; but it is typical of tropical forest cultivators that the actual latitude of choice is restricted very sub- 
stantially by the generally uniform nature of the ecology of the area. The sources and effects of such ecological variation as there is (Conklin 1961: 30) have already been partially explored in terms of village location and layout, and I shall examine other factors in due course.

Morphologically, the Nuaulu settlement pattern can be seen in terms of a series of dual components. First there is the distinction which can be drawn between the environment which is exploited by a single population isolate and the much more restricted area actually inhabited by that population, emphasizing the separation of resources and residence made in the last chapter. ${ }^{3}$ Secondly, a valuable spatial distinction can be drawn between the inner area of maximal exploitation, and the outer area in which man-environment interactions are much more diffuse. Finally, a distinction can be made between the domesticated and nondomesticated environments, resting on the nature of the exploitation of resources and therefore not necessarily implying spatial separation. It should be noted that although these three kinds of analytic distinctions are parallel they are in no way identical. ${ }^{4}$

In the chapters which follow, most of the analysis refers to the inner zone of concentrated exploitation of the domesticated environment, an area approximately bounded by the most distant gardens. In the present chapter the emphasis is on the latter, the outer zone of intermittent exploitation, but also with the non-domesticated environment as a whole. Since the greater part of this zone is occupied by mature and primary forest it is this which must be considered first.

\section{Mature forest}

For the Nuaulu, the principal distinguishing features of wesie (largely unowned and uncultivated forest land) and wasi (land that is owned and has been cultivated) are the trees from which they are composed, in particular their size. Thus, almost synonymous with the contrasting set wesie: wasi is the set ai jonata: ai jana wasi, 'great trees': 'trees of the garden'. Not only is this a simple dual classification of types of tree, of mature and secondary forest association, but it also has far-reaching ecological and cultural implications. Thus, the category ai jonata has the following cultural associations:

(1) the source of the principal components of the house frame and the village ritual house;

(2) the habitat of many of the most malevolent spirits known to the Nuaulu; 
(3) the source of major game animals, and of birds for consumption and decoration and ritual purposes - the hornbill (Aceros plicatus Forster), cassowary (Casuarius casuarius L.) etc.;

(4) the source of forest products such as resin (e.g. Agathis alba Foxw.), iane nuts (Canarium commune L.), and many fruits;

(5) the location of numerous natural objects with magical associations, and of mythical events, stories and such like.

But ai jonata removed from its natural forest context changes its character entirely: it ceases to be NATURAL and becomes CULTURAL; the transition is cognitive, and frequently linguistic. To a certain extent, the properties of natural species are thought to change as a result of this transformation; attitudes towards uncooked (WILD) game animals become neutralized by cooking and its presence in a DOMESTIC setting. For example, Python reticulatus is ritually dangerous for some clans in all its manifestations in a wild, live and natural state; once dead and cooked the only prohibition for those same clans is on its consumption. Parallel dichotomous attitudes could be given for many other natural products which are utilized culturally. Thus, it is the context, the ecological zone in which it is found, that $a i$ jonata exists and in which it manifests its significant characteristics.

Wesie has all the characteristics of ai jonata and more, for the vegetal component of the Nuaulu environment consists of basically three categories: $a i$, trees and woody shrubs; wane, lianas and trailers, and rahue, herbs and shrubby plants. All these are found in a particular combination to give wesie. Each separate and specific component of the flora has qualities by which the Nuaulu recognize it and utilize on appropriate occasions, but the forest as a whole is an entity which divulges its own pecularities. It has noises: the shrieks of birds, falling trees and boughs, game animals, the perpetual drone of cicades and other insects, the resonance caused by felling timber and the huge buttress roots being beaten. But the reason why such noises are so marked is because of the never-ending and all-pervading background of silence on which they are only superimposed incidents. It is said, 'there is no wind in the forest, it is evil.'

Nuaulu venture into the forest frequently, but always with diffidence, taking both practical and magical precautions (Ellen 1973: 54-6, 1425). Travel is largely by established major and minor paths (barisi and arena), using wellknown landmarks such as standing stones and prominent trees, together with artificial markers, for direction-finding. The most important of these thoroughfares are indicated by a broken line in 
MAP 6. Care of paths in the deep forest regions is deemed less important than those in the immediate neighbourhood of the village, but some of the rules of upkeep apply here also. At some strategic points huts (numa wanane) are built as halting places for long-distance treks, such as those to the north coast (Ellen 1973: 145).

\section{Distribution, structure and composition of 'wesie'}

The distribution of wesie at the present time in the vicinity of Ruhuwa is illustrated in MAP 8. It will be noted that the observable distribution falls into two categories: (a) the bulk of forest stretching from a very minimum of around 100 metres from the coast northwards and mountainwards, and (b) isolated patches and pseudopodia apart from the major block of forest and forming barriers between cultivated areas. This latter residual distribution tends to be along ridges and around steep knolls, unsuitable for cultivation under normal circumstances. As a result, these areas (together with the margins of the main forest block) within easy access of the village, are a principal source of construction timbers and certain other products, leading to gradual thinning and denudation.

Wesie consists of two basic types of forest association: the typical tropical rain forest, which stretches from sea-level mountainwards, and montane rain forest (including mossy forest areas), usually above 1000 metres. The lower tropical zone may include submontane rain forest, between 500 and 1000 metres, but the critical heights given, based on calculations by Van Steenis (1935) and Richards (1952: 348), are only approximate, due perhaps in part to the so-called Massenerhebung affect. This is usually defined as the differential rate of change of climatic factors with height varying from place to place and causing the actual altitudinal limits of the vegetation zones to differ on different mountain ranges and different parts of the same mountain (Richards 1952:347). But although the Nuaulu recognize zonal variation within wesie areas, as it is of no practical utility to them, it is an unimportant aspect of their environmental model. The only occasions on which montane zones are traversed are during journeys to north Seram, or on the longer hunting trips to the headwaters of the Nua, Ruatan, Kawa or Lata (MAP 2), or in collecting resin from the conifer Agathis alba Foxw., a particularly prominent feature of the higher forest zones.

Although no detailed studies exist, and there is undoubtedly considerable variation in profiles, the composition of lowland forest below 1000 metres (mostly on low hill land) can be said to be broadly typical of other 
afforested insular areas of Indonesia and New Guinea, with a structural complexity related to the great number of different tree species, approximately 80-100. Over 250 distinguishable Nuaulu plant taxa are apparently associated with wesie. These can be grouped into three broadly identifiable vegetation layers: large trees, woody lianas and perching plants, such as orchids and ferns (Robbins 1961). ${ }^{5}$ The variety of species means that the composition of tree communities vary considerably and that pure stands are comparatively rare. Canopy height is generally 30-40 metres.

In Seram, the typical dominant of the more inland and highland areas, kamane (Agathis), appears to be replaced towards the coast by other co-dominants, such as iane (Canarium commune L.), kaiane and nosate (species of Terminalia), ahutaune (Calophyllum sp.), asaherane (Myristica sp.), hardwoods such as kinai (Pterocarpus sp.), and ai jarine (Diospyros sp.), in favourable localities the giant sakaputi (Melaleuca leucodendron L.), and in riverine areas stands of nunu (Ficus sp.), and neune (Casuarina sp.). These same lowland areas contain seasonal sago swamp, and occasionally permanent swampland, of mixed species of some importance in Nuaulu subsistence economy. Ground cover, generally thin, consists largely of pteridophytes, principally ferns of various descriptions, but also the distinctive soka-sokai (a species of Selaginella), mosses, small herbs and tree seedlings (Ellen 1973: 45064).

\section{Exploitation of non-domesticated food resources}

One fact that has not received the attention it deserves, and which can have critically important implications for understanding the ecological and economic organization of communities such as the Nuaulu, is the crucial role of hunting and gathering of wild vegetable foods in societies nominally regarded as subsisting by swidden agriculture (Barrau n.d. 28, 30; Boserup 1965: 54). The Nuaulu, in particular, devote a considerable proportion of both their time and energy to these subsistence activities, and the food so obtained contributes a relatively high proportion of their energy intake. Indeed, although there is no Nuaulu concept of a primary and only dependable single source of food, sago and meat, both essentially products of the non-domesticated environment, rank at the top of lists of the most important foods. Activities in which the Nuaulu interact with and exploit the environment without cultivating it can be classified into the following six broad but economically distinctive categories: hunting; fishing; the collection of mis- 
cellaneous animal foods, such as insects and grubs; the cutting of sago; the collection of tree-food products, plants and fungi, and the extraction of non-edible forest products. The account given here is designed purely as a short discussion of these particular subsistence activities as elements in Nuaulu man-environment relations, and as determinants of settlement pattern; in consequence, only minimal attention is paid to the organizational and technological details involved.

Hunting provides the overwhelming proportion of animal protein consumed by the Nuaulu, although the consumption of fish is nutritionally important, almost certainly more so than in former times. In order of dietary importance, the major game animals are pig, cuscus, deer and cassowary. In this respect the actual frequency of consumption matches well the value attached to these animals as sources of food in Nuaulu thought. Theoretically, the Lord of the Land may impose ritual prohibitions, sasi, on the hunting and collecting of certain species, as he can for the gathering of vegetable products, though this seldom happens in practice. ${ }^{6}$ TABLE 13 condenses information collected from two Ruhuwa households over the equivalent of a four month period in 1970 regarding the major sources of animal protein and its consumption. ${ }^{7}$

Game is hunted all the year round, though supply is less plentiful during the height of the rainy season for obvious technical reasons. There are basically two types of Nuaulu hunting organization: (a), cooperative hunting involving a large number of persons recruited specifically for the purpose, sometimes on a clan basis, though not necessarily along genealogical lines; and (b), individual hunting, or hunting undertaken in pairs, where participants are usually closely related. In both cases, the most common weapons employed are longbows, spears of various kinds and occasionally breech-loading rifles. Hunting techniques vary from species to species, but the principal method for large game (particularly pig and deer) is to chase the animal into an open space, such as a dry river bed, where it is easily ambushed by strategically placed marksmen.

Individual hunting may extend over several days, in which case the special huts already mentioned are made use of, located in areas frequently visited by hunters, such as Lahati (MAP 6). A less elaborate structure used for the same purpose is the numa tepine, a bivouac or roughly constructed shelter, in which the occupants sleep on the ground, like - the Nuaulu emphasize with some disgust - animals. ${ }^{8}$ Garden huts are also used as bases for sleeping overnight and for cooking meat. On extended hunts wives and children may accompany hunters, though 


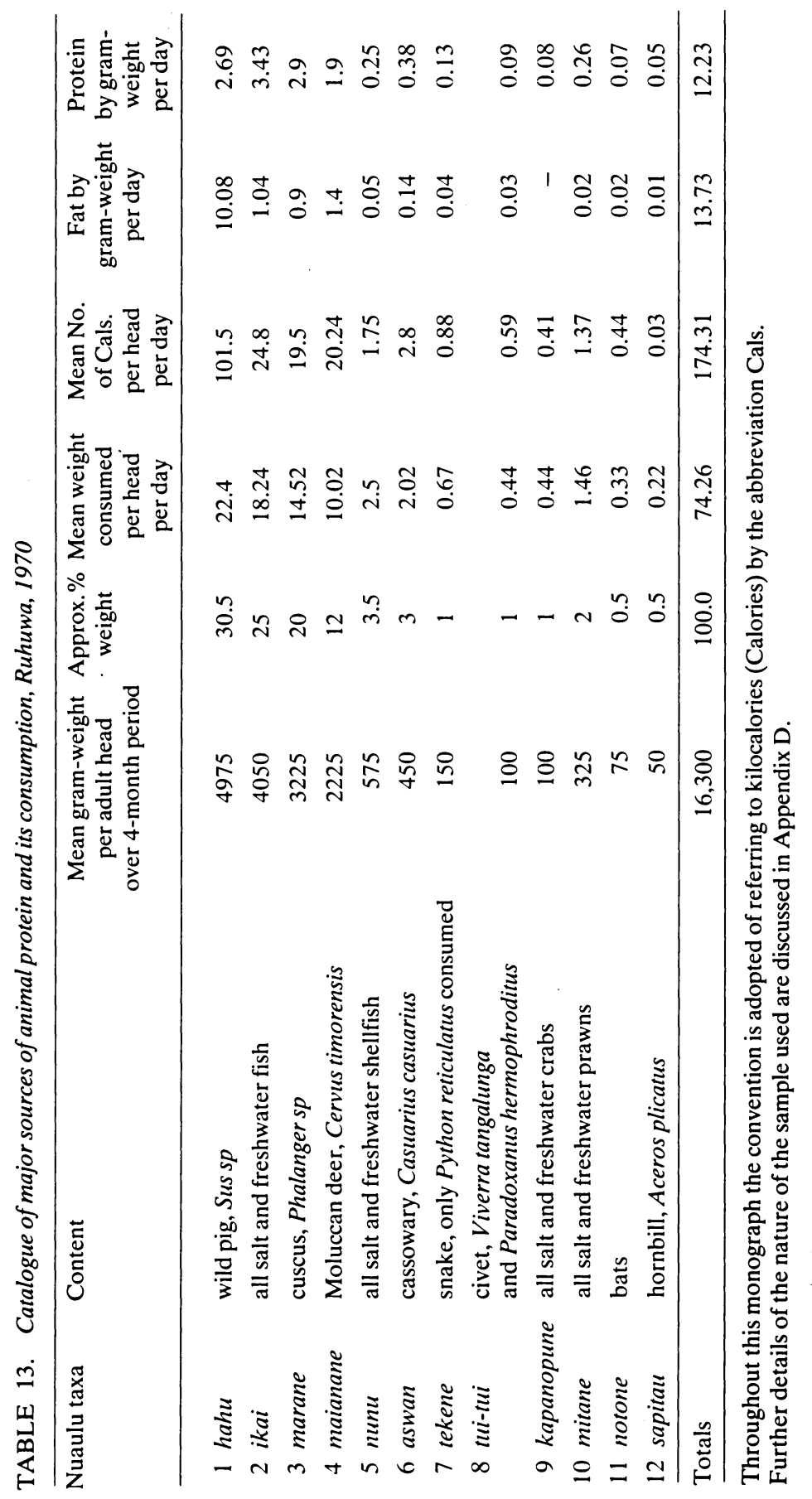


subsistence during such times comes entirely from forest products - the game that has been caught, roots, fruits and so on. Such expeditions may reach considerable distances from the settlement - Lasu, Satu, the river Jala and tributaries of the Ruatan - though normally they are confined to such easily accessible and commonly exploited areas as Lahati and Hatuhahu. This form of hunting is frequently undertaken at night.

In contrast, largely because of the numbers involved, group hunting lacks mobility and flexibility, and is therefore restricted to the inner zone of appropriation and is essentially a daytime pursuit. An expedition rarely exceeds 12 hours, for which time an ad hoc leader is usually chosen on the basis of seniority and experience, though most cooperation is simply by mutual agreement. Up to twenty individuals may be involved covering a wide range and excluding only the very young, senile, infirm and women (Ellen 1973: 151-4).

Trapping is quite common but largely restricted to the immediate area of the gardens (the inner zone), often as a protective device against wild animals. The most important of these are spear traps erected over known deer, pig or cassowary trails, often in series of up to ten at a time. In addition, weighted noose traps are used for cuscus, in series of up to twenty (Ellen 1972), spring noose traps are used for bush turkeys, civets, cassowaries (and occasionally deer and pigs) and a further kind of noose trap, manually operated, is used for a number of bird species, particularly hornbills, cackatuas and lories. The pit trap is known to the Nuaulu but not used by them.

Sea fishing is alien to the traditional Nuaulu way of life and engaged in only by a few men and boys, using baited lines of easily available trade nylon with simple steel hooks, or multiple-headed hooks for squid. It is generally restricted to littoral zones, although outrigger canoes are occasionally used. Freshwater fishing, on the other hand (an activity of both sexes), is sanctioned by tradition, and both fast-running streams and rivers and muddy reaches are exploited by a number of methods: by stupefaction with the root of Garcinia dulcis kurz.; with basket traps, particularly for freshwater prawns, when they are set in weirs and rapids; damming, and with ordinary or multiple-headed spears and arrows. The collection of shellfish for eating and the preparation of lime is common from both marine and freshwater localities.

A wide variety of other minor fauna are gathered, as recognized secondary sources of animal foods, such as grubs; as relishes and sweetmeats (e.g. honeycomb), and as occasional snacks, as in the case of frogs and grasshoppers (Ellen 1973: 446-9). Fauna are also the source of a 
variety of non-food products: bone and antler for tools and other artifacts; shell for lime, implements and decoration; skins for drums and hafting purposes; fur and feathers for ornamentation. Most of these things are obtained as by-products from hunting game for consumption as food. There are, however, some birds, for example nakatua putie (Cacatua moluccensis Grn.) and kihoke (Tanygnathus megalorhynchus Boddaert), which are sought solely for their plumage, for ritual reasons or to keep as pets.

Wild food plants and fruits collected are considerably more varied than the fauna. TABLE 14 lists the most important of these and their contribution to Nuaulu diet, as reflected in data collected during the four month survey period (see also Ellen 1973: 450-64).

Clearly, if abundant forest food plants exist close to the village, individuals are not going to go further than they have to to secure them, and generally speaking (but with the important exception of sago) such roots and fruits are relatively easily available, seldom requiring venturing far beyond the limit of the furthest gardens. In fact, most gathering of wild iane nuts (which are periodically consumed in large quantities in conjunction with important festivals), bamboo shoots and such like, takes place in secondary forest within the inner zone of appropriation, on the fringes of existing gardens. ${ }^{9}$ The conclusion may therefore be drawn that despite the extent of the total area of the non-domesticated environment, the intensity of its exploitation increases in inverse proportion to the distance from residential areas, such that the inner zone also represents the location of the most intensive exploitation of non-domesticated resources. This appears to be the case, both in terms of measurement of the number of man-days devoted to work in particular specified localities (TABLE 12a), and in terms of the index derived by dividing these figures by the approximate area the localities cover (TABLE 12b). Which of these measures is actually the more accurate indicator of productivity is difficult to determine, on account of the larger number of extraneous variables involved.

\section{The collection of naturally propagated sago}

Sago is seen by the Nuaulu as their most important food source, and no meal is considered complete without it. It is credited with strength-giving qualities and regarded as an aphrodisiac. In Nuaulu terms, hunger is the condition which prevails in the absence of sago.

Most sago consumed by the Nuaulu is derived from wild palms which vegetatively regenerate themselves by means of suckers. ${ }^{10}$ During the 


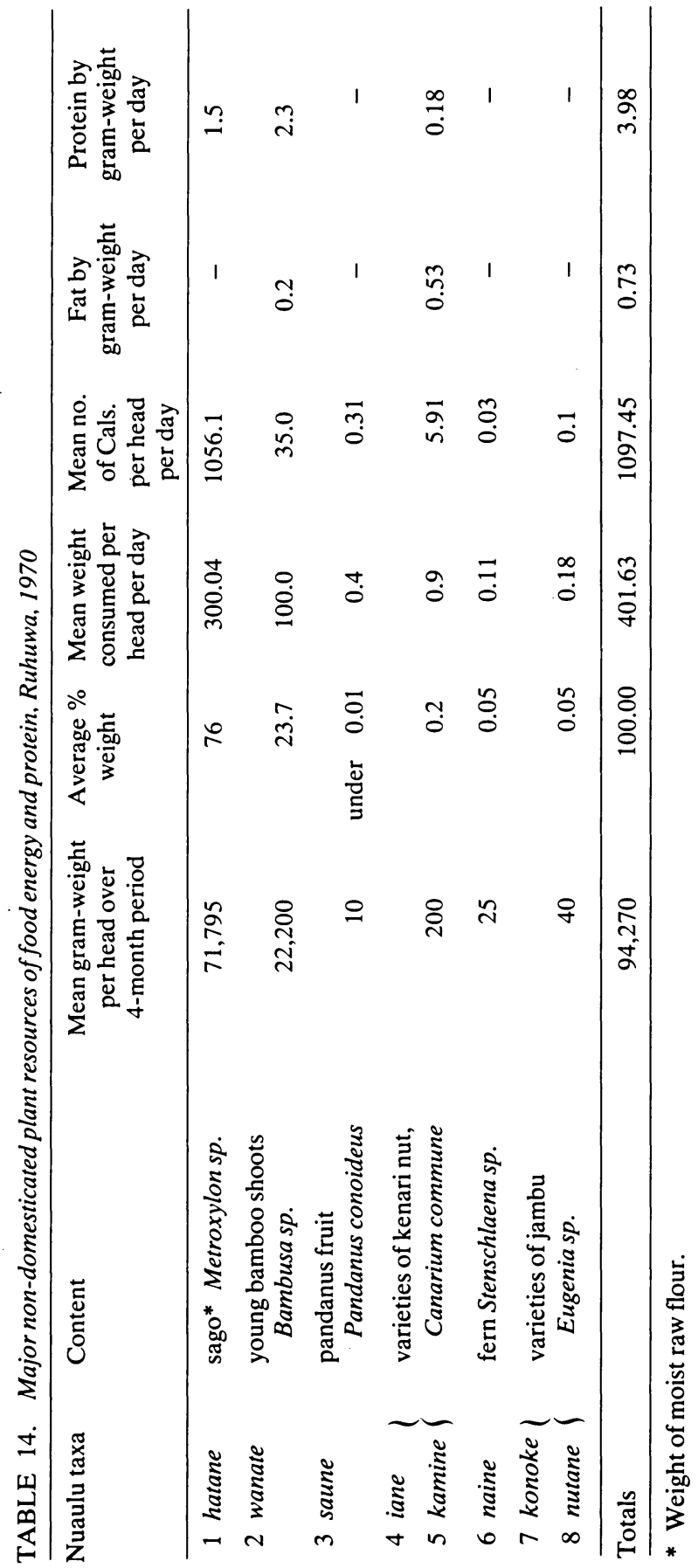


period from April to August 1970 I calculated that almost 54 per cent of all sago consumed was from non-domesticated sources. On the basis of the figures presented in TABLE 14 this would mean that about 1056 Cals per head per day are acquired in this way, representing 76 per cent of the total weight of non-domesticated plant resources converted into available food energy. However, since these data were obtained largely during the wet season, when conditions are least favourable to the exploitation of wild sago, the overall figures are probably higher.

By far the greatest proportion of wild sago comes from the rich, high-density, sago-palm forest areas towards the confluence of the Nua and Ruatan rivers, known to the Nuaulu as Somau and to the adjacent coastal peoples as Tehun (MAP 6, TABLE 12a). Measured orthographically, Somau is approximately 16 kilometres from Ruhuwa over hilly and riverine afforested country. Under normal circumstances, it is considered a six hour journey. In addition, wild sago palms are also cut at suitable localities, usually where the land is permanently damp or swampy, on the river Pia, at Lahati, at the mouths of the Lata, Pino and Satu, and as far eastwards as the mouth of the Jala.

Trips to sago localities may be individual or group activities involving parties of up to 15 males, either short or extended to five days or more, and usually organized on a kinship basis. Extended stays often allow for hunting to be combined with the cutting of sago, and when particularly large quantities are required for important ceremonies the occasion is accompanied by great festivity. Such expeditions often include women and children.

The constant exploitation of particular localities permits the construction of a hut for shelter, and although it is explicitly stated that in these areas no one individual or clan has rights in particular places, customary usage and convenience has led to the association of particular localities with particular villages. Palms in such areas are therefore sometimes referred to as hata niane, 'the sago of the village'.

With the cutting of these wild palms many individuals may work a single stand until it is exhausted and then proceed to another. However, separation of the flour from the pith is an individual or household oriented activity. Naturally set palms are always flowering or about to flower when felled, when starch reserves are at their maximum. This is not true for planted palms, where closeness encourages cutting before a stand has fully matured. Most wild sago is consumed by the worker and his immediate kin and affines, though occasionally small quantities are exchanged in the Muslim settlement of Sepa for trade goods. 
The method of extraction of sago flour has been discussed at some length by other writers for southeast Asia (e.g. Lea 1964: 120-22), and Nuaulu techniques are largely similar. The ground surrounding the chosen palm is first cleared of undergrowth with a bush knife, followed by the removal of the bark right round the trunk for a width of about 120 centimetres from the section which is to be cut. The palm is then felled, usually nowadays with a steel axe, as near to the ground as possible. Foliage and the woody petioles are then removed and a selected section of trunk split down the middle and removed. The exposed sections of pith are then excavated with a bamboo adze and the flour extracted by use of a device made from a membrane of coconut spathe, which separates the starch granules from the pith residue with the aid of water, the former passing through the membrane in suspension and separating out into a trough of sago leaf-stalk. Sago flour can be left here up to one month without deteriorating appreciably, owing to the protection afforded by fermentation (c.f. Oomen and Malcolm 1958: 20), though this change seldom happens since demand is so great. On average it was found that 100 cubic centimetres of trunk gave about 0.02 kilos of moist flour, which in Nuaulu terms means that a good palm can yield up to 20 casks (the equivalent of $106 \times 10^{4}$ Cals.).

\section{Available sources of non-edible forest products}

Mature forest, as well as the non-domesticated environment in general, is as much valued as a source of a wide range of non-edible products as it is for foods. The most important of these is timber for construction purposes and (almost as important, on account of its ritual as well as economic significance) kamane resin from the conifer Agathis. Most timber comes from within a radius of three to four kilometres of the villages, and usually from land bordering the gardens. Good kamane resin is much more difficult to come by and accordingly Nuaulu may travel considerably further to obtain it, sometimes 18 or 20 kilometres to the higher montane regions renowned for its abundance and quality, such as the headwaters of the river Kawa, Satu and Lasa (MAPS 2 and 6). Rattan of high quality is also regarded as worth the effort of travelling substantial distances to obtain, and areas frequented in this respect include Hatuhahu, Lahati and Sama (MAP 6). Other non-edible forest products are usually obtained from within a much shorter radius, rarely exceeding the boundaries of the most distant gardens. Such products include firewood, usually dry dead bamboo of the otherwise unusable Schizostachyum species, from interstitial and marginal thickets in and 
around gardens and unowned areas of secondary growth. Collecting firewood is almost solely an activity of females, though sometimes old men may assist them. A wide range of types of bamboo (Ellen 1973: 450-9) are also in great demand as raw materials for building, manufacture of utensils and basketry. The constant cutting of bamboo from areas near the village tends to transfer normally gregarious bamboo thickets into more open areas, with a greater diversity of shrubs, grasses, herbs and tree seedlings, despite its acknowledged fast growth rate. On the steeper river banks the succession is typically to the various hydrophilic herbs and ferns. Clearance of this kind can also result from a policy of marginal cultivation of fruit trees, coconut and sago palms, or be part of a deliberate programme of clearing land for gardens.

Minor forest resources include bark for bow strings and loin-cloths, varieties of herbs, climbers and roots for dyes, poisons and the manufacture and decoration of utensils and other objects. Apart from timber and bamboo, the most important source of house-building materials comes from the sago palm, the woody petioles of which are used for walling and the fronds of which give the most superior thatch (see also Ellen 1973: 450-64).

The obvious tendency to procure such products, in particular rattans, timber, bamboo and Metroxylon products, as near to the village as possible inevitably leads to the depletion of stable primary associations of forest the nearer one gets to the main loci of settlement. Consequently, when mature forest is cut for gardens it has almost always been considerably exploited already and contains plant associations more typical of regenerated secondary forest. This accounts, in part, for my reticence in using the term 'primary' with reference to mature forest. Such depleted primary growth, like open secondary associations, may become subject to marginal cultivation as well as complete clearance. Thus, we have the transformations:

primary forest, $\longrightarrow$ denudation $\longrightarrow \begin{aligned} & \text { depleted forest, } \\ & \text { open secondary } \\ & \text { association }\end{aligned}$
$\begin{aligned} & \text { marginal } \\ & \text { cultivation, }\end{aligned}$
complete
clearance

(see also Fig. 11).

Input-output aspects of exploitation of non-domesticated environment On the basis of the data provided above, and augmented by that supplied elsewhere (Appendix D, Ellen 1973: 446-64), the contribution of non- 
domesticated resources of the Nuaulu environment is clearly of some substance, in terms of the variety offered, satisfaction of acknowledged requirements and as a contribution to diet. Nutritionally, such sources provide in the region of 1272 Cals. of energy per head per day, while providing 64 per cent of the protein fraction of all consumed food. ${ }^{11}$ This food value may be obtained from a maximum of around 120 Linnaean species of fauna (about 146 named and edible Nuaulu terminal taxa) and around 48 Linnaean species of plants (about 92 named and edible Nuaulu terminal taxa). But although the total number of nondomesticated natural species exploited in this fashion is extensive, over 80 per cent by weight of plant-derived food comes from a single genus, Metroxylon, while almost 90 per cent by weight of animal-derived foods come from sources covered by only 4 Nuaulu primary taxa: hahu (pig), ikai (fish), marane (cuscus) and maianane (deer). Consequently, despite apparent variety, the principal sources of food energy and protein, which these two groups respectively represent, are extremely specific.

Given reasonably accurate data on energy consumption and expenditure, the relative importance of exploitation of the natural component of the Nuaulu environment can be expressed in simple iñput-output terms. Thus, although Nuaulu male labour input in terms of both time and energy resources, regarding the exploitation of the non-domesticated environment (TABLE 15), is more than the contribution to working domesticated resources (TABLE 35, p. 169) their reliance on it in nutritional terms is somewhat less.

In adjacent Muslim communities (even taking into consideration the importance of fish as a source of fats and protein) energy expenditure in the exploitation of the non-domesticated environment and the calorific contribution it makes to their diet is much less, while conversely, much more time is spent in the exploitation of domesticated resources. As a result the Ruhuwa Nuaulu exploitative environment is considerably greater spatially, despite the relative smallness of the population. This illustrates the subtle way in which the overall shape of the exploitative environments and settlement patterns of the respective communities diverge. The implications of the minimization of territorial overlap in terms of inter-group competition and conflict are considerable, leading to the conclusion that the manner in which the Nuaulu manage their relations with the non-domesticated environment help to regulate relations between them and adjacent communities, by relieving the pressure on garden land and other resources (c.f. Barth 1956). But an examination of the detailed mechanics of this process is inappropriate 
here. Rather, the point which perhaps should be emphasized is the ecological distinction between the exploitation of domesticated and non-domesticated resources which gives rise to this situation. It is usual for domesticated resources to be contained within a small area, since in ecological terms this is largely what the distinction implies - the concentration of usable food-energy and materials which is the conscious result of human manipulation of a natural ecosystem. While the biomass of non-domesticated resources is dispersed and unevenly distributed, domesticated resources are separated out and brought together. Hunting activities in particular require a large area since the animal species involved are invariably secondary or tertiary producers requiring a high ratio of plant biomass to support each individual member of the species. Consequently, it is not surprising that the ratio between the domesticated and the non-domesticated areas is much greater for the Nuaulu villages than it is for Muslim villages such as Sepa; and that despite the small population concentrations involved, the Nuaulu exploitative environment is considerably greater spatially even in absolute terms.

TABLE 15. Energy expenditure of males involved in exploitation of non-domesticated resources, Ruhuwa 1970

\begin{tabular}{lccc}
\hline Activity & $\begin{array}{c}\text { Percentage no. of } \\
\text { man-days devoted } \\
\text { to activity } \\
\text { during } \\
\text { test period }\end{array}$ & $\begin{array}{c}\text { Approximate } \\
\text { rate of energy } \\
\text { expenditure } \\
\text { (Cals. per } \\
\text { min.) }\end{array}$ & $\begin{array}{c}\text { Percentage energy } \\
\text { expenditure } \\
\text { devoted to } \\
\text { activity during } \\
\text { test period }\end{array}$ \\
\hline $\begin{array}{l}\text { 1. Fishing } \\
\text { 2. Hunting }\end{array}$ & $3.5(18)$ & 2.5 & 2 \\
$\begin{array}{l}\text { 3. Extraction } \\
\text { of wild sago }\end{array}$ & $41.5(215)$ & 4.0 & 45 \\
$\begin{array}{l}\text { Various } \\
\text { gathering } \\
\text { activities }\end{array}$ & $31.5(166)$ & 3.5 & 30 \\
\hline Totals & $23.5(125)$ & 3.5 & 23 \\
\hline
\end{tabular}

Figures in parenthesis in column 2 indicate actual number of man-days.

For notes on the methodology employed in these calculations see Appendix D.

* Estimates based on Hipsley and Kirk 1965: 43; Norgan, Ferro-Luzzi and Durnin 1974: $339-41$.

In concluding I wish to return to the question of the differential importance of various localities for the exploitation of non-domesticated resources, and consider once again the data presented in TABLE 12. 
Both above and in TABLE 15 I have illustrated the relative importance of different activities in terms of energy expenditure, but I have not related this to the locality in which the activity is undertaken. There are two important reasons for paying some attention to this question; the first is that the distance from the village will affect actual energy expenditure, and the second is the significance of the differential intensity of exploitation for an understanding of the settlement pattern.

In the computation of energy expenditure in TABLE 15 I was forced to rely on rates of expenditure for the same or similar activities on the work of others in comparable areas (e.g. Hipsley and Kirk 1965; Norgan, Ferro-Luzzi and Durnin 1974). The rates are estimates in which some attempt has been made to include travelling to and from work. For reasons which I explain in Appendix D, I believe that the inaccuracies incurred by so doing are insufficient to affect significantly the results obtained and the conclusions I have drawn from them. Had this been a specifically nutritional survey precise measurements would have been essential. The point ought to be made, however, that the time and energy devoted to travel in extracting wild sago, is substantially greater than, say, in fishing or even hunting (TABLE 12, p. 63).

TABLE 12a shows the number of man-days for various activities undertaken in a number of different localities. It indicates that more time was spent in two localities, the Upa river area and Somau, than in all other localities put together (some 62 per cent of the total number of man-days). Together, these areas occupy about 62 square kilometres. Compared with the total area exploited by the Nuaulu, say in the course of one year, this is very small, and it might be concluded that its productivity is therefore high. In a sense this is correct, but if productivity is measured by a man-day/area index (TABLE 12b) the picture that emerges is somewhat different. While real productivity by locality proves a difficult index to compute accurately, the numerical data do emphasize the most important fact to bear in mind: that exploitation patterns do vary quite considerably from area to area, according to vegetational cover, faunal composition, topography and relative accessibility.

From these data four main points emerge:

(1) that the area and intensity of exploitation of non-domesticated resources varies over time, and that the intensity of exploitation varies from locality to locality, together with the particular kind of activity involved; 
(2) that in terms of both energy input and output the importance of the exploitation of non-domesticated resources in Nuaulu ecological relations is considerable;

(3) that animal flesh obtained through hunting, trapping and fishing is the most important source of protein and fat in Nuaulu diet;

(4) that to a large degree emphasis on collecting and those activities in which the Nuaulu interact with the non-domesticated environment is determined by the prominent role of extraction of flour from wild sago palms. 
CHAPTER V

\section{SOURCES AND SOCIAL ORGANIZATION OF CULTIVATED LAND ${ }^{1}$}

\section{Historical introduction}

Parts of the area exploited by the Nuaulu at the present time were also in use before the period of re-settlement, by those clans which had always been situated relatively near the coast, on the larger rivers flowing into the Banda sea, such as the clans Kunia and Pia (MAP 3). With the establishment of coastal settlements these clans already had traditional claims to certain tracts of land. For the most part, however, large areas surrounding the already established coastal villages were cultivated, or otherwise constituted land owned by non-Nuaulu, mostly Muslim but also by smaller mixed Christian and Alifuru villages. Most of this land would have been adjacent to the sea, forcing the Nuaulu to cultivate land further inland, and thus ultimately leading to the present relative distribution of Sepa and Nuaulu land (MAP 8). As was pointed out in Chapter III, there were certain interesting exceptions to this, at some distance from Sepa, where apparently forest stretched as far as the shore at the time the Nuaulu first occupied their present settlement localities. This is reflected in the present Nuaulu ownership of land at certain places directly on the coast such as at Turiaro (W182) ${ }^{2}$ and Makoihiru (W8), land owned by the clans Nepane-tomoien and Matoke respectively. The prior claim to land by non-Nuaulu, and to a lesser extent other non-Ruhuwa clans, represents an important social limiting factor affecting land choice for the Nuaulu up to the present time. This situation is the first given which must be taken into consideration in terms of the generation of Nuaulu patterns of settlement. ${ }^{3}$

The remaining mature forest was, and remained, theoretically available for cultivation by those Nuaulu who wished to do so, principally those clans with no other easily accessible land in the area. In this way, parts of the coastal region gradually came into cultivation with the arrival of the various Nuaulu clans. This suggests that the earlier ones to descend to the seaboard were in a position to exercise a greater degree of choice in the selection of areas to put under cultivation. The principle 

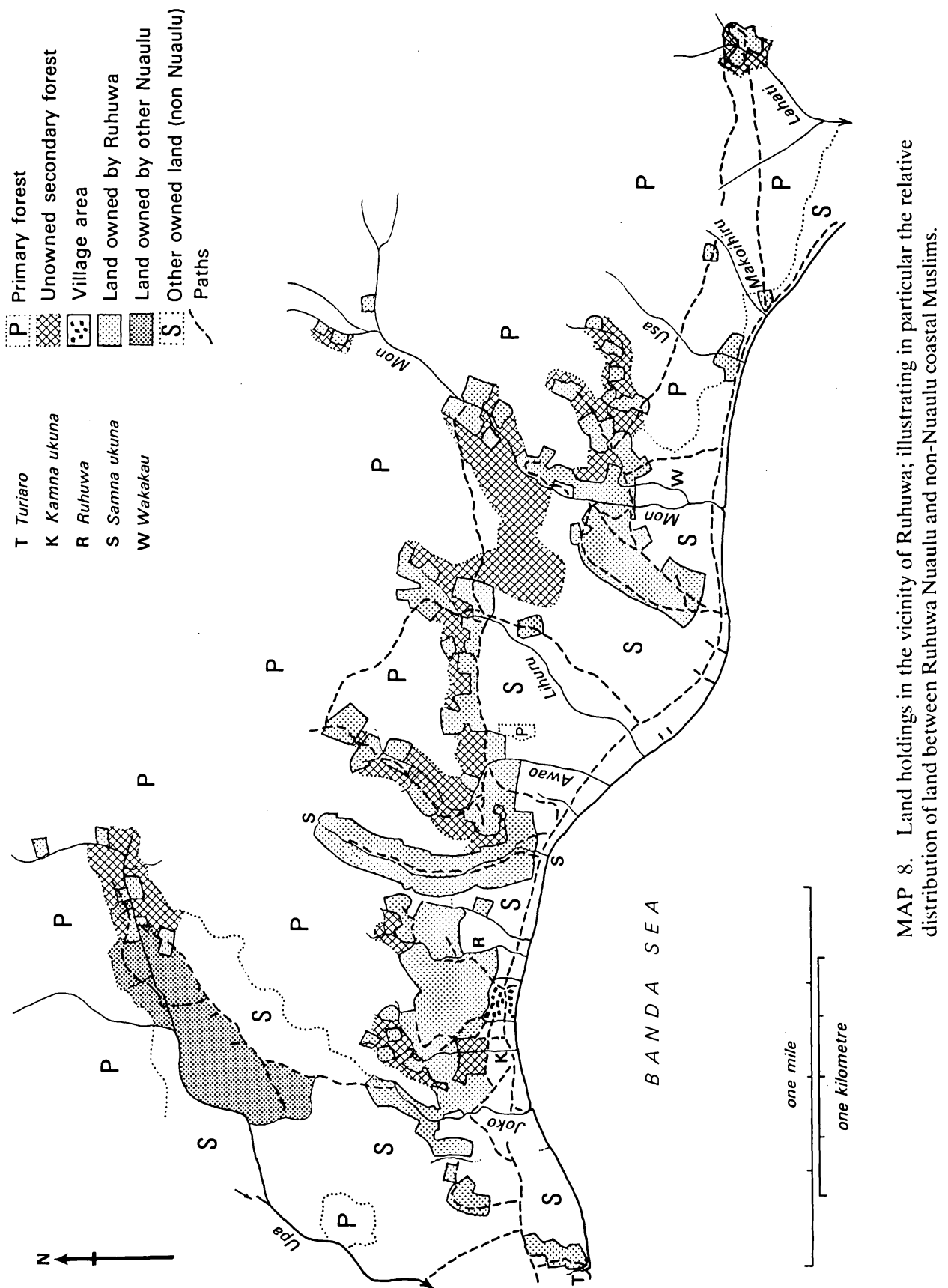
was one of 'first come, first served', the consequences of which are, to some extent, revealed in the present distribution of land. However, even with regard to empty mature forest, a certain proportion is unavailable for horticulture owing to a variety of environmental and sometimes cultural reasons, such as taboo lands. The fact remains that the ultimate source of all Nuaulu garden land is mature forest, wesie, the felling of which represents the first stage of every land-use succession.

\section{Cultivation and 'wesie'}

Of all new gardens created in a single year it was calculated, on the basis of data for 1969-70, 1970-71, that between 20 and 30 per cent are cut from mature forest growth. As such gardens tend to be larger than those cut from secondary growth (nisi ahue) the percentage area is somewhat greater -30 to 36 per cent, around 4-5 hectares (TABLE 21, p. 109). Of all wasi under cultivation during the period 1970-71 approximately 6 per cent had been cut from primary growth, representing 10 gardens.

This represents considerable expansion of settlement parameters for a sedentary community, and it might appear to be useful at this juncture to compare the Nuaulu figures with those available for other communities of swidden cultivators. To do so begs a very important question - are the figures strictly comparable? I have tried to be careful so far in attempting to specify precisely the kind of forest growth covered by the Nuaulu term wesie. It is all too easy to accept 'primary forest' as a convenient gloss for wesie. Indeed, to begin with, I made this assumption myself. The fact is that the terms are not only not necessarily interchangeable, there appears to be a lack of consistency in definitions of what constitutes primary forest in botanical terms. Moreover, it is difficult to know how far terms such as 'virgin forest' ${ }^{4}$ 'mature forest' and 'rain forest' can be equated with 'primary forest'. Here I have accepted Richard's use of the term (1952: 377), and take it to include both the climatic climax of tropical rain forest and mature forest approaching this condition. This is in contrast with typical secondary forest, largely a product of human interference, and which is regarded as being in a mature state after only ten years of regrowth. Little is known about the time-scale of secondary successions (Richards 1952: 400), but primary forest can be taken as being mature old forests which have reached a fairly stable equilibrium of ecological succession (Spencer 1966: 39). The problem, of course, is that in other ethnographic contexts the interpretations may have differed.

TABLE 16 contains some comparative figures for the annual 
percentage of new gardens cut from 'primary' forest for three rather different Malayo-Oceanic communities, the Tsembaga, Hanunoo and Iban. The figures must be interpreted with caution, but they are sufficiently interesting to warrant the comparison. What is clear is that the Nuaulu figures for the annual percentage of all new gardens cut from mature forest are substantially higher than those available for the other three communities. This is probably related in part to population increase (see below p. 81, note 3). In this respect the Nuaulu are similar to the Iban, who have a notorious reputation for territorial expansion. Certainly, the amount of garden land cut from wesie is related to population growth, but this in itself appears insufficient to account for the total amount cleared in a given year. It seems that there is a predilection among the Nuaulu for mature growth, not entirely explained by recourse to available material on demographic trends. To begin with, the horticultural advantages of land on which primary forest grows are appreciated - that root crops grow exceptionally well in such soils given the right weather conditions. It is known that untouched slopes of wesie, with their accumulation of humus and other nutrients, and despite the disadvantages involved in clearance and preparation, provide the best horticulturally productive land available and opportunities for accumulating valuable surpluses. Moreover, high yields are seen as desirable and prestigious in themselves, irrespective of their beneficial nutritive effect.

TABLE 16. Anmual percentage of all new gardens cut from 'primary' forest: some comparative Malayo-Oceanic data

\begin{tabular}{|c|c|c|c|c|}
\hline Community & Location & & Source & $\begin{array}{l}\text { Percentage land } \\
\text { cleared from } \\
\text { primary forest }\end{array}$ \\
\hline 1. Tsembaga & New Guinea & Rappaport & 1968: 14,42 & under 0.25 \\
\hline 2. Hanunoo & Mindoro & Conklin & 1957: 10,41 & approx. 4 \\
\hline 3. Iban & Sarawak Dyak & Freeman & 1970: 131,291 & approx. 23 \\
\hline
\end{tabular}

In addition to new gardens cut from wesie providing increased yields per unit area, it is obvious that the felling of mature growth increases the total amount of cultivated land available for planting. By cutting such land an individual, household and clan obtain certain rights of access and use as long as they may wish to perpetuate the claim. As well as the accumulation of land itself being seen as profitable in the narrow economic sense of increasing the area under cultivation, in the wider sense land is regarded as wealth, to be disposed of ostentatiously and in a 
prescribed manner to affines. To have extensive land is an indication of the prosperity of a household or clan. Nowadays the same prestige accrues to an individual who is in possession of substantial numbers of clove and coconut stands. This enhances his status in negotiation for a bride.

In his discussion of Iban land usage, Freeman (1970: 282-8) cites similar and additional factors which, he believes, explain the high incidence of cutting gardens from primary forest. One of these is that its cultivation brings advantages in terms of raw materials: timber for construction purposes, rattans, resin and so on. Among the Nuaulu this does not appear to be the case. Certainly, mature forest is exploited for all these things and more (see Chapter IV and Ellen 1973: 450-66), but they are not the spoils of cutting gardens. In fact, although occasionally wood or other forest products may be salvaged during clearing a garden plot, most of the growth is simply destroyed. However, there is a tendency to exploit secondary forest and mature forest adjacent cultivated land for the wide variety of products it contains. This has meant that such forest has already been partially transformed before it is actually cleared for gardens. Areas of this type are typically found bordering the areas of highly concentrated cultivation, such as along the valleys of the Samna ukuna, Awao and Ruhuwa (MAP 9). Such land consists of many of the characteristic species of secondary forest, tends to lack rattans and is considerably thinned down on account of the cutting of timber for constructural purposes. This gives rise to a marginal area which is in itself ecologically distinctive, creating an apparent blur between the natural and the cultural, wesie and wasi. It is therefore not surprising that Nuaulu attitudes to such areas are ambiguous and unclear, though they do not seem to be terminologically distinct. ${ }^{5}$ These areas, which have been subject to selected felling for the purposes of obtaining timber, have been termed by Richards (1952: 379, 400) depleted forest and by Fosberg altered forest (1962: 257). Ecologically, these consist of an amalgam of the properties of both primary and secondary forest growth. Natural, as opposed to man-made, marginal areas of this kind are usually found along river banks, and often give an appearance of impenetrability due to a lush undergrowth of lianas (Merrill 1954: 73).

In the Nuaulu case it is quite apparent that far from there being a reluctance to cultivate wesie itself, although certain fairly specific economic factors might make it appear so, there is a great significance attached to having cleared it, for both material and ideological reasons 
(Ellen 1973: 182; 185; 226 note 6; and 227 note 7). ${ }^{6}$ Nevertheless, the pressures inducing the Nuaulu to clear such land should be seen in the context of the competing advantages of medium growth and secondary forest.

Having established this, it should be stated that not all wesie is equally desirable wherever its locality. Some is undeniably inaccessible for ritual reasons or because of environmental disadvantages. Of the area remaining, certain localities are favoured in preference to others. The following points should be noted in this respect.

(1) It is common to cut an area as close to a watercourse as possible, as this provides relative ease of access.

(2) If in one year a garden has been cut from primary forest adjacent to a stream, it is usual to cut the next portion of forest immediately above it on the valley wall, certainly within a few years of having brought the lower area into cultivation.

(3) Areas of mature forest are usually cut as close to already cultivated areas (and, naturally, the location of residences) as possible, again for reasons of access, but also to maximize common garden boundaries.

The pattern developed in the ideal situation where each of these factors are coincident would be a consolidation of the land of any one individual along the length of watercourses. But seldom is this the case, due to lack of coincidence of the above factors and consideration of a wide range of others (see below Ch. VI). The result is that isolated portions away from the main centres of exploitation are cleared, developing as satellites around a focal garden hut (e.g. W1-4, W9, W183-190 ...). The reasons for this are various, but always dominant is the unavailability of other suitable land close to rivers, that is point (1) above, regarded as being of first importance. The process of selection and the relative weight of the factors is considered in more detail in the next chapter.

One further consideration should be added at this point. As has already been indicated, the Matoke clan personified in the jonate Matoke, is, through its status as senior and autochthonous clan to which all others owe their existence, guardian of all land which the Nuaulu consider their original territory - as far as the upland divide between north and south and around the drainage basins of the Ruatan and Nua (MAPS 2 and 3). The jonate Matoke is regarded as having ultimate jurisdiction over all Nuaulu cultivated land and tenurial arrangements, land-man relationships and man-environmental relationships. This is 
why the gloss of the equivalent Malay term is so appropriate - 'Lord of the Land'. He is considered as having no jurisdiction over land immediately bordering the coast, which is not traditionally Nuaulu land and which comes under the ritual authority of other non-Nuaulu Lords of the Land. If an individual wishes to clear a new garden from mature forest he must theoretically first seek the permission of the Lord of the Land. In practice this is typically quite informal. It becomes known that an individual is to cut a new garden from wesie, often at a meeting of adult males, and unless an objection is raised, it is assumed permission has been granted. Only rarely does the Lord of the Land enforce a ban (sasi) on the collecting from, or the cultivation of, certain areas of wesie.

\section{Clearance of mature forest}

The difficulties and time-consuming nature of clearing and burning mature forest, and also advanced secondary growth, means that there has to be some cooperation, although not nearly to the same extent as where plants propagated and climatic regime combine to make considerable demands for short periods, as with wet rice cultivation. In Seram ecological conditions and the cropping pattern spread the load of gardening activity. Nuaulu garden work groups are kept to a minimum size, rarely exceeding pairs of close relatives. Although the clearing of individual gardens does not usually require extensive recruitment of additional labour (despite the fact that it is the most labour-intensive of horticultural activities), when it does become necessary, as in the clearance of recently introduced village gardens, it is usually recruited within the households, the clan or among close affines. Traditionally this was also the method employed to recruit labour for purposes of construction in the village, and it is significant that although at the present time such labour may be recruited from a number of different clans by virtue of their presence in the same local group, it is still rationalized genealogically.

Normally, the selection of sites, arrangement of personnel and planning of work-effort is an individual concern, or arrived at through consultation with other household members. It is based on visits to potential garden localities, visual estimation of their potentialities and drawbacks and a certain degree of discussion with kinsmen or relevant affines. Methods and timing are also worked out at this stage in the proceedings. These matters are dealt with in detail in Chapter VI.

Mature forest is usually cut in December or January, allowing sufficient time for clearing, firing and planting before the heavy rains 
begin in April and May. The cultivation cycle begins with the Pokuwe rite in which malevolent spirits are requested to vacate the land and permission is asked to cultivate it (Ellen 1973: 186-7). As soon as the appropriate ritual has been performed the task of clearing forest may begin. This starts at the centre of the proposed garden (at the point where the magic rite has been performed), with the cutting back of undergrowth and small saplings with a machete - the most important single item, both tool and weapon, in Nuaulu technology. This is often used alone in clearing secondary growth, even that in an advanced state of regeneration, and in the cutting of mature forest it is still an important implement, commonly used for trees of up to 30 or 50 centimetres in diameter, only being replaced by trade steel axes for the largest stands. Normally, the tools required in a clearing operation can be supplied from a single household, but the scarcity of axes means that on occasions these are borrowed, but always from close kin. The clearing of the growth between the larger stands serves to create room for manoeuvre when it comes to tackling them. To begin with the area cleared is usually the central part of the intended garden, sufficient to work within, after which undergrowth is merely cut back as the larger stands are felled, as the workers work out towards the perimeter of the area to be cleared. During cutting, wood is sometimes taken back to the village for construction purposes or for fuel, but as has already been indicated, this accounts for a rather insignificant amount.

In felling the larger forest trees, which are left till last, the slope on which they are often growing and the presence of massive buttresses necessitates the erection of scaffolding from the debris of already fallen trees. These are usually sturdy structures, but seldom secured by binding, and are constructed to give either a near flat area surrounding the tree from which it can be effectively hewn or, in the cases of the largest trees, to minimize effort by cutting the trunk at the point where the buttresses merge with the trunk. This often requires the construction of platforms around three metres in height. ${ }^{\text {? }}$

All felling is arranged so as to maximize tree-fall with a minimum of effort. It entails a preliminary visual estimation of what stands and associated growth, such as lianas, will be brought down when selected trees are cut. By careful and experienced judgement, based on assessment of slope, wind-direction, composition and structure of the forest canopy and relative weight of particular trees, work can proceed rapidly. The aim is not to bring down individual trees but whole portions of forest. The Nuaulu are perfectly aware that the forest canopy is an 
organic whole and to cut even a fairly large tree is not to ensure that it will fall, due to entangled lianas and supporting branches from adjacent trees. Cutting is also arranged so as to maximize sunlight in the resultant garden.

The processes concerning the fortunes of all cleared land, in terms of the various basic tenurial and ecological alternatives, are summarily shown in FIGURE 6.

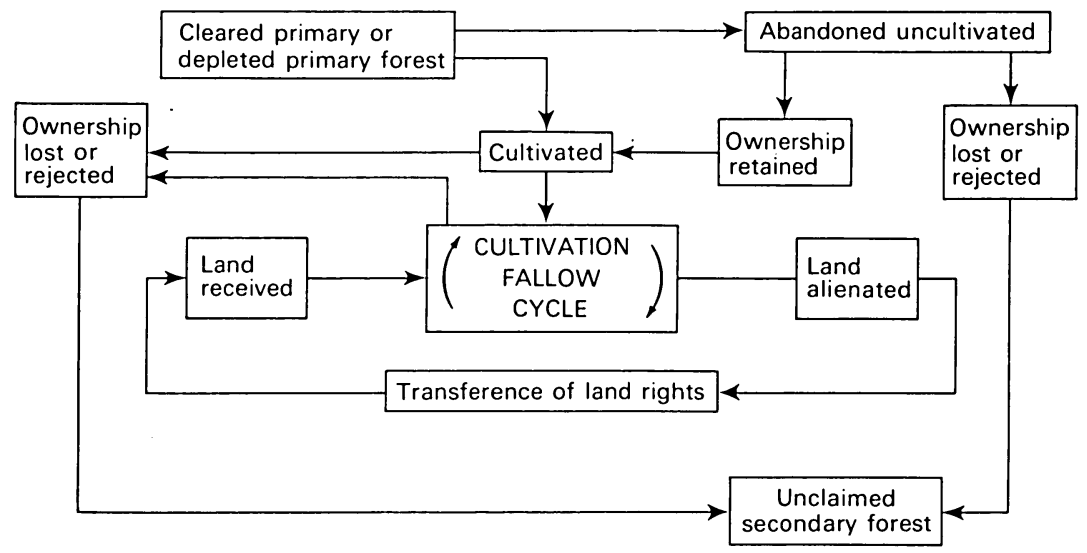

FIGURE 6. The fortune of land cleared from mature forest: a diagrammatic summary of the basic tenurial and ecological alternatives.

'Wasi' and 'nisi': the vocabulary of land use

As soon as mature forest has been cleared it has an entirely changed status. Ecologically it has undergone the transformation from the nondomesticated to the domesticated environment, from being part of the outer zone to being part of the inner zone of exploitation. In terms of the two contrasting categories which represent the highest level at which the Nuaulu distinguish vegetative cover, it is no longer wesie but wasi: no longer is it free and available to anyone, but it has become tied and unavailable to anyone else with the exception of those who have rights through clearance. It is by cutting such forest, by the exercise of labour, that an individual, household and clan obtains certain rights of access and use as long as the claim is wished to be perpetuated.

It has already been indicated (see below p. 24) that the term wasi as used by the Nuaulu at the present time is polysemous, representing both all cultivated land in which rights of access are vested, as well as individual social units of land. It is used therefore, in both a wide and narrow sense, as a term to indicate a single type of vegetational cover and 
plurally to indicate individual plots of land. In the second sense - the 'jural' sense - then, a wasi can be defined as a localized portion of cleared forest in which particular individuals and clans have rights of access; they may use and dispose of it as they wish. Rights are nominally held in perpetuity. Thus, in one of its senses the wasi is a legal unit of land and should not be confused with the nisi, a garden which is prepared and cultivated each year. The nisi can therefore be defined as the effective unit of Nuaulu swiddening, the object of productive activities. But the nisi has no existence except as a productive piece of land: that is, with crops on it. Nisi are created from rain forest (wesie), are used, discarded and ultimately return to it - in the normal course of events. The nisi does not exist except as an integral part of the continuing productive process. Certainly a wasi may be coterminous with a single nisi but this is by no means always the case. A wasi may sometimes consist of more than one cultivated plot, though a nisi can never be composed of more than one wasi. Furthermore, at any one time, a wasi may only be partly under cultivation, or various parts may be at different stages of cultivation and regeneration. TABLE 17 gives some data regarding the relationship of nisi to wasi and the proportion of recognized wasi under cultivation. TABLE 22 represents a breakdown of wasi in terms of local vegetational categories of cultivated land. The implications of this material emerge more fully in considering site selection in general and the processes of garden succession. The actual variation in number of nisi per wasi is $0-3$,

TABLE 17. Some numerical aspects of the relationship between 'wasi' and 'nisi', Ruhuwa 1970

\begin{tabular}{lcccc}
\hline & $\begin{array}{c}\text { Number } \\
\text { of wasi }\end{array}$ & $\begin{array}{c}\text { Percentage } \\
\text { number wasi }\end{array}$ & $\begin{array}{c}\text { Area } \\
\text { (hectares) }\end{array}$ & $\begin{array}{c}\text { Percentage } \\
\text { area }\end{array}$ \\
\hline $\begin{array}{l}\text { 1. wasi not under any form } \\
\text { of permanent cultivation }\end{array}$ & 32 & 16 & 27.63 & 27 \\
$\begin{array}{l}\text { 2. wasi coterminous with a } \\
\text { single nisi }\end{array}$ & 145 & 76 & 61.84 & 61 \\
$\begin{array}{l}\text { 3. wasi containing single nisi and } \\
\text { more than 25 \% secondary growth }\end{array}$ & 11 & 6 & 7.81 & 7 \\
$\begin{array}{l}\text { 4. wasi containing more than one } \\
\text { nisi under cultivation }\end{array}$ & 3 & 1.5 & 2.83 & 3 \\
$\begin{array}{l}\text { 5. wasi containing more than } \\
\text { one nisi and more than } 25 \% \\
\text { secondary growth }\end{array}$ & 1 & 0.5 & 2.08 & 2 \\
\hline \begin{tabular}{l} 
Totals \\
\hline
\end{tabular} & 192 & 100 & 102.19 & 100 \\
\hline
\end{tabular}


with an average of just over one nisi to the wasi. The general distribution of wasi is apparent from MAP 8

Part of the explanation for the significant proportion of uncultivated land within the wasi is the presence of ill-defined boundaries, nenene, ${ }^{8}$ sometimes to the extent that land may be unwittingly cut from someone else's land. In many instances there is little precise knowledge as to wasi, almost to the point of unconcern. It is frequently only in disputes that the exact borders come to light. Ill-defined boundaries are typical of isolated wasi in use or fallowing as nisi ahue. The situation is clearly one which must get progressively worse as gardens are transferred to new owners, principally by inheritance. Where nisi honwe and monai are clustered together and gardens are in constant use boundaries tend to be fairly clearly defined.

The lower and upper limits of wasi are usually indicated by streams and ridges respectively - it is the lateral boundaries where difficulties in identification occur. Trees and stones are used as markers and, where possible, paths and tributary streams running down principal valley walls. In some instances more specific and ingenious methods are devised, sometimes in response to new situations. On one occasion, for example, two individuals who had wasi bordering on each other, decided to turn first year gardens into coconut and clove groves, a decision with long-term implications. In view of this, and in order to be able to define the boundary between the two wasi for succeeding generations, it was agreed that one should plant only coconut while the other should restrict himself to cloves. This ensured that the demarcation between the two wasi (W122, W123) would be known by their descendents.

The most obvious and best means of indicating a boundary, by using a fence to completely enclose a wasi, is rarely employed by the Nuaulu, though fences are commonly used by the coastal Muslims, whose gardens often border those of the Nuaulu. Even on the rare occasions when a fence is erected, the area which is enclosed is the nisi and not the wasi as such. Fencing is considered further in the next chapter.

Occasionally a new wasi will be abandoned cut, but uncultivated. In such cases ownership is usually still acknowledged and in succeeding years may be recut and planted. However, it may equally be entirely neglected. In still other instances, though admittedly rarely, claims may be made to land that has never been properly felled and remains essentially mature forest with the addition of some secondary associations. Such land has usually been extensively thinned for wood, rattans and the like, and typically borders areas already under cultivation. 
Sometimes root crops, or, less commonly, clove or coconut, may be planted in the cleared soil of such depleted forest. This implies that a claim has been staked in that land and for all intents and purposes is considered part of the wasi to which it is adjacent. Commonly, such land is on the uppermost border of a garden situated along a valley side and would normally be cleared anyway in subsequent years.

\section{Group and individual access to land}

In the strict de jure sense all wasi, in the final instance, might be regarded as corporate clan property, and this appears to have certainly been the case in the context of traditional Nuaulu clan-hamlet settlements in the highlands. This is consistent with the view of the clan as the logical extension of the domestic group and the domestic mode of production, whereby through reciprocal ties it maintains a common community of interests. However, much of this land is equally seen as being effectively 'held' by individuals on behalf of the autonomous clan units in each village. In part this individualization of the ideology of land-holding is realised through internal structural shifts resulting from re-settlement, confrontation and participation with a new political and economic situation. In this sense it is possible to identify contradictions between the 'rights' of the individual and those of the clan. But it is clear that similar attitudes antedate such changes, in the sense that although the land was ultimately clan land the individual was responsible for day-today and general decisions regarding land use. Here the community of interests of the clan and the individual are identical and there can be no contradiction. The wasi first cut by a particular individual is at the same time regarded as his own and the property of his clan - both have rights in it; and since their community of interests is essentially the same no contradiction is involved. This relationship between an individual (or household) and such first generation land is typically much closer than that for longer established clan land. From a strictly jural approach, the situation appears to be somewhat ambiguous, for not only are they units of land 'held' by individuals, they are also regarded as being worked for a father or a household and ultimately for the clan as well.

Part of the problem can be clarified by bringing in the wasi/nisi distinction again, for although every mature male has his own nisi each year (sometimes more than one) and the contents are in a sense his through being the product of his own labour, the land (wasi) is not always regarded as his, being the corporate property of the clan. An individual uses land as a member of a group. This situation appears to be that which 
prevailed prior to re-settlement and has clearly persisted in a modefied form. So it is necessary to take care not to confuse nisi with wasi, although there is certain evidence that even this is tending to happen at the present time where the ideology of land is heavily influenced by a commodity economy. ${ }^{9}$

Even if we restrict ourselves to the notion of nisi, and consider the product of the land and not the land itself, produce is not seen as being entirely at the disposal of the individual. Land is cultivated for the clan and the household and produce must be disposed of according to particular modes of distribution and in a pattern that fulfills certain expectations. To a certain extent close kin, clan mates and affines have reciprocal rights with respect to the taking of crops from a garden. Since the food produced is for a common hearth and since, normatively, ultimate control is vested in the clan, the various gardens appear to some degree as communal property. It is said, nisi osa osa, nisiosanja, that 'the gardens are separated, but they are as one garden'.

It is possible to distinguish three effective levels of emphasis used by the Nuaulu when discussing genealogically based rights of access to land: that emphasizing association with an individual, that associating land with a group of closely related patrilineal kin (typically based on a single household) and that emphasizing association with the clan or subclan. Over the course of time the emphasis put on the kind of relationship will vary, depending in part on the kind of land involved and how long it has been under cultivation (c.f. Biebuyck 1963: 2-15, Brookfield 1968: $422-4$ ), such that individual rights become transformed into the rights of a localized group of kin and ultimately into undifferentiated clan rights, or vice versa. Land is associated with individuals, domestic groups and clans - the emphasis on any one level depending on the social or ecological context (c.f. Biebuyck 1963: 54).

Such flexibility in man-land relationships is clearly associated with a corresponding flexibility in the social relations within the clan; both are part of the pattern of generalized reciprocity associated with a domestic mode of production of the Nuaulu kind. For if there are reciprocal relationships between kinsmen concerning labour and the provision of food, then it is logical to expect a similar reciprocity in terms of access to land. Since all members of the clan are by definition closely tied to each other through kinship connections and depend on them for various goods and services, the denial of access to the object of any one person's labour through the emergence of property distinctions within the group, or the usurpation of economic power within the group with respect to 
critical resources, threatens its stability and the very basis of its organization. This kind of picture has only been altered with the introduction of entirely new kinds of social relations.

In traditional clan-hamlets, as in the village of Hahuwalan at the present time (TABLE 4), village land and clan land are one and the same thing. The movement from the interior meant that by-and-large the principle involved in determining village membership was radically altered; previously there was an identity between formal and local group, but then villages lost their genealogical homogeneity and in its place several different clans had access to the land on which the village was built and the land surrounding it. This has had quite radical implications for land relations in general. For example, traditionally clansmen have access to any clan land that is not being used. Under these conditions one might expect a member of clan $A$ in village $B$ to also have access to land belonging to clan $A$ in village $C$. However, this is not always the case at the present time. It is clear that there is a contradiction here arising out of the transition from clan-hamlet to multi-clan village. Two opposed principles are involved, that of kinship and that of locality. The pressure in support of the locality principle in this case appears to be the shortage of land in the immediate vicinity, an overall relative shortage in the coastal area. The ideological rationale is found in an independent ideology of village solidarity irrespective of clan, which is bolstered by the assertion of the autonomy of a local segment of a clan also found in other villages. In time this takes on the functions and characteristics of the parent clan (see above p.16).

In a situation where the formal group is coterminous with the local group no such contradiction arises; an assertion of local autonomy is an assertion of formal clan autonomy. This no longer holds when local and formal groups are no longer coterminous. For the first time land consciously appears as a scarce resource, among other scarce resourcesfood crops, game and so on. Scarcity provides an incentive to maintain relations with land over long periods of time, results in a greater emphasis on clear-cut, unambiguous, jural relations with land held in perpetuity and is inevitably a source of conflict between clans, villages and non-Nuaulu. The existing garden locality system, whereby plots of land cultivated in adjacent years (and which are therefore of different horticultural statuses) are also adjacent geographically and which emphasizes particular individual/household relationships over relatively long periods of time, is a traditional feature which has served as a means through which to realize this changing ideology. Traditional approaches. 
to mobile property have acted as another. Maintenance of relations is, of course, even more crucial with the introduction of cash crops. The situation is further legitimized in another ideology, the locality-based land regulations operative in the older coastal villages together with enacted Indonesian land law (Tichelman 1925: 696-8). The extent of the contact between Nuaulu and non-Nuaulu ideas in this field of relations is demonstrated by the dispersion of Nuaulu plots, often adjacent to those of non-Nuaulu, and by the almost daily contact of individuals from the two communities on the garden trails.

The narrow sense of wasi as a legal parcel of land is partly a product of internal structural changes - the emergence of the principle of locality, and fragmentation of clan land, compounded with the exploitation of elements in traditional ideology and the assimilation in part of an external ideology of land relations already present on the coast (c.f. Fried 1952: 410-12).

Some further ramifications of the locality principle can now be explored. In Ruhuwa the entire village is regarded as owning the village area, but trees planted by individuals on village ground are regarded variously as clan, household or individual property, usually depending on the age of the trees. While the land on which they are grown is regarded as being owned by the local group, the things grown on it are owned on a genealogical basis.

In recent years, under a certain amount of government pressure, gardens owned jointly by the entire village (nisi niane) have come into existence, with the aim of creating cooperatively held clove and coconut groves as subsidiary holdings of cash crops. Ruhuwa possesses an old wasi of some 0.44 hectares (W8) originally devoted to coconut palms. This particular grove was the first attempt at cooperative cultivation at the village level, as a result of Dutch initiatives. W7 is of considerably greater area ( 0.94 hectares) and was first cleared early in 1971 during the period covered by field research, again at the suggestion of the local district administration who provided assistance in the form of steel felling axes. The total area devoted to nisi niane is therefore 1.37 hectares, 1.3 per cent of the total land under cultivation. Although almost insignificant at the present time, it is to be expected that the percentage will increase following the intensification of efforts by Agricultural and Social Welfare departments to encourage such projects. While individuals regard parts of these gardens as theirs on a genealogical rationale, it is clear that their existence only strengthens the locality principle in determining access to land. 
Traditionally, large inland areas of naturally propagated sago palms, such as at Somau (MAP 7), are regarded as belonging to all Nuaulu, as opposed to individual clans or villages. This is not regarded as strict jural ownership, and the same areas are sometimes exploited by non-Nuaulu. To complicate matters further, some specified and named areas of such land, especially at Somau, have always been exploited by particular clans or communities. But again, this does not involve definite rights of ownership or even exploitation. The only property in such areas which is regarded as being of an individual nature are the temporary huts together with their contents, but it is generally acknowledged that these may be used by anyone who requires them. It is probably nearer the truth to see these as rights of exploitation of sago palms, rather than as land tenure, but the distinction is not altogether clear.

Rights in things growing from the land, in contrast to rights in land itself, are quite definitely exercised for particular species of trees. In Chapter III it was shown how trees planted within the village area may be regarded as the property of individuals in the short-term and the property of households and clans in the long-term. This progression is due to the fact that such trees are inherited by all male children as a block, thus automatically becoming common descent group property and ultimately the property of the clan as a whole. An exception to this would be in a case where there is one male offspring surviving, when the trees obviously remain individual property. This mode of inheritance also has the consequence that affines, by virtue of their status as husbands of clanswomen, have access to such trees, but not in perpetuity, unless rights in ownership are completely transferred by means of an outright gift. The same rules also hold for land outside the village where such trees may be found planted on owned wasi or in secondary forest where ownership has otherwise lapsed. However, right of access is also dependent to some degree on what exactly has been planted. As a result two separate categories can be recognized:

(1) those which have been individually planted but may be harvested by any other person, applying to kanai (the betel nut palm), kam (the betel pepper vine) and nutune (Eugenia sp.); and

(2) all other fruit trees, coconut, clove and iane (Canarium commune) (planted, as opposed to naturally propagated stands) which are such that right of access only runs along lines of kinship.

Sometimes the trees of one clan are found on the land of another. This situation may arise through either (a) retention of rights in trees by individuals or clans which have otherwise ceased to claim rights in the 
land on which they are grown, have alienated the land to affines or made gifts of it to others while retaining right of access to fruit trees, or (b) mistaken or conscious planting of such trees on the land of others. An outstanding example of this second type is the large number of Nepanetomoien trees on Sonawe-aipura land between the Joko and Upa, trees which are already large and old (MAP 9). In such cases Sonawe, or any other clan for that matter, are entitled to take fruit from the trees or be presented with gifts from them, irrespective of the species involved.

\section{Land and relations of exchange}

Among the Nuaulu land may be acquired in three main ways: by inheriting from a patrilineal ancestor who first cleared land or who acquired it in some other way; as gifts from affines or from the clan of a mother, and by the clearing of mature or secondary forest in an advanced state of generation. In addition, land may occasionally be obtained from clansmen in different villages or from non-clansmen, when an attempt is made to justify the transaction along genealogical lines.

Land may be disposed of in terms of the opposites of the sources of land just listed, but also by the conscious rejection of claims to land, the loss of land (where the same consequences as rejection apply, in that it either permanently or temporarily ceases to be part of the cultivationfallow cycle), and, rarely, sale. Land is very occasionally sold to coastal Muslims in exchange for specific trade goods, such as cloth, crockery,

TABLE 18. Mode of acquisition of 'wasi', held in Ruhuwa in late 1970

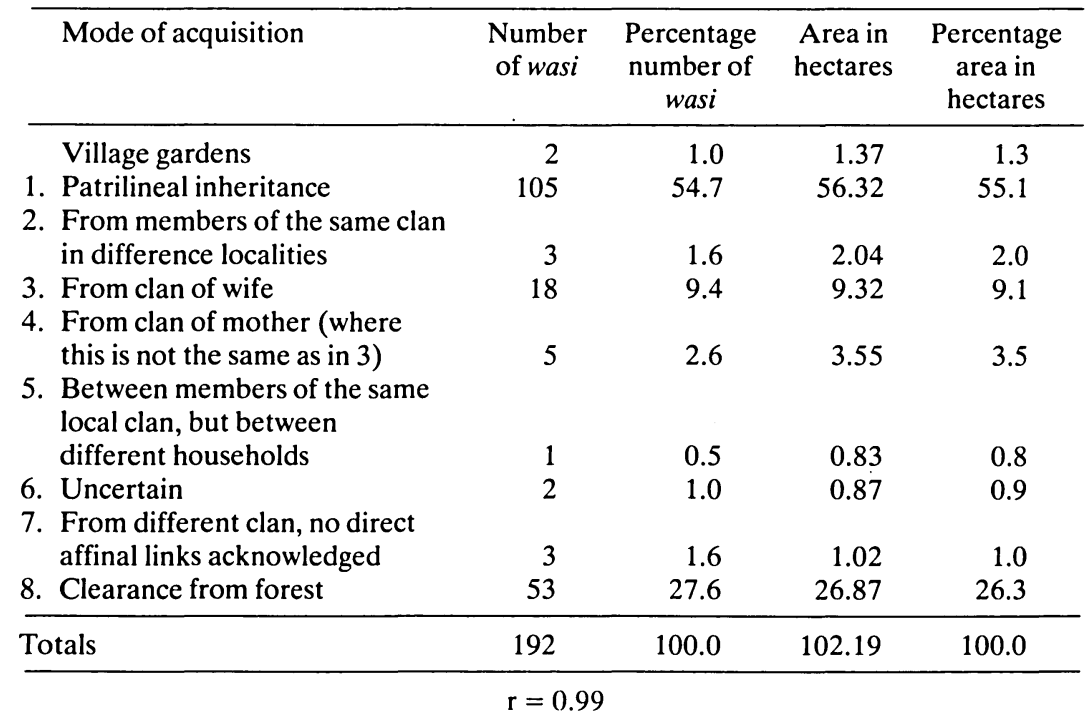


tools, jewellery. Although it exhibits in an incipient fashion these commodity-like features, brought about by participation in a commodity economy, it is not regarded as being like cash or food. It is not normally interchangeable with them, although together with valuables it is very much involved in the traditional exchange relationships between clans.

Some comparative numerical data on the various modes of acquisition of land are set out in TABLE 18. Most land is acquired simply through patrilineal inheritance, though the amount of land acquired by clearing unowned forest and that from kinsmen and affines is strikingly high. For the former, the remarkably high proportion in this particular table appears to be explained by the fact that Ruhuwa is a relatively new village site with a rising population and many first-generation males still living.

As Pelzer (1941: 78) has pointed out, the methods by which land is acquired may affect directly the uses to which it is put. As far as the Nuaulu are concerned this is related to the vegetation typically associated with different kinds of transfer. The ecological implications of the various types of land in terms of vegetational cover are shown in TABLE 19.

\section{Inheritance}

Land is most commonly acquired by directly inheriting it from a lineal ancestor, usually at the death of a father, such that it is passed on from one generation to the next within the clan, through males. Females may act as channels by which land is removed from the clan, though they do not strictly inherit it. But since land is seen as a clan resource and in view

TABLE 19. Implications of various types of land transfer for vegetational cover

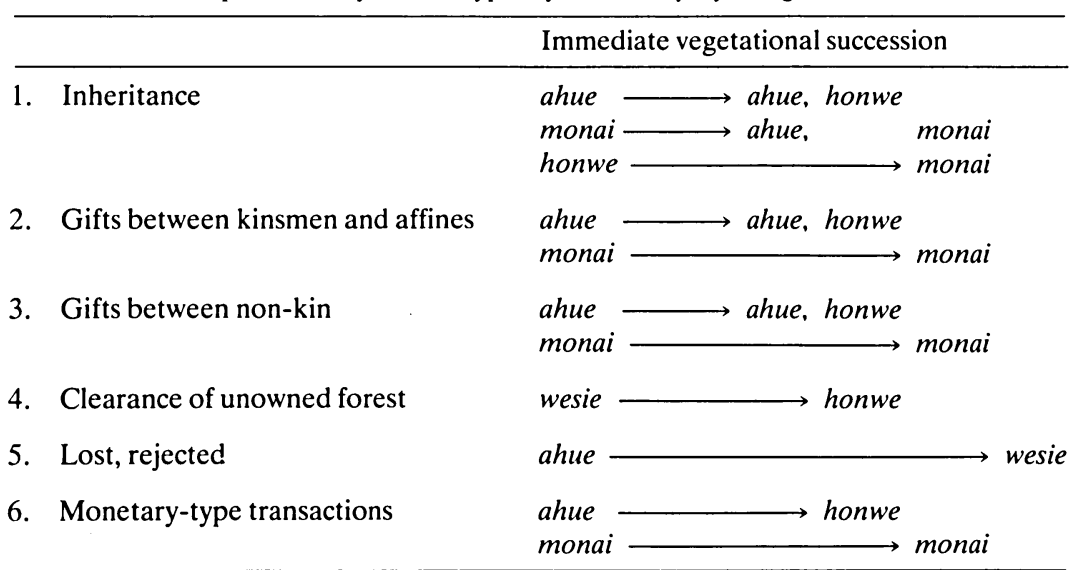


of the points I have made earlier, it may be spoken of as a son's land before his father is dead. Sons often receive land from their fathers while the latter are still alive and tend to regard land so obtained as their own, a principle which applies to groves of varying descriptions as well as fallow or undifferentiated old gardens. Land is split between all male siblings, though not equally, the eldest son ideally receiving twice as much as any other. The same is true of valuables and other categories of wealth, and to this extent land is being treated like mobile wealth. ${ }^{10}$

This method of apportioning land between all male siblings has a potential for increasing land fragmentation. But in practice it does not, and this is of some interest in demonstrating the flexible attitudes the Nuaulu take to land relationships. The reasons why this is avoided appear to be

(a) cooperation between siblings, such that they exercise joint rights over the same land and cooperate closely in cultivation;

(b) the fact that an individual seldom cultivates all the land theoretically available to him;

(c) a situation whereby the division of land between offspring is rarely ever precisely worked out.

Thus, the hypothetical quantity of land held for the purpose of inheritance is far greater than that recognized for the purpose of year to year cultivation. Factor (a) tends to mean that the inherited land loses its association with a specific individual and is seen more in terms of household or clan land. Factors (b) and (c) suggest considerable loss and rejection of land. To a certain extent this substantial loss of land over a period of years (which is by its very nature impossible to measure) may be another factor related to the high rate for the removal of mature forest and secondary growth in an advanced state of regeneration. Individual land is inherited, divided, and a group of closely related kin may have rights in it - but it is still frequently regarded as a unitary area since it is part of a single clan until alienated."

If all members of a clan should die out in a particular village then the land of that clan or subclan is redistributed to other clans along affinal lines. Thus, if any females from the final generation of the clan are living then their husbands are the first claimants, and all such have equal rights in its reapportionment. The second class of claimants in such an instance would thus theoretically be the affines of the penultimate generation, and so on. Members of the same clan, but resident in a different village, have no claim in such circumstances. This is consistent with the hypothesis that locality is becoming dominant over genealogy in some aspects 
of land relations (see above pp. 94-95 and Ellen 1977). Thus, even unnamed subclans do not consider land as ultimately the property of the named clan from which they are historically derived, at least not for practical purposes. The localized clan is the ultimate land-holding unit, however it may be manifested. However, this may be seen as a measure of relatively recent origin to protect land in a given village from alienation and in order to prevent having to work more distant gardens, which would result from the absence of such a prohibition. Nevertheless, it can be safely assumed that the practice whereby in the event of a man dying without male offspring land is divided among his male siblings, the eldest receiving twice as much as any other, antedates these more recent changes.

\section{Alienation of garden land}

Wasi can be transferred from one owner to another in one of three ways: gifts between kinsmen and affines (by which land may remain within the clan or become the property of another); gifts in which no link of kinship or affinity is regarded as the motivating factor, and transactions involving some form of immediate payment. Of all ways in which land may move between clans, the most common is through affinal gifts to that of the husband (TABLE 18), though the mechanics of such transactions in a highland context are difficult to determine and quite probably did not exist in their present form. Such gifts (airui wasi, to give land; sioroiki wasi, to make a gift of land to a specified person) are permanent and the land inherited by the descendents of the recipient. ${ }^{12}$ These usually occur soon after marriage and mostly involve nisi monai, particularly undifferentiated gardens and coconut groves, which together constitute 59 per cent of the total area involved. The very high percentage for coconut groves (some 35 per cent of the total area) is some indication of the cash importance these have assumed since movement to the coast, and the extent to which land is becoming a commodity (TABLE 20). The structural implications of this are considerable and ideally land transactions should be seen in the total context of inter-clan prestations.

Land may also be acquired through parental links with affines, that is, usually via the mother, often in situations where a father is dead and his offspring are residing with their matrilateral kin. Because Nuaulu connubial relations are ideally structured on the basis of bilateral crosscousin alliances, this situation is logically consistent. Further, the transactional nature of Nuaulu marriage establishes an alliance in which 
TABLE 20. Vegetative status of land alienated to affines at time of transfer

\begin{tabular}{lccc}
\hline & $\begin{array}{c}\text { Number } \\
\text { of } \text { wasi }\end{array}$ & $\begin{array}{c}\text { Area in } \\
\text { hectares }\end{array}$ & $\begin{array}{c}\text { Percentage } \\
\text { area }\end{array}$ \\
\hline 1. nisi ahue & 3 & 2.13 & 16 \\
2. nisi monai & & & \\
$\quad$ a. mixed short-term crops & 8 & 3.11 & 24 \\
$\quad$ b. coconut groves & 7 & 4.5 & 35 \\
$\quad \begin{array}{l}\text { c. clove groves } \\
\text { d. mixed sago and coconut }\end{array}$ & 1 & 0.1 & 1 \\
3. Mixed nisi ahue and nisi monai & 2 & 1.02 & 8 \\
Totals & 2 & 2.01 & 16 \\
\hline
\end{tabular}

$r=0.97$

bride-givers are superior to bride-receivers, in which marriage itself is conceived as the initiation or perpetuation of a new or renewed transactional relationship between clans via the marital bond for the life of the union. Alienation of land must be considered in this light. The single marital transaction is recognized as just one pivot in the total pattern of a constantly changing matrix of pivotal relationships (see below pp. 49-55). In consequence, land and other resources are continually being exchanged between clans. One clan makes a gift to another only to be in receipt of more land from yet another clan. Wife-givers are also land-givers and wife-receivers, land-receivers. The population structure of each clan will determine the degree to which it is obliged to part with the land and the ease with which it receives it, and may thus be a source of inequality of wealth.

In short, while women cannot own or inherit land in their own right, once married they are the vehicles for both inter-generational and inter-clan transference of land. However, although these affinal connections are the most common means of alienating land it may also be legitimately alienated in other ways. For example, if a man marries for a second time it is perfectly valid for him to give land to the son of his wife by a different husband, though he be of a different clan (Ellen 1973: 211-2). It is unclear whether the same would apply in the case of the husband of a daughter of the wife by a different husband. No such case could be recalled. In the most characteristic form of land alienation, land goes in the direction of outmarrying women. In both actual and hypothetical cases described here it is exactly the opposite. ${ }^{13}$ 
The very obvious corollary of this high incidence of alienation of clan land is an accordingly high degree of fragmentation of the holdings of a single clan (MAP 11). But while the social and ritual obligation to both give and receive land and the economic benefits consequent on the latter are regarded as being very important, fragmentation of land has very serious disadvantages: travel between gardens becomes more timeconsuming and economic activities of the garden cannot be centred in one or two localities only.

The modes of alienation considered above are all based on some kind of genealogical connection, in that land is transferred along certain recognized channels within or between descent groups. And yet land may also pass between clans in the form of gifts which have no obvious, or rather, no acknowledged basis in kinship or affinal relations. Gifts of this kind are usually outright, though the giver may informally retain certain rights in specific fruit trees for his own use.

\section{Sale of land}

Elsewhere I have pointed to some of the commodity-like characteristics of the land transactions described above (Ellen 1977). However, the transition from non-commodity to commodity characteristics is clear, final and irrevocable when land is sold to outsiders, for cash or its equivalent. As far as the Nuaulu are concerned, it is the recognition of sale that is important, irrespective of the frequency; the idea that its exchange value is generalized. Traditionally exchanges involving land are undertaken on the basis of status relations (usually those of marriage), as part of a matrix of social rights and obligations. In the case of cash exchange the transaction is narrowly contractual and singlestranded, the economic component of the transaction having been separated from the wider context of social relations. What was formerly a clear and unambiguous relationship between individuals and groups has now taken on the appearance, at least, of a relationship between a person and a thing.

Sale of land is a relatively new concept for the Nuaulu, and, though permitted, it is believed that it should be restricted. ${ }^{14}$ I have already suggested an ideological and relational reason for this, insomuch as it is a complete negation of the continuity and context of social relationships. The sale of land is not merely a material loss, it is also a denial of the value of traditional multi-stranded exchanges. A more pragmatic reason appears to be that alienation of land to non-Nuaulu (and such transactions could not take place among the Nuaulu themselves) threatens to 
limit the total amount of land at their disposal and to threaten in particular the better land. Land transferred to one clan within the general context of inter-clan prestations is never entirely lost, only temporarily so, since quantitatively the same assets may be realized through women marrying into the clan; land exchanged for other material wealth with outsiders is lost for ever from the total pool of village land resources.

Shortage of land in the Muslim settlement of Sepa has led to a demand for Nuaulu land and small portions have been sold. However, it is rare. During 20 months of fieldwork I have witnessed only one transaction in the entire Nuaulu area (Ellen 1973: 214-6, 229, notes 19 and 20). No one could remember a Nuaúlu ever having acquired land from Sepa, and only one other instance of sale of land in Ruhuwa could be recalled, involving a single wasi (W85) of 0.33 hectares. However, the idea of sale is known and the possibilities of land being a truly exchangeable commodity. The ideological framework to carry through such potential transactions is available, although it has scarcely been realized materially.

Contact with a market economy and the possibility of cash-cropping has meant that the familiar property concept of land becomes increasingly appropriate. The rules relating to land have become increasingly like those relating to other kinds of property (c.f. Bohannan 1963:110). Traditionally the relationship of people to land is like the relationship of a father to children; but this relationship is much more than metaphorical since land relationships truly reflect more generalized relationships. As a father is responsible to the ancestors for his children, so is the group for the land. This distinguishes it radically from other forms of personal property and highlights the fallacy of automatically assuming a unitary concept of property (c.f. Salisbury 1962: and discussion by Godelier 1972: 269-70). I would suggest that the plural/ jural concept of wasi (see above pp. 23-24 Ellen 1977) is to a certain extent a response to the new ideology of commodity property manifest in the ownership of groves, trees in the village area and elsewhere, and essentially mobile property. Coconut and clove groves constitute some $33 \%$ of the total land under some form of cultivation in Ruhuwa at any one time, and it is only to be expected that the rules governing the exchange of the produce of such land are going to affect to some degree attitudes to the land itself. This must be considered as an important channel through which new ideas about land tenure filter. Traditionally, swiddens were cleared, cultivated and neglected; their labour-value was 
temporary. With permanent or semi-permanent groves the human effort going into the transformation of the forest and maintenance of the land is continuous and hence the relationship is a more enduring and intensive one. Moreover, flat land ideally suitable for groves (along the watercourses, coast and major paths) is at a greater premium than that adequate for swiddens.

Increasingly also, the emphasis is on individual property in a jural sense as property, and not merely as an unreified relationship of a producer with the object of his production. The emphasis is increasingly one on ownership, on private property, merging traditional attitudes to land with those to personal belongings; and it appears that this merging is through the ideological mediation of cash - a generalized means of exchange. Since cash, like traditional mobile property objects, is essentially personal, and since cash is theoretically exchangeable for land, land therefore - by extension - takes on the characteristics of that other 'fictional' commodity - money, and like it, is individualized. Land ceases to be something apart and special and in some ways ideologically becomes a scarce resource among other scarce resources. While this is generally true of attitudes to land as a whole, it is particularly so for grove land and (especially) cash crops. The latter can be sold by individuals, so making it unnecessary to utilize a traditional set of kinship relationships in some circumstances. Cash is not distributed among kinsmen in the same way as traditional goods and services. However, the idea of land as a market commodity is still difficult for the Nuaulu to grasp fully, since it contradicts important features of their traditional social relations of land use. But changes are taking place. Indeed, the monetization of land relations represents a crucial point in the structural transformation of Nuaulu economy, prior to which monetary relations were restricted to a small separate sphere, and after which the greater part of the economy becomes subject to the hegemony of money. It is a point where ideological pre-conditions (in the form of changes in the intentional rationality governing land relations) are converted into a change in the unintentional rationality governing the economic system; there is a qualitative and marked shift in the structural articulation of the economy (c.f. Godelier 1972: 311).

\section{Land disputes and their resolution}

The 'fluidity' of land tenure arrangements makes it surprising that disputes over rights in land use are not more frequent than they actually are, although it could be argued that 'fluidity' itself is only possible 
because disputes are only rarely occasioned. Either way, there is a connection between the two issues. There appear to be two main reasons for this. The first is that the heavy reliance of the Nuaulu on nondomesticated food products tends to reduce the likelihood of conflict through competition over subsistence resources, both among themselves and with respect to the adjacent Muslim communities. The second reason is the relatively satisfactory situation with regard to pressure on land, relative, that is, to the situation in Ambon, Saparua, Haruku and Nusalaut. In these areas most primary forest has ceased to exist, extensive areas are covered with grassland, the population is high and increasing, with tenure strictly controlled through the dati system, a combination of customary and enacted colonial law. All this contributes towards frequent and bitter land disputes, sometimes involving open inter-village warfare. ${ }^{15}$

It would be wrong to assume that among the Nuaulu land shortage does not represent a contributory factor to conflict situations, but here it is mainly a question of differential land shortage, between Muslims and the Nuaulu themselves. The latter constantly make it plain that they feel aggrieved that the finest land (from the point of view of access and topography anyway) has always largely been exploited by coastal Muslims and that they have been forced to cultivate forest further and further away from their own settlements. As has already been noted, this alone by no means explains the high incidence for the cutting of wesie. Set within the context of ritualized and structured opposition to Sepa, however, it represents a tangible factor of some significance in their relations, manifested in physical conflict and subsequent litigation or in sorcery accusations. In ecological terms the conflict arises because the two different communities are essentially exploiting ecological niches in which there is considerable overlap. To a very substantial degree, they are in competition for the same resources (Barth 1964: 1; 1969 (1956): 374-5). Sale of land, however rare, only aggravates this situation. Most of the disputes for which I could obtain detailed case-histories were between Muslim and Nuaulu litigants, and these were surprisingly few in number (Ellen 1973: 217-20). Because of this, disputes can hardly be said to affect in any major way the selection of land, although the possibility of dispute is undoubtedly a sanction restricting the likelihood of encroachment by one group on the other's land.

Land disputes between Nuaulu clans, either of the same or of different villages, are rare. A man's clan is his first line of retaliation if a wrong is committed against him by non-clan members. In all cases of disputes 
between members of different clans it is very difficult to limit the outcome simply to conflict between the two litigants. All clan members become involved. In such cases the dispute is resolved by consultation between the headmen of the clans involved, or through the use of oracles, though the ultimate authority in such matters is the Lord of the Land. Nowadays, the village headman is frequently cast in an arbitrating role. Land most commonly subject to inter-clan disputation is that received as a gift.

That disputes should occur within the clan over land is regarded by the Nuaulu almost as a contradiction in terms, for the simple reason that ultimately individual and clan land are one and the same thing. But those disagreements which might conceivably arise (such as relating to the ownership of trees), I was assured, were rapidly settled by both parties concerned, in consultation with the headman and elders.

\section{Conclusion}

The foregoing discussion raises a number of important issues concerning local arrangements for acquiring, holding and transferring rights in land and what is planted on it. Some of these are dealt with in a separate paper (see above footnote 1). The purpose of this chapter has been not so much to undertake an analysis of Nuaulu social relations of land use, but rather to present some data which have a bearing on the broader problem of the generation of the Nuaulu pattern of settlement. There are just two important points that should be stressed in conclusion.

The first is the question of the overall flexibility in the system of land tenure and the absence of anything which resembles a uniform Nuaulu theory. This evident fluidity of Nuaulu ideas and practices concerning man-land relations appears to be related to a number of factors. It is partly to be explained in terms of the persistence of customary ideas in changed circumstances. It is also partly due to the structural changes in Nuaulu social relations accompanying movement from the highlands to the coast, the change from the political autonomy of the clan to subjection to colonial administrative constraints and participation in a monetary economy. Also of importance is the balance between domesticated and non-domesticated resources, such that flexibility in landholding arrangements must be seen in terms of their historically minor importance in production. After all, rules relating to the cultivation of land are only part of all those rules governing the appropriation of resources. 
The second point to note is the direct and reciprocal relationship between particular kinds of land relations and general patterns of settlement. Thus, it should be borne in mind that the clan land map is constantly changing - land rights are established, transferred, allowed to lapse and so on. Changes in concepts of ownership and recognition of new and different ways of holding and transferring land have both social and ecological implications for the pattern of settlement. Conversely, land rights vary according to land use and land type (Biebuyck 1963: 215; Brookfield 1968: 422-4). Indigenous ideas about the social use of land may have consequences for man-environment relations, but manenvironment relations also affect both the ideas and concrete manifestations of rules concerning the handling of land. The adoption of cash-cropping by the Nuaulu is a case in point here (see below p. 187). That the relationship is not a simple one is already apparent from what explanations I have provided for the structure of existing Nuaulu land relations. The complexity of the issues involved makes it all the more necessary to undertake careful, systematic and intensive investigations of the interaction between both the theory and practice of land tenure, land use, settlement histories and other generative factors in systems of settlement. 
CHAPTER VI

\section{SITE SELECTION AND GARDEN PREPARATION}

\section{Introduction}

The exact number of gardens cleared each year by a household is closely related to needs and the available alternative sources of garden products. An examination of the data presented in TABLE 21 shows that for both 1969-70 and 1970-71 $32 \%$ of the households did not create new gardens. In terms of all mature males the percentage is considerably higher. The reasons for not cultivating new land involve a combination of factors, such as sufficiency of already existing gardens, perhaps rejuvenated by partial replanting, or reliance on gifts from kinsmen and affines. The precise reasons will depend on the circumstances of each household, but the larger the household the greater the pressure to clear gardens each year. There are only three instances where gardens were not cleared for two years in succession and in these cases the households were small.

Of those gardens which are created in any one year, the location of an individual site and the overall distribution are not made at random, but are subject to a large complex of factors - manifest and latent, involving both conscious and unconscious decisions as to the priority of a wide range of pressures of different kinds. The central task of this chapter is to attempt to sort out and discover how conflicting pressures are resolved. The approach is a demonstration of generative processes at work in Nuaulu site selection.

\section{Some environmental limitations on cultivation}

Within the Nuaulu exploitative area particular localities are chosen for intense utilization, and as with many other communities of cultivators there is a choice between available sites in terms of a recognized series of the most desirable priorities in socio-ecological terms. It is theoretically possible to select sites purely in terms of what appear to be the most desirable locations in terms of the agricultural productivity of the land: that is, on the basis of the relevant environmental factors touched upon earlier. Thus land might be rejected for any of the following reasons: 


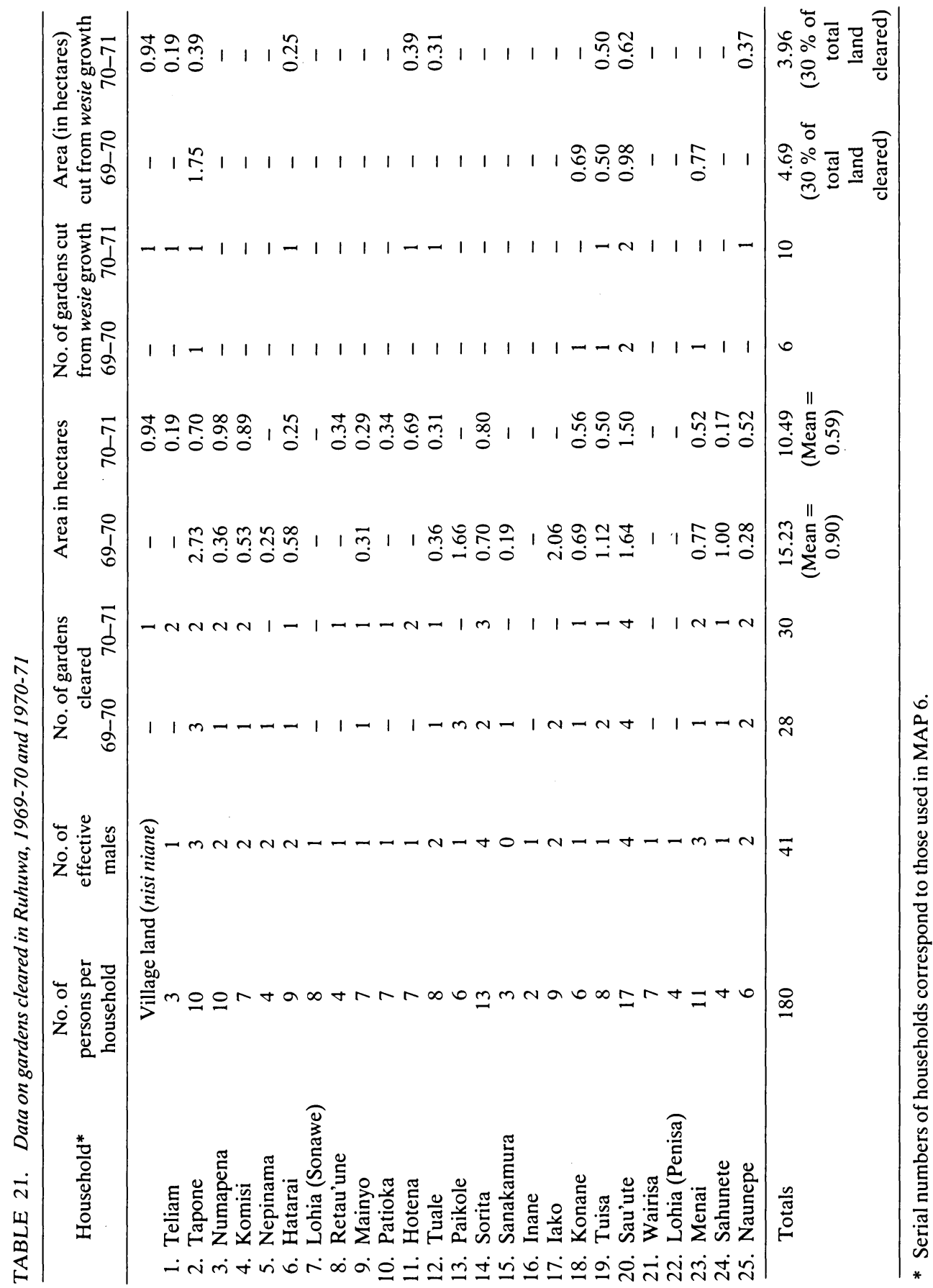


(a) poor drainage (including swamp land);

(b) limiting surface conditions such as rocky, sandy or eroded terrain;

(c) topography (including slope);

(d) soil conditions;

(e) limiting vegetation (e.g. some grassland associations, such as that in which Imperata sp. is dominant);

(f) exposure to sun and wind;

(g) previous use of land (e.g. fallow).

More sophisticated information that may be taken into account includes comparative yields from various soil types and the most suitable conditions for specific cultivators. It is now possible to estimate the degree to which these represent relevant limiting factors in Nuaulu land choice.

Topographical conditions in the vicinity of Ruhuwa and the rest of the Nuaulu area are such that the region is well drained. Watercourses tend to be short, averaging around 1100 metres, descending through steepsided valleys from heights between 100 and 500 metres to the coast (MAP 9). ${ }^{1}$ Wet season flooding (between April and August) often occurs at the point where the larger of these rivers meet the sea. Here the level alluvium, together with natural obstacles, such as the shingle barriers that are thrown up in the course of the dry season, combine to create a situation that makes travel along coastal paths, the main arteries of inter-village communication, very difficult. Nuaulu gardens, however, situated as they usually are on the steep valley walls, are not generally subject to drainage problems, and neither does the occasional possibility of flooding appear to be of much concern to the cultivators themselves. Sometimes gardens may be extended across valley floors where this permits and during the wet season become partially waterlogged (e.g. W93, W97). The Nuaulu recognize that excessive water is not good for some crops and avoid planting them in such sections of gardens, relying instead on well-tried hydrophilic species such as taro (Harlan 1972). In general though, flooding does not pose a serious problem and would not normally be taken into close consideration in selecting suitable sites for cultivation. On the other hand, rapid drainage facilitated by steep gradients and soil composition means that soil moisture, particularly in exposed gardens, is not retained. This is an important factor for specific crops such as cloves and sometimes yams, as is temperature alone. But usually the almost daily rain (even in the dry season) is sufficient to keep an adequate soil moisture (Appendices A and B).

There are certain physical features which prevent or hamper cultivation in a particular locality. Outcrops of rock are obviously to be 
avoided, but tend not to be an important limiting factor, because (a) they tend generally to be untypical of those areas immediately surrounding the settlement used for gardens and (b) where they do occur they tend to be found in places otherwise unsuitable for garden land, such as along the banks of watercourses. This is also true of cliff faces and steep gullies. Outcrops tend to be characteristically of a Quarternary coralline limestone known to the Nuaulu as nokase, which together with alluvial deposits containing conglomerates, sandstones and schists makes up the dominant formation of the immediate area (Germeraad 1946: 34, 103, and Appendix B). Isolated nokase is found throughout the vicinity of Ruhuwa, including the cavernous outcrop (hatu nohuwe) which serves as the cemetery and by virtue of which function is anyway unavailable for garden land. Similar prominent and awe-inspiring localities are always chosen for Nuaulu cemeteries. Nokase appears to be most prominent in the peripheral areas of the Ruhuwa exploitative environment and there is a clear line running just to the east of the river Mon, between Ruhuwa and the Muslim village of Tamilau, marking an effective boundary between the sandstone and schist-bearing alluvium and coralline deposits (MAP 4). The only localities in which coralline outcrops seem major obstacles to gardening are found east of this line, at the mouth of the river Makoihiru (W5, W6). Here it is only one of a series of disadvantageous factors (not the least being the great distance from the village). In this case the shortage of available land nearer the settlement makes such inconvenience tolerable.

Erosion of soil from exposed gardens takes place, especially as a result of heavy wet season rains, and on parts of the coast and along river banks rockfalls of loose shale occur, sometimes sufficient to block main pathways (e.g. Seran 1922, photographs 104 and 105). No steps are taken to prevent excessive erosion. Although the problem is recognized, it is disregarded, and the fact that most land is seldom without substantial vegetational cover makes the deleterious effects of soil erosion slight. ${ }^{2}$ Exposure to the elements in general rarely constitutes a reason per se for rejecting land. Moreover, there is apparently no recognition of the possible advantages of erosion in exposing more fertile soils. Temperature in itself can be critical for the development of crops such as cloves, and (according to some Nuaulu informants) yams also (Coursey 1967: 71). In such cases the remedies are usually to plant the tubers or seedlings in sheltered spots in shaded localities apart, higher up the valleys. Monsoon winds can play havoc with palms and trees but apart from magic there is no conception of taking preventative measures. 


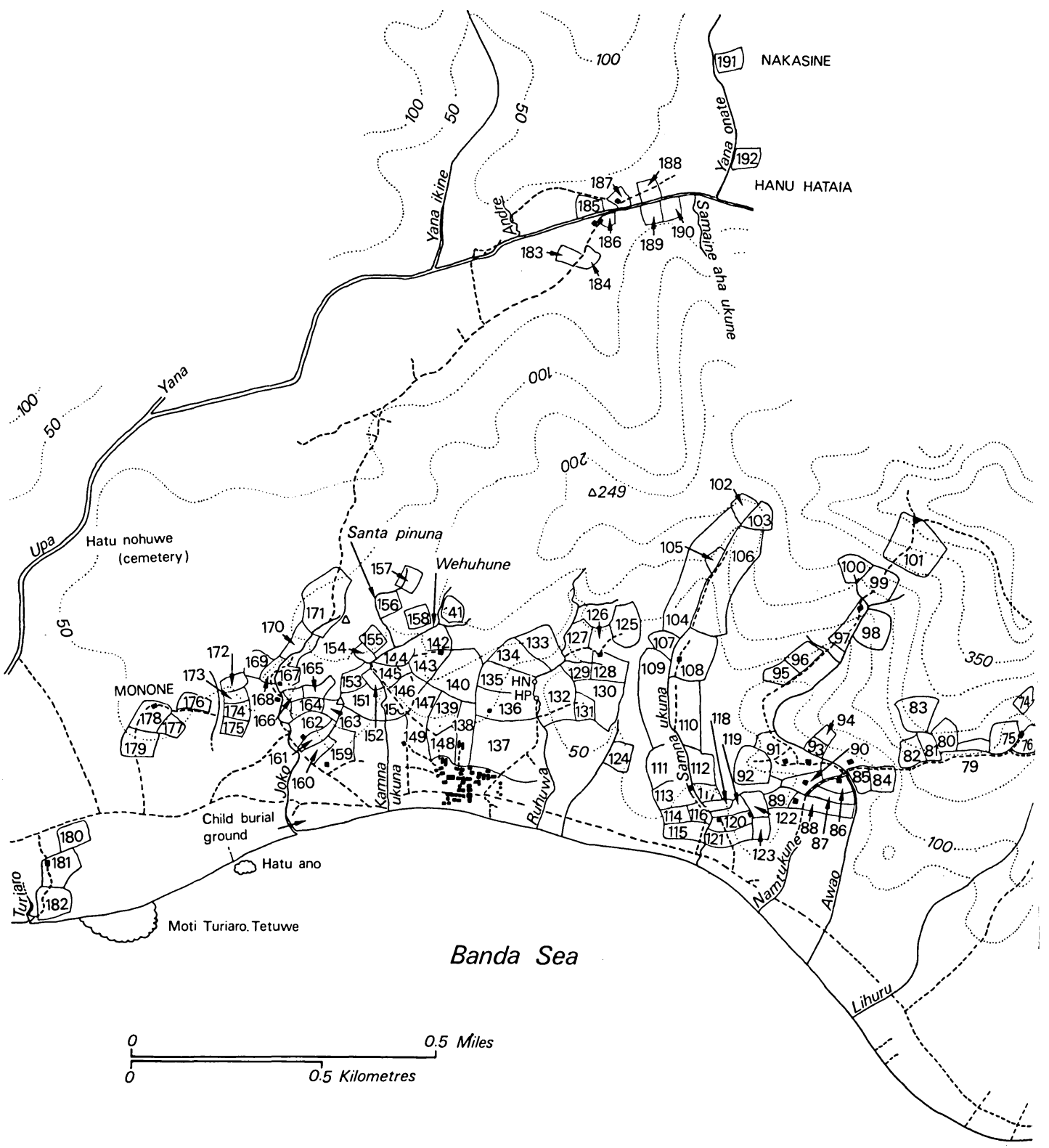

Contours in metres

HN HATU NOKASE

HP HATU PINAMO

MAP 9. The vicinity of Ruhuwa, showing all wasi for which ownership was recognized during 1970-71. (Based on Topographische Inrichting 1919, Schetskaart van Ceram (Scale $1: 100,000)$, Batavia; considerably modified on the basis of field cartographic data and notes.) 


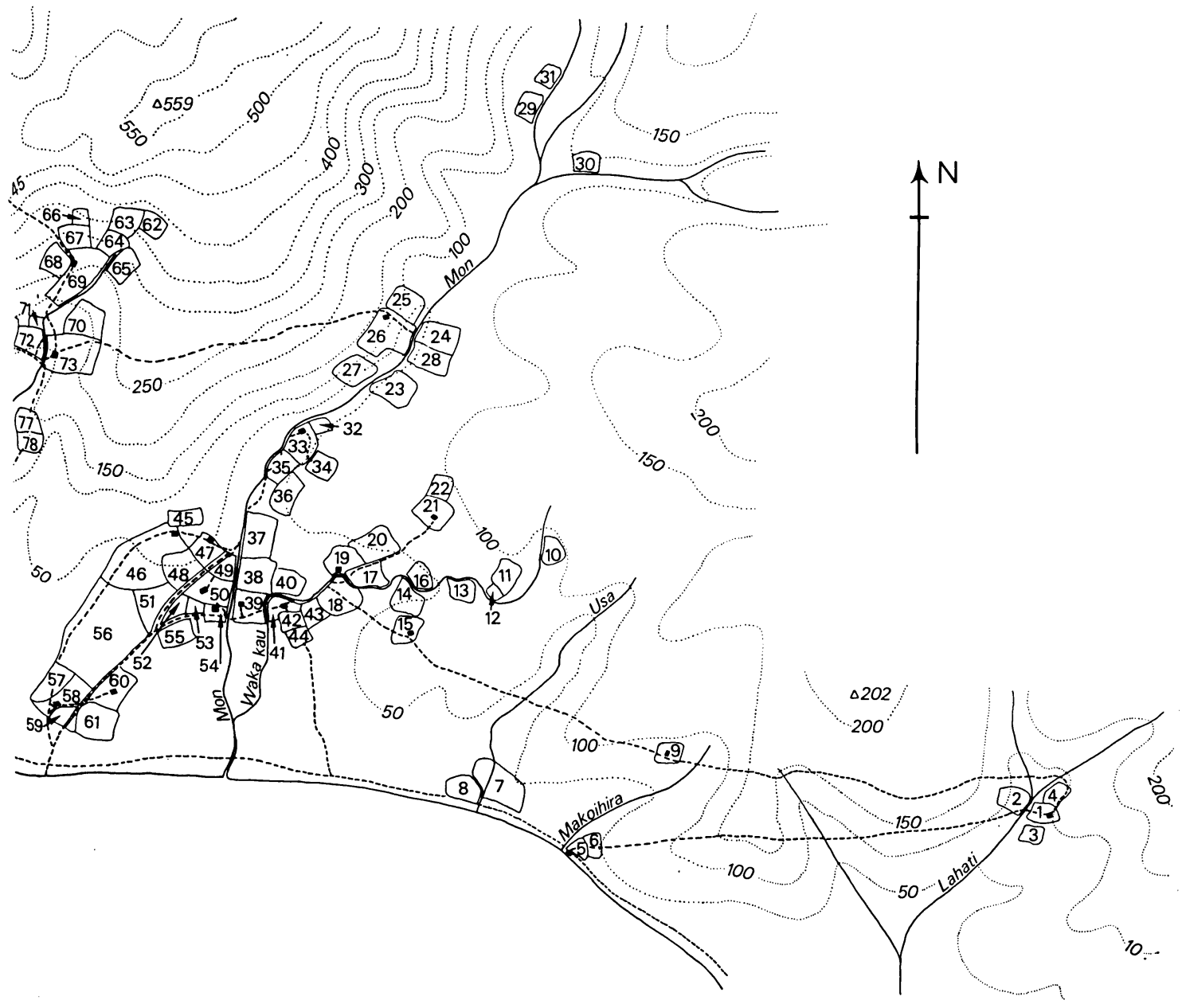


Local relief represents a more tangible factor. Elevation is considered to be of great importance, but the average degree of slope is such that there is no choice but to cultivate land on extreme gradients. The Nuaulu classify their topographic environment into four categories:

(1) watane: flat areas, the coastal margins, valley floors, alluvium;

(2) sanene: valley sides;

(3) pupue: ridgeland, crests, the higher reaches of valley walls;

(4) tinete, pupue tinete: mountains, peaks.

In MAP 10 the boundaries of cultivated areas are shown on a contour map superimposed according to local topographic categories. It can be seen that most cultivated land (over 70 per cent) falls into the category sanene which may contain cultivated slopes of around 35 degrees. Such

TABLE 22. Areas of cultivation according to local categories of topography*

\begin{tabular}{lcc}
\hline & $\begin{array}{c}\text { Total area } \\
\text { (in hectares) }\end{array}$ & $\begin{array}{c}\text { Percentage } \\
\text { area }\end{array}$ \\
\hline 1. watane & 30.71 & 30 \\
2. sanene & 69.64 & 69 \\
3. pupue & 1.84 & 1 \\
4. tinete, pupue tinete & - & - \\
\hline Totals & 102.19 & 100 \\
\hline
\end{tabular}

* Measured orthographically.

exceptionally steep land is known as tinete reroke. The Nuaulu prefer to cultivate watane land, but because this is usually already claimed by coastal Muslims, turned over to coconut or sago groves by themselves, or is too small or unsuitable in other respects, they are forced onto sanene, which thus represents the standard topography of Nuaulu garden land. ${ }^{3}$ This preference for flat areas of land may not have existed in the past. Indeed, some informants pointed to the advantages, in terms of drainage and clearance, of sloping land.

The soils of south Seram are by-and-large favourable dark-red and reddish brown latosols with little variation (Dudal and Moorman 1964: 72-4). ${ }^{4}$ The Nuaulu verbally distinguish only two basic kinds of soil, good or bad - tuamai iake or tuamai iake tewa, though more specifically (and much more commonly) they are referred to as either makai or mane, with which are associated very definite qualities. Thus: tuamai makai: hard, strong, difficult ..... small, round tubers tuamai mane: soft, weak, easy................ large, long tubers 


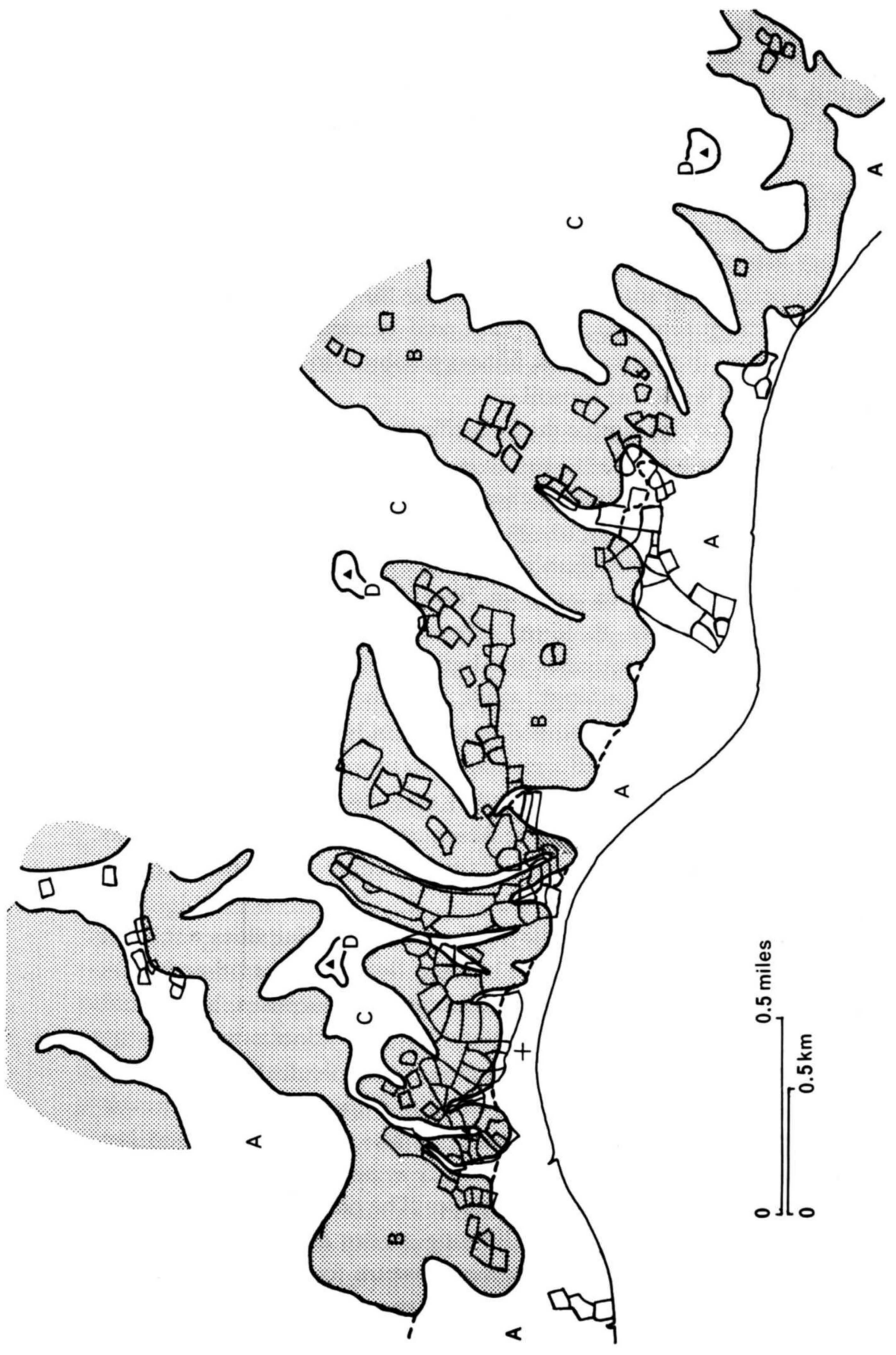


As they clearly prefer larger and longer tubers, whatever the crop manioc, yams, taro or sweet potato, there is a tendency to avoid difficult soils, not so much by never making gardens on such ground, but by differential planting. Similarly, hard soil is discriminated against by preferentially uprooting tubers (particularly manioc in old gardens) from soft soils and allowing those in difficult soils to become woody and run wild. The ultimate effect of this is that hard soils tend to revert to secondary growth more rapidly. Curiously enough, with respect to soil, sanene has certain advantages over watane, in that the alluvial deposit of the valley bottom tends to consolidate and become difficult to work, while gardens on the valley sides, although subject to marginal erosion, retain a light and workable topsoil.

The existence of this simple dual classification of soils does not mean that there is no awareness as to variation within the categories, or rather across the categories, for the other important characteristic of a soil in terms of Nuaulu requirements is its stoniness. It has already been pointed out that the coralline nokase is generally avoided, largely because of its tendency to occur in large masses. But there is some confusion over whether, in terms of parent material, nokase or the sandstones and schists provides the better soil. The coralline rock is softer and - I was told - 'cold', while the others are hard and 'hot', referring to their friability and ability to retain heat. In general, it was agreed that nokase gave best sustenance to crops, and indeed its lime content does render it superior, but it was considered bad in other respects. The distinction is not one which appears to enter closely into the decision-making processes of site-selection for most gardens (Appendix B).

Limiting vegetation as such, like soil parent material, does not seem very important to the Nuaulu; not because they consider other factors more significant, but because, for all intents and purposes, it does not occur. The notorious Imperata association not only does not exist in the Nuaulu area, but it is not distinguished terminologically from other vegetational associations. Isolated patches of Imperata exaltata Brongn. (oni) occur in coconut groves near the coast and as a pathside weed, but it appears that the low population density is insufficient to create the conditions in which Imperata sp. flourishes. The only vegetation which is regarded by the Nuaulu as really limiting garden choice is (like grassland) also a climax association, namely mature forest. Although presenting technological and labour problems, mature forest is regularly cut for garden land. However, particular sections of forest, on account of the 
size of individual stands or location in areas posing technical difficulties and problems of access, can be regarded as representing limiting conditions. Similarly, particular trees - such as Canarium sp. (iane, ananate), Sterculia sp. (pomane), Diospyros ebenaster Retz. and D. elliptifolia Merr. (ai jarine) - pose such formidable difficulties or are seen as providing such valuable concentrations of certain forest products that they too limit the total amount of forest available for cultivation.

All socially available secondary growth sets the cultivator few problems which will significantly affect what land he choses to cut, but informants made it quite clear that some attention is paid to the matter. Secondary growth can be grouped according to four types of association (Merrill 1954):

(1) young secondary growth: recently deserted clearings with rapidly growing herbs, shrubs and small trees of a relatively few number of genera - for example, Trema orientalis (L) Blume (sapane), Euphorbia hirta L. (mononute), Homalanthus populifolius Graham (hunua) and many kinds of pteridophytes;

(2) medium secondary growth: one to ten years, with small trees gradually becoming dominant - for example, Aleurites moluccana (L.) Willd. (kaheo pokune) and Melastroma malabathricum L.;

(3) mature secondary forest: great variety of small and medium-sized trees, shrubs and vines in areas with over ten years of secondary growth;

(4) bamboo thicket, also found in combination with the three above associations.

It might seem that there is always a great temptation to cut young secondary growth, since it represents less hard work. However, although the attention paid to fallowing might not be as much as among certain other swidden horticulturalists for whom we have adequate ethnographic information, a discarded garden will hardly ever be recleared in less than a year after it has been abandoned. On the other hand, very little mature secondary forest exists, as opposed to owned wasi containing fruit-bearing trees and palms. The reason for this is that it has usually been recleared before it has had a chance of reaching this stage. Gardens cleared from bamboo thicket possess the advantage of drying uniformly and burning quickly and completely (c.f. Conklin 1969:228). It is the medium secondary growth areas, together with bamboo thicket, which are cut, rather than the other characteristic quick-growing small trees and shrub associations. 


\section{Social limitations on cultivation}

Even in terms of the kind of preliminary ecological considerations cited above, certain social factors are closely involved, for it must be continually stressed that the indigenous ecological model will not necessarily conform to the environmental model of the observer. On the same interpretative level, land may be classified as unavailable for cultivation on account of:

(1) religious taboos (cemeteries and other sacred ground);

(2) uncultivated land in which an individual has no rights;

(3) uncultivated land in which an individual has rights, but of a different kind (such as in the village); and

(4) land already under cultivation.

However, very rarely would knowledge of these categories of unusable land (even if based on a thorough understanding of the indigenous ecological model) be sufficient to generate the observable pattern, as the result of an evaluation of this kind would not be entirely consonant with what is most desirable in other respects. Thus, preferences are also affected by:

(1) conflict of individual interests;

(2) anticipated labour requirements (energy input);

(3) time considerations, both in terms of such long-term problems as length of fallow and simply in relation to man-hour expenditure.

These considerations are dealt with in some detail below, but first it is necessary to look at the 'givens' affecting land choice which take the form of prescriptive rules of ritual prohibition.

\section{Ritual limitations on cultivation}

Ritual prohibition on the cultivation of particular areas of land relate to that regarded by the Nuaulu (for some reason or other) as being sacred (tuamai mone). Prohibitions involving a ritual sanction such as a sasi or other type of taboo sign are regarded as coming within a separate category, since the prohibition is on the taking or harvesting of crops and does not affect the initial selection of land for cultivation. However, the Lord of the Land may theoretically prohibit cultivation of certain areas of mature forest or wasi in some instances, the prohibition being known as sasi tuamai. It is possible that this helps to conserve the soil. However, as I was unable to observe this phenomenon and make the appropriate tests and enquiries (both on account of its infrequency and the practical difficulties involved) it must remain a case for some speculation.

The other reasons for land being unavailable for cultivation because of 
ritual limitations are less problematic. They are basically of four kinds, each represented by a separate term, the terrain implications of which are made quite clear in any discussion of site-selection: bosune nisi, matahene, hatu nohuwe and sowe. I shall deal with each of these in turn.

1. Menstruation huts are sometimes erected near the gardens, where they are known as bosune nisi, 'garden menstruation huts', and used by women in the event of a menstrual period occurring while away from the village. These are minimal structures commonly consisting of a single piece of sago frond thatch supported by slender uprights and with the sides left open. In former times all bosune were located away from the village in the belief that their presence near residential areas was harmful to men. As I have shown in Chapter III, this position has now been modified. It is this polluting quality of menstrual blood, the bosune and the land upon which it is built, which makes associated terrain taboo as far as other uses are concerned. It was agreed, though, that its harmful effects disappeared quite rapidly and that it was only in the short-term (one or, at the most, two years) that such land was unavailable for horticultural purposes.

2. Another short-term taboo is placed on the cultivation of land which has been used recently for the male initiation ceremonies, matahene. Such land typically consists of a cleared area of secondary growth (usually owned) in the centre of which is erected a platform of cut lengths of tree. This is especially taboo for women, who are warned away from the site by a taboo sign, made by crossing two slender bamboo lengths over the place where the neophytes stand during initiation. This also has the effect of protecting the area from the malevolent effects of evil spirits prior to the ceremony. Sacred areas used for male initiations are usually once again available for economic exploitation by the time the platform has rotted and has become heavily overgrown, after two or three years.

3. Land which under no circumstances can be cultivated is that on which cemeteries are located. For Ruhuwa this involves two locations, the child burial ground on the left bank of the river Joko just before it meets the sea and the main cemetery on the left hand bank of the river Upa, Hatu Nohuwe, 'the cavernous rock' (MAP 9). All Nuaulu cemeteries are located on the left hand bank of rivers and those of adults are invariably near rocky outcrops and caves, such areas being of a sacred nature in their own right. Further, there is an optimum distance from the village at which cemeteries should be located - near enough to afford easy access and simplicity in funerary arrangements and distant 
enough to feel secure from the incessant interference of the shades of the corpses and other evil spirits which have their abode in such places. The ghosts of dead children are considered less dangerous than those of adults and the burial ground is consequently nearer the village.

The land chosen for cemeteries, being rocky and cavernous, is unlikely to be selected for garden land. Moreover, Nuaulu would never work land adjacent to that on which the corpses and bones of their ancestors lie. For the most part, however, the land surrounding Hatu Nohuwe (and to some extent its counterparts in other Nuaulu villages) is good horticultural land, flat alluvium thrown up by the large river Upa on whose bank it lies. Coastal Muslims, though far from indifferent to the close proximity of the pagan graveyard, have laid claim to large areas of land nearby, which now consists of gardens, coconut groves and secondary forest. This has meant that the rocky outcrop remains an island of primary vegetation owned by the Nuaulu in a sea of cultivated land (or partially cultivated land) belonging to the Muslims of Sepa. Sometimes Hatu Nohuwe is visited while out on hunting expeditions, but only out of curiosity, as in general it is considered a dangerous place. All this is also more-or-less applicable to the child burial ground on the Joko.

4. Prior to pacification each Nuaulu village possessed a small piece of land near to the village on which was built a structure for containing the skulls of enemies taken during the course of head-hunting (Stresemann 1923:322). Both the structure and the land upon which it was erected was, and still is, known as the sowe (MAP 9). At the present time it is, in effect, a ritual wasi planted with ceremonially important shrubs required for ritual activities associated with the suane. The sowe is in the guardianship of, and maintained by, the Lord of the Land. Like the cemetery, it is unavailable for cultivation on a long-term basis, that is for all plants with a purely mundane economic function.

In addition to these four rather specific categories of land made inaccessible for horticulture through ritual prohibition, there are many sacred trees, stones and other natural features (such as wai pusate, 'hot springs'), all known and named, which are carefully avoided when working adjacent or nearby land. ${ }^{5}$ In themselves, however, they do not really constitute a genuine limitation on cultivation so much as hazards to be circumnavigated. The appearance of evil spirits in some areas of forest must also be considered as factors limiting cultivation. Sometimes their alleged interference may result in abandonment after or during clearance. 


\section{Tenurial limitation on cultivation}

The most important single factor limiting the area of choice available to an individual engaged in selecting a site for a new garden is land used or claimed by others; that is, land in which he has no rights of cultivation. TABLE 23 shows all land within a four kilometre radius of Ruhuwa, approximately 2432 hectares, according to its degree of social accessibility. The four kilometre radius has been chosen as it represents the absolute limit of garden cultivation in terms of distance from the village, approximately marking the boundary of the inner area of the Ruhuwa Nuaulu exploitative environment. This device is used in the absence of a tangible circumscribed region that can be called Nuaulu 'territory'. The problems of measuring territory emerge later with respect to the calculation of carrying capacity.

TABLE 23. Land within a four kilometre radius of Ruhuwa, classified to show relative accessibility

\begin{tabular}{lcc}
\hline & $\begin{array}{c}\text { Approximate } \\
\text { area in hectares }\end{array}$ & $\begin{array}{c}\text { Percentage } \\
\text { area }\end{array}$ \\
\hline $\begin{array}{l}\text { 1. Land unavailable for environmental } \\
\text { reasons (including rivers) }\end{array}$ & 20 & 0.8 \\
2. Unowned primary and secondary forest & 1500 & 61.7 \\
3. Garden land owned by non-Nuaulu Muslims: & 520 & 21.4 \\
$\quad$ a) Sepa & 20 & 0.8 \\
b) Tamilau & 178.75 & 7.3 \\
4. Village areas & & \\
5. Land owned by Nuaulu clans outside Ruhuwa: & 75 & 3.1 \\
$\quad$ a) Hahuwalan & 10 & 0.4 \\
b) Bunara & 6 & 0.3 \\
c) Watane & 102.19 & 4.2 \\
\hline 6. Land owned by Nuaulu clans in Ruhuwa & 2432 & 100 \\
\hline Totals & & \\
\hline
\end{tabular}

By far the largest area of inaccessible land of this kind is that occupied by Sepa gardens and groves (MAP 8), the total amount of land within the specified area belonging to all Muslim communities (that is, Sepa and Tamilau), being 540 hectares or 22 per cent of the entire area. Not only does this considerably affect the choice of Ruhuwa gardens, it is also the source of conflict and animosity between the two groups (see Chapter V), effectively reinforcing the opposition between Alifuru and nonAlifuru Seramese. But it is not merely the quantitative aspect of this distribution which affects the total pattern of settlement for Ruhuwa and 
aggravates relationships between Ruhuwa and the Muslims. As has been shown in the brief excursion into Nuaulu ethnohistory, Sepa, through always having been situated on the coast, had prior claim to most of the land immediately adjacent the shore. This is the flatter and the generally more superior area; in terms of the Nuaulu classificatory schema it is the most extensive area of watane. Coastal land of this type represents about 76 per cent of all watane and 62 per cent of all Sepa land in the area covered by MAP 10 . In contrast, only 40 hectares of watane (W8, W18, W41-44, W37-39, W49-61, W86-88, W115-116, W180-182), in all 29 wasi, or only 15 per cent of the total number of plots, were cultivated during 1970-71 by Ruhuwa. In terms of a percentage of all cultivated land, the area of wasi on coastal watane is probably considerably less. Furthermore, the priority of choice for the coastal Muslims has also meant that land nearest Sepa could be chosen in preference to more distant areas. Consequently, another factor affects the distribution of Nuaulu gardens, namely that the area of choice is effectively increased the further the land is from Sepa. As a result of these pressures the distribution of wasi is skewed such that (a) most of it lies east of Ruhuwa, and (b) Nuaulu gardens tend, on the whole, to concentrate towards the mountains, while Sepa gardens are concentrated along the coast. Not only does the latter have implications for the procedures and results of subsistence activities, but it also helps to maintain the traditional mountain and inland orientation of Nuaulu economy and consequently represents a physical manifestation of the wider conceptual and structural opposition between COASTAL Muslim and INLAND Alifuru life-styles.

As well as land being unavailable through ownership by Sepa (or Tamilau), other land near Ruhuwa is inaccessible through being held by Nuaulu clans resident in other villages, principally Hahuwalan and Bunara (MAP 8). However, this represents an almost insignificant proportion of such land compared with that in the possession of Sepa. In some cases genealogical connections provide Ruhuwa individuals with access to such gardens and occasionally land may be effectively transferred to Ruhuwa clans by affinal gifts (e.g. W113). Consequently, such land represents a significant but not absolute limitation on cultivation.

Having considered all this, there is still a very large sector of land unavailable for cultivation for tenurial reasons. This is land owned by clans other than that of the individual or even (very occasionally) land within his own clan to which access is, for some reason, barred or difficult to obtain. Precisely how significant such factors are in site-selection will 
largely depend on which clan an individual is a member of, or perhaps ultimately what household. In sum then, access to Ruhuwa Nuaulu land is very largely dependent on an individual's clan and genealogical affiliation. ${ }^{6}$

During $1970-71$ a total of 102.19 hectares were described to me as being owned land, and of this about 75 hectares were under some form of cultivation (nisi honwe or nisi monai). To this land every male individual in the village has some rights or potential rights of access. On average each Ruhuwa clan possesses 20.44 hectares, each household 4.08 hectares and each individual 0.57 hectares. Almost all of this land is productive to some degree, although the actual per hectare yield will vary considerably from plot to plot. As might be expected, nisi ahue is the least productive and nisi honwe provides the highest per hectare yields. The latter also represents the greatest contribution of domesticated resources to Nuaulu diet. However, land is not equally divided between either clans, households, or individuals. TABLES 24 and 25 show the total area of land owned by Ruhuwa split up according to clan and household respectively, to show their percentage share of the total. What is quite clear from these data is that (with respect to land anyway) there is no great inequality in the distribution of wealth, the area owned being approximately in proportion to the population of each clan $(\mathrm{r}=$ 0.99), although the correlation with the population of each household is not so strong $(\mathrm{r}=0.73$, and $\mathrm{r}=0.78)$ for the number of wasi. ${ }^{7}$ This means that at the clan level there can be no parity, the largest possessing more than seven times the land of the smallest.

TABLE 24. Distribution of Ruhuwa land according to clan

\begin{tabular}{lrrrrc}
\hline \multicolumn{1}{c}{ Clan } & $\begin{array}{c}\text { Number } \\
\text { of } \text { wasi }\end{array}$ & $\begin{array}{c}\text { Area in } \\
\text { hectares }\end{array}$ & $\begin{array}{c}\text { Percentage } \\
\text { area }\end{array}$ & $\begin{array}{c}\text { Popu- } \\
\text { lation }\end{array}$ & $\begin{array}{c}\text { Percentage } \\
\text { population }\end{array}$ \\
\hline Village land & 2 & 1.37 & 1 & - & - \\
1. Somori & 16 & 5.85 & 6 & 16 & 8 \\
2. Penisa & 11 & 5.33 & 5 & 9 & 4 \\
3. Matoke & 30 & 19.66 & 19 & 35 & 18 \\
4. Sonawe-ainakahata & 67 & 37.29 & 37 & 61 & 38 \\
5. Nepane-tomoien & 66 & 32.69 & 32 & 59 & 32 \\
\hline Totals & 192 & 102.19 & 100 & 180 & 100 \\
\hline \multicolumn{5}{c}{$\mathrm{r}=0.99$}
\end{tabular}

Nuaulu land transfer as a means of compensatory adjustment

Given the situation just described, it is necessary to explore the mechanism (apart from cutting mature forest) by which an individual 
and clan can increase the amount of suitable garden land they have access to so as to meet changing economic requirements. It has already been noted in Chapter V that an individual Nuaulu has (apart from inheritance) only three ways of doing this: by an affinal gift of land, by a gift which is not recognized as part of the ritualized structural relations between clans but is nevertheless genealogically linked (such as from an adopted father), and by a gift in which no genealogical connection is the motivating factor. It has also been demonstrated that of these affinal gifts are the most frequent, and something of the context and mechanism by which they are brought about has already been discussed (see above pp.100-102), including some of the ecological implications. It remains to explore the quantitative and directional aspects of this phenomenon; to see how much land actually passes through clans in this way, of what kind and between whom. Some aspects of this are represented in TABLE 26, on the basis of which it is apparent that quite significant amounts of land do change status in this way. If it is assumed, quite arbitrarily, that the changes shown in TABLE 26 represent all such transactions over a period of ten years, then it would take about 50 years for an area equivalent to the entire area owned by Ruhuwa to change hands. Of the transactions listed in the table, nineteen appeared to have been nisi monai at the time the transfer was made (about half of which were groves of one kind or another) and the remaining ten nisi ahue. For reasons that are obvious nisi honwe is never subject to a transfer of this nature.

Such a degree of alienation might be assumed to result in a correspondingly high degree of land fragmentation. As has been indicated already, and as an examination of the distribution of clan land in MAP 11 and FIG 7 shows, there is, on the contrary, a certain consolidation.

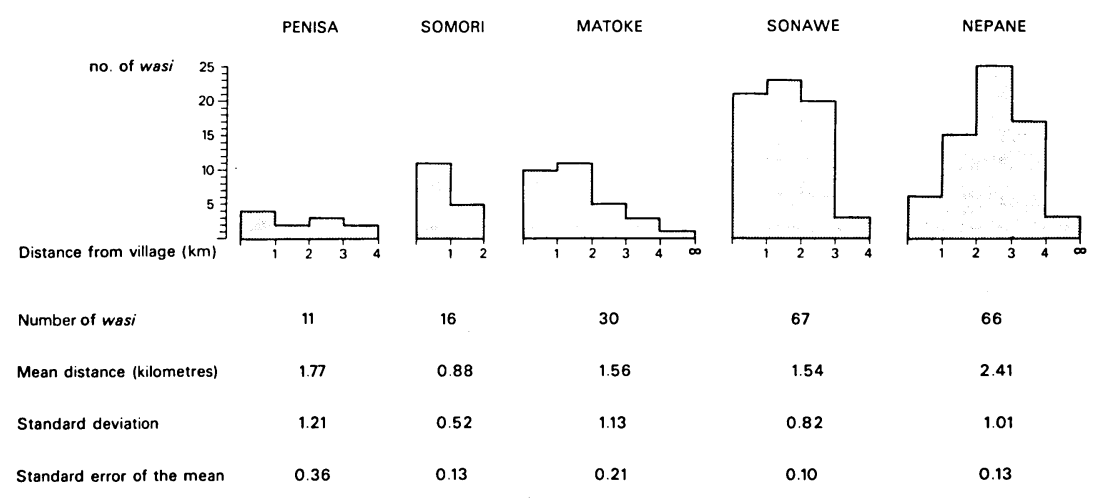

FIGURE 7. Distribution of wasi in terms of distance from Ruhuwa for each clan. 


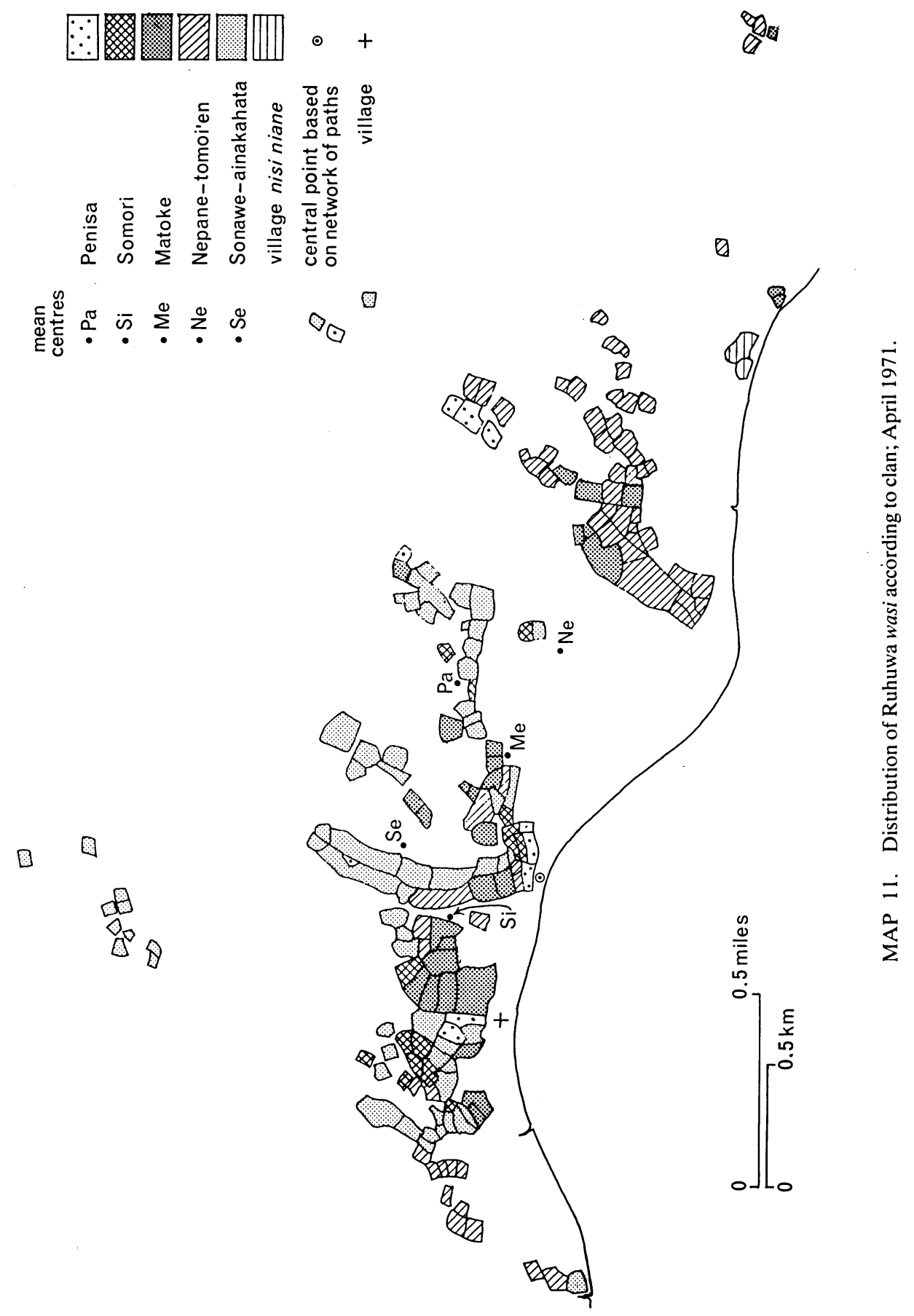


While it must be admitted that even in a random distribution of the points shown in MAP 11 there would be a tendency for a clustering pattern to emerge, particularly for the two largest clans, a ' $t$ ' test calculated for Somori and Nepane indicates that the distribution is highly significant statistically $(\mathrm{t}=5.84, \mathrm{p}=0.00000012$ for 79 degrees of freedom). This picture can only be explained if (a) land is not alienated permanently, or (b) land received is preferentially adjacent to wasi

TABLE 25. Distribution of Ruhuwa land according to household

\begin{tabular}{|c|c|c|c|c|c|c|}
\hline Household & $\begin{array}{c}\text { No. of } \\
\text { persons } \\
\text { per } \\
\text { household }\end{array}$ & $\begin{array}{l}\text { Percentage } \\
\text { of total } \\
\text { village } \\
\text { population }\end{array}$ & $\begin{array}{l}\text { Clans } \\
\text { present }\end{array}$ & $\begin{array}{c}\text { No. of } \\
\text { wasi }\end{array}$ & $\begin{array}{l}\text { Area in } \\
\text { hectares }\end{array}$ & $\begin{array}{c}\text { Percentage } \\
\text { area }\end{array}$ \\
\hline & village land & & & 2 & 1.37 & 1.3 \\
\hline 1. Teliam & 3 & 1.6 & Matoke & 7 & 2.79 & 2.7 \\
\hline 2. Tapone & 10 & 5.5 & $\begin{array}{l}\text { Sonawe, } \\
\text { Somori }\end{array}$ & 23 & 13.18 & 13.1 \\
\hline 3. Numapena & 10 & 5.5 & Sonawe & 77 & 5.94 & 5.9 \\
\hline 4. Komisi & 7 & 4 & Somori & 10 & 4.31 & 4.2 \\
\hline 5. Nepinama & 4 & 2.2 & $\begin{array}{l}\text { Sonawe, } \\
\text { Somori }\end{array}$ & 3 & 1.00 & 1.0 \\
\hline $\begin{array}{l}\text { 6. Hatarai } \\
\text { 7. Lohia }\end{array}$ & 9 & 5 & Sonawe & 12 & 5.75 & 5.7 \\
\hline (Sonawe) & 8 & 4.4 & Sonawe & 6 & 1.61 & 1.5 \\
\hline 8. Retau'une & 4 & 2.2 & Somori & 2 & 0.19 & 0.1 \\
\hline 9. Mainjo & 7 & 4 & Nepane & 5 & 1.98 & 1.9 \\
\hline 10. Patioka & 7 & 4 & $\begin{array}{l}\text { Nepane, } \\
\text { Sonawe }\end{array}$ & 3 & 1.92 & 1.8 \\
\hline 11. Hotena & 7 & 4 & Nepane & 8 & 4.67 & 4.6 \\
\hline 12. Tuale & 8 & 4.4 & Nepane & 6 & 2.84 & 2.7 \\
\hline 13. Paikole & 6 & 3.4 & Sonawe & 5 & 3.28 & 3.2 \\
\hline 14. Sorita & 13 & 7.2 & Matoke & 15 & 9.01 & 9.0 \\
\hline 15. Sanakamura & 3 & 1.6 & Somori & 1 & 0.59 & 0.5 \\
\hline 16. Inane & 2 & 1 & Matoke & 4 & 2.45 & 2.4 \\
\hline 17. Iako & 9 & 5 & Matoke & 5 & 5.55 & 5.5 \\
\hline 18. Konane & 6 & 3.4 & Nepane & 8 & 4.13 & 4.0 \\
\hline 19. Tuisa & 8 & 4.4 & Nepane & 8 & 4.61 & 4.5 \\
\hline 20. Sau'ute & 17 & 9.4 & Nepane & 21 & 11.64 & 11.5 \\
\hline 21. Wairisa & 7 & 4 & Sonawe & 3 & 1.19 & 1.1 \\
\hline $\begin{array}{l}\text { 22. Lohia } \\
\text { (Penisa) }\end{array}$ & 4 & 2.2 & Penisa & 5 & 2.31 & 2.2 \\
\hline 23. Menai & 11 & 6 & $\begin{array}{l}\text { Matoke, } \\
\text { Sonawe, } \\
\text { Tanlai }\end{array}$ & 10 & 4.76 & 4.7 \\
\hline 24. Sahunete & 4 & 2.2 & Penisa & 3 & 2.00 & 2.0 \\
\hline 25. Naunepe & 6 & 3.4 & $\begin{array}{l}\text { Penisa, } \\
\text { Nepane }\end{array}$ & 10 & 3.12 & 3.0 \\
\hline Totals & 180 & 100 & & 192 & 102.19 & 100 \\
\hline
\end{tabular}

$r=0.94$ 
TABLE 26. Movement of land between clans in Ruhuwa, on the basis of garden distribution in 1971

\begin{tabular}{|c|c|c|c|c|c|c|c|}
\hline Clan & $\begin{array}{c}\text { Number } \\
\text { of wasi } \\
\text { received }\end{array}$ & $\begin{array}{c}\text { Area } \\
\text { in } \\
\text { hectares }\end{array}$ & $\begin{array}{l}\text { Percentage } \\
\text { of total } \\
\text { clan land }\end{array}$ & $\begin{array}{l}\text { Number } \\
\text { of wasi } \\
\text { given }\end{array}$ & $\begin{array}{l}\text { Area } \\
\text { in } \\
\text { hec- } \\
\text { tares }\end{array}$ & $\begin{array}{l}\text { Percent- } \\
\text { age of } \\
\text { total } \\
\text { clan land }\end{array}$ & $\begin{array}{c}\text { Net loss } \\
\text { or gain } \\
\text { in hec- } \\
\text { tares }\end{array}$ \\
\hline Uncertain & - & - & - & 3 & 2.31 & - & - \\
\hline 1. Somori & 4 & 2.03 & 35 & 1 & 0.41 & 7 & +1.62 \\
\hline 2. Penisa & 2 & 0.48 & 9 & 2 & 0.53 & 10 & -0.05 \\
\hline 3. Matoke & 9 & 6.38 & 32 & 5 & 3.11 & 16 & +3.27 \\
\hline $\begin{array}{l}\text { 4. Matoke } \\
\text { (Aihisuru) }\end{array}$ & - & - & - & 3 & 1.63 & - & - \\
\hline $\begin{array}{l}\text { 5. Sonawe- } \\
\text { ainakahata }\end{array}$ & 8 & 4.78 & 13 & 8 & 4.36 & 12 & +0.42 \\
\hline $\begin{array}{l}\text { 6. Nepane- } \\
\text { tomoien }\end{array}$ & 6 & 3.66 & 11 & 5 & 3.2 & 10 & +0.46 \\
\hline 7. Pia (Bunara) & - & - & - & 2 & 1.78 & - & - \\
\hline Totals & 29 & 17.33 & & 29 & 17.33 & & +5.72 \\
\hline
\end{tabular}

already owned by the recipient or his clan, or (c) such land is not cultivated or recognized beyond one or two years. As is indicated by the data already given, except in the rare instances where there are no male offspring from a marriage, factor (a) is unlikely to affect the situation. It does appear, though, that recipients are wary of planting long-term cultigens, such as coconut, sago and clove, on such land before the birth of an heir. It is the second factor (b) which provides the most credible explanation of the situation as it exists, particularly in view of the emphasis placed on the clustering of gardens. The third explanation, while rather an unlikely contributory factor by itself on any large scale, almost certainly acts in combination with the second, such that the more relatively isolated, distant and detached wasi become neglected. Since it is generally incoming gifts of land which tend to fall in these categories and since there is a desire to consolidate garden resources (particularly the long-term cultigens of the groves) and to maximize accessibility, it is not surprising that there is a tendency for them to be neglected, and perhaps ultimately forfeited. ${ }^{8}$ It is, of course, quite impossible to calculate with any degree of accuracy the amount of land lost in this way.

In terms of the ideal pattern of Nuaulu connubial relations, and very probably to a much greater extent in former times, the relationships between clans are based on permanent wife-taking/wife-giving 
bonds, such that land and women are obtained from one genealogical direction and disposed of in another. If the terminologically prescribed pattern of bilateral connubium is adhered to, the direction of receipt and that of disposal are one and the same; in directional terms, reciprocity is then balanced and symmetrical. However, the divergence of current patterns of alliance from this model has been stressed (see above pp. 50-51). In FIGURE $8 \mathrm{I}$ have attempted to portray diagrammatically the movement of land between the various Ruhuwa clans. The only point of significance to emerge from an examination of this flowdiagram is the high degree of village endogamy which inter-clan land transfers appear to reflect (see also TABLE 26). Since there is no particular preference for village endogamy, it is possible that land received from affines in other villages is only rarely utilized on account of its distance from Ruhuwa. Cases were recorded where land obtained in this manner was neglected, though in none of these were rights actually forfeited. As is only to be expected, marriage with outsiders is generally disadvantageous in terms of increasing the total amount of accessible land; indeed it may even result in an overall decrease in village land. Village endogamy ensures both relatively easy access and prevents

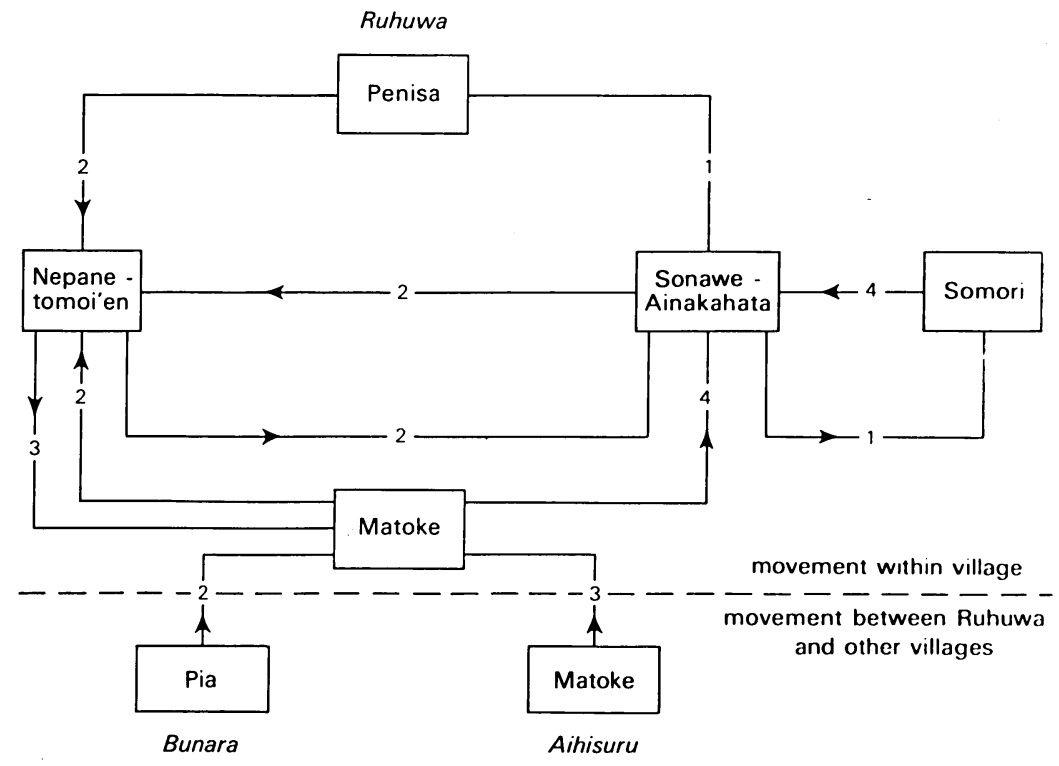

FIGURE 8. Flow diagram illustrating the recent movement of land between clans, based on 1971 wasi distribution for Ruhuwa. Figures refer to the number of wasi passing in a specified direction. 
undue outflow of land from the total pool. Apart from this interesting aspect of inter-clan land transfers, there appears to be no measurable evidence for any systematic structure in the directional features of exchanges of land between clans. Though idealized,. symmetrical exchanges occur with no consistency, and although the evidence suggests a matrilateral bias in both wife-selection and in-flow of land (TABLE 18), there is little attachment to the idea of unidirectional transactions. The important thing is that land exchanges do occur between different clans, and on a significant scale.

What is emerging from this discussion is that the constant transfer of land between clans acts as a type of equilibrium-seeking process. This kind of process has been the subject of extensive examination in Malayopolynesian ethnography since Goodenough (1975: 71) noted that to vest land rights in formal kin groups creates a problem due to the fluctuations in kin group size through time. Goodenough has suggested that the necessary flexibility to counter this can be achieved by keeping the kin groups non-unilinear. However, the Nuaulu manage to solve this problem while at the same time adhering rigidly to patriclan recruitment norms. Further, this pattern is not associated with any critical pressure on land or absence of inter-clan transfers of land (Meggitt 1958; 1965).

As to the situation in former times, with the clan-hamlet pattern of settlement, excessive uxorilocal residence might be expected to have resulted in some confusion in the organization of ideologically rigidly structured marriage relations. At the present time there is absolutely no question of an individual male transferring clan allegiance, except in the exceptional circumstances of hunoni tau mansia, 'paying with a person'. Here the first child of a union adopts the clan of its mother in the event of the inability to pay bridewealth (c.f. above pp. 52-53 and note 24). Rather, it is by the kind of marriages contracted that a clan increases the land which is available to it. In the case of a negotiated union, the prestige of the marriage is sufficient for there to be little difficulty in obtaining land from affines. However, it is the forfeiture of virilocal residence by means of a 'marrying-in' union which provides the traditional and, as far as can be judged, the most common means of acquiring access and subsequent ownership of affinal land. Unions formed by elopement traditionally preclude this kind of gift, although the tendency to convert unions established by elopement effectively into 'marryingin' unions through uxorilocal residence and a general permissiveness in modern Nuaulu connubial relations means that they are by no means absent. In short, it is the exploitation of connubial possibilities and 
affinal relationships, rather than by any so-called 'weakening of agnation' by forfeiture of patriclan membership, which provides the mechanism by which local imbalances over land resources are alleviated. This applies both to the total area of land available to an individual clan and holdings of land in different vegetational categories (TABLE 20). This simply reaffirms the proposition that there is no consistent formula to explain the kinship system implications of land shortage. Rather, as Raymond Kelly has pointed out (1968: 61,63), it must be emphasized that 'any given society's response to pressure of land resources is mediated by the existing structure and established lines of cooperation within that structure'.

\section{Economic factors in site-selection}

In the first section of this chapter certain environmental considerations were noted which influence Nuaulu land choice. As opposed to the social factors considered subsequently (concerning ritual and tenurial limitations on cultivation), these represent a class of factors which in the general sense relate to what are traditionally understood as 'economic' decisions, in this case, the assessment of environmental resources. And yet resource quality is only one aspect on the input side; three others (which are frequently of more importance) are demand, time and energy considerations. Of course, these aspects are closely interrelated and environmental quality will affect both yield and the amount of energy and time involved, and vice versa.

Overall demand is a very important factor influencing decisions as to what area of land should be put under cultivation at any one time, as is differential demand for various crops. Demand is also mirrored temporally in the way individual garden and garden-complex successions develop. The changing composition of the household and the developmental cycle of the domestic group is reflected, through demand, in the number and dispersion of those plots selected. Some data on the nature of these pressures are outlined below on pages 151-154 and in Chapter VII. Most of what remains in the present chapter is devoted to a detailed examination of the ways in which time and energy considerations affect decision-making with respect to site-selection, though it will become apparent that it is quite impossible to isolate them completely from a variety of other social factors to which they are inextricably bound. The most important respects in which these factors are manifested for the Nuaulu are in connection with communication between gardens and the village and between one garden and another. It 
is to these questions that much of the discussion which follows is devoted.

\section{Communications}

Although Ruhuwa is situated directly on the coast, waterborne transportation is of little significance as a means of communication. During the period in which fieldwork was undertaken the village possessed one old eight metre dugout canoe, and four outrigger canoes. Two of the outrigger canoes and the dugout were the property of a single individual (Sau'ute), another belonged to the village headman (Komisi) and the fourth to a non-Nuaulu married to a Ruhuwa girl. All craft were used relatively rarely, usually for the little seafishing which the Nuaulu sometimes engage in. No other Nuaulu village possess water-craft of any kind and the Ruhuwa owners of these vessels are very much regarded as atypical individualists. On a few occasions craft are used for the transport of garden produce and game from distant gardens, but this is rare. In this respect the Nuaulu do not take full advantage of their coastal location, a fact which can largely be ascribed to the tradition of a mountain-oriented existence and certain ritual attitudes towards the sea (see above pp. 17, 38, note 15).

The most important means of communication are paths. The main arterial pathways between settlements (barisi) are regularly cleared in conjunction with other villages coming within the area administered by the raja of Sepa, while secondary pathways to the gardens and in the forest (arena) are cleared informally. ${ }^{9}$ If any path becomes impassable it is the task of the persons who first discovered it to remove any obstacle or to remedy the situation in the way thought most appropriate. If a path is excessively muddy it is covered with branches, banana leaves, coconut or sago fronds. The same applies to bridging, when a path is made for the first time or when it falls into disrepair. In such cases new logs are cut or thick young bamboo is laid across the stream bed to be bridged. Bridging, though, is generally regarded as being unimportant, as only flooded or large rivers pose problems, and in such situations the Nuaulu do not possess the technology enabling them to erect suitable structures. The outcome of a general adherence to such rules concerning the use of thoroughfares is that, except for heavy rainfall or unforeseen natural hazards, paths in use remain in a reasonable state of upkeep.

Wet season travel provides the greatest problems for communication, and access to gardens becomes difficult. On the whole, visits to the gardens during the wet season (ihate, the season of the east wind) tend to 
be less frequent and of shorter duration than at any other time of the year. FIGURE 9 shows graphically the amount of time spent in the gardens over a period of six months in relation to monthly rainfall. Heavy rains, fallen trees, fast growing and wet undergrowth all make travel between village and garden difficult. Paths frequently become streams themselves (or at best quagmires), and streambeds (easily used as thoroughfares in the dry part of the year) become rushing torrents. The flooding of rivers in the flat coastal watane areas presents a special hazard in communication. Occasionally, an effort is made to clear the undergrowth from along the sides of the paths and to widen them before the worst of the rains of the southeast monsoon set in. However, this is usually only for paths directly adjacent to the village, such as those leading to water conduits, and is not feasible for ordinary garden trails. Coastal travel at particular times of the year, especially at the beginning and (to a lesser extent) throughout the rainy season, is hindered by exceptionally high tides, which make it impossible to travel along the shoreline.

The coastal paths are by far the best means of communication and are often used in preference to shorter but more demanding routes inland. Thus, it is common for access to all principal river valleys to be measured in terms of how far from the sea the garden is up the watercourse. This is exemplified in the case of the siting of the new nisi niane for Niamonai. During the course of a meeting it was decided that it would be more

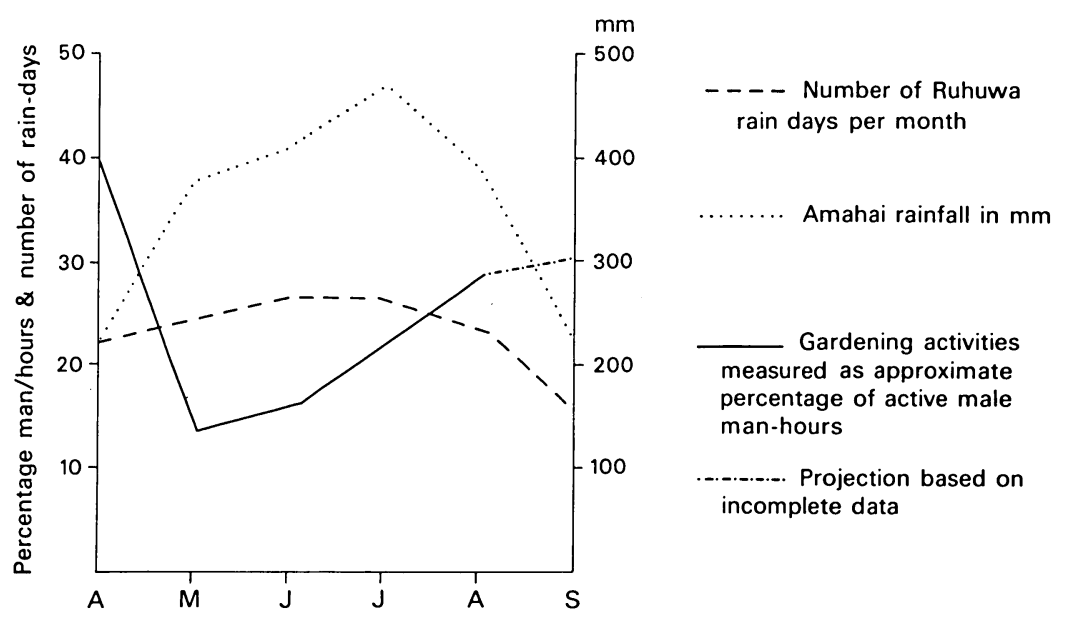

FIGURE 9. Time devoted to Ruhuwa garden activities in relation to rainfall, from April to September 1970. 
desirable to have a village garden on the river Usa, some eight kilometres from the village than on the river Pia, a mere three kilometres away. The reason was that the former had the advantage of being nearer the coast, while the latter could only be reached by traversing awkward inland paths. It should also be mentioned, though, that the Usa site had a further advantage, in that it was adjacent to an older Niamonai nisi niane. Consequently, since the coast offers, on balance, better conditions for travel than many inland routes, the tolerable distance travelled is proportionally increased. Further, the ideal distribution of Nuaulu garden land should lie along the line of easiest communication, which is by-and-large the coast.

In consequence of all this, the quality of communications, affected by the environmental factors of topography, vegetation and weather, together with the available technological repertoire, directly influences the relations between villagers and their land. ${ }^{10}$ It would seem that it becomes advantageous to limit the time and energy devoted to travel to a minimum, as a means of conservation of effort and to maximize the time available for directly productive activities and pleasure. This can be done in three ways:

(1) by reduction of village-garden distance,

(2) by reduction of the distance between gardens,

(3) by reduction of the total time and energy resources accorded to garden activities. ${ }^{11}$

\section{A note on time and distance}

Before considering the factors affecting site-selection which involve measurement of distance, some explanation is necessary. To use the term distance unqualified can lead to certain ambiguities. I therefore make the methodological distinction between three different basic measures:

(1) horizontal distance,

(2) linear or topographic distance - horizontal distance adjusted to account for undulating elevation,

(3) time or pheric distance ${ }^{12}$ - measured in unit-time to cover a specific distance.

Unless otherwise specified, the term distance as used here refers to horizontal distance measured by the shortest and most commonly used route. I use the expression orthographic distance for this, to distinguish it from direct horizontal distance, measurement between two points as the 
crow flies. ${ }^{13}$ Having made these distinctions it is important to assess which one of the measures is analytically the most useful. ${ }^{14}$

The Nuaulu have no units of linear measurement greater than a pace and this is awkward for calculating distances between garden and village, it being usual to use time as a measure of distance wherever possible. Short periods of time are simply measured by the position of the sun, the diurnal arc being composed of six named phases, or the position of the moon and stars at night. Longer units of time-measure include days, four named phases of the moon, lunar months, seasons and years. Insomuch as time is a locally prescribed way of computing distance, being regarded as a resource in itself and the standard means of measuring the cost of subsistence activities, and since it appears to reflect the energy-cost of travel in some ways more accurately than spatial distance, it could be argued that it represents the most superior measure of distance from an analytical point of view. Nevertheless, I feel it has at least three distinct drawbacks. In the first place, to record the time taken in travelling from a village to each one of 192 separate wasi is not only impracticable and time-consuming, but for any reasonable degree of accuracy to be obtained both outward and return journey must be measured on several different occasions and for different individuals. The second drawback concerns the problem of variation more specifically. If time distance is plotted graphically against distance measured orthographically for a statistically valid random sample of Ruhuwa wasi, it is found that for distances up to three kilometres time distance is approximately directly proportional to orthographic distance (that is $f(d) \alpha t$, and vice versa), after which there appears to be no consistent correlation except that the graph rises steeply. ${ }^{15}$ The reason for this is simply that three kilometres approximately represents the distance that can normally be tolerated without resting, after which rests become frequent and of irregular duration. Consequently, time distance cannot be taken as a good indicator of energy expenditure above distances of about three kilometres, and neither can it be taken to reflect actual distance travelled. The third drawback, and the one which is crucial to my rejection of the utility of time as a meaningful measure of distance in this analysis, is not so much methodological as concerned with the appreciation of Nuaulu concepts of measurement. I argued above that time is an important indigenous means of assessing energy-cost and is frequently utilized in estimating garden-village distance. This is all quite correct, but it would be naive to believe that on account of this Nuaulu are unable conceptually to distinguish time and spatial distance. Although travel is measured 
according to unit-time, it is recognized that though the spatial distance between the same two loci may be finite the time taken to travel the same distance is variable. While macro-units of measurement do not exist for the computation of linear or topographic distance it is well appreciated that in the final analysis it is this means of reckoning that is the ultimate distance function determining accessibility.

Having rejected time distance as a convenient and useful measure it is necessary to justify the kind of spatial measurement I have adopted. By implication I have already indicated a preference for orthographic distance and feel it quite unnecessary to spell out why the use of a direct horizontal distance is unacceptable for this kind of field study (see footnote 13). However, orthographic distance too is in some respects an unsatisfactory measurement when considering such questions as garden accessibility. Clearly, linear distances give a much more accurate picture but involve much effort in computation. In my own cartographical work in the field (Appendix C) I relied on a combination of given horizontal distances from an existing base-map and original linear measurements corrected to their horizontal equivalents. Although the Nuaulu concept of spatial distance is understandably also a function of topography, I am reasonably confident that the more easily calculable orthographic measurement (as computed from the large scale original of MAP 9) provides the most practical and analytically meaningful distance function. ${ }^{16}$

One further practical problem in the measurement of orthographic distance ought to be mentioned at this stage, that which arises when there is more than one route available between two loci. In such a case the shortest route will normally be given. However, sometimes a longer route may be preferred by the Nuaulu, if for example the terrain is easier and the paths superior. That this is so has already been mentioned in the last section. The shortest route of access for some gardens is to cut across high ground from one river valley to the next, but occasionally it is seen as more desirable to walk along the coast until the relevant river is reached. For instance, the shortest route from Ruhuwa to W26, high up on the river Mon (MAP 9), is 2.62 kilometres measured orthographically across the steep garden land and secondary forest of the Awao and Lihuru valleys. The preferred route is 3.25 kilometres, but along good coastal track and then up the river Mon from its outlet to the sea. The difference is 630 metres. 
The factor of garden-residence distance

The deceptively obvious and simple factor of distance may greatly affect the absolute size and complexity of a pattern of settlement (Chisholm 1968: 43-67, 111-36, Brookfield 1968: 424). Though theoretically possible for sedentary communities such as the Nuaulu to expand under swidden cultivation to substantial limits, the sheer problem of getting from garden to garden and from residence to garden poses a crucial limitation on the size of the population, though pressures against moving the village are equally considerable. This is true to a lesser extent for rotational systems since far less land is devoted to fallow. ${ }^{17}$

It is now necessary to look a little closer at field-residence distance among the Nuaulu. The relationship consists of two broad aspects:

(1) the relationship of the residence unit to the area of exploitation as a whole, and

(2) the relationship of the residential units to particular plots.

The first of these aspects is often expressed in terms of the gross determining effect of the overall size of the area exploited and the mechanism of exploitation on the dispersion of residential units. For purposes of analysis a more precise and computable index is required, such as is expressed in the relationship of residential units to specific plots of land.

For communities based on subsistence horticulture one of the most crucial factors with respect to the organization of the settlement pattern is expressed in terms of the rule to the effect that the distance between house and field be kept to an absolute minimum. The reasons for the desirability of this situation are obvious and the rule is applicable in all agricultural communities, though the consequences may vary from place to place. Among the Nuaulu pressures acting in opposition to the implementation of this rule are considerable, the final outcome representing the optimum walking distance between garden and house. This is also true for the great majority of other southeast Asian communities of swidden cultivators; the logical minimization of distance, represented by the location of a house actually within the garden, obtaining only rarely. The component determinants of this rule, as far as the Nuaulu are concerned, include the following:

(1) the conservation of time and energy involved in travelling between house and garden, especially over difficult terrains and gradients; ${ }^{18}$

(2) the conservation of time and energy in subsidiary tasks required to make communication possible - maintenance of arena paths and the cutting of new trails; 
(3) the conservation of time and energy in the construction of elaborate garden huts;

(4) ease of protection for gardens from thieves and marauding animals;

(5) the conservation of energy with respect to the carrying of heavy garden produce, timber and tools;

(6) nearness to village in the event of important rituals or meetings, visits from government officials and such like; 19

(7) nearness to village in the event of danger from man or beast, or from natural hazards such as falling trees;

(8) rapid recruitment of labour if required for certain tasks, such as hunting;

(9) less likelihood of trouble from malevolent spirits, ogres and such like;

(10) nearness to village in order to fetch or borrow tools and containers, if required;

(11) lack of any necessity to provide garden menstruation hut for women;

(12) secondary growth nearer the village typically younger and therefore some advantages in clearing (but see above pp. 84-86, 117 and below pp. 150-151).

The list is extensive, but is still, no doubt, not comprehensive. However, the operational importance of any one factor depends very much on specific circumstances.

If garden-house distance is so fundamental it is necessary to examine the actual resulting situation on the ground. TABLE 27 shows the numerical distribution of wasi for Ruhuwa with respect to their orthographic distance from the village. There are two important facts

TABLE 27. Distribution of 'wasi' with respect to distance from village, Ruhuwa 197I

\begin{tabular}{lcccc}
\hline $\begin{array}{l}\text { Distance in } \\
\text { kilometres }\end{array}$ & $\begin{array}{c}\text { Number } \\
\text { of wasi }\end{array}$ & $\begin{array}{c}\text { Area in } \\
\text { hectares }\end{array}$ & $\begin{array}{c}\text { Percentage } \\
\text { area }\end{array}$ & $\begin{array}{c}\text { Average size } \\
\text { of wasi, } \\
\text { in hectares }\end{array}$ \\
\hline 1. $0-1$ & 56 & 30.1 & 29.5 & 0.54 \\
2. $1-2$ & 53 & 32.2 & 31 & 0.60 \\
3. $2-3$ & 57 & 30.2 & 29.5 & 0.53 \\
4. 3-4 & 22 & 8.48 & 9 & 0.35 \\
5. More than 4 & 4 & 1.21 & 1 & 0.3 \\
\hline Totals & 192 & 102.19 & 100 & \\
\hline
\end{tabular}


concerning the distribution pattern in this table; first the apparently almost equal use of land for each class up to three kilometres, after which the disadvantages of distance begin sharply to outweigh any of the advantages the gardens might otherwise have, and second, the fact that over forty per cent of the gardens are over two kilometres from the village. In fact, there is quite a strong inverse relationship between distance from village and both number of wasi and area in hectares $(\mathrm{r}=$ -0.89 , in both cases). This relationship is broadly reflected in the position for each clan, with the exception of Nepane (FIGURE 7).

How can the figures presented in TABLE 27 be accounted for in more specific terms ? Clearly, there must be some very important reasons against minimizing the garden-house distance and, indeed, some which actually prohibit it. There are two classes: absolute givens which make cultivation impossible, and others which just make it undesirable. Some of the former have already been considered separately as limiting factors. To recapitulate, they are:

(1) land under cultivation by non-Nuaulu;

(2) land under cultivation by other Nuaulu;

(3) land ritually prohibited;

(4) land incapable of supporting permanent cultivation.

It might be thought possible (at least theoretically) to obtain rights in the cultivation of land nearer the village by marriage. Although by contracting a particular marriage an individual may indeed gain access to land near the village, marriages do not appear to be contracted with this in mind. However, sheer quantity of land, irrespective of distribution, may be a factor contributory to the forming of a particular alliance.

While not actually prohibiting cultivation in areas near the village, there are other reasons why a mininum garden-house distance may be considered undesirable. A number of these are associated with the desire for secrecy, impossible at short distances from the villages. They include the following:

(1) traditional use of garden huts as rendezvous for illicit sexual unions and courting;

(2) the use of garden huts as resting points when out hunting or collecting in the forest;

(3) use of garden huts as staging camps for work in forest, the exploitation of timber resources, game and other forest products;

(4) use of gardens as places of solitude and rest, as locations for much work of a solitary nature; 
(5) penal use of garden huts, especially for offences by women;

(6) avoidance of unwanted affines, kinsmen, village-mates or strangers and enemies, self-segregation in disputes;

(7) distribution of generally poorer soils in vicinity of village, on account of more intensive cultivation.

But even if the reasons against minimizing garden-house distances are real, it might still be expected, in view of the advantages listed earlier, that some positive correlations can be found between distance and, say, such variables as plot size and yield. Considerable work of this kind, such as showing the deleterious consequences for production as distance increases, has been undertaken by economic geographers for rural European communities where it has been shown that as average distance increases so the per hectare return declines (Chisholm 1968: 49-53). It is therefore of some interest to see how such figures compare with the situation among swidden cultivators of the Nuaulu type. If the average size of a wasi for each class is taken as a crude indicator of yield, then it can be seen from TABLE 27 that this shows a general decrease the more distant the garden is from the village, though the correlation is not as striking as in the European data. It should be noted, particularly in view of point 6 above and the inevitable fragmentation of the historically older wasi near the village, that this does not hold good for gardens less than one kilometre from Ruhuwa. Certainly, the importance of this kind of information warrants much greater attention from anthropologists and others engaged in the analysis of agriculture in small-scale communities. ${ }^{20}$

\section{Altitude and garden distribution}

Although altitude itself is not a factor affecting the choice of Nuaulu gardens, since the highest wasi does not even reach 500 metres above sea-level, it is of some importance as an aspect of time distance and energy conservation. Gardens at high altitudes are difficult to get to, both in terms of terrain and in terms of the time and energy expended on climbing steep slopes. It is no wonder that the Nuaulu appear to dislike cultivating gardens high up on valley sides, despite the increased sunlight falling on upper slopes and ridges and the general absence of riverine rodents and other pests. It might be thought that the height of the tops of ridges above stream beds would be a much more useful indicator of the relevance of such factors than absolute altitude, but even when considered in relation to this it is the lower mid-valley slopes which are preferred. TABLE 28 illustrates the gradual decrease in area under 
cultivation with an increase in height. An interesting feature of the distribution lies in the fact that such a large proportion of the wasi lie below 50 metres. In view of what has just been said it may not seem particularly surprising, but what must also be taken into account is the substantial share of flat coastal land owned by non-Nuaulu clans and the distribution of wasi in terms of indigenous Nuaulu topographic categories (see above pp. 114-116). A final point to be borne in mind is that it is altitude, as it is reflected in unsuitable terrain and immense problems of communication, which inhibits extensive expansion inland.

TABLE 28. Distribution of 'wasi' according to fifty-metre contour-intervals, Ruhuwa 1971

\begin{tabular}{lc}
\hline Contour-interval & Number of wasi $^{*}$ \\
\hline 1. $\quad 0-50$ & 80 \\
2. $50-100$ & 74 \\
3. $100-150$ & 11 \\
4. 15()$-200$ & 11 \\
5. $20(-250$ & 7 \\
6. $250-300$ & 4 \\
7. $300-350$ & 2 \\
$8.350-400$ & 3 \\
$9.400-450$ & - \\
\hline Total & 192 \\
\hline
\end{tabular}

* Where a wasi straddles a contour-line the interval in which the largest part lies determines allocation.

\section{The distance between gardens and the 'numa nisi'}

Not only is the distance between residence (numa) and work (nisi) unit of very great importance in accounting for the distribution of gardens and the shape of the settlement pattern in general, but the distances between the gardens themselves are of some significance. The reasons for this are to some extent the same as for minimizing residence-garden distance, the conservation of energy with respect to travel and transportation and associated subsidiary tasks. In other ways it may be considered valuable in regard to the same features, but for different reasons. This is the case in as much as the minimizing of the distance between individual gardens discourages damage from wild amimals and, so the Nuaulu believe, from the malevolence of evil spirits. But there are also other reasons why there is a minimization of the distance between gardens. Not the least is that it results in a minimum number of wild vegetation boundaries, valuable in terms of the protection of gardens 
from marauding animals and weeds with a minimum expenditure of time and energy. It can be seen as a substitute for adequate fencing arrangements, but is even more effective used in conjunction with it. The common result of these two desiderata is the clustering of gardens.

Clustering is therefore a principal objective in Nuaulu garden planning. ${ }^{21}$ When new wasi are created from forest this is typically done adjacent to a stream in the first year, in the second year the garden will be cut from land immediately above it. But wherever the new plot is located it will always be within easy access of a garden hut, numa nisi. In fact, the garden hut and the system of horticulture arranged in relation to it, is the principal means by which disadvantages imposed by distance from settlement are resolved (Chisholm 1968: 131). This arrangement, whereby the garden hut is the focus of activities for a number of strategically grouped gardens, I propose to term the garden-complex.

\section{The 'numa nisi' and the garden-complex}

Garden huts are of essentially two kinds: the true numa nisi and the numa ainatai. The latter is really only a small shelter and typically consists of four slender wooden uprights, over which is placed a slanting portion of sago thatch or ainatai, about 150 centimetres in height and 200 centimetres square. It is usually only erected on individual isolated gardens or on plots so near the village that an elaborate construction would be quite unnecessary. In essence, it is a shelter from the heat or from the rain, although it is sometimes used to store seed and tobacco (commonly in the thatch), roots or tools.

The numa nisi proper is a much larger and more elaborate structure, although there may be some considerable variation in size. The largest of them may be larger than ordinary village dwellings, sometimes measuring up to 1000 centimetres square. The largest one for which I have details is that of Sau'ute on the Wakakau (MAP 9), which measured 765 to 960 centimetres in its ground-plan, but normally they are between 300 and 400 centimetres square, reaching a height at their apex of in the region of 200 centimetres. The size of a numa nisi is closely related to the size and composition of the household it serves, the distance from the village and the extensiveness of the garden-complex it is designed to service. Timber for the framework, together with rattan for lashing the spars together are fetched from nearby mature and advanced secondary forest. The roofing is of sago thatch, which is sometimes used for walls which are, however, rare and restricted to the most exposed side. The worst of the elements are kept out by large 
overhanging eaves. Half the interior is taken up by a raised platform covered with split bamboo flooring, above which is a shelf running the entire length of the hut and on which is stored food, utensils, seed and the like. Essentially, the garden hut is an imitation, in all important respects, of the ordinary village dwelling.

A numa nisi may be constructed soon after a new garden has been burned. Clearly it would be unwise to erect it before this stage, although a roughly made numa ainatai may be built. More often it will be erected on nisi monai land, usually at a slack period during the dry season, such as just after planting. Since it is serving a residential purpose for certain times of the year, when gardening activities of one kind or another occupy much time, its location must be suitable with respect to all gardens of a single complex and in terms of access to drinking water and other resources required for normal domestic living. The exact site must also be chosen with some care, being not only central but on suitable flat land, somewhat elevated and not susceptible to flooding. The building of a numa nisi is exclusively a male task, though the periodic clearing back of undergrowth from the immediate surrounds is the work of both sexes.

Garden huts serve a wide variety of purposes: storage of raw materials such as wood and rattans; drying of tobacco and kinawane leaves (Agave cantala Roxb.) for matting; storage and drying of seeds, nuts and roots; depositing of tools and a variety of utensils; as shelters from the sun and rain; locations for the preparation of food while in the gardens; for resting and relaxing; as a place to safely leave children and for illicit and secret sexual encounters; as locations for the manufacture of a wide variety of items, including baskets, arrows, combs and such like; as bases for hunting and overnight stays when journeying; for the cooking of meat (especially that which is taboo for other clans) before returning to the village; as the location for the first fruits ceremony, hunting and sago magic; storage of large quantities of sacred trivia (such as betel nut shells used in divination) which must not be thrown away, and numerous other things. It does not necessarily mean, as the Nuaulu themselves stress, that to go to the garden implies the undertaking of purely gardening activities. The garden hut is the focus of much activity quite apart from garden work. All this, together with the long absences spent by some households or their garden-complexes suggests a conflict between pressures to live in the village and settle at garden hut locations. The opposing sets of pressures of course exist, but the paramount importance of the village as the locus of clan and local group oriented political and ritual activities classes the issue as beyond consideration at the present time. 
Each household has an average of just over one hut in actual use, the exact number depending on the size and composition of the household concerned and the dispersion pattern of its wasi (TABLE 29). Garden huts are accessible to any other person to use for rest, and if an individual possesses an isolated plot near the hut of another person, it is common practice for him not to bother to construct his own. Within a household particular mature males may lay claim to ownership of particular huts, based on their responsibility for construction.

TABLE 29. Household composition, size and number of garden huts, Ruhuwa I97I

\begin{tabular}{|c|c|c|c|c|c|}
\hline Household & $\begin{array}{c}\text { Number } \\
\text { of persons } \\
\text { per } \\
\text { household }\end{array}$ & $\begin{array}{l}\text { Number } \\
\text { of } \\
\text { effective } \\
\text { males }\end{array}$ & $\begin{array}{l}\text { Number } \\
\text { of } \\
\text { nuclear } \\
\text { families }\end{array}$ & $\begin{array}{c}\text { Number } \\
\text { of } \\
\text { garden } \\
\text { huts }\end{array}$ & $\begin{array}{l}\text { Locations } \\
\text { of } \\
\text { garden } \\
\text { huts }\end{array}$ \\
\hline 1. Teliam & 3 & 1 & 1 & 1 & W5 \\
\hline 2. Tapone & 10 & 3 & 1 & 3 & W69, W76, W101 \\
\hline 3. Numapena & 10 & 2 & 1 & 1 & W73 \\
\hline 4. Komisi & 7 & 2 & 2 & 2 & $\mathrm{~W} 120, \mathrm{~W} 143^{*}$ \\
\hline 5. Nepinama & 4 & 2 & - & - & $\begin{array}{l}\text { (jointly with } \\
\text { Hatarai) }\end{array}$ \\
\hline 6. Hatarai & 9 & 2 & 1 & 2 & W162, W187 \\
\hline 7. Lohia (Sonawe) & 8 & 1 & 1 & 1 & W186 \\
\hline 8. Retau'une & 4 & 1 & 1 & - & $\begin{array}{l}\text { (jointly with Lohia } \\
\text { Penisa) }\end{array}$ \\
\hline 9. Mainjo & 7 & 1 & 1 & 1 & W 178 \\
\hline 10. Patioka & 7 & 1 & 1 & 1 & W108 \\
\hline 11. Hotena & 7 & 1 & 1 & 2 & W39, W181 \\
\hline 12. Tuale & 8 & 2 & 1 & 2 & W33, W58 \\
\hline 13. Paikole & 6 & 1 & 1 & 3 & W97, W88, W129 \\
\hline 14. Sorita & 13 & 4. & 2 & 1 & W46 \\
\hline 15. Sanakamura & 3 & - & - & - & $\begin{array}{l}\text { (jointly with } \\
\text { Tapone) }\end{array}$ \\
\hline 16. Inane & 2 & 1 & 1 & 2 & W86, W113 \\
\hline 17. Iako & 9 & 2 & 1 & 2 & W91 (1), W136 \\
\hline 18. Konane & 6 & 1 & 1 & 1 & W19 \\
\hline 19. Tuisa & 8 & 1 & 1 & 3 & W50, W60, W91 (2) \\
\hline 20. Sau'ute & 17 & 4 & 2 & 7 & $\begin{array}{l}\text { W1, W9, W15, W21, } \\
\text { W } 41, \text { W } 47 \text {, also hut } \\
\text { on coast near } \\
\text { river Mon }\end{array}$ \\
\hline 21. Wairisa & 7 & 1 & 1 & 1 & W90 \\
\hline 22. Lohia (Penisa) & 4 & 1 & 1 & 1 & W122 \\
\hline 23. Menai & 11 & 3 & 1 & - & (jointly with Inane) \\
\hline 24. Sahunete & 4 & 1 & 1 & 1 & W26 \\
\hline 25. Naunepe & 6 & 2 & 1 & 1 & W54 \\
\hline Total & 180 & 41 & 26 & 39 & \\
\hline
\end{tabular}

* numa ainatai only. 
To a certain extent, the presence of the garden hut makes it unnecessary to cultivate gardens near the village, as the advantages of a minimum residence-garden distance are found in the garden-complex pattern. Actual residence in the hut over periods of time conserves time and energy which would otherwise be spent in travel, and any associated ancillary tasks, between garden and village. This becomes a very real advantage during those periods when it is necessary to spend a large proportion of work-time in gardens and groves: when preparing copra, clearing, burning or planting. ${ }^{22}$ It is also useful in other ways, as it:

(1) encourages minimum garden-garden distance, which is both efficient energetically and economical in the use of land, through the elimination of wasteful garden/forest borders;

(2) facilitates efficient clearing, discourages rapid regeneration and encroachment of weeds and wild animals, through a minimum number of wild vegetation boundaries;

(3) protects gardens from wild animals, thieves and malevolent spirits;

(4) makes a wide variety of land at different stages and under different crop regimes readily accessible;

(5) inhibits spread of uncontrolled fires.

Every year the locus of horticultural activity for a household and its garden hut partially shifts. Further, while a piece of land moves through the cycle wesie-nisi honwe-nisi monai-nisi ahue and so on, this same sequence may be seen in static form on the ground at any given time. The temporal evolution of the garden-complex is therefore mirrored by a linear/spatial movement within the complex (c.f. Stauder 1971: 37). However, although the clearing of land adjacent to old gardens allows the garden-complex to maintain its spatial continuity, as might be expected, it is rarely possible to have all gardens, for which the hut is the focus and which are sufficient to fulfil annual household requirements, closely clustered together. ${ }^{23}$ This is largely due to the intervention of land owned by others and unsuitability in other respects. For example, tree-cropped areas make it difficult to have extensive joined gardens, and the necessity for adequate fallowing often means that isolated and more distant wasi must be used. It is such factors which go to determine the exact number and pattern of gardens in any complex. Of course, in the event of many gardens becoming overgrown and unusable, the hut will be moved to an entirely new location. Careful land use and the capability of almost any land to support some useful vegetation has made this an extremely rare occurrence. 
Gardens are on average around 375 metres from the nearest garden hut owned by the cultivator, or the village, if that be nearer. That this average is in fact as high as it is is very largely due to the tendency to accept a greater tolerance distance from shelter the nearer the garden is to the village. MAP 12 gives some idea of the way a particular complex works out in practice. In this instance, three households of the clan Nepane-tomoien with land around the river Wakakau have been selected (MAP 9), (a) to show the pattern of gardens in single complexes, and then (b) to show the stages of growth and an outline of land utilization within one garden-complex. ${ }^{24}$

The garden-complex system only operates through the ability of household members and other near kin and affines to maintain it, and reflects what is an increasing concern for security of tenure. It also plays a vital ecological role in communities of swidden agriculturalists such as the Nuaulu (c.f. Freeman 1970: 161-5), acting as a regulator. In the absence of this system land would have to be worked nearer the village. This would lead to the exhaustion of land around residential areas after a relatively short time-span, and the need to look farther afield for suitable land for cultivation. Failure to do so would inevitably mean the working of increasingly poorer soils and consequent poorer yields. So even if delayed, land would eventually have to be sought elsewhere. Ultimately, the distance necessary to travel would become unbearable and shifting of the actual settlement would become inevitable. The garden-complex system makes actual shifting unnecessary, as long as a population does not rise to its absolute critical limits, since land distant from the village can be cultivated at little extra expense of energy than cultivating gardens near the village. In this way fallowing and regeneration can also be more complete.

To a certain extent, this clustering effect is set within an overall scattered distribution of sites available to a single household or individual. This has the effect of acting as some kind of security against the dangers of over-dependence on specific localized resources, which may become subject to unforeseen or new problems (cultural and noncultural) in cultivation. Dispersed land is more likely to contain areas from different topographical categories, of different soil type, aspect and degree of accessibility. Such variation can prove important in dealing with specific contingencies, such as flooding and drought. In the event of disputes over land, conflict can be avoided by segregation of the parties involved by the cultivation of gardens distant from each other. So while the advantages of clustering and the garden-complex are both real and 

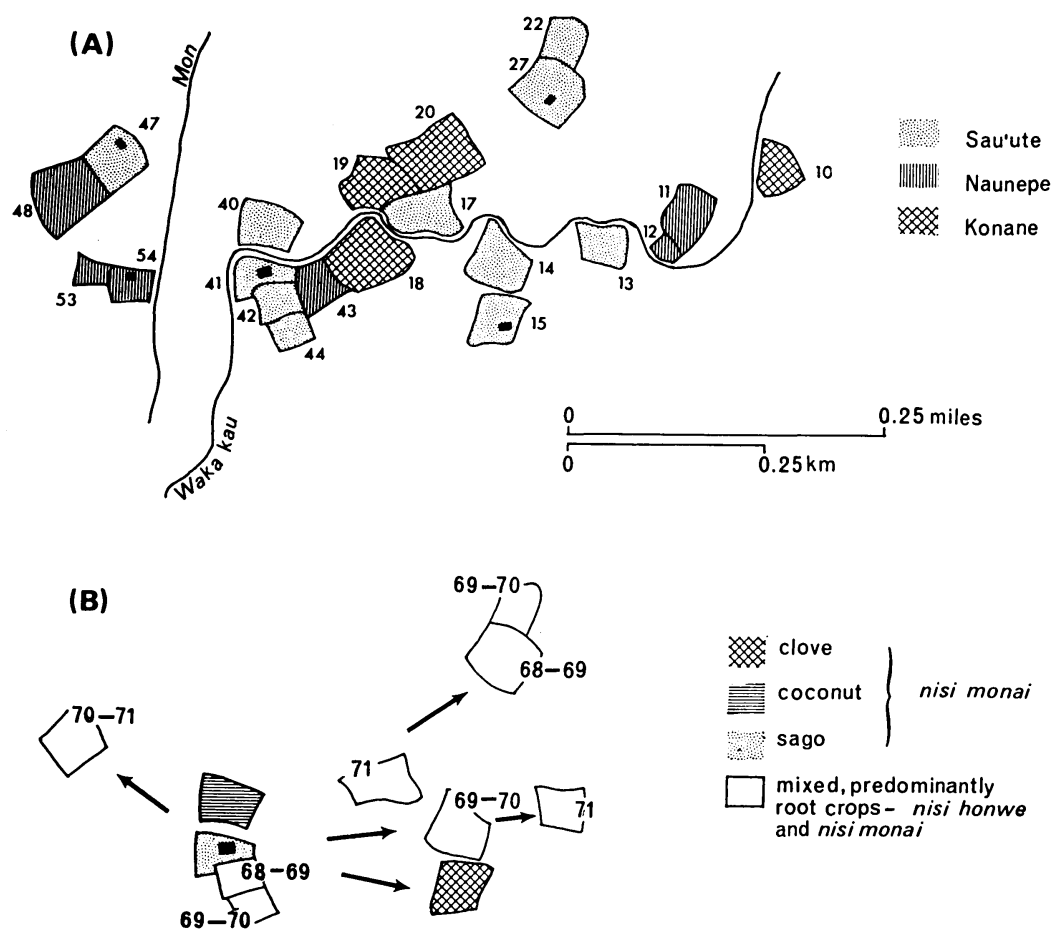

MAP 12. Some examples from the clan Nepane-tomoien of individual garden hut complexes, showing (A) the distribution pattern of wasi focussed on three separate major huts (in wasi 19,41 and 54) and (B) land utilization and stages of growth for a single garden hut complex. For the exact location of these wasi MAP 9 should be consulted.

recognized, the stratagem - if it is one - of scattered resources to combat differential disadvantages is also apparent.

A logical outcome of the Nuaulu garden-complex system might seem to be the establishment of satellite hamlets, occupied periodically by households with gardens in the general vicinity. This might be expected when very distant gardens are being cultivated or when the population has risen to the critical limits for the immediate village area. This situation has not yet been reached for Ruhuwa, or any other Nuaulu village, but the phenomenon is found with respect to the larger Muslim villages along the coast. The garden hut hamlet on the headland between the rivers Mon and Lihuru is an example of this with respect to Sepa (MAP 9), largely connected with the extensive Sepa-owned coconut plantations in this locality. Such settlements ultimately, unless aban- 
doned, become permanent communities, such as Ampera, a new hamlet between Jalahatan and Tamilau (MAP 2) on the coast east of the Nuaulu; eventually they become independent villages such as Haruru, a satellite of the Butonese village of Jainwelo.

\section{Garden shape and size}

Individual gardens are not cut to a preconceived shape and even size may not be entirely the product of expected needs. Shape is generally simply a function of the possibilities offered by the topography, in terms of aspect, gradient, the occurrence of rock outcrops, ridges, knolls, hollows, spurs and other landforms; or the nature of the vegetation cover, for example the presence of large trees which it is not practical to fell and already felled trees which are immovable. All these mould the shape of the garden perimeter and its overall topography.

Size is also affected by a similar set of factors, but additionally by the size and shape of already existing garden and wasi boundaries. But primarily, as is emphasized by the Nuaulu themselves, the size of a nisi is essentially the result of demand and the manpower available to a given household to undertake all the necessary tasks involved. If an individual is able to secure the assistance of others, either members of the household, relatives or, in the case of an unmarried male, other unmarried clan-mates, the size of the garden may be proportionately larger. Sometimes, weather conditions at the time of clearing may have an effect. Further, there is the relationship between distance from village and the size of a wasi.

It might be expected that there is a tendency for wasi quite close to the village, say within a radius of one kilometre, to be smaller, on account of the greater pressure for fragmentation resulting from the desire to cultivate land as near as possible to the village. An examination of the figures in TABLE 27 shows that this is demonstrably not the case. In fact, wasi within 0.5 kilometres of the village have a slightly greater average size, 0.66 hectares. This is partly related to, and indeed shows the effectiveness of, the garden-complex system, though the simple numerical index of wasi size fails to reveal certain interesting features otherwise observable. Since all clans own at least some land within this fairly narrow radius of the village, and for obvious reasons wish to retain it, fragmentation tends to be less common. Further, such areas never entirely revert to an unowned state, although less peripheral land is wasted and fallowing is less thorough. Such intensive cultivation appears to have resulted in a decline in soil fertility and there is a general 
reluctance to cut nisi honwe in the area. The overall picture, however, would be even more apparent if nisi plots instead of wasi were to be measured, since parts of the same wasi near to the village are commonly under different land-use patterns.

In summary, it is possible to isolate six principal factors determining the shape and size of Nuaulu gardens: (1) economic requirements, (2) work capacity available, (3) topography, (4) distance from village, (5) previous vegetational cover, and (6) shape of existing wasi and nisi boundaries.

There is general consent that larger nisi are preferable to small ones, not only for the obvious economic reasons, but because a large garden means prestige for the individual who cleared it and represents a significant addition to the land accessible to him, his household and clan, with all the social advantages which accrue from this. A nisi of about 0.4 hectares was considered large. W80 ( 0.41 hectares) was considered a large wasi, so it would appear that the Nuaulu concept of 'large' in this respect is lower than the average size of a wasi. However, a wasi can be an agglomeration of a number of nisi cut at different times. W98, at 0.83 hectares, was considered enormous.

\section{Enclosures and the protection of gardens}

Very closely related to garden shape and size is the question of enclosures. The Nuaulu are generally uninterested in enclosing their gardens and appear to pay very little attention to it, in contrast to the coastal Muslims among whom it is almost universal. This may be partly related to the nature of the terrain, Nuaulu gardens being generally built on valley sides where the steep gradient does not favour the construction of fences. Even when Nuaulu gardens are adjacent to enclosed gardens belonging to Sepa they are only rarely fenced. Contrariwise, some Sepa gardens high up on the steep valley of the river Mon are still provided with sturdy bamboo fencing. ${ }^{25}$ Tradition may be an important factor in Nuaulu attitudes to fencing, as the terrain surrounding the inland locations once occupied by Nuaulu villages is even less suitable in this respect than is the land in the present location. The absence of domesticated animals on any scale also means that there is no pressure for fencing from this direction. Additionally, the need to bring wood and other fence building materials over a distance and the general effort required in their construction is regarded as inhibiting.

Although it increasingly appears that what distinguishes Nuaulu gardens from those belonging to peoples traditionally living along the 
coast is the rarity of fencing, it is not entirely absent. While none were observed during fieldwork on gardens owned by Ruhuwa, they were found on some gardens belonging to individuals from Hahuwalan and Bunara, near the rivers Upa and Iseh respectively. Garden fences of this kind are known as tone, as opposed to fences erected within the village area (pakelo). Typically they are constructed either entirely from bamboo of the wanate variety, or from bamboo in combination with other materials - bark from the sago palm, wood and sago and coconut palm fronds. Fences of this type do not have a very long life, largely on account of wet weather and a high relative humidity, and may rot before a new garden (nisi honwe) has been exhausted of its primary crops. As little trouble is taken to repair them their disintegration is all the quicker. This may shed some light on the dislike among the Nuaulu of erecting fences; they seldom seem worth the effort.

The only advantage which the Nuaulu attribute to fencing is that of keeping away large animals which consume leafy parts and sometimes root tubers. These are principally cassowaries, deer and wild pig, but may also include smaller rodents. Thus, one reason given to me for not having fencing on a particular wasi was that it was near the village and therefore would not be disturbed by animal marauders. However, the presence of traps in the same vicinity appeared to contradict this.

In the absence of fences, traps partially protect crops from wild animals. These are almost entirely of the spring noose-trap and speartrap varieties. The spear trap is that most commonly found in, or on the peripheries of, gardens, where it is used to catch cassowaries, civets, deer and wild pig. In addition to the various techniques of trapping animals, fires are lit in the garden (often within the garden hut) to prevent wild animals, and even malevolent spirits, from entering. 'They smell it and keep away,' I was told. Even after a fire is dead the aroma remains for some time. Thus, if a fire is lit last thing before leaving to return to the village, or garden hut, at the end of the day, the fire is often an effective guard until the following morning. However, even if , as the Nuaulu say, 'when a fire dies the smell of humans lingers', in event of prolonged absence from a garden, there is usually little effective protection from predators. Garden protection is also seen as being accomplished through invocation to relevant ancestral spirits, the use of sundry charms, sasi and other taboo signs erected following a theft.

\section{Cropping procedures}

Land is clearly of considerable value to the Nuaulu and a substantial 
proportion of the time allocated to subsistence activities is taken up in its cultivation. However, an examination of the composition of their diet, in terms of calorific value and weight consumed, shows that the contribution made by garden produce is surprisingly low. The numerical data on which these statements are based are presented in detail in Chapter VII. The situation contrasts markedly with that found in several other welldescribed Southeast Asian and Melanesian swidden communities (Rappaport 1968: 42; Freeman 1970; Conklin 1957). There is certain evidence that similar situations exist elsewhere. ${ }^{26}$

There is no rigid calendar of Nuaulu horticultural events and all procedures are characterized by a considerable variability in their timing. The cycle usually begins after the end of the rainy season in September or October with the clearing of the intended site of the nisi honwe. Harvesting of annual root crops always falls before the beginning of the next rainy season in May of the following year. The processes involved and their approximate timings are outlined in TABLE 30. Although it is true that the scheduling of garden activities (when to plant and cut, length of drying period and fallow, and so on) depends heavily on the weather, individual inclination and commitment to other economic and ritual activities must also be taken into consideration.

The clearing of mature forest has already been dealt with in Chapter V and no further attention need be paid to it here. Much of what has been said concerning mature forest clearance also applies to the clearing of secondary growth and therefore need not be repeated. For example, in the same way that mature forest has often been thinned somewhat before it is finally cleared for garden land, so secondary woody vegetation is plundered for fuel and construction materials. In the case of secondary forest more attention is paid to sparing trees of value (such as Canarium commune L., Pandanus and Eugenia spp.), which may have been naturally set or planted at an earlier date. The main distinctive features of the clearance of secondary growth are as follows:

(1) since the land is already usually acknowledged as wasi, that is definite rights are exercised with respect to it, the first clearance ritual is unneccessary;

(2) clearing is undertaken almost entirely with a bushknife, and is seen as a task of a single individual, or at the most two persons;

(3) clearing is rapid and a 0.5 hectare garden may be cut from low secondary growth in only a few days;

(4) clearing is more complete and an all-round easier task, involving less energy expenditure. For example, the saplings of hunua 
TABLE 30. Main stages in the Nuaulu horticultural cycle

\begin{tabular}{|c|c|c|c|c|c|}
\hline & \multicolumn{2}{|c|}{ PHASE } & \multicolumn{2}{|c|}{ VEGETATIVE TRANSFORMATIONS } & \multirow[t]{2}{*}{ TIMING } \\
\hline & Nuaulu term & Gloss & Nuaulu term & Gloss & \\
\hline 1. & ranatutau nisi & clearing & $\begin{array}{l}\text { wesie or } \\
\text { nisi ahue } \\
\text { nisi ahanatanja }\end{array}$ & $\begin{array}{l}\text { primary forest } \\
\text { or fallowed } \\
\text { secondary } \\
\text { growth } \\
\text { cleared garden }\end{array}$ & $\begin{array}{l}\text { August - } \\
\text { November }\end{array}$ \\
\hline 2. & akanupu nisi & firing & $\downarrow_{\text {nisi akanupunja }}^{\text {nisi ahanatanja }}$ & $\left.\right|_{\text {burned garden }} ^{\text {cleared garden }}$ & $\begin{array}{l}\text { September - } \\
\text { December }\end{array}$ \\
\hline 3. & rahui nisi & planting & $\left.\right|_{\text {nisi rahunja }} ^{\text {nisi akanupunja }}$ & burned garden & $\begin{array}{l}\text { September - } \\
\text { December }\end{array}$ \\
\hline 4. & naurahui nisi & harvesting & $\left.\right|_{\text {nisi naurahunja }} ^{\text {nisi rahunja }}$ & planted garden & March ... \\
\hline
\end{tabular}
nisi huje
empty garden
nisi honwe new garden
(2) $-(3)$
(4) $\longrightarrow$ nisi monai

(Homolanthus populifolius Graham), one of the most common secondary growth trees, can be lopped very close to the ground, and other stands can be felled much more conveniently. In secondary growth buttresses tend to pose fewer techniçal problems.

In all these respects nisi ahue is regarded as more advantageous than wesie, though it should be pointed out that the more advanced regeneration is, the less significant any such advantages become. In fact, cutting from advanced secondary growth can sometimes present greater difficulties than cutting mature forest, not the least of these being the heavy and impenetrable undergrowth of bamboo scrub and the like found in the former. It therefore becomes clear that the kind of vege- 
tation to be cut affects the procedures, timing and labour arrangements of garden preparation, and consequently has a direct bearing on the selection of those plots to be cultivated.

Drying is usually a long and difficult process, owing to the high rainfall in the area. It was thought that with constant hot weather one week might be adequate to dry out the debris, but in wetter weather two weeks or more would be necessary. Observations appeared to bear this out. Further, cut mature forest has to be left much longer than thin and relatively rapid drying secondary growth, such as bamboo and bushes.

Firing, which the Nuaulu maintain is necessary in order to clear excess ground cover and to nourish the tubers which are subsequently planted, is usually done by one or two people. More substantial teams were not observed during fieldwork, though apparently, on occasions, groups of individuals assist in burning (akanupu amanane). The individual gardener is normally on hand to prevent the fire spreading, to feed it in places where it looks like burning out prematurely and to watch for changes in wind direction, although the main firing rarely lasts more than an hour. However, a garden may be left before it has finally burned out and although fire hazards are recognized they seldom seem to occur in practice, perhaps because it is never possible to dry out garden debris completely with such a high monthly precipitation. Nuaulu tend to discount the amount of harm an out-of-control fire can do, and seem to take few fire precautions. Certain trees, such as coconut palms and fruit trees, are protected during firing by clearing the debris from a wide area around each tree. There is no clearing of land around the perimeter of a plot to assure sufficient sunlight or to provide more fuel for firing and charcoal is not taken away from the garden to be used for other purposes. Similarly, there is neither a spreading of the cut debris during drying to improve the burn, or of charcoal after firing. The properties of charcoal as a fertilizer are readily appreciated. Although some wood is removed for fuel or other purposes before firing, a very high percentage of the debris is actually burned.

A plot usually requires at least two firings, unless the cover is exceptionally thin. Sometimes a garden may need up to ten firings, but under normal circumstances such a difficult plot would be rejected before reaching this figure. Even so, after burning considerable debris frequently remains, which is simply left to rot. For example, I measured stumps of over three metres in height in some planted gardens recently cleared from mature forest. The difficulties of firing explain the typically long gap between clearing and planting. 
The ecological effects of burning a slashed plot are basically to accelerate the process of decay and to direct the nutrients so produced to meet the needs of certain selected food-producing plants (Geertz 1963: 22). But although a significant proportion of the mineral energy upon which garden cultigens depend for growth comes from the ash remains of the fired forest rather than from the soil itself, burning is an inefficient means of energy transfer and incompleteness of burn becomes a crucial factor in yield determination (Gourou 1961: 26). Although the Nuaulu recognize the necessity of a good burn, in practice much ash is wasted through a general reluctance to spread both debris and charcoal evenly over the surface of the garden. They further recognize the important role of decaying matter (nimoi) in returning nutrients to the soil. The process of decomposition is a theme which is repeatedly found in myths. Despite this, 'humus' is not a terminologically distinguished category, and this may tell us something about its perceived significance as a nutrient compared with ash. The only conclusion that can be drawn from the divergence between Nuaulu theory and practice in these matters is that, in the normal course of events, yields are considered adequate for subsistence requirements without attention to such details.

Planting.usually takes place as soon as a garden has been adequately burned. Although the timing is up to the individual concerned, there is a certain amount of pressure to conform to the needs of the household of which he is a member, and/or the needs of the household of his father-inlaw. Similarly, it is largely up to him when ripe crops are to be harvested or when, and if, the gardens are to be weeded. Weeding is a task which is generally neglected in most Nuaulu plots. ${ }^{27}$ The various types of edible aroids covered by the Nuaulu primary taxa sikewe (Colocasia spp.) and johoru (Xanthosoma spp.) are always the first crops to be planted, apparently on account of the fact that, with the exception of readily accessible manioc, they are the root tubers on which they feel most dependent in dietary terms. These are followed by several principal types of yam (Dioscorea spp.): siahuwe, weni, kawasine and akai. Planting is effected simply by turning the soil over in selected places with a digging stick, to give small mounds of about 40 square centimetres each, approximately 75 centimetres apart. On top of these are laid taro stem cuttings (consisting of the very top of the tuber and about 100-150 centimetres of stem) or yam tubers, which are then planted firmly and deeply into each mound with the hands. Frequently such tubers have begun to sprout before they are planted. Taro and yam planting is followed by the planting of bananas, sweet potato and sugar-cane, and a 
little later manioc. The intercropping of a wide variety of other useful and purely novelty species takes place at this time, though no specific sequence of planting is acknowledged (TABLE 31; Ellen 1973: 460-4).

The total number of different species which may be put under cultivation is very considerable. The number of different types in a particular garden at a given time is somewhat less, but still substantial (TABLE $31)$. However, the various types of staple species are generally intercropped and not separated out according to type and to meet different cropping conditions. ${ }^{28}$ This approach has the advantage that within the range of potential conditions to which different varieties are best adapted at least some of the crop is bound to come through. Irrespective of whether or not this represents a conscious 'strategy', the advantages of planting a mixed and undifferentiated garden with a large number of different cultivars are quite clear. ${ }^{29}$ And quite apart from the more obvious economic benefits, there are certain ecological advantages in polycultural planting, for example to the extent that it checks the buildup of populations of insect predators. However, as a garden develops the species-count decreases dramatically, cultigens either almost disappearing completely and the area succeeding to nisi ahue, or a garden becoming dominated by a particular species, or association of species, before eventually reverting to the wild state.

The density and extent of planting is usually closely related to expected needs, which sometimes means that surplus land reverts to secondary associations unplanted. Yet even in quite densely planted gardens, land is rarely cultivated right up to the edges of main paths, resulting in a border between the latter and cropped areas. Minor paths, however, may actually run right through gardens. In the same way, crops do not normally extend up to the garden hut, so that there is a small area of secondary growth around them.

\section{Labour arrangements for gardening activities}

Sometimes all the cropping procedures may rest in the hands of a single mature male, and garden activities are largely male in character. The usual work unit is the household and variation in composition automatically determines variation in the size and nature of the unit working a single garden, or group of gardens. Consequently, the pattern of personnel arrangements for gardening, as for all other economically relevant activities, is significantly affected by the numerical disparity between sexes, age groups, households and clans (TABLES 7, 8, 24 and $25)$. There is no reason to suppose that the characteristic type of Nuaulu 
household structure is any less effective for the working of scattered garden resources than a more extended family (c.f. Sahlins 1957: 44962 ). The reason for this lies principally in the peculiar ancillary role of horticulture in the overall pattern of energy transfers in the local ecosystem.

Given the place of cultivation in Nuaulu economy, the sexual division of labour with respect to gardening activities might seem a little curious. Most of the horticultural labour falls to men. This includes decisionmaking relating to site-selection and overall management, the clearing, burning and planting of land, hut and fence building, garden magic and general responsibility for garden protection, carrying, collecting and preparing cash crops and a number of ancillary tasks. On the other hand, the female role is essentially a supportive one and largely restricted to protecting the garden and garden hut, food preparation, and some harvesting, collecting and carrying. This pattern differs considerably from that found in other (largely Muslim) coastal villages. In Sepa, female labour in gardens is at least equal to, if not more than, that of males, with the principal responsibilities for burning, weeding, planting and harvesting in gardens, as opposed to groves. A partial explanation of this may be that gardening tasks are of less arduous nature, on account of a generally favourable location of gardens on coastal land, and being cut from easily-worked secondary growth associations. Sepa gardens tend to be much smaller than those of the Nuaulu and cultivated over much longer periods of time.

The reasons for the Nuaulu sexual division of labour outlined are partly ideological, partly social convention and partly the physical appropriateness of one or other of the sexes for a particular task. Those tasks requiring greatest energy and strength fall to men. It is also men who are responsible for garden magic and all important decisions in site-selection and subsequent management. Women's labour is usually onerous and time-consuming, but only rarely energy-intensive. The actual planting of crops and selection of seed, corms and tubers is regarded as unsuitable work for women, in that pollution from the association with menstrual blood is deemed likely to affect the subsequent growth and yield of the crop. Other tasks are rejected by young men as being essentially non-masculine, requiring little opportunity for display of strength and ability. Thus, while they willingly engage in the felling of mature forest, they feel ashamed and open to ridicule in performing such menial jobs as weeding. On a few occasions when an old man was witnessed weeding within the village area he was mocked by 
young men and children. Old men, it is admitted, become feeble like women and therefore become appropriate for women's work. In certain other special circumstances, such as those times when a wife is ill or confined to the bosune, a man is compelled to engage in at least some female labour. This is done with great reluctance, but as the female contribution to garden labour is minimal anyway, it is extremely rare. The reverse situation, whereby women are compelled to engage in garden work normally reserved for máles, is never encountered. Sometimes women are left in charge of a garden hut while a husband works sago or goes out hunting. On such occasions women manage the gardens, collecting roots and greens or perhaps weeding - but, nevertheless, always restricting themselves to labour appropriate to their sex. This meagre role accorded to women in horticultural activities provides a striking contrast with those New Guinea communities where women are deeply involved in the cropping procedures. This imbalance between the sexes may be partially interpreted as a hangover from a time, in the not too distant past, when gathering activities in which females actively participate were even more important in Nuaulu economy than they are today.

The role of children in garden work is subsidiary, though their contribution at certain times may be of considerable significance, particularly in a small household. Young boys between five and ten are often provided with small knives, which they use to cut back undergrowth and remove small saplings, and are encouraged to learn to care for gardens from an early age. These younger boys as well as girls assist their mothers in weeding and carrying, and girls participate in other obvious female roles, such as food preparation and baby minding. By the time a boy is 14 and a girl 12 years old they are actively cooperating in all adult tasks. Among adult males cultivation of distant and new gardens is typically undertaken by the youngest and strongest, while those older and weaker generally carry out lighter tasks in older gardens nearer the village. But the lifespan for intensive adult work is long-in the region of forty years.

\section{Regeneration of cleared garden sites}

In some instances, land which has been cleared, or partially cleared, immediately reverts to secondary forest growth without being fired or planted (FIGURE 6). The reasons for this may be numerous. Sometimes, in cases where a substantial amount of land is under cultivation by a single household, another garden may be considered surplus to requirements and will just simply be abandoned. Alternatively, practical 
difficulties in clearance, separately, or in conjunction with problems in the recruitment of sufficient labour, may be responsible. Another important factor may be rapid weed growth related to neglect due to prior commitments to other economic or ritual activities. Again, poor soil or rock outcrops may be the cause. It can even be due to malevolent spirits preventing work or annoying the worker, or the occurrence of disasters in which persons are seriously injured or killed, and which are believed to be caused by supernatural interference. Sometimes at this stage, just prior to planting, garden magic (seute) is performed to clear potentially malevolent spirits from the site. In cases where the threat of supernatural interference is regarded as being severe the clan chief will placate the spirits with gifts of betel-chewing requisites and kunie root (Fibraurea chloroleuca Miers.). These are placed on a large leaf and the officiant formally requests the spirit to remove itself to another locality, which is specified. The spirit is then accompanied by the clan chief to that locality where the gifts are deposited. Land cleared of evil spirits in this way must then be made accessible to the entire village, that is it becomes nisi niane.

The same factors of surplus, rapid weed growth, prior commitment to other activities and supernatural meddling can just as easily become relevant after a garden has been burned. An inadequate or incomplete burn (usually caused by excessive rainfall preventing thorough dryingout) can lead to abandonment. This and all other factors just discussed, are generally more likely to occur with land cut from mature forest than that cut from secondary growth, owing to the increased physical difficulties involved in the former.

Thus, although site-selection may be an intricate process, involving the assessment of a wide variety of different factors, certain unpredicted or unpredictable factors can lead to rejection of land before crops are actually planted on it. As has been shown, this does not necessarily mean that it is rejected on subsequent occasions also. Indeed, unless the disadvantages are really overwhelming, such land is commonly cleared and planted again in the following year, when the physical effort involved is considerably less.

\section{Integration of factors in garden distribution}

This chapter has considered a wide variety of factors affecting in an equally wide variety of ways, the siting of garden plots. Some are much more important than others, but almost all influence (if only minutely) some aspect of garden form and distribution. The final outcome is 
obviously the product of all this, the effect of a complex decision-making process which amounts to a definite (though unformalized) policy with regard to land choice and the distribution of new gardens. So far, two rather different classes of decisions have been considered:

(1) those made prior to the cutting of a garden, concerning the most favourable locality in terms of economic, cultural and environmental factors; and

(2) those made during the actual period of preparation, either on the basis of new information acquired during the process, on reflection or by default.

There is a third class of decisions affecting the total pattern, namely those concerning the future of a garden after the first year. These are discussed in Chapter VII.

The first class of decisions may be further subdivided into those made prior to the clearance of wesie, land which has never before been cultivated, and those which simply concern the selection of an already existent wasi for planting. In each case different factors may vary in their degree of importance, though in both the selection of sites is the subject of extensive debate, formal and informal; potential sites are visited and surveyed in a preliminary fashion, their relative advantages and defects discussed in detail. Apart from the rites already discussed, there is little that can be regarded as location augury, and their performance does not appear to be of much significance in accounting for overall garden distribution. The same holds for dreaming, which was cited as responsible for the siting of some gardens. It would be a mistake, however, to regard site-selection as an easily differentiated stage in the horticultural cycle, such as might be inferred from the meticulous 'composite outline of topics to be investigated in the study of shifting cultivation' offered by Conklin (1961: 30-5). On the contrary there is a constant re-assessment of the potential of new sites and a rejection of old ones.

In the foregoing sections I have attempted to isolate the principal factors affecting the overall process of selection of garden sites, in the belief that it is only by investigating these that the domesticated component of the Nuaulu settlement pattern can be fully understood. In view of this it is of some importance to try to isolate any definite processes by which integration of the many factors takes place. As has been pointed out, there are certain recognized priorities, but these are never accepted to the detriment of all other opposing, but advantageous, factors. It would appear that it is impossible to select one class of factors as being more desirable en masse than any other, so that a rank order of priorities 
in terms of classes of factors could be devised. Rather, there is a fine interaction of individual factors on their own merit in particular circumstances. The classes of factors - topography, soil, ritual and so on - are merely analytical constructs used here to arrange the ethnographic data. It was made clear in Chapter II that the Nuaulu model of the environment and its interaction with man is integrative and holistic; they recognize the connectedness of natural phenomena. Despite this it is possible to arrange the factors involved in site-selection in terms of interpretative schemes which integrate them in such a way as to generate the observable dispersal pattern of gardens. In the first place such factors can be grouped rather generally on the basis of whether they are integrative or disintegrative. Examples of such factors listed according to these categories include the following:

INTEGRATIVE
clustering
garden-complex
minimization of garden-
$\quad$ village distance
easy clearance of land
close proximity of
accessible land

\author{
DISINTEGRATIVE \\ dispersion \\ absence of garden-complex \\ maximization of garden-village \\ distance \\ difficulties in clearance of land \\ intervening inaccessible land
}

If the relative significance of each factor can be assessed from the assembled data the analyst is in a position to make certain statements about the interaction of the various generative elements. In the second place, but only after the various factors have been grouped according to their general tendencies, more specific decision-making pathways can be isolated which generate specific features of the settlement pattern. FIGURE 10 illustrates this for generative processes resulting in clustering of cultivated land around the village. It is equally possible, of course, to formulate decision-making chains of this type which result in contrary processes - the dispersal of land, or in garden hut oriented patterns; the point being that recognition of opposing, parallel or integrative processes allows for the measurement of deviation from ideal or standard patterns. That I have not traced all logically possible decision-making pathways is, I think, unimportant for the present analysis. It has been sufficient to show the intricate nature of relevant factor-interactions; the contradictions and conflict inherent in what is overall a complex decision-making process, involving ramifications not apparent in a more 
superficial analysis. The complexity, however, lies in the dialectic of the process, not simply in the minds of the individual Nuaulu who have to make the decisions.

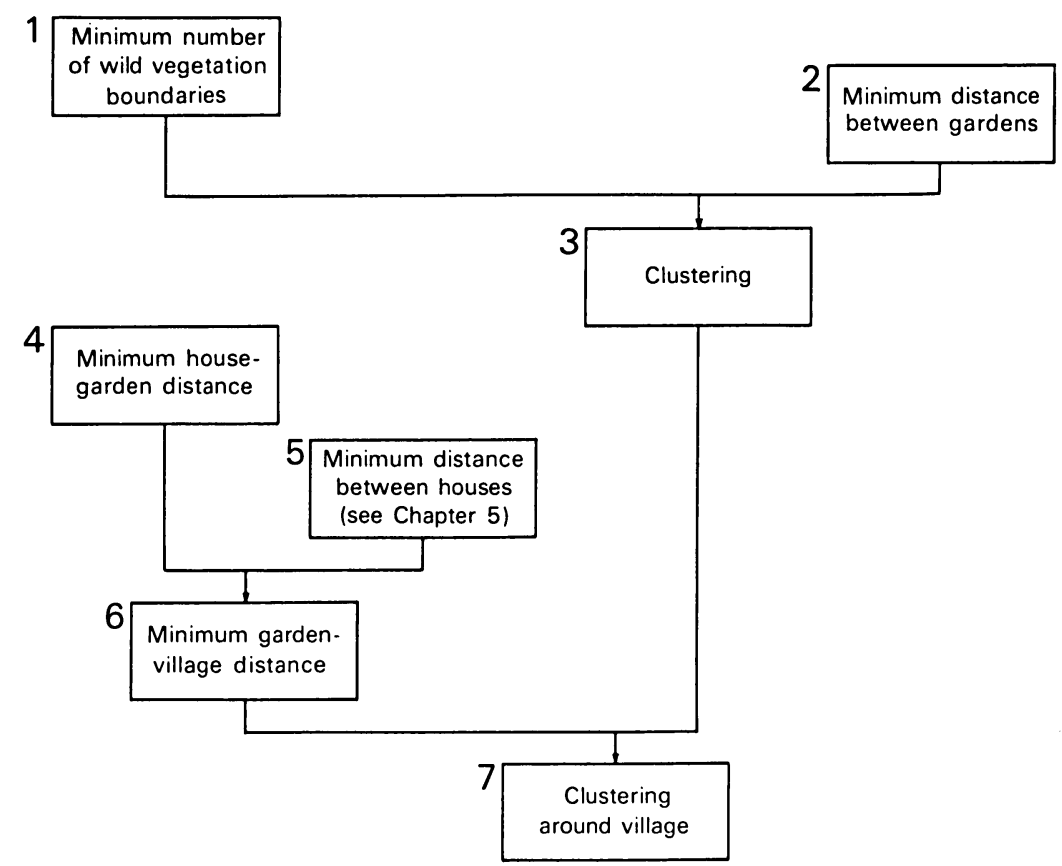

FIGURE 10. Generative processes resulting in the clustering of cultivated land around village. 


\section{CHAPTER VII}

\section{GARDEN DEVELOPMENT AND ECOLOGICAL SUCCESSION}

\section{Introduction}

The destiny of a Nuaulu garden is usually decided during the first year of cultivation, that is while it is still nisi honwe, by the decision to intercrop or not cultivars other than sub-annuals and annuals. It is therefore appropriate that an examination of garden sequences should begin prior to the completion of the account of first-year cropping procedures and a treatment of harvesting techniques. Broadly, the principal possibilities with regard to land succession may be expressed schematically as shown in FIGURE 11, but to begin with it is necessary to return to the composition of the nisi honwe and examine how this affects the vegetational associations which follow it in time.

\section{Implications of first-year crop pattern}

Precisely what happens to a garden after the annual root tubers and sub-annuals have been removed will be very closely related to both the other cultivars intercropped and the overall proportions and quantities planted. The actual number of different cultivars planted (Ellen 1973: 460-4) and their quantities varies to some extent - seasonally, subseasonally and spatially - but a nisi honwe immediately antecedent to harvesting will always bear certain typical characteristics of composition. TABLE 31 gives the crop inventory just prior to the beginning of harvesting, for a single nisi honwe, 0.8 hectares in area and cut from young secondary growth. The garden, effectively extending round the head of a small stream, was cleared in 1969 and harvested by the middle of 1970. Though a single inventory of this kind cannot be expected to take into account the variation I have spoken of, it does give some idea.' The relevant characteristics to note in TABLE 31 are the following.

(1) New gardens are planted with only a limited quantity of manioc, and sometimes it may be omitted altogether. This appears to be related to the fact that manioc grows and reproduces vegetatively with some 


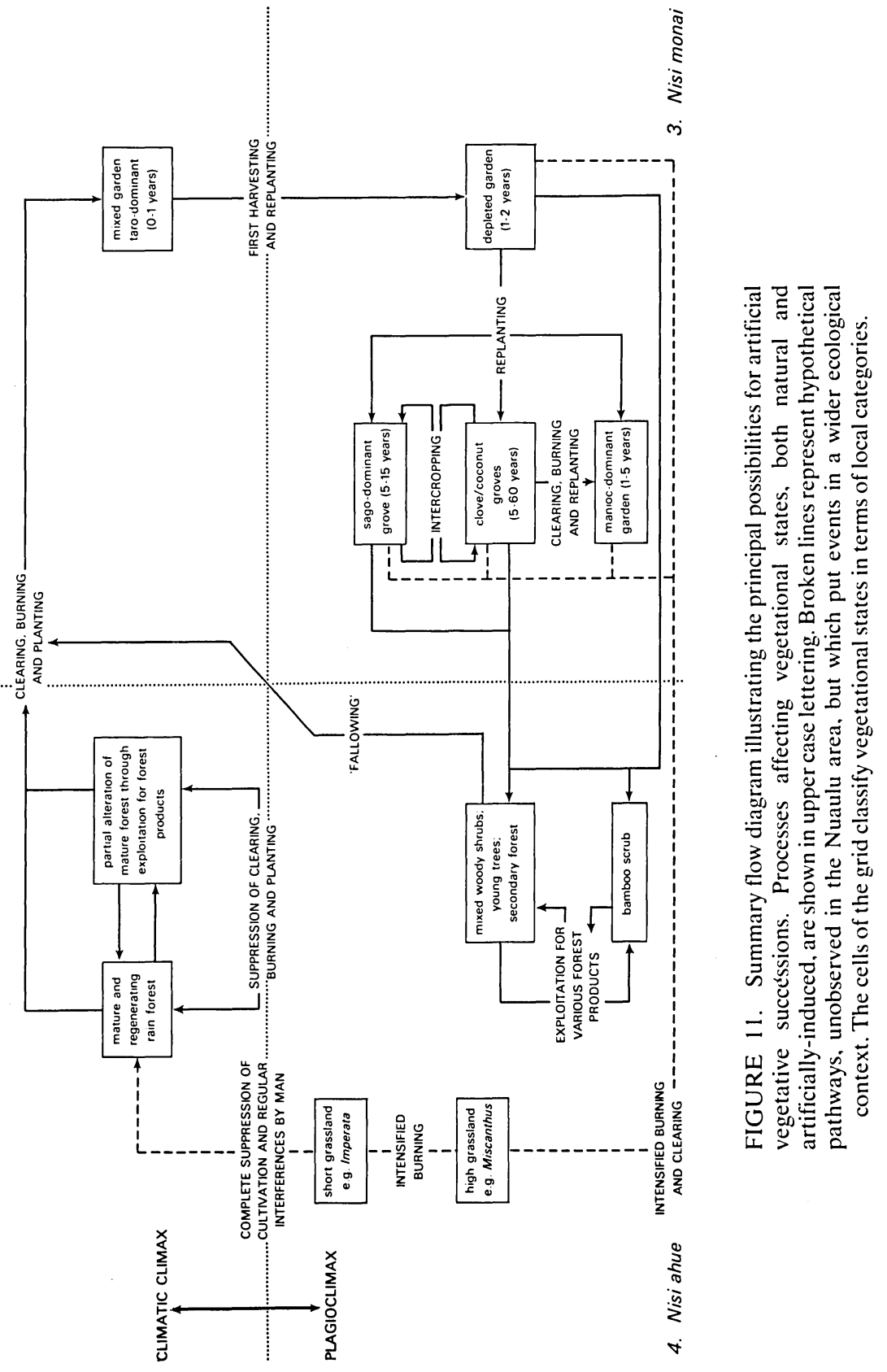


TABLE 31. Sample crop-inventory for a single 'nisi honwe', with estimation of plant numbers (W92: Tuisa Matoke, river Awao: 21.6.70)

\begin{tabular}{|c|c|c|c|}
\hline Nuaulu taxa & Content & $\begin{array}{l}\text { Number } \\
\text { of plants }\end{array}$ & $\begin{array}{l}\text { Percentage } \\
\text { of total number } \\
\text { of plants }\end{array}$ \\
\hline
\end{tabular}

A: Root crops:

1. kasipi

manioc,

Manihot utilissima

2. sikewe, johoru

varieties of taro

260

Colocasia antiquorum,

Xanthosoma sagittifolium

3. siahuwe, weni and $a k a i$

varieties of yam,

Dioscorea sp.

4. kasitena

sweet potato,

Ipomoea batatas

B: Other edible crops:
5. topikane
6. karatupa
7. tone

Setaria palmifolia

chilli, Capsicum

8. kaisan $\quad$ ground nuts,
Arachis hypogaea

aubergine,

Solanum melongena

9. tomati

tomato,

Lycopersicum esculetum

10. manahute

11. papai

12. uri

13. tohu

C: Non-edible crops:

14. tobako

15. napu
Celosia argentea

papaya,

Carica papaya

bananas and plantains,

Musa sp.

sugar-cane,

Saccharum officinarum tobacco,

gourd,
60

39

7

45

34

6

10

2

- $\quad 35$

50

15

5

20

3

10

2

$5 \quad 1$

$30 \quad 5$

57

10

$5 \quad 1$

- 5

142

$15 \quad 3$

Curcubitasp.

Lagenaria leucantha

Totals

569 100

rapidity and can easily smother other crops. It is found extensively in nisi monai and even along the edges of paths, where it can soon become a persistent weed (monote). As other root crops, such as the annuals taro and yam, are taken from the garden, so the proportion of manioc tends to increase. At the very least, for every manioc plant 
removed for food, one other stem is replanted in the same place automatically. This is simply done by removing the tubers and cutting all the stem away except for a short length near the base from which new adventitious roots and leaves quickly regenerate. If a garden is neglected after the first year it frequently happens that manioc speedily comes to dominate the area in association with other weeds. Consequently, consciously or by default, a first year garden with taro as its dominant crop is almost inevitable transformed within 12 months into a garden dominated by manioc; a transition which appears to coincide with the change in ecological terminology:

taro garden
nisi honwe $\begin{aligned} & \text { manioc garden } \\ & \text { nisi monai }\end{aligned}$

(2) Over 60 per cent of the total number of plants in a nisi honwe are various types of root tubers - sweet potato, manioc, taro and yams; about 20 per cent vegetable plants, 15 per cent fruit trees, 5 per cent non-edible species and less than one per cent of other types. The main focus is therefore upon root crops.

(3) The most important plant quantitatively-speaking is taro, in the region of 45 per cent of the total number cultivated. ${ }^{2}$ This grows best in a freshly cut garden, and although taro may be planted for a second season, this is not at all common. In general terms, it is probably true to say that the older the garden the less suitable it becomes for taro. The coastal Muslims, who cultivate a single garden much longer and to a greater intensity than the Nuaulu, complain bitterly of this fact, and often barter other crops and fish for taro with Nuaulu villagers.

(4) While yams are valued highly as food, few are grown, because - say the Nuaulu - the horticultural conditions are exacting, and a crop can easily suffer from exposure to the elements. This does not seem an altogether convincing reason (Coursey 1967: 70-2 and passim) though premature harvesting and lack of attention to developing vines may well be factors affecting yields. Yams are hardly ever planted for two seasons in succession on the same garden.

(5) All crops coming within category B, plus tobacco (but with the exception of chilli bushes), are typically never continued into a second year. Some greens, such as manahute, may run to seed and propagate themselves.

(6) Dendritic forms, such as bananas, papayas and mangoes (Mangifera indica $\mathrm{L}$.) normally survive into a second or even third year. 
It can be seen that unless a garden is exploited or rejected completely by the end of the first year, even without intercropping plants which would not come to fruition during that year, a nisi monai association is ensured, being at the very minimum simply a manioc garden, but typically an association of three dominant types: manioc, bananas and plantains, and papaya. All this implies a further difference between nisi honwe and nisi monai (of whatever kind) - that the number of different taxa in the former far outweighs that found in the latter, in the ratio of about $3: 1$, and that it is accompanied by the increasing domination of a smaller number of species (Ellen 1973: 460-4). But it is the planting, or otherwise, of additional species - clove, coconut and sago - at this stage which determines the long-term future (which may mean up to 60 years) of a particular plot.

\section{Harvesting}

While crops are maturing (TABLE 32) invocations may be made to ancestors and relevant garden spirits in regard to the health of the plants and yields (seute), often of a crop-specific nature - seute johoru, seute sikewe and so on. But the most important rite is that which occurs when yams, sweet potatoes and taro are ready for harvesting, the precise timing of which is determined by the individual garden owner, usually with reference to two factors: (a) the maturity of the root crops, but specially the various varieties of yam (but see p. 158 above) and (b) the nutritional demands of the household and its members.

This seute, or first fruits ceremony, is accompanied by a small feast held in the garden by the household of the owner. No root-crops may be taken from a garden until the ceremony has been performed (indeed, taro is sometimes still immature and small, even at this stage), although occasionally vegetables (such as tomatoes and groundnuts) may be removed. Such a restriction, however, is not significant in dietary terms, as other root crops and other older gardens are always accessible (Ellen 1973: 343-6).

Storing of seed tubers is usually done in baskets with lids, and more rarely in openwork containers. The Nuaulu appreciate the need to protect them from bruises and cracks, which would otherwise ruin them (Coursey 1967: 86, 178-86). Except for seed tubers, though, there are no elaborate storage procedures, and little food is stored over long periods, except where deliberate surpluses are accumulated for special festivals.

Following the first fruits ceremony a garden is usually quite rapidly 
denuded of first yams, and then eventually sweet potatoes, and taro. ${ }^{3}$ Yams are regarded as a luxury, harvested rapidly and then consumed within a relatively short period of time. Moreover, yields appear to be affected adversely by temperature and are therefore harvested during the wet season. ${ }^{4}$

As successive crops are harvested so the micro-composition of the garden changes. With information regarding approximate planting times and harvesting dates and/or length of time required for crops to mature it is possible to give an approximate compositional cross-section of a nisi honwe at any point of time in its developmental history, as gradually the composition comes to typify that of an early nisi monai. (TABLE 32). However, it should be noted that intercropping is a continuing process, resulting in harvests overlapping to an even greater extent than plantings. This does mean, though, that larger and more varied crop inventories are possible.

TABLE 32. Developmental history of a typical 'nisi honwe', showing approximate period of horticultural availability of each major crop type from the time of maturation of first-planted and most rapidly maturing variety. Based on field data and checked against Cobley (1956) and Barrau (1958).

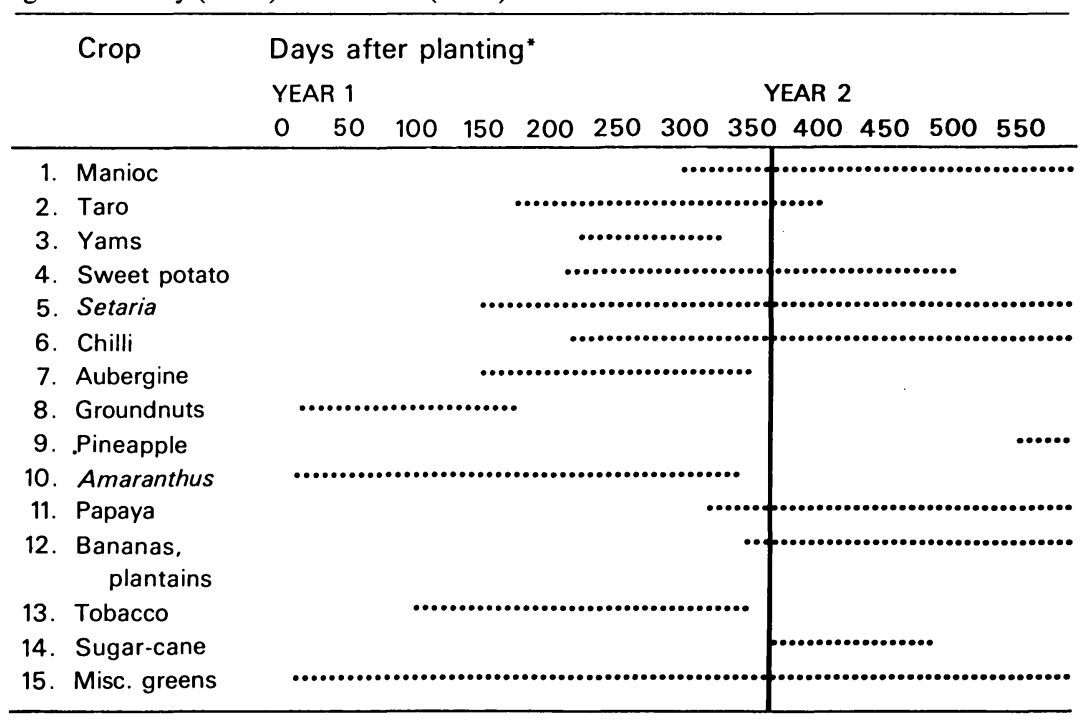

Input-output aspects of relations with the domesticated environment

The facts of continuous harvesting and the variety of major cultivars, together with the practical problems involved, make estimations of yields for individual gardens and the cultivated area as a whole very 
difficult under normal fieldwork conditions. TABLE 31 gives an approximation of relative yields for each species and for the garden as a whole by simple quantitative analysis for a single nisi honwe. Although this gives some indication of the order of yields in individual plots, it is difficult to relate it to actual consumption because of additional sources of energy (horticultural and non-horticultural) and the notorious problems of assessing calorific values for multi-cropped gardens. Therefore TABLE 33 presents the consumption pattern of major domesticated plant foods from both nisi honwe and nisi monai, based on the dietary survey discussed in Chapter IV and Appendix D. ${ }^{5}$

From an examination of TABLE 33 the total energy derived from domesticated resources per head per day appears to be in the region of 1,813 Cals., compared with 1,272 Cals. derived from all non-domes-

TABLE 33. The contribution of major domesticated plant resources to Nuaulu diet

\begin{tabular}{|c|c|c|c|c|c|}
\hline Nuaulu taxa & Content & $\begin{array}{l}\text { Mean gram } \\
\text { weight } \\
\text { consumed } \\
\text { per head } \\
\text { per day }\end{array}$ & $\begin{array}{l}\text { Mean } \\
\text { number } \\
\text { Cals } \\
\text { per head } \\
\text { per day }\end{array}$ & $\begin{array}{l}\text { Fat } \\
\text { by gram } \\
\text { weight } \\
\text { per day }\end{array}$ & $\begin{array}{c}\text { Protein } \\
\text { by gram } \\
\text { weight } \\
\text { per day }\end{array}$ \\
\hline 1. tone & aubergine & 1.8 & 0.4 & - & 0.02 \\
\hline 2. manahute & Amaranthus & 0.6 & 0.29 & - & 0.03 \\
\hline 3. tomati & tomato & 0.1 & 0.02 & - & - \\
\hline 4. sikewe & Colocasia leaves & 0.02 & 0.06 & - & - \\
\hline 5. napu & $\begin{array}{l}\text { squashes, gourds, } \\
\text { pumpkin and marrow }\end{array}$ & 0.1 & 0.04 & - & - \\
\hline 6. rorong & & 0.3 & 0.08 & - & 0.01 \\
\hline 7. kasipi & manioc leaves & 20.7 & 5.8 & 0.06 & 0.41 \\
\hline 8. papai & papaya leaves & 0.3 & 0.8 & - & 0.01 \\
\hline 9. papai & papaya & 1.6 & 0.62 & - & 0.01 \\
\hline 10. nione & coconut & 40.4 & 151.5 & 14.14 & 1.62 \\
\hline 11. utatam & Gnetum gnemon & 0.2 & 0.13 & - & - \\
\hline \multirow{2}{*}{$\begin{array}{l}\text { 12. sunai } \\
\text { 13. uri }\end{array}$} & breadfruit & 0.4 & 0.45 & - & 0.01 \\
\hline & $\begin{array}{c}\text { bananas and } \\
\text { plantains }\end{array}$ & 102.5 & 125 & 0.25 & 1.02 \\
\hline 14. kasipi & manioc & 299.4 & 458.1 & 0.6 & 2.1 \\
\hline 15. johoru & Xanthosoma & 76.9 & 102.3 & 0.23 & 1.54 \\
\hline 16. akai & Dioscorea & 4.3 & 4.5 & 0.01 & 0.09 \\
\hline 17. kasitena & sweet potato & 18.4 & 21 & 0.06 & 0.28 \\
\hline 18. weni & Dioscorea & 29.2 & 30.4 & 0.06 & 0.58 \\
\hline 19. ana & rice* & 1.5 & 5.28 & 0.01 & 0.1 \\
\hline 20. sikewe & Colocasia & 3.2 & 3.62 & - & 0.07 \\
\hline 21. siahuwe & Dioscorea & - & 1.04 & - & 0.02 \\
\hline 22. hatane & sago & 256.2 & 901.8 & - & 1.28 \\
\hline Totals & & 859.3 & 1813.23 & 15.36 & 9.22 \\
\hline
\end{tabular}

* Including that obtained by trade. 
ticated resources. Over forty per cent of an estimated daily adult intake of about 3,085 Cals. (a figure which is in itself quite high by comparative standards), ${ }^{6}$ is derived from the natural component of the environment among a group of sedentary swidden cultivators; and there is no evidence that the area under cultivation is inadequate to meet the necessary nutritional requirements - in fact there are small surpluses. However, the fact that this last figure is as high as it is is almost solely dependent on the importance of the exploitation of wild sago in Nuaulu economy. The picture is even more striking for the protein fraction, which represents only 36 per cent of the total consumed. Some further data on the overall consumption pattern in Ruhuwa are given in Appendix D, but the figures presented here should also be seen in the context of the discussion in Chapter IV.

TABLE 34. Energy expenditure of males involved in the exploitation of domesticated resources, Ruhuwa 1970

\begin{tabular}{|c|c|c|c|}
\hline Activity & $\begin{array}{l}\text { Percentage no. } \\
\text { of man-days } \\
\text { devoted to } \\
\text { activity during } \\
\text { test period }\end{array}$ & $\begin{array}{c}\text { Approximate } \\
\text { rate. of energy } \\
\text { expenditure } \\
\text { (Cals. per min.)* }\end{array}$ & $\begin{array}{l}\text { Percentage energy } \\
\text { expenditure } \\
\text { devoted to } \\
\text { activity during } \\
\text { test period }\end{array}$ \\
\hline
\end{tabular}

1. Activities associated with cash-primarily copra production

$\begin{array}{lll}6.4(27) & 4.0 & 7\end{array}$

2. Sago extraction

$36.8(154)$

3.5

36

3. All other gardening activities; including tending of groves

Figures in parenthesis in column 2 indicate actual number of man-days.

For notes on the methodology employed in these calculations see Appendix D.

* Estimates based on Hipsley \& Kirk 1965: 43; Norgan, Ferro-Luzzi and Durnin 1974: $339-41$.

TABLE 34 gives data on approximate labour and energy input for the domesticated component of the Nuaulu environment, based on broad time/activity data. This has then been condensed with that already given in TABLE 15 to show the relative respective labour-time and energy contributions to the exploitation of domesticated and non-domesticated environments (TABLE 35). Again, the importance of the non-domesticated component in Nuaulu man-environment relations (an ostensibly horticultural people) is effectively demonstrated; at least 56 per cent of the total energy expenditure for subsistence activities during the test 
period being devoted to exploitation of such resources, compared with around 44 per cent for cultivation. From these figures it appears that overall energy expenditure is directly proportional to overall labour time. The general absence of sophistication in gardening activities (the lack of fencing, techniques of soil preparation and classification, weeding and so on) is as much related to heavy reliance on hunting and collecting as it is to the low population density which it supports. But the data also illustrate in a vivid way: (a) the bias introduced by purely geographical approaches to settlement patterns which tend to emphasize only those readily observable cartographic features of human manipulation of the environment, and (b) parallel bias hitherto associated with ethnographic accounts of communities comparable to the Nuaulu. After all, they are unlikely to be totally exceptional in these respects (c.f. Spencer 1966: 49, 125-128). And so there is left the great contradiction in Nuaulu bio-energetic and environmental relations: that gardens are not ultimately of overriding importance in nutritional terms, and yet the actual operation of gardening is both energy-intensive and has enormous implications in terms of the pattern of settlement and management of man-environment relationships. ${ }^{\text {? }}$

TABLE 35. Total labour and energy expenditure of males involved in subsistence activities, Ruhuwa 1970

\begin{tabular}{lcc}
\hline & $\begin{array}{c}\text { Percentage no. of } \\
\text { man-days devoted } \\
\text { to activities } \\
\text { during test period }\end{array}$ & $\begin{array}{c}\text { Percentage energy } \\
\text { expenditure devoted } \\
\text { to activities } \\
\text { during test period }\end{array}$ \\
\hline $\begin{array}{l}\text { 1. Domesticated environment } \\
\begin{array}{l}\text { 2. Non-domesticated } \\
\text { environment }\end{array}\end{array}$ & 44 & 44 \\
\hline Totals & 56 & 56 \\
\hline
\end{tabular}

Having made this diversion and drawn some important general conclusions concerning the energy relationships between the Nuaulu and their environment as a whole, I wish to return to the discussion of the domesticated component in particular and continue the examination of garden development.

\section{Ritually-imposed delays on harvesting}

The harvesting of crops may be delayed by two types of ritual: the first fruits ceremony or the erection of a sasi taboo sign. Both of these events represent a passive means of ritual regulation of the environment, in 
contrast to the active role of pigs suggested for some New Guinea peoples (Rappaport 1967: 17-30).

In a first year garden, as far as root crops are concerned, sasi are redundant, since such species may not be touched before a seute first fruits ceremony has been held. Furthermore, sasi are seldom used in conjunction with root crops of any description, being typically associated with fruit trees of various kinds - durian, ${ }^{8}$ sago, coconut and clove among others. Nevertheless, the Lord of the Land may theoretically impose a sasi on land, forbidding any cultivation on it until the ban has been lifted.

The institution of a sasi, the physical manifestation of which is simply a pair of uprights with focal parts of the plant concerned placed across it, is normally a corporate village effort in order to prevent certain resources (or a range of resources), usually fruits, being collected or thieved before they are physically mature or before they exist in a specified quantity in a particular locality. They may be three or four months in duration and sometimes longer. Fallen fruits may be collected, and sometimes individual owners may be permitted to collect restricted amounts direct from the plant or tree, providing this privilege is exercised with care. The decision to erect a particular sasi sign is taken at a meeting of adult males at the formal request of the Lord of the Land. This, however, is always the outcome of a more general discussion among elders, to whom individual representations have been made. The actual construction of the sasi sign is nowadays the task of the village headman. Formerly, of course, it would have been entirely an internal clan matter.

If fruits are taken while a sasi is in force the offender must pay a ritual fine to the headman: 1 large red plate, 5 lengths of red cloth, 5 long machetes. If the individual fails to do so he is summoned before a meeting, asked to account for his action, following which he is obliged to work for the Lord of the Land for 40 days on his gardens. Further, if the village headman requires his services during this period, such as for cutting sago, he is additionally obliged to assist him.

Sometimes sasi are arranged between villages, in which case infringement is punished by both settlements. If both are Nuaulu, 5 lengths of red cloth must be paid to each village headman, if between a Muslim village (almost always Sepa) and a Nuaulu village 5 lengths of red cloth and 5 lengths of white cloth must be paid to the raja and 5 lengths of red cloth to the Nuaulu village headman concerned.

Sasi periods are terminated by general consensus expressed formally in another meeting called by the Lord of the Land. It is unusual for them 
to be in operation in one village every year, and (with the exception of durian) are avoided if at all possible. Eventualities which call for a sasi are commonly when an annual crop is particularly poor or when demands seem excessive, in this way ensuring their availability in quantity and full maturity at a specified point in the future. The sasi is therefore acting in the capacity of a ritual regulator of the environment and indeed they appear almost entirely effective as conservation measures (c.f. Cooley 1962: 77-80; also Volker 1925: 293-313).

\section{Nisi monai}

Nisi monai are of basically two types, undifferentiated and differentiated. Lexically, the term exhibits the same kind of polysemy already met with for wasi (see above p. 24), such that to use it in a specific context usually refers to the undifferentiated form. ${ }^{2}$ References to advanced gardens dominated by a single species (groves) are made according to the name of the particular dominant or association of dominants, most commonly nisi nione and nisi hatane:

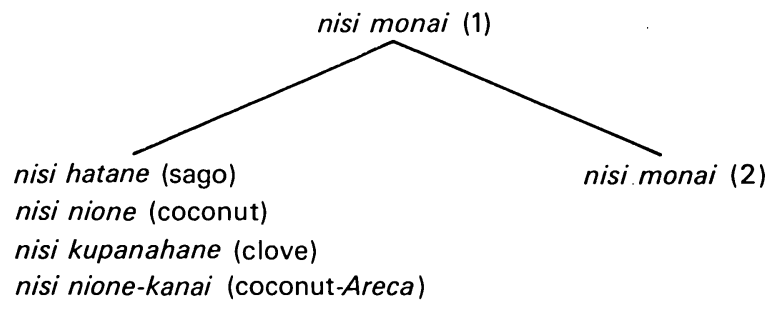

The undifferentiated form is typically the phase immediately following the removal of the annual root crops, vegetables and pulses, up to the time when other mid-term cultivars such as bananas, plantains and papaya finally die. This is usually from the end of the first year, through the second, and perhaps even a third. Consequently, without replanting, a garden may still be used into its third successive year and sometimes land which is already heavily overgrown with secondary associations may still provide a limited source for certain fruits and roots. Such land can be characterized (following Barrau 1958: 25) as 'semi-fallow', since, though its diminishing resources are still being exploited, it is undergoing vegetational regeneration. Occasionally, a section of an undifferentiated nisi monai in its second or third year may be recleared and planted. This practice, however, is more common among non-tribal coastal and Ambonese communities, where pressures on land are greater. 
The reasons why a garden may not be cultivated further and abandoned are numerous: the land may be in excess of present requirements (either because the total complement of land is sufficient or because there are two or more nisi honwe accessible); labour resources may be inadequate; the wasi may be in relative isolation, distant from the village or other gardens; soil may have proved difficult to work, weed growth excessive; there may have been a bad omen, augury or curse associated with the land, or it may have been subject to dispute, alienated or neglected due to residential changes. Unless a garden has been abandoned for one of these reasons, even before or shortly after harvest, crops are planted which determine its long-term future: principally areca palms, coconut, cloves and sago. Nevertheless, it does happen that sometimes a garden may be allowed partially to regenerate for a longer period before the undergrowth is again cut back and the seedlings planted out.

As the species of the first planting begin to disappear, and unless more have been planted subsequently, the young coconut or sago palms begin to become dominant. Rarely do all these long-term crops occur in equal proportions, even if they were originally planted as such, and in a relatively short time it becomes legitimate to speak of nisi hatane (sago groves), nisi nione (coconut groves) and so on. ${ }^{9}$ This is usually around the fifth year after a garden has first been cleared, and by this time it has undergone the transition from an undifferentiated garden, with a certain degree of ecological instability, to a differentiated garden. While it is still an artificial association, it is one approaching climax and with a consequent relative ecological stability. It is, in effect, also a transition from horticulture to silviculture.

Approximately beginning with the last of the first year annuals, or, as sometimes happens, when a nisi honwe has been partially or wholly recleared, and ending when the first crop from the long-term species is harvested, there is a period when productivity is almost negligible. During this period, which may last seven or eight years, a certain amount of attention may be paid to the garden, such as in the cutting back of undergrowth, the transplanting of trees and the planting of further seedlings. Some rapidly growing species may be introduced at this stage, such as pineapples, bananas, plantains and manioc, but manioc itself must be carefully controlled and is sometimes cut back on account of its tendency quickly to dominate and eliminate smaller and slower growing plants and saplings. The introduction of such crops has the effect of maintaining the maturing grove in a horticulturally beneficial state. 


\section{Nisi monai: groves and silviculture}

Nuaulu groves may be defined as gardens of an advanced state of development in which the dominants are a single or a small number of tree species providing edible or otherwise valued fruits. The set of activities and body of knowledge directed towards the establishment and maintenance of such a permanent or semi-permanent association in areas previously dominated by other associations, may be termed Nuaulu silviculture (c.f. Rappaport 1968: 55), though the Nuaulu themselves have no separate term for this set of interrelated activities.

Many different species are planted by the Nuaulu, mostly in groves, but sometimes individually within the village area, in unowned secondary forest, or on the land of other genealogically related persons. Furthermore, many trees occurring in groves are also found in the wild state. The most important species are those already encountered - sago, coconut and clove, but a wide variety of others (including durian, nutmeg, citrus fruits of various descriptions, but of which the areca palm is the most significant) are either intercropped or occur as single stands. Groves also represent an instance of the type of land to be cultivated (flat, swampy, shaded) being very heavily determined by the kind of crop to be planted. However, most cash crops (in the Nuaulu case clove is an exception to this rule) are grown on flat, easily accessible land. While this may appear sensible in terms of the cash economy, it can have farreaching implications for systems of subsistence horticulture, since it has the effect of removing good land from the normal cultivation-fallow cycle, which lowers horticultural efficiency and generally accelerates the process towards dependence on a commodity economy. Each of the three major dominants may now be treated in turn.

(1) Unlike areas devoted to the cultivation of coconut and clove, which are largely a recent response to a cash economy and coastal conditions, sago groves appear to have been created and maintained by the Nuaulu as a part of their traditional assemblage of subsistence activities..$^{10}$ Moreover (see above p. 72 , note 10), the distinction between naturally-set and cultivated sago has connotations which transcend the mere question of locality and economics.

The principal advantage of cultivated sago palms over the naturally set type is simply a question of relative accessibility. The distances travelled to obtain wild sago are (in local terms) quite considerable, while cultivated sago may be planted from suckers as close to the village as is environmentally and tenurially feasible, sometimes actually within it. Typically, cultivated palms are found in areas where the soil is moist, 
such as along stream banks, and young palms are sometimes planted for a short while at the end of conduits. But it is this very ease of accessibility, coupled with the relative scarcity of cultivated stands, that leads almost inevitably to their being cut prior to flowering, when the yield and quality of the starch has not yet reached its possible maximum. Yields from different localities show a general tendency to increase the greater the distance from the village. ${ }^{11}$

If the question of accessibility is phrased in terms of rights of access, three different categories of sago grove may be recognized:

(a) hate niane: naturally-propagated palms in various localities to which all Nuaulu have equal right of access;

(b) hata ipan or ipan hatana: individual stands or areas of palms in which particular clans have the sole right of access, vested in the group as a whole, and which are usually referred to with reference to the specific clans to whom they belong: Somori hatana, Nepane hatana .... etc.;

(c) ruaka hatana: a category referring to specific individual rights in sago palms.

This final category refers to the individual who first planted the palm by transplanting a young shoot, or to his offspring who have inherited it. Although this is regarded as a perfectly legitimate and separate form of ownership, the passage of time, particularly since a sago palm must remain for up to 15 years before it is fully mature and ready for harvesting, tends to transform individual rights into undifferentiated clan rights: ruaka hatana becoming ipane hatana. In any event, kin and affines have the same rights of access to sago palms for which individual ownership is acknowledged, as they are regarded as having with respect to undifferentiated clan rights in palms.

(2) The Nuaulu recognise that varieties of coconut can be classified according to which are considered most suitable for the production of copra and oil and which are regarded as being quite unsuitable for copra but more pleasant to eat. The main morphological distinction is the softer pulp of the latter varieties. Although the Nuaulu appear always to have been familiar with coconut as an element in their diet, it is only with the incentive to obtain trade goods and acquire cash for this purpose that a system of clearly defined groves has developed. This has undoubtedly been accompanied by the relative increase in the number of palms of the varieties most suited for copra production.

The palm is usually first planted on any available flat land, along valley bottoms and by streams where secondary growth has been sufficiently 
cleared, but lack of suitable watane land has meant the increasing use of sanene for this purpose. In this way an undifferentiated garden is eventually transformed into a coconut grove, though small by comparison with those of local Muslims. Unlike sago groves, these are rarely monospecific, being commonly interspersed with areca palms, clove, nutmeg, pineapple, sometimes isolated stands of sago, and even larger trees such as durian, Eugenia and Canarium. It is estimated that the density of actual coconut palms is something less than 300 stands to the hectare, with an increase in density towards the coast. Often young seedlings are planted in between the older palms, while others germinate naturally from fallen fruits, so prolonging the active life of a grove, though it is possible that overcrowding negatively affects yield in some cases (Brookfield with Hart 1971: 139). In terms of the active life of the average coconut palm (in the region of fifty or sixty years), most Nuaulu groves are very young and with no historical predecessors, making them (together with the much smaller groves of clove) a recent factor in long-term ecological succession, and therefore in settlement shape. It is this fact which makes prediction about the ultimate destiny of such groves uncertain, though on the basis of the established pattern for other coastal communities, groves might be expected to be perpetuated almost indefinitely by the continual intercropping of seedlings, eventually succeeding to mixed secondary associations, often of the bamboo scrub type but with a wide range of coastal weeds. Sometimes parts of old groves are cleared and swiddens created, but these are usually only of a temporary character. Cultivation of coconut palms in groves is a recent innovation and the tenurial implications of the overall succession pattern have yet to be fully worked out by the Nuaulu themselves. It is of some interest to note, however, that coconut groves are, on balance, less distant from the village than land not devoted to cash crops (MAP 13). Though this would fit with the explanation of least effort with regard to bulk carrying offered by Brookfield and Hart (1971: 227), the Nuaulu case is much more probably a function of suitable topography.

(3) Cloves, even more than coconut palms, are a recent introduction and regarded simply as a means of obtaining cash. The number of trees and the area under cultivation are still relatively small. Much of what has been said for the establishment, development and succession of coconut groves applies equally to cloves.

Clove seedlings may be planted out during the first or subsequent years of a nisi honwe, but it is generally recognized that the susceptibility of the seedlings to heat and bad weather demands cool sheltered locali- 


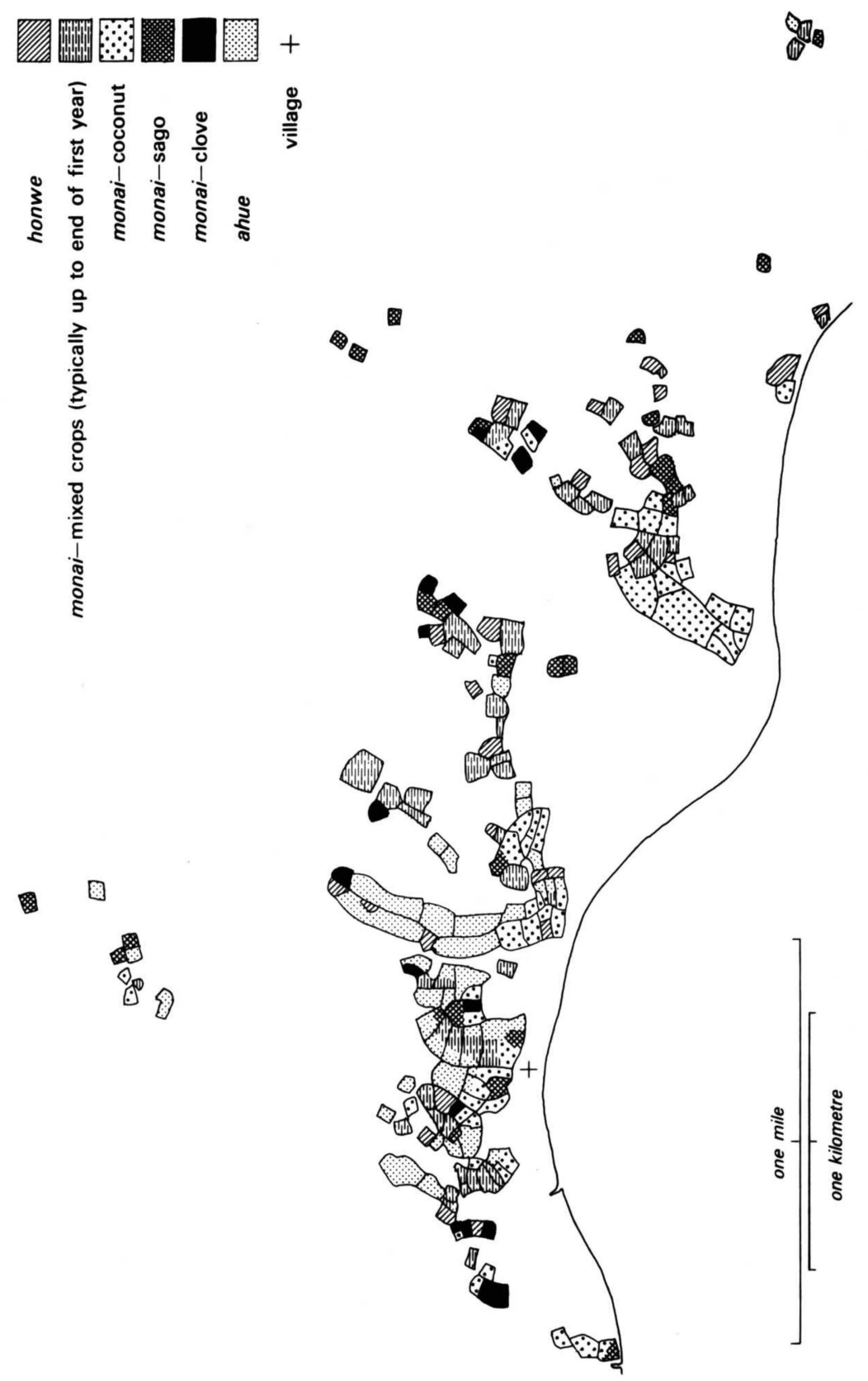


ties and shaded slopes. Seedlings may be grown from seed in protected nurseries actually within the garden or sometimes in the village area and then planted out or grown from naturally set seedlings. The young clove trees are widely spaced (or at most in groups of two or three), in the shelter of suitable bushes or the suitably adapted large-leafed taro, and marked with crossed sticks. The general impression gained was that the planting of new groves (and there are relatively few old trees in the Ruhuwa area) is an altogether difficult undertaking, with a high proportion of seedlings dying, though relatively good cash prices provide the incentive for perseverance in establishing this as a permanent and significant cash crop. Clove trees take eight or nine years to fully mature (Cobley 1956: 206).

\section{Secondary growth}

Even if a nisi honwe has been well cleared and thoroughly fired, weeds tend rapidly to regrow, and some are hardly affected by burning at all. As has been shown, little attempt is made to halt their advance. To some degree, large plants such as taro exclude sunlight from the area immediately surrounding them, making it near impossible for weeds to take hold, while the adaptable and persistent manioc tends to combat weed growth through sheer domination.

The overall pattern of weed growth, like that of the cultivars with which they are in competition, changes as a garden gets older and as the artificial associations of cultivars either change or are neglected. In the long term, regeneration of cultivated land to mature forest can be divided into the three distinct phases already outlined in the last chapter. Generally speaking, the rate of secondary regeneration of forest trees is at first slow, the time taken to reach a diameter of five centimetres equalling that from five to forty centimetres (Richards 1952: 48, 384).

Not only are there temporal differences in weed associations, but there is also a variation from site to site, dependent on such factors as the nature of the artificial garden association, the structure of the associations prior to clearance, surrounding vegetational associations, topography and soil. For example, it was noted that on low land with little or no slope with little sunlight nisi monai weed growth tended to be dominated by mononute (Euphorbia hirta L.) and kau-kau (Pteris sp.), while on high sloping land and ridges (much more exposed to sunlight) the dominants tended to be Compositae species, such as mono manhutanane and mono mahusine. Grove land also has its typical interstitial weed growth, one of the most important group of dominants again being 
pteridophytes (such as Pteris spp.), Cyperus diffusus Vahl. and Selaginella, tree saplings and sporadic clumps of bamboo, principally wanate (a variety of Bambusa). In fact, sometimes after a garden has been completely abandoned it is bamboo which first takes hold, rather than shrubs and small trees. Eventually (though this stage is typically quite protracted; Burkill 1935: 290-1) the gregarious dense stands of bamboo are replaced by the dominant trees which are representative of the surrounding forest (Merrill 1954: 67). ${ }^{12}$

The fact that Imperata and other stable stoloniferous grassland associations (such as Themeda) do not occur in the Nuaulu area to any significant extent has already been stressed in relation to their nonoccurrence as a general ecological feature on Seram as a whole and as a possible limiting factor in site selection (see above pp. 5, 116). Though oni (Imperata exaltata Brongn.) may occur transiently in isolated patches, only rarely will it form stable associations, owing to the presence of seedlings of characteristic pioneering tree species. On Seram such grasslands are generally restricted to certain densely populated areas in the south-east and west of the island, together with a few localities along the coast, where soil has been exhausted. It would appear that the population has never been substantial enough at any one time in any one place to give the characteristic climax grasslands that are found in parts of New Guinea. The possibility of diverting cultivated land into monospecific groves may have been a factor leading to the avoidance of this in some of the more heavily populated settlements.

\section{Fallow and soil conservation}

The Nuaulu appear to have no formulated or precise idea of just how long a garden should lie fallow. The term ahue is best glossed as 'secondary growth association'; to translate it as 'fallow' would be to suggest connotations which plainly do not exist in Nuaulu thought. It is not the time element in fallowing which is recognized by the Nuaulu as being important. Indeed, sometimes their reaction is one of amazement that it should be necessary for time to elapse at all. Rather, it is a recognition of the types of vegetational cover which, when cut, result in the most productive gardens. It comes as no surprise then, to learn that no definitive procedures exist for the enrichment of fallow and controlling of regeneration. Though there is no formal calculation in terms of years as to the predicted adequacy of the underlying soil, judgements are made as to the agricultural potential of plots on the basis of the state of their vegetation. In practice, the actual period varies greatly 
depending on: (a) location of the garden, (b) general availability of land, (c) nature of soil, (d) seasonal weather, (e) topography, (f) previous and current vegetational cover (for example, presence of productive fruit trees and degree of weed growth) and, (g) current requirements. Eight years was quoted as a typical period, but sometimes it is as short as one (e.g. W100, 1969-71). TABLE 36 shows the systematic annual location of gardens for a single mature male over a 10 year period, which includes the recultivation of the same site three times in the course of 5 years (W94) and the restriction of fallow periods to 2 or 3 years only.

TABLE 36. 'Nisi honwe' locations selected by one individual (Lihuta Matoke) over a 10 year period

A.

\begin{tabular}{|c|c|c|c|}
\hline Year & Watercourse & $\begin{array}{c}\text { Wasi } \\
\text { identification }\end{array}$ & $\begin{array}{c}\text { Present } \\
\text { vegetative cover }\end{array}$ \\
\hline 1. $1961-62$ & Awao-headwaters & - & secondary forest \\
\hline 2. $1962-63$ & Ruhuwa-headwaters & - & secondary forest \\
\hline 3. $1963-64$ & Ruhuwa & W134a & coconut, clove, manioc \\
\hline 4. $1964-65$ & Ruhuwa & W134b & $\begin{array}{l}\text { banana and plantains, } \\
\text { secondary growth }\end{array}$ \\
\hline 5. $1965-66$ & Awao & W93 & $\begin{array}{l}\text { banana and plantains, } \\
\text { manioc }\end{array}$ \\
\hline 6. $1966-67$ & Awao & W94 & secondary growth \\
\hline 7. $1967-68$ & Mon & W37 & $\begin{array}{l}\text { banana and plantains, } \\
\text { manioc, coconut }\end{array}$ \\
\hline 8. $1968-69$ & Awao & W94 & secondary growth \\
\hline 9. $1969-70$ & Awao & W93 & manioc, taro \\
\hline 10. $1970-71$ & Awao & W94 & - \\
\hline
\end{tabular}

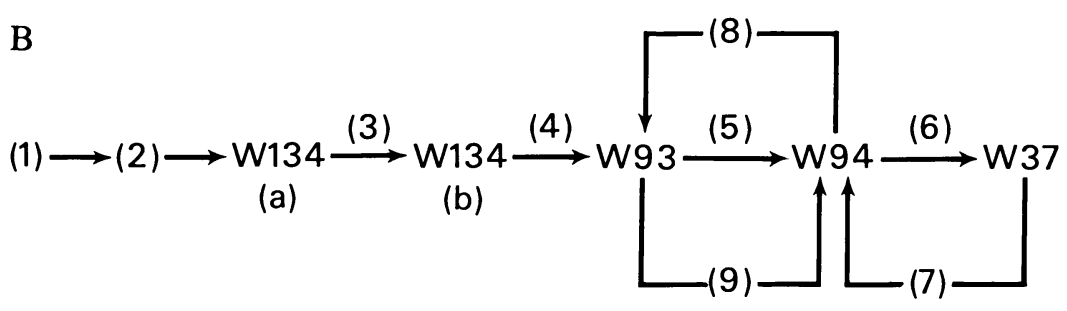

Generally, the nearer the garden to the village the shorter the fallowing period. Sometimes, of course, the problem is circumvented by choosing a non-fallow alternative, in the planting of long-term species or the continued use of the garden in another form, and this policy is becoming increasingly adopted with the incentive of acquiring cash. There is consequently considerable variation in the length of fallow from site to 
site, varying from only 2 years between plantings to up to 25 years, and it is precisely this which is responsible for the recognised problems associated with their estimation (Conklin 1969: 231). For obvious reasons estimations of the longer fallow periods are difficult to make. ${ }^{13}$

Estimation of the adequacy of Nuaulu fallowing presents certain difficulties also. Soil samples collected at a small series of gardens and other localities provide slender evidence for gross depletion in the quality of the soil (Appendix B). The reasons appear to lie in a combination of the following factors:

(1) rapid weed regeneration and neglect of weeding gardens, resulting in the deep penetration of the roots of tree seedlings into the substrate such that nutrients that might otherwise be lost in leaching are recovered; ${ }^{14}$

(2) debris from incomplete firing, incomplete slashing of primary vegetation, rapid growth of cultivars and weed regeneration, preventing substantial erosion and avoidance of grass domination (c.f. Rappaport 1971: 122);

(3) protection of gardens from erosion due to heavy precipitation by presence of tall stands round garden perimeters;

(4) abandonment of gardens, unless intended for groves, relatively rapidly after the main root crops have been exhausted;

(5) most gardens cut from medium secondary growth, bamboo thickets, or advanced secondary growth and mature forest within the category wesie;

(6) relative availability of suitable unused land.

In view of all this, Nuaulu fallowing can be considered adequate, although the high degree of variation should be noted, together with the corollary that therefore there are always a very small number of gardens (usually undifferentiated nisi monai) where intensive cultivation leads to soil depletion.

\section{Carrying capacity}

Having discussed the question of fallow and attempted to specify the energy requirements of the Ruhuwa Nuaulu, it is possible to give some kind of estimation of the maximum population that Ruhuwa land can support for an indefinite length of time (and without leading to degradation of the environment), that is the carrying capacity. On the basis of Nuaulu environmental relations and horticultural practices already described it also allows for the computation of other related indices. 
As Rappaport has pointed out (1968: 88), this index does not necessarily indicate the population that could survive on a given territory and neither does it mean that other environmental limiting factors do not operate below this level. The Nuaulu's heavy reliance on non-domesticated resources is also likely to interfere with the accuracy of predictions. In fact, carrying capacity is in many respects an inadequate, indeed, potentially misleading index, largely due to the inevitable problems associated with the determination of the correct values of the variables involved. This has meant that the comparative problems are almost insuperable (De Josselin de Jong 1967: 174-8). For these reasons the precise mathematical formulation which Carneiro (1960: 229-34) confidently envisaged is really very imprecise. Some attempts have been made to improve upon the pioneer approaches of workers such as Carneiro and Allan (1949) (e.g. Brookfield and Brown 1963: 108 ff.), while others have dismissed it outright, regarding 'such a mechanical approach to the problem as fallacious' (Lea 1964: 12). Here I follow Rappaport (1968: 88-96, 285-96) in adopting Carneiro's original formulae, (1960: 229-34) in the knowledge that their use is accompanied by immense difficulties.

The basic Carneiro formula involves the calculation from field data of five variables. For Ruhuwa these were calculated as follows:

(1) Population $(P)$ supported under present circumstances. $P=180$.

(2) Total arable land $(T)$. In earlier chapters the difficulties involved in area measurement have been mentioned (in particular the lack of congruence between orthographic and topographic measurements) and the question of the accurate determination of Nuaulu 'territory' raised, something which has acquired further dimensions of difficulty since re-settlement. At the present time it is possible to attach at least three separate values to the variable $T$ in Ruhuwa, thus:

$$
\begin{aligned}
& \mathrm{T}_{1} \text { total productive cultivated land } \ldots 102.19 \text { hectares } \\
& \mathrm{T}_{2} \text { high energy-yield cultivated land } \\
& \left(\mathrm{T}_{1}\right. \text { minus nisi ahue, clove and coconut } \\
& \text { groves) } \ldots 68.97 \text { hectares }
\end{aligned}
$$

$T_{3}$ total potentially cultivatable land $\ldots 1602.19$ hectares

For the computations made here $\mathrm{T}_{3}$ has been adopted. This is computed by correcting the land area within a four kilometre radius of 
Ruhuwa, to eliminate land unavailable for cultivation for either social or environmental reasons. ${ }^{15}$

(3) Length of fallow period $(R)$ necessary before plot may be recultivated. The notorious difficulties involved in calculating this variable have already been discussed. Consequently, the unknown variables involved in the three permutations of the Carneiro formula used here are calculated for both an absolute minimal fallow of 2 years and a hypothetical maximum of 25 years.

(4) The area of cultivated land $(A)$ necessary to provide a hypothetically 'average' individual with the energy normally derived from cultivated plants per year. TABLE 33 shows that the mean number of Cals. per day obtained in this way for a mature individual is 1,813 . Of the Ruhuwa population of 180,80 can be described as 'mature' (over 15 years) (FIGURE 14, Appendix D), giving an approximate average daily intake of domesticated plant matter for an 'average individual' of 1,309 Cals, that is 471,240 Cals. per year. This is provided principally from 0.25 hectares of high energy-yield land per person (c.f. De Josselin de Jong 1967: 175). Calculation of calorific values for individual nisi honwe, as well as being tedious arithmetically, are unlikely to give accurate results on account of the consumption of cultivated food plants from other sources - undifferentiated nisi monai, sago groves and to a lesser extent, from the extensive but otherwise low energy yielding coconut and clove groves. Nisi honwe and nisi monai cannot be equated in trophic terms. Another difficulty in this respect is the variable composition of individual nisi honwe, in connection with which the discrepancy between composition of individual nisi honwe, and actual dietary intake should be noted.

(5) The number of years $(Y)$ before a productive garden is abandoned. Again, this presents problems of definition, but in view of the discussion under points (2) and (4) above, Y refers to areas of high energy-yield land only and has been given an approximate value of 3 years.

TABLE 37 summarizes the methods and results for the computation of predicted values for variables obtained from the three standard permutations of the Carneiro formula. The results indicate (a) the capability of the present locality to support at the very least a fivefold increase in population and in all probability a population over twenty times that existing at the present; (b) that the present population is capable of being supported on substantially less arable land than is currently available (at the very minimum in the region of the area at present devoted to high energy yield crops); and (c) that the length of time the present 
population can remain exploiting the environment at the current rate is dependent on the question of fallow, but, since for most gardens $\mathrm{L}$ is likely to be equal or greater than $(\mathrm{R}+\mathrm{Y})$, it is highly probable that occupation can continue for an almost infinite period of time.

TABLE 37. Values for Ruhuwa carrying capacity under various conditions

\begin{tabular}{|c|c|c|c|c|c|}
\hline Unknown variables & Formula & Fallow & $P$ & $\mathrm{~T}$ & $\mathrm{~L}$ \\
\hline $\begin{array}{l}\text { 1. population }(\mathrm{P}) \\
\text { supported permanently } \\
\text { in same locality }\end{array}$ & $\frac{\mathrm{T}}{\frac{(\mathrm{R}+\mathrm{Y}) \mathrm{Y}}{\mathrm{A}}}$ & $\begin{array}{l}\text { minimum } \\
\text { maximum }\end{array}$ & $\begin{array}{r}3829 \\
684.1\end{array}$ & & \\
\hline $\begin{array}{l}\text { 2. smallest area }(\mathrm{T}) \text { of } \\
\text { cultivatable land } \\
\text { capable of supporting } \\
\text { village }\end{array}$ & $\mathrm{T}=\frac{\mathrm{PxA}}{\mathrm{Y}} \mathrm{x}(\mathrm{R}+\mathrm{Y})$ & $\begin{array}{l}\text { minimum } \\
\text { maximum }\end{array}$ & & $\begin{array}{r}74.9 \\
418.1\end{array}$ & \\
\hline $\begin{array}{l}\text { 3. length of time }(\mathrm{L}) \\
\text { community able to } \\
\text { remain in same locality }\end{array}$ & $\mathrm{L}=\frac{\mathrm{T}}{(\mathrm{PxA})} *$ & $\begin{array}{l}\text { minimum } \\
\text { maximum }\end{array}$ & & & 11.84 \\
\hline
\end{tabular}

* If $\mathrm{L}$ is more than $\mathrm{R}+\mathrm{Y}$ the locality is capable of infinite occupation (Carneiro 1960:231).

These predictions represent densities of between 40 and $200 / \mathrm{km}^{2}$. The upper limit is exceptionally high compared with the actual densities for other groups of swidden agriculturalists for which accurate information exists (see footnote 15). It would appear that yet again it is the factor of heavy Nuaulu reliance on the natural component of their environment (reflected in the value of $\mathrm{A}$ ), as well as the value of $\mathrm{Y}$ (De Josselin de Jong 1967: 176), which is responsible for this situation. Of course, it would be absurd to suggest that a constant proportion of energy and protein requirements would necessarily continue to be catered for by existent non-domesticated resources if there is uninterrupted population growth. Rather, a rising population would result in increased exploitation and consequent depletion of such finite accessible resources. This is almost certain to result in an intensification of horticultural activity to accommodate diminishing resources in the nondomesticated sector. Increased growth of the area under cultivation would, in turn, affect the accessibility of those same natural resources whose depletion was set in motion by over-exploitation. And yet, still other factors should be taken into account in any predictions concerning future land use patterns, if any reasonable degree of accuracy is to be claimed. The two most important of these are the introduction of cash- 
cropping and technological innovation. They are dealt with in the final section of this chapter.

Having surveyed some of the general problems involved in the use of the concept of carrying capacity and explored some of the more specific local factors which must be borne in mind when making and interpreting predictions, I am inclined to agree with Clarke (1971: 190), in envisaging it more as a gradient than a 'critical limit'. Any changes in population density are inevitably bound to lead to environmental changes which have repercussions for the entire system.

The domestic component of the environment in time and space

So far the discussion of the domesticated component of the Nuaulu environment has proceeded more or less developmentally, in order to illustrate stage by stage, process by process, the micro-evolution of a major sector of the Nuaulu settlement pattern. In doing so I have, in local terms, attempted to trace the history of a piece of land as it moves through the cycle wesie-nisi honwe-nisi monai-nisi ahue-nisi, or anysub-cycles involving the same categories. From this examination it will be evident that the energy flow and interaction between individuals and plots of land varies over time - seasonally, annually, and over periods of years - acccording to the vegetational condition of that land. This intentional emphasis on process may have resulted in partly obscuring the overall view of this component at any one point in time. To remedy this, MAP 13 illustrates the distribution of wasi in terms of local categories, together with some indication of the principal vegetational covers for the category nisi monai, for Ruhuwa during the horticultural cycle for 1970-71. The numerical analysis of garden type in terms of actual area is indicated approximately by the figures presented in TABLE 38.

Accurate determination of the vegetational status of land is by no means easy: for three reasons. First, while the threshold between nisi honwe and nisi monai can be accurately enough determined (since creation of a new nisi honwe automatically means that that of the previous year is termed nisi monai), the threshold between nisi monai and nisi ahue is much more indeterminate, adoption of the latter term depending on the degree to which secondary forest vegetation has re-established itself. Secondly, it is almost impossible to establish the percentage of land cleared each year which is abandoned or subsequently transformed into differentiated or undifferentiated nisi monai, without intensive study over a period of years. Finally, as was pointed 
out earlier (see above pp. 89-92), each wasi may contain portions of land at different stages of vegetational development. Consequently, in TABLE 38 the figures for the number of wasi in each category refer to all those which can reasonably be classified unambiguously, plus half the number of wasi in which the category applies to around fifty per cent of the area. The average size of wasi for each category is obtained by dividing this number into the total area of land in hectares devoted to that category.

TABLE 38. Ruhuwa cultiv'ated area in terms of garden types, 1970-1971

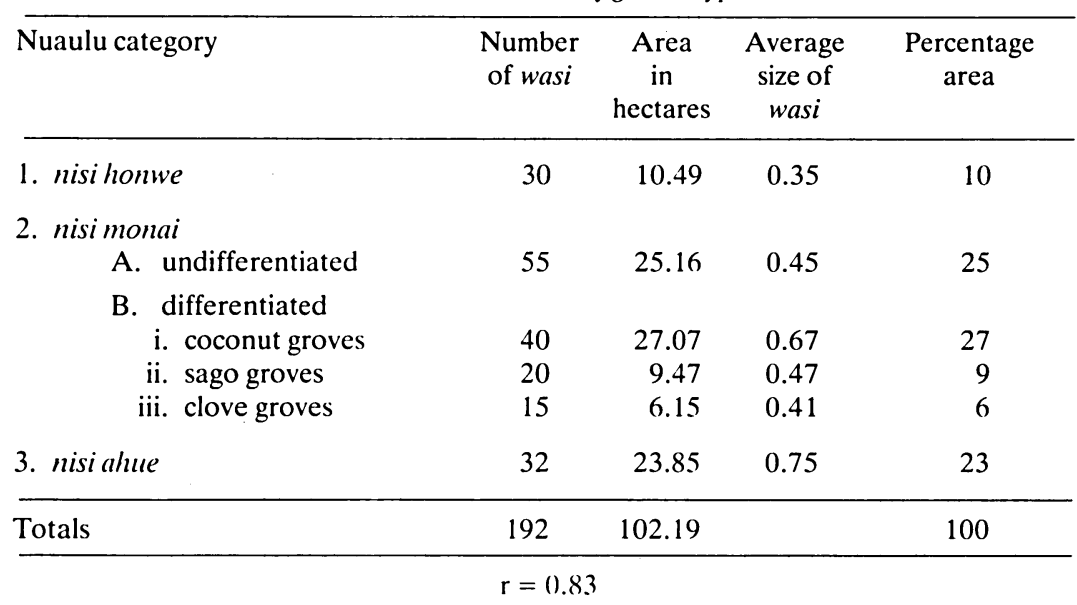

What is immediately apparent is the very high percentage area devoted to nisi monai (67 per cent) and the increase in the size of wasi through the land use cycle. While it is only to be expected that the quantities involved in the ratio nisi honwe: nisi monai would be heavily weighted towards the latter, that these quantities are so disproportionate (in the ratio $1: 7$ ) is clearly a reflection of the amount of land devoted to coconut groves, in itself 27 per cent of the total cultivated area. Prior to the introduction of cash crops the ratio would naturally have been much smaller, perhaps in the order of $1: 3$, equal to the present ratio between nisi honwe and undifferentiated nisi monai (plus sago groves) alone. The difference in the average size of wasi in each of the categories is not entirely unexpected, since it has already been pointed out that precise boundaries are forgotten or ignored after a time, particularly if an individual or household possesses a number of closely clustered areas. In such circumstances it becomes unneccessary to remember internal wasi boundaries of the cluster. 
The percentage of nisi ahue is an outcome of, on the one hand, relatively heavy exploitation for new gardens, and, on the other, a certain degree of renunciation of title. However, the increasing pressures on land accompanying the present coastal location, especially with respect to the requirements of non-Nuaulu, have inevitably meant a greater awareness of tenurially accessible land in this category. It is possible that formerly the degree to which nisi ahue was recognized as such was somewhat less, owing to the absence of these pressures, but it is equally probable that the total area described by this term will decline in the future, as more land is turned over to groves. Since systems of swidden cultivation involve a faster rate of land exhaustion than recovery, the area of regenerating land must be several times greater than the area actually cultivated (Carneiro 1960: 229) if new land is not to be used. The depletion of these reserves among the Nuaulu will therefore mean increased felling of forest.

The alteration in the balance between nisi honwe and nisi monai and between swidden and grove is of very great ecological significance in its relation to the changing structure of the Nuaulu economy. The swidden system (at least under ideal conditions) is essentially one which maintains the existing natural ecological structure (e.g. Geertz 1963: 16-17). With the transformation from undifferentiated to differentiated nisi monai, not only is there a breaking out from the swidden cycle, but there is a fundamental change in the ecological structure of the domesticated environment, largely achieved through a reduction in the diversity per hectare. The process is undoubtedly a cumulative and selfamplifying one, which ultimately must result in even more drastic changes in local ecological balance. In some respects such a process represents a more significant change than that from reliance on nondomesticated resources to swiddening, since in the creation of a swidden plot the cultivated plants are fulfilling a similar spatial and functional role to equivalent wild species, while the diversity index is comparable (c.f. Harris 1969: 6). With the shift to plots dominated by a single species, which may occupy the same space for periods from 15 to 70 years without fallow, the structure and functional dynamics change considerably. To take only one example: the reduction in diversity leads to a corresponding reduction in bio-energetic efficiency through an impaired capacity to maximize the use of available solar energy. Cropping periods overlap less or do not overlap at all. This in turn means greater demands on land by the same population and possible changes in the overall pattern of settlement through expansion. 
These factors, together with those discussed in the previous section, illustrate clearly the inadequacies of predictions stemming from the computation of carrying capacity. Here is a situation in which there are obviously very substantial ecological changes taking place, in which the indigenous categories of the domesticated environment are being radically re-arranged, broadly characterized as a transition between impermanence and permanence of cultivated areas. Apart from changes brought about as a direct function of population increase and progressive technological competence associated with introduced steel axes and dibbles, the most significant alteration is being brought about by increased attention to the creation of coconut groves, with the associated increase in the value of $\mathrm{T}$ (total cultivated land) and theoretical decrease in the value of L. Formerly only a small percentage of land cut would have been cultivated after three years - now the percentage is considerably higher. In terms of the overall pattern of sites in the domesticated component, this will probably lead to an increase in the tolerable distance to its ultimate perimeter (Brookfield with Hart1971: 227). In sociological terms it will almost certainly mean a greater emphasis on individual claims, an appreciation that cash crops represent one of their most important assets (together with the land they are planted on) and monetary values being associated with such property holdings. Because the life-cycles of such cultigens are generally long, the association of individuals and domestic groups with the land they are grown on is proportionately longer than under swidden cultivation. The situation is effectively one of continuous plant tenure, and the transition from this to the idea of atomized 'ownership' of the land which supports it is not difficult, particularly in the presence of a new and potent ideology which sustains it (Ellen 1977; c.f. Sorensen 1972: 371). I expect Nuaulu concepts of land relations to become less flexible, much more formalized and jural than they are at present.

The synchronic distribution of land types in the domesticated component of the Nuaulu environment can be seen as representing different successional stages within a single community (c.f. Clarke 1966: 347). Temporally it can be seen as a series of variable changes over time in its horticultural status, recognized by the Nuaulu themselves as changes through a series of ethno-ecologically distinct phases. Depending on the phase, there will be different implications for the future succession and the development of the land around it, affecting vegetational cover, the nature and intensity of exploitation in the vicinity and the patterning of 
such specific artifacts of settlement as fences, garden huts and paths. It is possible to isolate the following five distinct types of succession in terms of Nuaulu categories (FIGURE 12). Employing botanical criteria the chains would be considerably more complex.

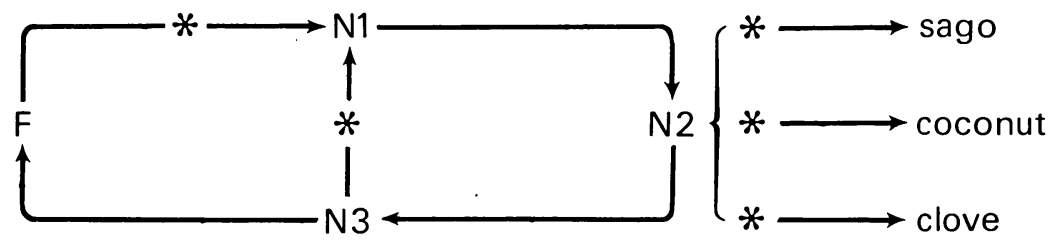

1. $\mathrm{F}-\mathrm{N} 1-\mathrm{N} 2-\mathrm{N} 3-\mathrm{F}$

2. $\mathrm{F}-\mathrm{N} 1-\mathrm{N} 2(-$ sago)

4. $\mathrm{F}-\mathrm{N} 1-\mathrm{N} 2$ (-clove)

3. $\mathrm{F}-\mathrm{N} 1-\mathrm{N} 2$ (coconut)

5. $\mathrm{F}-\underline{\mathrm{N} 1}-\mathrm{N} 2-\mathrm{N} 3-\mathrm{N} 1$

FIGURE 12. Succession possibilities in terms of Nuaulu vegetational categories.

Of these, two are cyclical: 1 returning to the same stable climatic climax condition $(F)$ and 5 in which unstable secondary growth (N3) is recleared. 2, 3 and 4 are linear successions between a climatic climax and an artificial but nevertheless reasonably stable plant association (N2). In the long-term, of course, all these are in fact cyclical in nature (FIGURE 11). It is also to be noted that every chain contains the unit F-N1-N2, there being no possibility of $\mathrm{N} 1$ succeeding to another association without passing through N2. Similarly, N2 cannot succeed to F without passing through $\mathrm{N} 3$.

In terms of decision-making the most crucial transitions are those marked with an asterisk in FIGURE 12, since at these points in the network the natural course of succession is artificially altered. In 5, for example, there is a conscious effort to prevent land reaching forest by continually converting it back into nisi honwe before it reaches the social and ecological point of no return. Of course, it is also true that the natural succession continues because of negative decisions. Such decisions can thus lead to (a) cyclical and (b) linear changes within the traditional ethno-ecological frame of reference and (c) linear changes outside the traditional ethno-ecological frame of reference. The first type is associated with processual changes in the annual horticultural cycle or the developmental cycle of domestic groups, relating to changing needs within the household, local and seasonal horticultural problems (concerning such matters as the adequacy of burns, weather, nature of 
yields and fallowing), and resulting in the creation or relocation of garden huts, exploitation of new areas, new hut complexes, abandonment or intensification of exploitation of others, and so on. The second type is related to established successional policies, while the final type is concerned with introduced horticultural and silvicultural strategies and with (what are effectively) non-reversible changes due to these or other environmental, demographic or cultural factors, such as succession to grassland. Concentration on the last two of these would amount to a description of Nuaulu agricultural history.

The point that emerges from all this is that such differential cultural control over the micro-ecological succession of plots is at once a product of, and a factor in, the processes of decision-making and the formulation of the domesticated component of the Nuaulu settlement pattern. Changes of an environmental, sociological, demographic and agronomic kind will naturally alter the relative importance of individual rules, as well as (in extreme cases) the form of the rules themselves. 


\section{ANALYZING SETTLEMENT: THE WIDER RELEVANCE OF THE NUAULU CASE}

In this monograph the focus has been on the pattern of settlement and environmental relations of the Nuaulu, but there have also been attempts to go beyond the ethnography and examine wider implications. In this final chapter particular emphasis is placed on putting the Nuaulu material in a broader theoretical perspective.

\section{Environmental relations, information and ethnoscience}

If a generative analysis claims to describe the processes which underlie observable forms and to do so - at least to some extent - in locally prescribed terms, in accordance with local conventions and desirability, then it is patently clear that to understand the generative process at work in any aspect of a given culture, it is necessary to be conversant with local cognitive structures and behaviour. It is true that a structure may be generated in terms of an interpretative model alone, but in the final instance it can only be completely understood when the modus operandi of the relevant cognitive structures have been described and analysed. ${ }^{1}$ Decision-making, after all, can only operate in relation to the environmental categories as they are locally perceived. This is a point which Frake has consistently stressed (1962: 53, 1962a, 1964: 113). And it is in this respect that it is tempting to suggest that ethnographic description should resemble linguistic description; or, in Frake's terms, to communicate what is necessary in order to respond accurately in a given socio-ecological context. In view of this it is not surprising that this particular approach is closely allied to, and developed in conjunction with, the study of folk-taxonomies. Both have a common relationship with pre-transformational linguistic method, with a common interest in the importance of understanding indigenous decision-making behaviour in terms of the kind of cognitive and classificatory apparatus available; but in the precise nature of that relationship the two diverge. I would maintain that whereas in the study of folk-taxonomies the relationship is clearly a homological one, in generative method (as portrayed by Frake) it is only analogical. 
It is clear that the most relevant source to tap with respect to problems dealt with here is the indigenous reservoir of ecological knowledge; what is required is an 'ethno-ecological' approach (Conklin 1957: 20, 1962: 457-64). It is this which I have tried to incorporate in the present analysis, by emphasizing the importance of understanding the way in which the Nuaulu divide up the landscape, classify gardens according to vegetational cover, and so on. But although the relevance of cognitive behaviour to ecology is, as Anderson has pointed out (1969: 443), an obvious one, often those concerned to build up an interpretative ecological perspective have sneered at attempts to formulate statements about classificatory behaviour (Harris 1969: 568 and passim).

It is of fundamental importance to distinguish between the local environmental model, which Rappaport (1963: 159) has characterized as

the class composed of the sum of phenomena ordered into meaningful categories by a population,

and the interpretative (or operational) model. He continues:

operational and cognized environments will include many of the same elements, but they may differ extensively in the structuring of relationships between elements.

After all, the reality of the natural environment is in many ways continuous, and to be comprehended and decisions made with respect to it (or certain parts of it), a model of discontinuities must be superimposed on it, involving artificial (and sometimes distorting) cultural boundaries to categories. In this way the natural environment is reworked in cultural terms (Douglas 1972a). It is just because of this that a proper understanding of indigenous classificatory behaviour and the local environmental model is crucial to any appreciation of ecological relationships. ${ }^{2}$

One of the most important prerequisites for an adequate field-analysis is that it should be closely geared to an understanding of the rationale of indigenous decision-making and resource evaluation. In some cases this will entail a consideration of folk-taxonomies for a wide variety of domains, in fact, all those which have relevance to the analysis of socio-ecological patterns. Thus, in the present study I have touched upon Nuaulu classification of vegetational types, soils, plants, rockformations, village space and so forth. Of particular significance in understanding decisions with regard to land use, and thus the pattern of settlement as a whole, has been the local classification of land-forms. In 
the preceeding chapters I have found it necessary to draw heavily on Nuaulu ideas in this sphere. In so doing I have been able to demonstrate that they, like other swidden agriculturalists, possess an extensive and ecologically meaningful classification of land-forms, in this case tending to be a mixture of primary and secondary land formations and vegetational associations, that is both naturally and culturally determined terrains. ${ }^{3}$

Additionally, it is vital to understand the rationale, frequently reflected in the classification, which orders preferences in decisionmaking and evaluation of resources. After all, resources are themselves no more than those parts of the environment given value by cultural perception (Brookfield with Hart 1971: 41). And further, since the settlement pattern is usually represented by its spatial coordinates, it should not go unrecognized that often indigenous mental maps of local geography lack meaningful distinctions between horizontal and vertical distances in the conception of space and relative size and distance (see, for example, above pp. 133-135). The most important features are much more usually ones of orientation and degree of individual interaction (Weule 1915). As has been pointed out already, it is only with reference to the perceived environment that decision-makers can possibly operate.

The significance of such an approach is underlined in the context of generative method, for if analysis is restricted solely to the use of an interpretative model of classification and choice preference patterns, the pattern generated cannot logically conform to actuality and neither can the processes be fully understood. The Nuaulu evidence would appear to bear this out. Nevertheless, to use the interpretative approach in this sphere of enquiry by itself can be a useful exercise and may indeed help in understanding the critical categories of choice, as they contrast or conform with it in the decision-making process. For example, the inadequacy of classical locational analysis in generating the observable settlement of Ruhuwa only emphasizes the importance in Nuaulu decision-making of other factors not normally considered central to the issue. Moreover, it strongly suggests that their entire approach to locational problems is rather differently framed.

For the unwary, the use and enumeration of taxonomic and other cognitive data possess many pitfalls, not the least being the trap of inviting spurious uniformity. There are immense analytical problems involved in the lack of congruence between 'real' and perceived taxa, between the perceived and the verbalized, and in the absence of a sharp 
distinction between the visible and non-visible. However, it has been research into ethnoscience which has thrown these very problems into high relief. The criticisms of Burling (1964), that verbal behaviour does not necessarily give an adequate indication of mental operations, while (consciously or unconsciously) the informant does not always present the ethnographer with a complete or accurate picture, are a valuable reminder that indigenous models can never be described exhaustively or with absolute veracity. Nevertheless, it is up to the analyst to use those elements he does possess intelligently. Furthermore, the elucidation of folk-taxonomies in vacuo is not enough and can easily become esoteric and meaningless. Marvin Harris (1969: 591-2) and David MayburyLewis (1967), among others, have criticized in no uncertain terms the value of ethnoscience, including the justified charge that some formal approaches have not been worth the effort expended, since their initial problems have been profoundly trivial. There is, indeed, a grave danger that researchers in this field may become 'so enamoured of methodology that content will be restricted to the banal' (Altschuler 1968: 251). Moreover, the method itself with much of its underpinning theory is beginning to look a little inadequate, for example in the face of postChomskyian linguistics (e.g. Keesing 1972). The view adopted here is that ethnoscience is not a theory of culture (or even of ethnographic method), but rather a technique, 'a discovery-procedure for eliciting system where before it had not been thought to reside' (ibid.) The value of such a procedure to me is that it can in many cases provide a locally defined cognitive basis for the principles which govern environmental relations and finally generate settlement form, as well as structuring the framework of Nuaulu decision-making in locally prescribed terms.

From what has just been said, it is clear that my commitment to the formal approaches embodied in a linguistically-oriented ethnoscience is only to the extent that they render interpretative analysis more meaningful. The tendency to emic reductionism is only to be deplored, and has been justifiably pilloried by its critics. Rather, I submit that in dealing with emic material (itself necessary to understand decision-making) the emic must always be tied into the etic framework. It cannot constitute an analysis in itself. What is important, ethnographically, is not so much the abstract conception of the perceived, but the operational relationship between it and the interpretative environment (Ellen 1975). In this way it is possible to focus attention on that area where the unintentional rationality of the system articulates with the intentional rationality of the actors (Godelier 1972: 10-13 and passim). 


\section{Settlement pattern as a unit of analysis}

As Demangeon recognized (1962 [1927] : 506), the description and classification of settlement-patterns can only be achieved through the study of the influences which determine them, and the pattern is a function of the interrelationship of a variety of sociological and ecological elements combined with the use and allocation of productive resources (Brown and Brookfield 1967: 119). In terms of the approach adopted here it concerns the relationship of a population to culturally important natural resources, as well as relationships internal to the cultural framework as reflected in spatial patterns (Demangeon 1962 [1927] : 506-16). It is 'the most obvious physical expression of the local organization of a society, where statistical generalities ... meet behaviour particularities' (Brookfield with Hart 1971: 221).

Despite this, social anthropologists have generally tended to attribute settlement patterns with great rigidity. Those of sedentary peoples have been seen largely as unrelated things in themselves (c.f. Leach 1961: 305), either unimportant or static arrangements worthy of minimal attention only. The epistemological background as well as some elementary practical reasons for this situation are to be found in Gellner's assessment of the reluctance of many social anthropologists to tackle relationships between physical and social systems (1963: 251). As Brown and Brookfield (1967: 119) have pointed out, there have been very few studies of a particular society which have taken the pattern of settlement as the central point of enquiry. Exceptions to this tradition include the work of Leach (1961) and Orenstein (1965), emphasizing the positive moulding effect of micro-ecology on social relationships in hydraulic societies; that of Conklin $(1957: 2,1968)$, with his insistence on the integration of subsistence activities into the overall socio-cultural matrix; the work of Brookfield and Brown (1963) on land adequacy, agriculture and group territories; Sorenson (1972) on a specifically ecological study of settlement patterns; and even, to some extent, the treatment of settlements as visible referents of cosmology and structural realities of social life apparent in the work of Lévi-Strauss (1956). And then there are the two sources which I have selected as being of particular theoretical interest, the work of Frake and Barth on different but related aspects of generative analysis. Although Barth has not paid special attention to the generation of settlement patterns, he has acknowledged a debt to the earlier work on the developmental cycle of domestic groups (Fortes 1949; Goody 1958), which can be seen as a contribution to the processual analysis of the compositional aspect of 
settlement. These contributions are important in that they are attempts to incorporate settlement pattern within the general framework of a particular ethnographic analysis, instead of relegating it - like ecology to an early chapter of a monograph and dealing with it as essentially local geography or as a disparate collection of details on villageplans, the dimension of cultivation plots, pastures and the like (Leach 1961: 305). The point I should like to emphasize is that when I speak of $a$ settlement pattern I am not referring merely to a ground-plan or necessarily any kind of concrete localization, but rather to the relationship between the critical variables of settlement (Harris 1972). A settlement pattern defined simply in terms of its geographical discreteness inhibits analysis.

Although the studies mentioned emphasize the centrality of settlement pattern to anthropological explanation, they have not always placed it in its broad ecological context or considered how a pattern becomes what it is. Although in the past certain workers have provided limited explanations of an aspect of settlement patterns, they have generally neglected to interpret them fully. ${ }^{4}$ This last point is in line with the criticisms levelled by Barth against functionalist social anthropology, and which I have taken as my point of departure in Chapter 1. Only by the discovery and description of the processes which generate form can one ultimately explain form itself. My principal concern has been to illustrate how the overall shape of the Nuaulu settlement pattern may be generated in terms of culturally-determined rules operating within the framework of a particular ecosystem.

\section{The differentiation of factors affecting settlement}

The processes which determine the overall settlement pattern must, as I have indicated, be composite. Nevertheless, it is frequently apparent that in terms of either cognitive or interpretative models factors can be conveniently grouped into wider categories of determinants of social form, some of which are quantifiable and others not. In handling the data presented here, in order first to isolate and then integrate significant generative processes, I have found it useful to distinguish three basic analytical categories. Each of these contains rules of behaviour which the Nuaulu regard as necessary for maintaining the proper cultural and ecological order in their existence - the intentional rationality of the system as they see it. These are as follows: 


\begin{abstract}
Rule class 5 Derivation
ideational concrete demonstration of a cosmological, ideological and cognitive system; essentially non-personal.

organizational need for short-term balanced social relationships; maintenance of group and individual interests (e.g. politics, kinship, defence); concerns inter-personal relations and group composition.

ecological need for short-term, balanced input-output economic and energy relationships; optimal use of resources; avoidance of environmental obstacles.
\end{abstract}

The application of such rules by the Nuaulu represents the transformation of information about the environment as it is perceived and understood into action which has an identifiable effect on the structure of the system. The term rule in this context, despite its apparent ambiguities, simply refers to a device to generate form. It does not mean that it is necessarily regarded as such by the Nuaulu themselves, and neither do the classes which group them together have any particular indigenous significance. Rules in this sense are a particular kind of factor (translating information into behaviour) which interact with the system and may affect the pattern of settlement. Factors not embodied in cultural rules of desired relationships are considered further below.

The degree to which these rules are applicable varies between different settlements and between different sectors of the same settlement pattern. The Nuaulu village-plan, for example, in common with many other eastern Indonesian communities (as exemplified classically in the work of Onvlee (1949) on Sumba) is ideally and traditionally largely a function of ideational rules (c.f. Cohen's 'symbolic' orientation, 1973: 45-61), where what is important is that the pattern should reflect idealized social structure and cosmology. I think that the account presented here of ideological factors in village structure adequately portrays their significance in the Nuaulu situation, in as much as religion is closely tied in with the existing relations of production: in reinforcing the male-female dichotomy, defining the locus of domestic activity and in terms of enforcing measures of conservation. In addition, there are the more incidental products of religious activity (for example, cemeteries), which, while affecting to some extent the pattern of settlement, are not among its primary determinants at any level. In other societies such 
factors (whether fundamental or incidental) may be of minimal importance only. In highly mobile and simply-structured societies interpersonal relations become the dominant social concomitants of village form. In the Nuaulu village such organizational rules seem to operate only within the framework generated by ideational ones, although they may be instrumental in determining location and composition. However, they are of critical importance in determining garden location, whereas in this regard ideational rules are highly specific and limited in their affect. Rules relating to preferred ecological relationships are more difficult to isolate in such terms, but rather tend to affect all aspects of settlement generation. In terms of the non-domesticated environment they are paramount, tending to define the ultimate geographical parameters of settlement. In terms of village structure and location they are clear and quite specific, while their effect on the cultivated areas of the settlement pattern is quite clearly profound but much more difficult to analyse on account of the corresponding complexity of organizational factors. The problems of analysis, however, by no means undermine the possibility of usefully discussing the overall environmental context and general swidden ecology. Part of the problem is simply that tropical agricultural systems are highly peculiar to their local environments (Wikkramatileke 1959: 79). This is the reason why particular attention is paid in what follows to the domesticated sector of the pattern of settlement. It is also the reason why so much of the preceeding analysis has been devoted to it.

Rules regarding the most desirable arrangement of the components of settlement patterns should, however, be distinguished from other factors of generation. Normally these consist of basic environmental factors over which the population has little or no control. This does not mean that they are constant, but only that relative to the rules of generation their rate of change is so much slower than the conscious change possible in rule application that they may be taken for the purposes of analysis as being constant. Thus, it has been suggested by Frake (1962) that in any particular analysis two sets of components should be considered - a set of cultural rules (as discussed above) and an abstracted set of givens or constraints. By the latter is meant a range of socio-ecological facts of life, for all intents and purposes, irreducible to the mere employment of formal rules. Thus, while an insistence on the minimizing of distances between gardens is a cultural prescription, the factor of weed growth which makes it in part necessary is not one. The same thing is highlighted in the distinction drawn in Chapter VI between factors which make 
cultivation impossible and those which simply make it undesirable. It is not suggested that givens are timeless, indeed, what should be emphasized is the very continuity between change in rule patterns and changes in givens. In analytical terms, however, the distinction serves as a practical aid in separating those factors that can be consciously manipulated at will and those that cannot. They provide the basic coordinates for any generative analysis of settlement patterns. It is the constancy of these givens which permits the element of predictability in discovering the outcome of the process of settlement generation under given circumstances and it is of considerable analytical importance in the comparison of processes.

Givens fall into two complementary categories - cultural and environmental. The former category consists primarily of the relatively slowly changing elements of cognitive organization and social structure. Nuaulu ecological categories, local measures of time and space, ways of dividing up the environment, and so forth, have already been discussed where relevant in the text, and in general such concepts and categories may be assumed to have a severe limiting effect on the expression of the kind of choices made, though alternatively they may allow for subtle and complex decisions to be made with regard to environmental relations. But analysis must begin with a consideration of the latter category. It must determine just how far immutable environmental givens, distributed spatially and temporally, can explain settlement form (c.f. Leach 1961: 306). Thus, pattern generation must accord with what is possible within the maxima and minima of altitude distribution, of precipitation, of temperature; the distribution of major ecological zones, cultivable crops, topography and other major environmental aspects of locality at any given point in time, and over time. Only then can the more capricious factors be adequately considered. But it is these very changeable environmental factors of short-term vegetational successions, seasonal climatic conditions, micro-topography, relative distribution of resources over localized areas and time periods, which interact so closely with cultural variables at the local level. It is often these which deserve closer attention and have the most direct implications for relations between man and environment. It is with such factors that this monograph is particularly concerned. In each of the analytical chapters the nature and influence of such factors have been considered as they fluctuate and integrate with other generative processes within the parameters set by environmental givens.

I have been able to demonstrate that in considering the Nuaulu 
settlement-pattern it is necessary to consider carefully the relative weights of all these different pressures in order to arrive at the actual outcome. A consideration of one type of factor or a short series of varying factors is insufficient to generate an observed pattern of settlement, since there exists no one overwhelming class of factors or orientations which can be said to dominate the Nuaulu relationship with their environment. It is necessary to work out the specific consequences resulting from the influence of a wide range of factors characteristic of a particular locality at a given period of time. In a sense we are dealing here with what Percy Cohen has termed (in a slightly different context) 'a model of interrelated processes, some of which reinforce one another in their present state, others of which disrupt one another' (1968: 204). Thus, although ideational, organizational and ecological factors, as entire categories and at the level of individual factors, may oppose each other, this is not necessarily so, and in certain circumstances what is ecologically desirable conforms to what is structurally determined or socially preferred, and so on. But part of the significance of such an approach is that in analyzing actual decision-making pathways (for example, those related to the location of particular garden plots), it is possible to examine actual conflict between factors as diverse as the symbolic and the bio-energetic (c.f. Erik Cohen 1973: 8).

In terms of the rules formulated by these pressures, what is quite apparent is that they are 'pliable', in practice if not in theory. While they are applied in order to generate an ideal model of settlement, this is in fact purely theoretical - it can never be achieved in practice, their actual application resulting in only an approximation of all that is considered desirable in settlement arrangements. Thus, paraphrasing Frake (1962a), the Nuaulu settlement pattern is not a fixed entity, but rather represents the outcome of a great number of individual decisions, not made on a simple random basis, but representing an evaluation of the immediate circumstances in terms of a set of quite explicit principles about the most desirable relations concerning, in this case, household and garden, the relation of one cultivation site to another, one vegetational association with another, village to non-domesticated resources, and so on. It is in these terms that it might be considered possible to generate the existing pattern appropriate to a given set of conditions from a finite formalized set of rules. In the analysis which I have presented, where it has been possible to isolate particular rules as concise statements of desired associations I have done so. However, to assess fully all factors involved in the generation of the Nuaulu settle- 
ment pattern, as these are actually expressed in terms of elicited rules of desired relationships, would be both tedious and impracticable. It would be incorrect to claim therefore (in contrast with the analogous linguistic procedure) that because the analyst has been able to specify the actual pattern of settlement in terms of a specified number of abstracted rules and other elements, it is therefore possible to predict, in any but a most general fashion, changes brought about by changes in one or more of the variables. The predictive value of the generative approach adopted here is therefore limited.

\section{Integrating the generative elements of settlement}

In trophic terms the input and output of the non-domesticated and domesticated components of the Nuaulu environment have been shown to be approximately equal, with even a somewhat higher energy expenditure and consumption related to the former. The primary source of subsistence energy, sago starch, is derived from both domesticated and non-domesticated sources in approximately the same ratio as for the overall energy contribution. In terms of protein intake, input is almost entirely from non-domesticated sources. However, in terms of input/ area and output/area indices, interaction with the domesticated components is much more intensive than with the non-domesticated. This is despite the fact that the total biomass required to provide the same number of calories is much greater in the latter, owing to the exploitation of secondary sources of energy (fauna) from this sector.

It is because of the intensity of exploitation within the domesticated component of the Nuaulu environment that the cultivated areas in which major and visible changes in the vegetational landscape take place become dominant in determining the observable shape of the settlement pattern. In Brookfield's words, 'the study of settlement pattern and location is thus intimately linked with the study of the agricultural system' (1968: 426). As was pointed out above, it is these areas which provide the most complications in isolating the factors involved in the overall generative process, and the reticulation between them. To treat the material in a developmental fashion, beginning with the creation of new gardens from mature forest, following through the factors involved in selection and finally turning to successions and abandonment, provides the most suitable framewcik for the discovery of those rules and givens which generate the actual settlement pattern. But in the very attempt to create these ideal analytical conditions, the sheer quantity and diversity of factors involved and the complexity of their interaction 
demonstrates the immense difficulties still contained in this approach.

One of the problems faced in analysis is that rigorous generative techniques appear to embody the assumption that generation is simply linear. Confrontation with the complexities of ethnographic fact should illustrate that this is not so. The assumption is basically that given a particular ecological situation $\left(A_{1}\right)$, together with a finite set of cultural factors $\left(a_{1}, a_{2} \ldots a_{n}\right)$, a new socio-ecological pattern $\left(A_{2}\right)$ is generated. Of course, it is possible to isolate instances of this kind of mechanism frequently, if only because it is the basic logical component of any generative analysis. In the Nuaulu case this is sufficient to explain the location of garden huts, new garden sites, groves and residential units. But these things constitute part of a much more extensive and involved pattern of settlement. Having generated a component $\left(A_{2}\right)$, this itself becomes a new factor in the generation of further components. For example, the existence of a newly created nisi honwe becomes an integral factor in explaining the pattern in which land around it is exploited, both during its existence and following it in time. Its implications are synchronic in the sense that $A_{2}$ must be taken into account in generating $A_{3}, A_{4}, A_{5} \ldots A_{n}$, as they can be observed at any one time, and diachronic in that a given situation $\left(\mathrm{A}_{2}\right)$, or the reticulation between it and other components, leads to the creation of changed and historically new patterns. Additionally, while the generation of $A_{2}$ may be a factor in the generation of other synchronic components of the settlement pattern, those same components are frequently factors in the generation of $A_{2}$. Thus, the existence of an individual garden-complex has implications for the spatial arrangement of others.

The factors affecting decisions and the kind of rule applied must be expected to vary according to the point in time at which they are made, while the effects of decisions made at one point in time will tend to have different effects at different points in the future. The reason is simply that socio-ecological conditions are constantly changing. Many of these changes are more or less predictable, since they occur as parts of cycles. For the Nuaulu, it is possible to isolate the annual agricultural cycle, the long-term swidden cycle represented in the key progression $n$. honwe-n. monai- $n$. ahue and the developmental cycle of domestic groups. The latter cycle, in this case, represents changing economic requirements (reflected in the number and distribution of plots cultivated) related to the household development, physical changes in village layout related to the same and changing patterns of relations with other groups (with their implications for land accessibility, labour cooperation and so on). The 
sum of changes in each domestic unit will be reflected in observable changes in village size and composition. As each separate cycle progresses it brings visible changes in the pattern of settlement and new conditions are brought to bear on decision-making. The implications of the inter-relations between each cycle must therefore be correspondingly complicated. The interaction of this multiplicity of linear and cyclical processes integrates the capricious environmental factors which I distinguish above, in such a fashion that it becomes extremely difficult to extricate them as separate entities for the purposes of analysis. The general point to be made is simply that there are immensely close inter-relationships between cultural and ecological variables at a microethnographic level.

Apart from demonstrating the close interrelationship of factors, the discussion so far in this section has indicated the crucial distinction between those short-term processes attendant on the functioning of a system and processes which alter the character of the system itself, the distinction between cyclical and linear, and the necessity of the juxtaposition of the synchronic and diachronic in efficient explanation (e.g. Godelier 1972: 259-60, 278-9). As Millar puts it, 'there is a circular relation among the primary aspects of systems - structures change momentarily with functioning, but when such change is so great that it is essentially irreversible, a historic process has occurred, giving rise to a new structure' (1965: 209, quoted in Langton 1973: 136). Some of these latter developments in the Nuaulu case have already been briefly examined in Chapter VII, but here I want to pursue some related problems a little further.

Environmental factors can either exercise their effect directly or indirectly. Examples of such factors which affect parts of the generative process directly include such matters as the distribution of rock outcrops, the nature of soil parent material, the overall topography of small steep-walled valleys contrasted with the flat alluvium of the coast and valley bottoms, types of primary vegetational cover and the location of watercourses. Examples of environmental factors which affect parts of the Nuaulu generative process indirectly include the nature and distribution of secondary associations of all kinds, land which has ceased to become economically productive or which has been manipulated by human activity in any way. It is frequently these factors, generated in the artificial ecosystem of cultivated and densely settled areas, that are the subtle, but significant, proximate factors involved in decision-making concerning both short-term selection of sites and long-term succession. 
This leads to a further point of some theoretical interest. To talk of 'decision-making processes' tends usually to imply some kind of immediacy of action (but see e.g. Firth 1965: 29-31). However, as the Nuaulu evidence suggests, and as is implicit from the above discussion, decisions made at any one point in time may affect different phases of future action, resource distribution and environmental exploitation. For the domestic sector these may occur at any point in the horticultural cycle: prior to the cutting of a garden, during its preparation or after the first-year harvest. Decision-making is an on-going process. It might therefore be considered methodologically advantageous to distinguish between decisions concerning the short-, mid- and long term; though such a classification in itself would be something of an artificial construct. In Nuaulu terms this would allow for an analytical distinction between, say, those made with respect to the immediate annual horticultural cycle, those made with respect to the short-term ecological succession and the rather longer term implications discussed in the last part of Chapter VII. It would also allow for the implications of decisions made relating, say, to the location of a new garden hut, to be classified in terms of the future development of the garden-complex for which it is the nucleus. There is no doubt from the Nuaulu evidence that this approach is justified, but it does leave in its wake a thorny problem - that analysis of decisions made at a given point in time simply in terms of their immediate economic maximization is inadequate. Perhaps there is a need for some conceptual revision to allow for the consideration of time-sequences involved in decision-making behaviour.

The interrelations between the Nuaulu system of swidden horticulture, silviculture and the general pattern of settlement are complicated. According to the degree to which the artificially created plot is subsequently culturally controlled, by active technological intervention or passive acceptance of natural ecological tendencies (through skill, care and negligence), new and culturally meaningful ecosystems are formed. Thus, the general conclusion may be drawn that the pattern of Nuaulu land-type distribution is a function of the culturally moulded course of ecological succession (c.f. Conklin 1968: 109-11). The picture at any one time is the result of both manifest and latent decisions, within the limits of what is ecologically possible, as to the type of land use required in a particular place. And it is only by discovering those processes which go to form the pattern of settlement that it can ultimately be understood (Barth 1966: 2). From the ethnographic point of view, this underscores the assertion that land use is no less than the manipulation of ecosystems to reach desired ends. 
I have shown now that it is possible to isolate certain significant operational rules which reflect indigenous principles with regard to the ideal constellation of elements of the settlement pattern, particularly with respect to the domesticated component of the environment. But I have tended to be cautious as to what degree an analysis can completely rely on this approach. The problem is to a large extent associated with what is understood by the term rule. Is there, for example, any essential difference between a rule and any cultural preference? The Nuaulu material appears to show that sometimes this can be a rather arbitrary distinction and its usage might easily obscure certain other very relevant factors. There is also the fact that the general generative principles which I have found possible to formulate, are themselves composed of a large body of determinants of varying importance. Generally speaking, the more critical the individual components the more important the rule which is composed from them. Thus, the Nuaulu distance rule designed to minimize garden-residence distance, is very largely viewed in terms of the trophic and economic advantages, though, as I have shown, the Nuaulu feel that it concerns much more than this (see above pp. 136-139). The actual number of components must, of course, affect the status of the rule, but it would seem that this is less important than taking into account the serious disadvantages of not complying with a single but crucial rule component. In setting out generative elements for analysis there must always be some selection in the choice of factors, either dependent on the degree of comprehension of the ethnographer or the thoroughness of his informants. It is impossible to reduce rules to a finite set or to see them as self-contained and irreducible statements of desirability. It is with respect to these facts that the linguistic analogy and formalism per se will not hold, and to insist on their applicability only leads to spurious uniformity of dubious analytical value. To a certain extent this is implied in the work of Barth (1966: 5); the linguistic comparison is generative in an analogical sense, it is not homological. It seems most unreasonable to expect that it is possible to construct elaborate 'cultural grammars' for large domains of activity by imitation of linguistic approaches, though it might very well be expected that similar logical mechanisms occur in decision-making processes. Further, while it is true as Barth suggests that a generative approach allows, in some instances, for complex empirical forms to be described in terms of relatively few specifications (1966: 11,22), it is extremely unlikely, as the material presented suggests, that this will always be the situation. It also cannot be automatically assumed that the processes specified, and 
which adequately produce the observed social form, are necessarily the proximate factors involved. For this reason the element of predictability is diminished considerably.

Bearing these limitations in mind, I have attempted to follow through, as illustrations, the possible process of decision-making for specific operations, such as is exemplified by those processes resulting in the clustering of cultivated land around the Nuaulu village (FIGURE 10). It is equally possible to formulate decision-making chains of this kind for processes which achieve different or even opposing results and in doing so it is empirically possible, though undoubtedly sometimes practically involved, to measure deviation from particular ideals. Moreover, it is at this level that analysis comes closest to some ideas formulated by Barth: namely, that the processes represent 'clearly abstracted parts', a 'series of logical operations' and that

... the logical operations whereby forms are generated should mirror actual, empirical processes which can be identified in the reality which is being analysed (1966: v).

Further, it is in this sense that the nature of the linguistic analogy of Frake permits analysis to be firmly rooted in the data.

A procedure of the kind described does not identify the kind of individual rules and factors involved in decision-making processes. In a methodological sense no one type of element has priority over another, and it is this feature which permits integration of the different kinds of factors and rules distinguished in the foregoing section. The outcome of individual decision-making chains represents specific instances whereby direct and indirect environmental factors are closely integrated with the different types of overtly culturally-determined desiderata, ideational and organizational. All these are determinants, to a greater or lesser extent, of the resultant pattern. Nevertheless, I have been able to illustrate with specific reference to the material presented here, how (despite this close interaction between different classes of factors) particular principles and factors will vary, assuming a greater or lesser degree of importance, from one locality to another, from one sector of the settlement-pattern to another, in the last resort dependent on the overall constraints offered by the environment. Thus, in terms of generation of the Nuaulu village layout, the framework, within which other variables operate, is provided by quite specific ideas of the ritual concomitants of the component parts. In the domesticated sector of the settled areas, organizational factors appear clearly as of crucial importance in the 
selection of site, in combination with both indirect and direct environmental features. It is, however, in the non-domesticated sector that environmental factors most clearly determine exploitative patterns, inasmuch as these affect the distribution of culturally-preferred food resources. Exploitative activities, nevertheless, are closely geared to culturally-determined work patterns, and physically and economically imposed limitations concerning distance, terrain and so on.

From the above discussion it will be apparent that the diagrammatic representation of the integration of factors given in FIGURE 10 might be considered somewhat misleading, since branching has been shown as symmetrical. A more useful indicator of the relative weight of factors in the final outcome of a decision-making process is to introduce asymmetry into the diagram by (a) thickness of line (as in a flow diagram) or (b) by the structure of the 'junctions'. In this way it is possible to assess rapidly the relative importance of factors for different processes and in different sectors of the settlement-pattern.

(a)

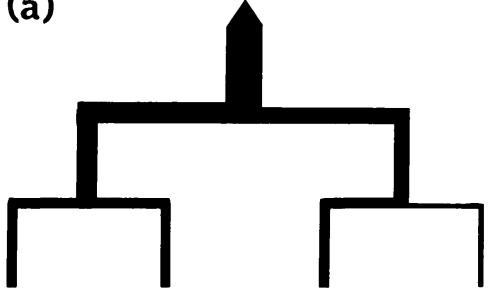

(b)

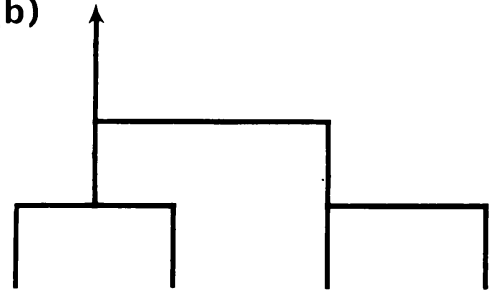

The final point I wish to make at this stage concerns the role of local taxonomies and models of man-environment relations, an understanding of which are a logical prerequisite of the generative analysis of settlement patterns. It has become increasingly clear as Nuaulu exploitation of their environment has been systematically reviewed that they possess an extensive and complex vocabulary relating to the use of critical food resources, and an extensive and ecologically relevant classification of land-forms from various stances - horticultural, topographic and symbolic - with a set of recognized priorities in terms of selection for particular purposes. Decisions in terms of such models also take into their reckoning some account of short-term dynamic variation in the environment, and involve, as has been shown, concepts of future phases of action. While orogonies and secular climatic changes do not concern or affect Nuaulu models of decision-making behaviour (Brookfield with Hart 1971: 57), their resource evaluation and environmental models are based on the acceptance of shorter term linear changes and 
phases of socio-ecological cycles. Taken in conjunction with the overall complexity of the data, this makes it altogether more difficult a task to isolate key variables (as Barth's approach necessitates) without thorough exploration of relevant indigenous models. But an ethnoecological approach, which must involve much more than attention to local systems of classification, is not in itself enough. It must be part of a fully integrated approach.

Geographical techniques and the ethnographic analysis of settlement From one conceptual standpoint - the very isolation of settlement pattern as an object of analysis, as an element of areal differentiation the approach adopted here is essentially geographical (Hartshorne 1959: 12-21). In fact, I would argue that traditional anthropological approaches to settlement must be re-examined and the problems and data reframed, particularly in the light of some recent geographical research on land use in rural communities. It is in this way that settlement patterns can be seen as important cultural phenomena in their own right, that the implications can be far-reaching for an understanding of social and economic organization, and that therefore the operation is well within the terms of reference of traditional descriptive ethnography.

Apart from the general insensitiveness of many anthropologists to the influence of environmental factors, many of whom are poorly informed on matters relating to topography, climate, soils and biota,${ }^{6}$ it is possible to see the contribution of geographical approaches in this sphere as operating in several inter-related fields: (1) the cartographic, (2) the use of quantitative methods as a general research tool, and (3) the use of specific techniques combining areal measurement and quantitative analysis.

The reluctance of anthropologists to accept detailed and reasonably accurate mapping procedures as a normal part of their corpus of field techniques is disappointingly extensive, perhaps largely because of the practical problems which they pose (Wikkramatileke 1959: 79-95 and Appendix $\mathrm{C}$ below). And yet, as recent studies have shown (Conklin 1968: 99-121), the amount of relevant ethnographic data which such techniques result in eliciting can be quite substantial, and the perspective it allows valuable. Nevertheless, cartographic or even aerial photogrammetric techniques do not in themselves adequately delineate settlement patterns or map their composition. External and internal boundaries are often mental and cultural. Unless maps are culturally annotated, distinctions between land cultivated by the Nuaulu them- 
selves and their neighbours and between the various ethno-ecological categories of land use cannot be adequately distinguished. Again the analyst is forced to consider the disparities between indigenous classifications and observed ones.

Anthropologists have been somewhat less reluctant in their acceptance of quantitative data in attempting to understand subsistence economies, not to mention its use in other directions. It is probably true to say though that with few exceptions their use of such methods up until quite recently has been somewhat unsophisticated, both with respect to data-collection and general standards of analysis. This has been such that sceptics such as Groves (1963: 277) have been able to argue that the employment of numerical procedures has frequently led to circumlocution and statement of the ridiculously obvious. I have used numerical data here especially in the treatment of energy intake and expenditure, in relation to distance as a factor in the generation of the settlement pattern and in more general considerations of areal differentiation. While it would be presumptious for anyone engaged in ethnographic research to claim unqualified accuracy in statistical data and erroneous to assume that measurement is a worthwhile pursuit in itself (Lea 1964: 169), I feel confident that its use in the present work is both analytically productive and integrated into the overall argument. While the use of statistics in any generative type analysis of patterns of settlement may be suggestive of particular important economic priorities, man-environment correlations and social values, it can never have any real analytical meaning studied apart from the various decision-making processes (ibid p. 170). Moreover, it is in this context that statistical norms become of interest for the very reason that they diverge from stated ideal situations: that is, they become a measure of the importance of particular generative factors.

In the adoption of more specific techniques developed by geographers, an equal, if not greater degree of caution is required. These may be taken to include those research tools considered so much a part of the conceptual apparatus of modern economic geography: varieties of locational analysis, central place theory and network models, as well as the lower level methodological procedures and methods of data-presentation. ${ }^{7}$ It is focus on the factor of distance which these things have in common, and which, with very few exceptions (Izikowitz 1951: 42-3), has been neglected in the ethnographic analysis of cultivators. The detailed analysis which has been presented here of garden distribution and site-selection illustrates clearly the importance of distance as a 
factor in assessing the significance of the numerous variables at work. At the same time it demonstrates the very failure of simple numerical indices and classical types of cost-benefit analysis, employed by investigators such as Chisholm (1968), to account adequately for culturally determined variables. Exactly what weight is to be attached to cultural content and determinants, has been a problem for geographers (Brookfield 1968: 414). Brookfield and Hart (1971) have even apologised for ignoring cultural content, but have tried to justify this by pleading the necessity to simplify data which might otherwise appear only confusing and meaningless.

One possible way of resolving some of these problems is offered by an overall ecological perspective. This has already led to an increasing cooperation between geographers and anthropologists, representing as it does a convergence of interests in man-environment relations (Brookfield 1968: 413). Geographers themselves have been increasingly adopting an ecological approach (e.g. Stoddart 1965: $242-51$ and 1969: 511-58), and with it a recognition of the utility of the ecosystem in conjunction with recent emphasis placed on micro-studies of rural communities (Brookfield 1962: 242, 1964a). With a parallel interest among some anthropologists in systems-analysis and the conceptual devices of biological ecology (Vayda 1965, 1969; Vayda and Rappaport 1968 ) and the implications of man-environment relations (as illustrated by the work of Leach (1961)), both disciplines find a common analytical and methodological meeting ground (e.g. Clarke 1971 and Waddell 1972).

However, and perhaps predictably, even the ecological context still highlights the distinction between the primary foci of these respective approaches: for the ethnographer the main focus of interest remains still the human behavioural element and social network, while the geographer's main concern has traditionally been with the physical manifestation of that behaviour, the environmental network (Frake 1962a) and the distribution of resource use (but see e.g. Goodey 1971). On the one hand the context is ethnographic, on the other chorographic (Lea 1964: 4-5). It is in the analysis of settlement patterns that these two approaches fuse. The two aspects are, of course, interdependent, and Brookfield is right in emphasising the crucial importance of understanding indigenous models and decision-making behaviour for a geographical description (1968: 413; 1962: 15-16), although his enthusiasm is at times timid. Nevertheless, this dual allocation of analytical responsibilities means that geographical approaches are not focussed on 
the decision-making processes per se. In adopting a generative approach in an overall ecological context, while offering an integrated account and using (where applicable) geographical techniques, the analysis is rooted firmly in the actual processes involved. In doing so I have tried to support the argument that statistical data of this kind cannot be interpreted except in relation to local models. In the absence of a cultural, cognitive approach it is impossible to assess accurately the relative significance of the factors involved in settlement, or to determine with any degree of precision what are the results of positive decisions regarding environmental exploitation, and what are the results of genuine environmental, demographic and cultural stresses (Lea 1964: 170).

\section{Generative approaches to problems of settlement and ecology}

The analysis presented here has been something of a test case, and its degree of success I leave the reader to judge. However, a number of concluding observations seem to be in order.

The generative approach represents a method by which the data may be followed through progressively, developmentally and systematically. In view of this it is appropriate that much of this analysis should deal with aspects of horticultural procedures, since the study of primitive gardening systems, by their very nature, lend themselves to a processual treatment. By this I mean that procedures are tied to a regular sequence of events and cycles which involve ongoing and readily recognizable processes. In this manner, comprehensiveness, together with a recognition of the diversity of factors involved, is theoretically achieved through the sheer mechanics of the operation. ${ }^{8}$ But attainment of this must clearly rest on comprehensiveness in fieldwork and rigorous subsequent analysis. While demanding, it is procedurally extremely straightforward. Paradoxically, while comprehensive the generative approach is logically economical. This rests on the fact that the comprehensiveness is (theoretically, at least) entirely relevant to the subject under discussion. In the present case this refers to the processes which result in the generation of the Nuaulu settlement pattern in its widest sense.

Another, and more fundamentally important, characteristic of a processual treatment is the integrated approach it offers to an understanding of settlement patterns. Within a general ecological context, such that cultural, environmental and biological variables have been treated as parts of a single system, I have been able to bring to bear a wide range of different factors which singly, and in various combinations, affect the resultant pattern. This leads to the necessity of crossing 
analytical boundaries, hesitancy at which has often hindered analysis in the past and engendered the 'logical vacuity' in the explanation of cultural and social phenomena discussed by Gellner. ${ }^{9}$ The particular value of a generative standpoint is just this: that it directs attention to investigable questions about how and to what degree different traits or variables interact.

Finally, as descriptive techniques, the procedures of a generative approach themselves involve analysis, illustrating the dynamics of decision-making and rendering ethnographic description as meaningful as possible. This is attained through concentrating on process and not form. For irrespective of any of the specific difficulties which arise from Barth's generative model, his most important contribution is quite simply his insistence that to explain form it is imperative to discover and describe the processes which generate it. ${ }^{10}$ In so doing, model construction becomes subservient to the aims of empirical sociology, and the observable operations involved hold a significance they might otherwise lack. In this analysis of the Nuaulu settlement pattern, some justification can be found for the type of approach advocated. Certainly I have been able to demonstrate my initial hypothesis: broadly, that settlement patterns have cultural meaning, and narrowly that this meaning can be understood only by seeing the form as a result of a process rather than a collection of elements that can be mapped out, but signify little else. After all, the kind of processual analysis portrayed here is less a novel theoretical approach, than a useful method which, with a certain degree of analogical reasoning in an essentially empirical piece of research, clarifies the process of description and systematically guides interpretation. But given the advantages of such an approach the investigator is in a much stronger position to test predictions concerning the correlation of ecological and cultural data within respectable limits of accuracy. The weakness of many correlative analyses has hitherto been lack of the firm ethnographic foundation which a generative approach provides. 
APPENDIX A

\section{LOCAL CLIMATIC DATA AND NUAULU ECOLOGY}

Data on temperature, relative humidity, cloud cover, wind force and number of rain days recorded during fieldwork in Ruhuwa are presented in TABLE 39. Absence from the Nuaulu area on several occasions resulted in incomplete data for the months of February and October. I have preferred to leave the record blank rather than insert estimates not based on my own measurements. Figures for monthly rainfall recorded at Amahai and Wahai (in the north of the island) over a period of 25 years (Seran 1922) are given in TABLE 40, while FIGURE 13 gives a much more recent and detailed picture for Amahai alone.

Moluccan rainfall varies seasonally and in amount depending on the locations of individual islands in relation to wind-direction. Seram, in particular, shows a striking contrast in the rainfall pattern between north and south coasts owing to relief barriers. While Amahai and Wahai are only 140 kilometres apart they are separated from each other by the central mountain range which reaches 3055 metres at its highest point (MAP 2). This means that the north receives the greater part of the rain from the summer northwest monsoon whereas the south coast gets most of its rain from the winter southeast monsoon. This season commences around May with high tides and galeforce winds, reaching its rainfall peak during July. Landslides, flooded rivers, paths like quagmires and fallen trees all hamper communication and interrupt normal subsistence activities for this part of the year. It ends around September giving way after a short transitional period to the west monsoon, which runs through from December to March, when (after a further transitory period in April) the southeast monsoon returns.

The total average annual rainfall for the Nuaulu area (most of which falls in the late afternoon) is around 2750 millimetres, higher than that for the north coast and firmly within the 2000-3000 millimetre isopleth which includes most coastal areas of the Moluccas (Fisher 1964: 35; see also Schmidt and Ferguson 1952). There is never really a dry season, 
TABLE 39. Meteorological data recorded at Ruhuwa, 1970-1971*

\begin{tabular}{|c|c|c|c|c|c|c|c|}
\hline & \multicolumn{2}{|c|}{ Temperature } & \multicolumn{2}{|c|}{ Relative humidity } & \multirow{2}{*}{$\begin{array}{l}\text { Percentage } \\
\text { cloud cover } \\
(08 .(0) \mathrm{hrs} \text {. }\end{array}$} & \multirow{2}{*}{$\begin{array}{c}\text { Wind } \\
\text { force } \\
08.00 \mathrm{hrs} \text {. }\end{array}$} & \multirow{2}{*}{$\begin{array}{c}\text { Number } \\
\text { of rain } \\
\text { days }\end{array}$} \\
\hline & $\begin{array}{c}08.0() \\
\text { hrs. }\end{array}$ & $\begin{array}{l}18.00 \\
\text { hrs. }\end{array}$ & $\begin{array}{c}08.0() \\
\text { hrs. }\end{array}$ & $\begin{array}{l}18.00 \\
\text { hrs. }\end{array}$ & & & \\
\hline \multicolumn{8}{|l|}{ Feb. } \\
\hline March & 25.3 & 28.2 & 92 & 81 & 90 & 2.8 & 20 \\
\hline April & 25.7 & 25.8 & 88 & 92 & 5() & 2.8 & 21 \\
\hline May & 25.5 & 26.5 & 88 & 92 & 60 & 3.1 & 23 \\
\hline June & 24.2 & 24.6 & 91 & 96 & 78 & 2.3 & 25 \\
\hline July & 23.7 & 24.3 & 91 & 91 & 88 & 2.1 & 25 \\
\hline Aug. & 23.2 & 23.47 & 96 & 96 & 80 & 1.8 & 22 \\
\hline Sept. & 24.46 & 25.4 & 91 & 92 & 74 & 2.2 & 14 \\
\hline \multicolumn{8}{|c|}{ data incomplete } \\
\hline Nov. & 24.7 & 26.7 & 92 & 88 & 73 & 2.1 & 15 \\
\hline Dec. & 24.7 & 26.0 & 92 & 92 & 80 & 2.7 & 14 \\
\hline Jan. & 25.0 & 26.8 & 92 & 84 & 84 & 2.2 & 12 \\
\hline
\end{tabular}

* Temperatures are given in degrees Centigrade and windforce is according to the Beaufort scale. The first six columns represent monthly means.

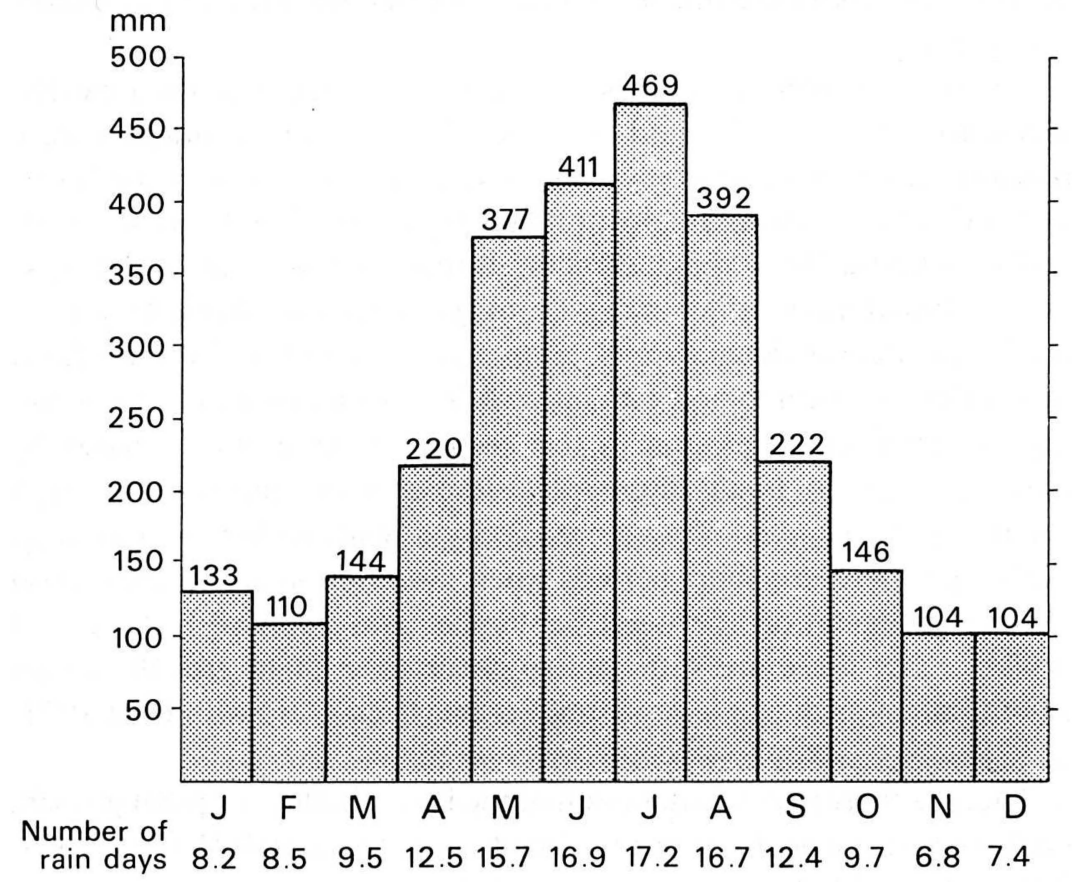

FIGURE 13. Amahai: mean monthly rainfall (in millimetres). Total mean annual rainfall $=2832$. Annual number of rain days $=141.5$. Duration of records: 59 years to present. Source: Huwae 1973, personal communication. 
TABLE 40. Mean monthly rainfall (in millimetres) over 25 years. (Seran 1922)

\begin{tabular}{|c|c|c|c|c|c|c|c|c|c|c|c|}
\hline & Jan. & Feb. & March & April & May & June & July & Aug. & Sept. & Oct. Nov. I & Dec. \\
\hline Wahai & 300 & 445 & 307 & 200 & 142 & 101 & 105 & 79 & 85 & $102 \quad 102$ & 211 \\
\hline Amahai & 112 & 101 & 146 & 198 & 309 & 380 & 456 & 431 & 247 & $152 \quad 110$ & 107 \\
\hline
\end{tabular}

though the Nuaulu regard the period between October and March as such.

In this situation high humidities and extensive cloud cover (quite exceptional in the case of Ruhuwa) are to be expected, resulting in relatively low sunshine levels (Brookfield with Hart 1971: 17) and indirectly affecting plant growth through a lessening of radiation. The range of mean monthly rainfall is, nevertheless, great (100-470 millimetres for Amahai), such that Fitzpatrick, Hart and Brookfield (1966) classify Seram as part of their 'large range - heavy to light, heavy dominant' rainfall regime type. In general, the rainfall situation in south central Seram is a good illustration of local variation related to a complex topography.

Within such regions of high rainfall, such as the Nuaulu area, the incidence of dry spells and periods when the soil contains excess moisture are of special importance as regards plant growth and horticultural activity (Brookfield with Hart 1971: 14-15; Fitzpatrick, Hart and Brookfield 1966). Excess soil moisture commonly leads to leaching and continual wet weather makes burning of gardens difficult. Dry spells tend to check crop development, despite their often short duration. Data on precipitation combined with information on evaporation rates is also an important consideration in this respect. Evaporation is naturally closely linked to temperature, but despite high temperatures, high relative humidity and abundance of cloud leads to low evaporation. Although there are short periods when evaporation and transpiration exceed precipitation (between September and February), it appears unlikely that these are sufficient to check most plant growth in high rainfall areas such as south central Seram (Brookfield with Hart 1971: 18-21).

There is therefore a domination of the basic rhythms of plant growth, ecology and horticulture in the Nuaulu area by rainfall (Dobby 1969: 31 ), but moulded by a multiplicity of other micro-climatic variations caused largely by vegetational and terrain factors (Brookfield with Hart 1971: 44). 


\section{APPENDIX B}

\section{LOCAL MINERALS AND SOILS}

The geology of the coastal area of south central Seram discussed in this monograph is essentially Quaternary, being composed primarily of alluvial deposits containing conglomerates and the characteristic outcrops of coralline limestone ('karang'). The phyllite formations further inland, together with areas of elevated reefs and conglomerates, complete the basic petrographical structure of the Nuaulu exploitative environment, although these latter deposits tend not to encroach on the cultivated areas of the villages (MAP 14; see also Germeraad 1946: 20-2, 34, 105 and map).

The Nuaulu recognize 11 primary mineral categories, (hatu: stone, rock, mineral), all of which have acknowledged properties on which their cultural evaluation is based. The categories nokase (predominantly a soft white porous 'karang' limestone), tapune (sandstones) and the various schists represent the major types as far as distribution is concerned. The others either have a general alluvial distribution (e.g. tinar), occur as beach pebbles (e.g. aki akai), are physically different manifestations of the major types (e.g. maija) or occur as veins in such formations (e.g. putie). In Nuaulu terms, however, each represents a distinct category on a level with other categories. Geological determinations and basic characteristics of Nuaulu rock categories are set out in TABLE 41.

Nuaulu formal classification of soils is minimal, consisting only of two categories (mane and makai), though a more precise description may be obtained with reference to acknowledged parent material and colour (e.g. tapu msinai, tuamai metene).

Of the soil samples collected in the field only five proved subsequently suitable for laboratory analysis. The results, based on an examination carried out under the supervision of Dr. D. Brunsden are shown in TABLE 42. Numbers 6 and 7 comprise $\mathrm{pH}$ readings undertaken in the 
TABLE 41. Nuaulu mineral categories

\begin{tabular}{|c|c|c|c|}
\hline & Gloss & Content & Notes \\
\hline 1. nokase & - & $\begin{array}{l}\text { Neogene soft white } \\
\text { porous coralline lime- } \\
\text { stone; 'rock-like' } \\
\text { corals - Stylophoro, } \\
\text { Goniastraea, Leptoria }\end{array}$ & $\begin{array}{l}\text { Several sub-varieties } \\
\text { ai ukuna: forest, inland } \\
\text { forms } \\
\text { marai: 'blue-green', } \\
\text { lichenous } \\
\text { nau nuai: offshore }\end{array}$ \\
\hline 2. ina inate & mother & $\begin{array}{l}\text { Weathered muscovite } \\
\text { schists (usually } \\
\text { ironstained) }\end{array}$ & - \\
\hline 3. lalima & - & Unidentified & - \\
\hline 4. maija & $\begin{array}{l}\text { As maija, the flat } \\
\text { cake consumed on } \\
\text { major ceremonial } \\
\text { occasions - pro- } \\
\text { duced by baking a } \\
\text { mixture of sago } \\
\text { flour and ground } \\
\text { Canarium nuts } \\
\text { between hot } \\
\text { stones. }\end{array}$ & $\begin{array}{l}\text { Heavily weathered } \\
\text { schists, friable, } \\
\text { splitting lengthwise } \\
\text { into lamina }\end{array}$ & $\begin{array}{l}\text { Considered useless for } \\
\text { toolmaking, but used as } \\
\text { ovenstones in the cooking } \\
\text { of maija }\end{array}$ \\
\hline 5. makai & hard & $\begin{array}{l}\text { Course-grained } \\
\text { basic rocks }\end{array}$ & - \\
\hline 6. metene & black & $\begin{array}{l}\text { A general term for } \\
\text { pebbles and outcrops } \\
\text { of mainly fine-grained } \\
\text { biotite schists }\end{array}$ & $\begin{array}{l}\text { Most suitable for making } \\
\text { of percussion tools, such as } \\
\text { barkcloth beaters }\end{array}$ \\
\hline 7. putie & white & $\begin{array}{l}\text { Quartzite pebbles, } \\
\text { vein quartz etc. }\end{array}$ & $\begin{array}{l}\text { Better formed stones are } \\
\text { kept as valuables }\end{array}$ \\
\hline 8. tapune & - & $\begin{array}{l}\text { Quartzose sandstone } \\
\text { (usually ironstained) }\end{array}$ & $\begin{array}{l}\text { The ironstained form (tapu } \\
\text { msinai) occurs particularly in } \\
\text { the Wakakau, Upa and } \\
\text { Samna'ukuna valleys, where } \\
\text { it gives a red colour to the } \\
\text { earth }\end{array}$ \\
\hline 9. tinar & thunder & $\begin{array}{l}\text { Easily fracturing } \\
\text { siliceous rocks: } \\
\text { flint, chert }\end{array}$ & $\begin{array}{l}\text { Believed to fall from the } \\
\text { skies during thunderstorms, } \\
\text { some are so large they are } \\
\text { believed to have killed men. } \\
\text { Large outcrops in the interior } \\
\text { have sacred properties. } \\
\text { Termed kinonote they are } \\
\text { used as fire-flints. } \\
\text { Formerly probably used for } \\
\text { toolmaking }\end{array}$ \\
\hline 10. itone & - & Unidentified & - \\
\hline 11. aki akai & - & Light porous lava & Used as pumice stone \\
\hline
\end{tabular}




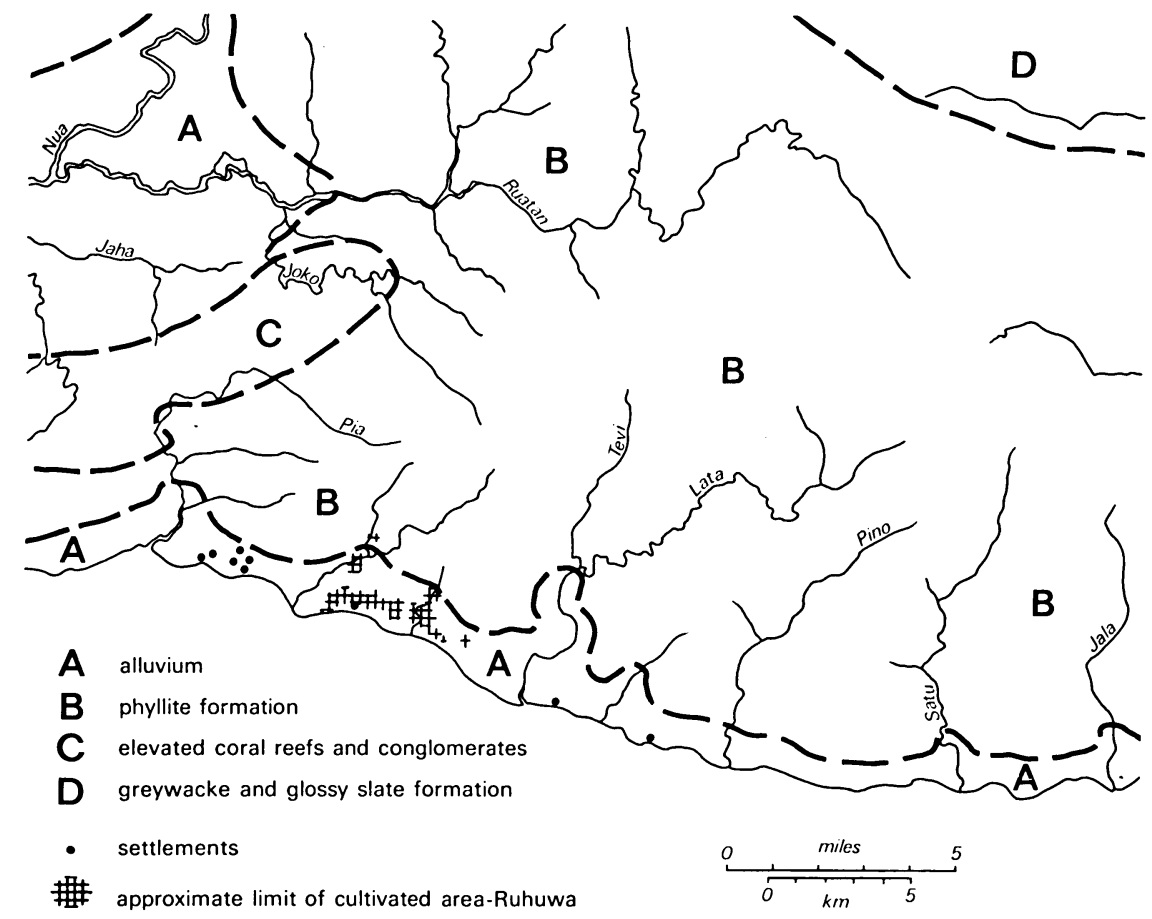

MAP 14. Basic geological composition of the Ruhuwa Nuaulu exploitative environment (based on Germeraad 1946).

field for sample types not represented in the laboratory series. All come from the A horizon $(1-10 \mathrm{cms})$.

By comparison with soil analyses undertaken in conjunction with fieldwork among other Southeast Asian swidden agriculturalists (e.g. Conklin 1957: 24-6; Rappaport 1968: 244-6), $\mathrm{pH}$ is low to medium, which is associated with the generally high organic content of the soil samples. This is to be expected with samples taken from the surface litter and uppermost horizon. In the terms of Greenland and Nye (1961:478), Nuaulu soils can therefore be regarded as horticulturally fertile. This is generally supported by the chemical analysis, though, as the same authors have recognized (Nye and Greenland 1960: 98), this is a limited index of actual fertility. In the circumstances, however, plant tissue and fertilizer response tests were impossible.

From photographic records of soil profiles it is clear that below the A horizon level organic matter rapidly decreases, while mineral salts would 
TABLE 42. Chemical analysis of Nuaulu soil samples

\begin{tabular}{|c|c|c|c|c|c|c|c|c|c|}
\hline $\begin{array}{l}\text { Lab Vegetative } \\
\text { no. cover }\end{array}$ & $\begin{array}{l}\text { Sample } \\
\text { description }\end{array}$ & $\begin{array}{l}\text { Organic } \\
\text { percent- }\end{array}$ & $\mathrm{pH}$ & $\begin{array}{l}\text { Total } \\
\mathrm{Fe}\end{array}$ & & & $\begin{array}{l}\text { ts per } \\
\text { llion }\end{array}$ & & $\begin{array}{l}\text { Total } \\
\text { nitro- }\end{array}$ \\
\hline & & & & & $\mathrm{Mg}$ & $\mathrm{Na}+$ & $k+$ & $\mathrm{Ca}++$ & \\
\hline 1. nisi ahue & $\begin{array}{l}\text { surface sample, } \\
\text { old groveland } \\
\text { adjacent village } \\
\text { (W148); fine gravel* }\end{array}$ & 5.2 & 5.5 & 316 & 9 & 1 & 16 & 25 & 5 \\
\hline 2. nisi monai & $\begin{array}{l}\text { surface sample, } \\
30 \text { metres above bed } \\
\text { of river Joko (W162); } \\
\text { undifferentiated third } \\
\text { year garden; sandy } \\
\text { gravel }\end{array}$ & 3.1 & 5.6 & 141 & 17 & 6 & 14 & 145 & 8 \\
\hline 3. nisi monai & $\begin{array}{l}\text { surface sample, } \\
\text { highest point of } \\
\text { garden on river } \\
\text { Kamna' ukuna } \\
\text { (W145); second } \\
\text { year; gravelly loam }\end{array}$ & 5.2 & 5.0 & 266 & 9 & 1 & 8 & 65 & 2 \\
\hline 4. nisi honwe & $\begin{array}{l}\text { surface sample, } \\
\text { newly cleared } \\
\text { primary forest on } \\
\text { river Usa (W7); } \\
\text { gravelly loam }\end{array}$ & 49.3 & 6.5 & 269 & 26 & 6 & 30 & 424 & 5 \\
\hline 5. nisi honwe & $\begin{array}{l}\text { surface sample, } \\
\text { newly planted garden } \\
\text { on river Wakakau } \\
\text { (W13); gravelly loam }\end{array}$ & 5.2 & 4.3 & 219 & 9 & 1 & 10 & 11 & 1 \\
\hline 6. nisi honwe & $\begin{array}{l}\text { surface sample, } \\
\text { including light ash } \\
\text { newly fired garden on } \\
\text { river Mon (W54); }\end{array}$ & - & $\begin{array}{l}6.5 \\
7.0\end{array}$ & - & - & - & - & - & - \\
\hline 7. niane. & $\begin{array}{l}\text { sandy surface } \\
\text { soil from village } \\
\text { area (Ruhuwa); }\end{array}$ & - & 5.5 & - & - & - & - & - & - \\
\hline
\end{tabular}

* Physical description of the soil is based on the mechanical sieve analysis of particle size.

be expected to increase through leaching. In general, the samples illustrate the classic picture of initially rich soils in recently cleared gardens (sample 4) leading to gradual depletion during the subsequent phases of the cultivation cycle (samples 5, 2 and 3), with improvement during fallow or regeneration to mature forest. Groveland appears to allow for. 
improvement related to its 'semi-fallow' nature (sample 1). The samples provide no evidence of any appreciable differences between the soils of valley side and bottom.

In terms of the variation of soil quality from location to location, there is a quite definite correlation with parent rock material recognized by the Nuaulu. In physical terms, soils associated with nokase limestone are not easy to cultivate, owing to their stoniness and abrasive nature of the rocks, while tapune sandstones and the schists provide a soil that is easily worked. However, chemically nokase soils tend to be superior on account of their high lime content (sample 4). With these exceptions, significant soil variation in localized Nuaulu terms is slight, though on a wider scale it has been shown that different types of tropical forest induce minor differences in their underlying soils (Dobby 1969: 82). These, of course, can assume major significance when the forest is cleared for cultivation, since the balance between soil and vegetative cover is upset and soluble salts are easily washed away. In short, clearance always means the intensity of outflow of nutrients, regardless of those lost by intensive horticulture. 


\section{A NOTE ON DATA COLLECTION RELATING TO LAND HOLDINGS}

In the absence of suitable aerial photography, a base map for plotting land holdings and local terrain features in the Ruhuwa area was obtained by enlarging to a scale of $1: 2,500$ sheet VIII of the $19221.100,0$ map of Seram (Topographische Inrichting, Batavia[13 sheets]), the most recent, accurate and detailed one available. This was then sectioned into work sheets of 30 by 42 centimetres each. Again, due to the unavailability of aerial photographic data, corrections of scale for local topography and water-course systems proved somewhat time-consuming, laborious and difficult, but were accomplished within reasonable limits of accuracy through simple standard surveying procedures - plane-tabling, traversing, triangulation and height-measurement with a clinometer (but see Wikkramatileke 1959: 84-5). Individual holdings were located over a period of time during normal ethnographic enquiries and entered on the work sheets. Details of wasi and garden dimensions (from which areas were subsequently computed) were collected separately in consultation with informants over a period of about one year, care being taken to file individual garden histories for the entire duration of fieldwork. Such details of dimensions, ownership, tenurial and agricultural successions were entered on prepared cards and in the main body of fieldnotes, the maps providing simply a record of their spatial distribution. On completion of fieldwork work sheets were corrected with reference to cardindex and fieldnote data and reduced by plan-variagraphic and photographic techniques to give the master MAP 9.

The problems encountered in the calculation of wasi and actual garden size should not be underestimated. In many cases the existence of easily distinguishable natural and cultural boundaries (such as paths, ridges and stream beds) considerably eased the task, but uneven terrain, difficulties in accessibility, the general absence of abrupt cultivationwild borders and uncertain knowledge of informants hampered accurate measurement. A linen tape, chain and pacing were used for this purpose, in conjunction with a prismatic compass. During the processing of the 
data correlation coefficients were obtained for the key variables in TABLES 17, 18, 20, 24, 25, 26, 27 and 38. A high correlation was found between the number of wasi in a particular category and the total area in that category $(r=0.97)$, such that the former could be confidently assumed a reasonable proxy for the latter. It is improbable, therefore, that minor errors remaining at this stage in any marked way affect the general computations and distribution with which this monograph is concerned. 


\section{APPENDIX D \\ MEASUREMENT OF CONSUMPTION AND ENERGY EXPENDITURE}

\section{Food consumption}

For almost sixteen months during the course of fieldwork, a qualitative record was kept for dietary intake in Ruhuwa, though at any one time only a small proportion of the actual population was involved. This partial record over a long time-span serves as a useful indicator of seasonal variation and periods of exceptional consumption.

For the quantitative measurements used in this study the consumption of two Ruhuwa households (numbers 4 and 14 on MAP 6), each representing a single hearth with seven and thirteen persons respectively, were intensively recorded over the equivalent of a four month period between March and December 1970. Because of the small size of the sample community these households were not chosen at random, but carefully selected in terms of their representativeness of the general pattern in the village.

Types of food were recorded in full, but (except where this became obviously necessary) were not weighed on every occasion, estimations being of almost equal value after some experience. All collected information referred to the edible portion, obviating the necessity to estimate a primary waste factor. Measurement of consumption in this way proved easier, and certainly a great deal more accurate, among the Nuaulu (whose eating habits are comparatively regular) than either measurement of gross yields or raw food. In the case of sago porridge, where the weight of the prepared food is considerably greater than the raw flour on account of the addition of water, a standard factor was devised to calculate the amount of raw flour from the prepared porridge. Water taken up by other foods during cooking is much less, and has been ignored in this study. Also, there is no need for me to stress here the problems associated with deriving estimates of the nutrient content of cooked foods using values calculated for the raw products. In any rigorous nutritional survey some allowance would, of course, have to be made for this; here no such allowance has been made. 
There are two main meals in the Nuaulu day, in the morning prior to the major work activity and again in the evening. Snacks were not included in the computations, and had they been the contribution of bananas, plantains, coconut and other fruits would have been somewhat higher. In addition, sugar-cane would have had to be introduced into the computations. This is eaten solely as a snack while working in the gardens.

As might be expected, not all the sample were present on every occasion food was consumed and from time to time outsiders were also fed. Further, consumption varied between individual members of the household according to sex and age. However, to have calculated the actual intake of individual consumers would have been tedious and quite impracticable. Consequently, since the principal aim of this piece of research is broadly ecological and not nutritional, it was proposed simply to assume that all individuals over 15 years of age (FIGURE 14) constituted adult consumers (or one unit of consumption) and children below this age half-consumers. Unweaned children were not considered as consumers at all. The average 'adult' daily intake is therefore calculated from the equation

$$
\frac{E}{\left(n+0.5 n^{\prime}\right),}
$$

where $E$ is the total daily intake for the sample, $n$ is the number of full consumers and $\mathrm{n}^{\prime}$ the number of half-consumers.

On the basis of this procedure the mean gram weight of different foods consumed per head over a four month period (for both households) can be readily calculated. This method gives reasonable working values, but admittedly could possibly be improved by employing ratios for different sex and age categories such as those suggested by Langley (1947: 134) and utilized by Rappaport (1968: 282-3). For example, FIGURE 14 illustrates the fact that over half of the total population for Ruhuwa are below 15 years of age, and that it is this very category which is subject to the greatest inter-individual variation of consumption. Nevertheless, such age-related computations have the disadvantages of being both time-consuming and almost equally beset with problematic assumptions and other complications.

Given the values obtained in the way suggested for a four month period, the conversion to the mean amount consumed by the same number of adult units in a single day is easily obtained (see, for example, TABLE 12), while average intake per person can be calculated simply by dividing the total amount consumed daily by the total numbers of real 
consumers (see above equation). The latter index (while used widely see below p. 254 note 6) is unsatisfactory on account of the wide divergence of individual intakes, and variation from household to household. It was felt that to determine values for average adult consumers was a more accurate and meaningful index within the context of this particular work and the problems with which it is concerned. The usefulness, as Rappaport has indicated (1968: 283), of such figures is limited to the purposes of comparison, and for proper evaluation within the framework of an individual analysis more specific values are desirable.

From food weight intake the consumption of total calories, protein and fat was calculated using food composition tables. The values presented here (TABLE 43) are derived from tables compiled by Platt (1962). IN an earlier version of this analysis (Ellen 1973) values were obtained from the older literature (e.g. Chatfield 1949). Recompilation has resulted in the change of some of the mean weights for various nutrients, such that (for example) the total adult calorific intake has increased by about 200 Cals. The revised figures, in fact, increase the significance I have attached to the critical ratios discussed.

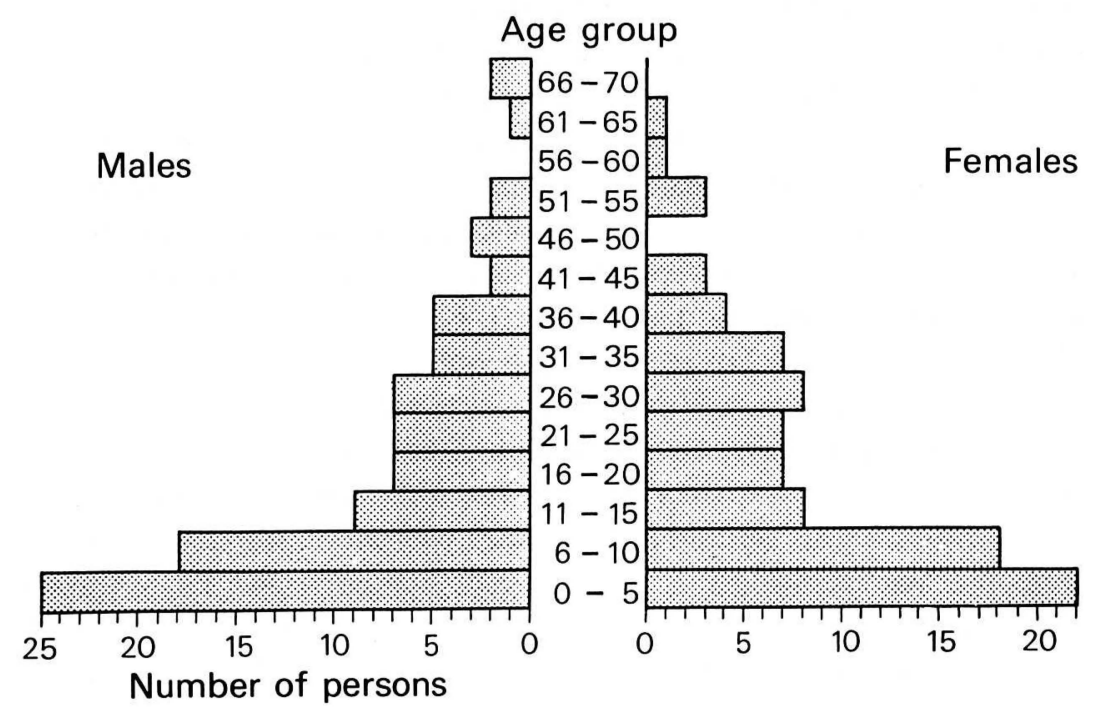

FIGURE 14. Age and sex structure of Ruhuwa population, January 1971. The total number of individuals is 180 ( 93 males and 87 females). 
TABLE 43. Composition of principal foodstuffs per 100 grams, calculated from the raw weight of edible portions

\begin{tabular}{|c|c|c|c|c|}
\hline Item & Cals. & $\begin{array}{l}\text { Protein } \\
\text { (g) }\end{array}$ & $\begin{array}{l}\text { Fat } \\
(\mathrm{g})\end{array}$ & Notes \\
\hline Amaranthus & 48 & 5.0 & 0.7 & Treated as high carotene leaves \\
\hline aubergine & 22 & 1.0 & $\varnothing$ & \\
\hline bamboo shoots & 35 & 2.3 & 0.2 & \\
\hline bananas and plantains & 122 & 1.0 & 0.25 & $\begin{array}{l}\text { Mean for both Musa sapientum and } \\
\text { M. paradisiaca }\end{array}$ \\
\hline bat & 134 & 20.0 & 6.0 & Treated as rabbit \\
\hline breadfruit pulp & 113 & 1.5 & 0.4 & \\
\hline Canarium nuts & 657 & 20.0 & 59.0 & Treated as almond nuts \\
\hline cassowary & 139 & 19.0 & 7.0 & Treated as unspecified poultry \\
\hline civet & 134 & 20.0 & 6.0 & Treated as rabbit \\
\hline coconut & 375 & 4.0 & 35.0 & Treated as fresh mature kernal \\
\hline Colocasia & 113 & 2.0 & $\varnothing$ & \\
\hline leaves & 28 & 2.0 & 0.3 & Treated as medium carotene leaves \\
\hline crab meat & 94 & 18.0 & 1.5 & Treated as unspecified crustacean \\
\hline cuscus & 134 & 20.0 & 6.0 & Treated as rabbit \\
\hline deer & 202 & 19.0 & 14.0 & Treated as lean beef \\
\hline Dioscorea & 104 & 2.0) & 0.2 & \\
\hline Eugenia fruits & 56 & 0.6 & $\varnothing$ & Treated as E. jambos \\
\hline fern leaves & 28 & 2.0 & 0.3 & Treated as medium carotene leaves \\
\hline fish & 132 & 18.8 & 5.7 & Treated as unspecified fish \\
\hline Gnetum gnemon & 63 & 0.8 & 1.1 & Treated as unspecified tropical fruit \\
\hline hornbill & 14.3 & 22.4 & 5.2 & Treated as unspecified bird \\
\hline manioc (cassava) & 153 & 0.7 & 0.2 & \\
\hline leaves & 28 & 2.0 & 0.3 & Treated as medium carotene leaves \\
\hline pandanus & 78 & 0.4 & 0.3 & \\
\hline papaya & 39 & 0.6 & $\varnothing$ & \\
\hline leaves & 28 & 2.0 & 0.3 & Treated as medium carotene leaves \\
\hline pork & 453 & 12.0 & 45.0 & $\begin{array}{l}\text { Mean for both fat and lean } \\
\text { whole carcase }\end{array}$ \\
\hline prawns & 94 & 18.0 & 1.5 & Treated as unspecified crustacean \\
\hline rice & 352 & 7.0 & 0.5 & Treated as milled white rice \\
\hline rorong & 28 & 2.0 & 0.3 & Treated as medium carotene leaves \\
\hline sago & 352 & 0.5 & $\varnothing$ & \\
\hline shellfish & 70) & 10.0 & 2.0 & Treated as unspecified molloscs \\
\hline snake (python) & 132 & 18.8 & 5.7 & Treated as fish \\
\hline $\begin{array}{l}\text { squashes, gourds, } \\
\text { pumpkin and marrow }\end{array}$ & 36 & 1.0 & $\varnothing$ & Treated as unspecified Cucurbita \\
\hline sweet potato & 114 & 1.5 & 0.3 & 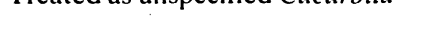 \\
\hline tomato & 20 & 1.0 & $\varnothing$ & \\
\hline Xanthosoma & 133 & 2.0 & 0.3 & \\
\hline
\end{tabular}




\section{Work time and energy expenditure}

A similar approach to that used in obtaining basic data on consumption was adopted in the field to estimate work time and energy expenditure for various activities (Weiner and Lourie 1969: 265-81). For a period spread over eight months between March and October 1970 data on the work schedules of males were systematically collected, including:

(1) a representative record of the work pattern of selected individuals over long periods, through a combination of regular sub-daily interviewing and direct observation by the investigator, and

(2) checks (on a more or less random basis) from time to time on the overall work pattern of a large number of individuals.

While it may be admitted that this approach (albeit demanding) has something to be desired in research design, a more rigorous approach would have been quite incompatible with the undertaking of other work. It also has the very important merit of throwing into relief significant intra-individual and seasonal variation in work patterns, which intensive nutritional studies over short periods have not always allowed for (ibid p. 267).

During the period 1969-71 systematic information on work patterns was gathered for mature males only. Comparable data for female labour proved difficult to obtain, not only because the investigator was male, but also because female Nuaulu labour tends to consist of a greater number of different minor activities, while in the subsistence field their contribution tends to be irregular and for short periods. It is difficult to say to what extent the inclusion of data on female activities would affect the critical ratios discussed in Chapters IV and VII. The principal subsistence activities in which females engage are collecting shellfish, crustacea, gathering certain wild food products and (of great importance) firewood, and a variety of support activities in connection with gardening and cash-cropping. It would seem that female involvement in the domesticated and non-domesticated sectors is about equal, suggesting that this additional data would not make a lot of difference to the ratios given. However, compared with the activities of males, a much larger proportion of female time is taken up with activities other than those considered here, such as food preparation, child minding and other village activities.

On the basis of samples for 15 effective males, over a total of 1,538 man-days, ${ }^{1}$ the number devoted to 14 distinctive activities were determined. Seven of these are most relevant to an understanding of the exploitation for food in the various components of the Nuaulu environ- 
TABLE H. Number of man-days devoted to various activities by mature males

\begin{tabular}{lr}
\hline & $\begin{array}{c}\text { Number of } \\
\text { man-days } \\
\text { in sample }\end{array}$ \\
\hline A. subsistence activities: & \\
1. fishing & 18 \\
2. hunting and trapping & 215 \\
3. the extraction of wild sago & 166 \\
4. various secondary gathering activities & 125 \\
5. activities connected with cash-cropping & 27 \\
6. gardening & 240 \\
7. the extraction of domesticated sago & 154 \\
& \\
B. non-subsistence activities: & 227 \\
8. communal labour & 12 \\
9. housebuilding (other than that & 162 \\
$\quad$ classified under 8) & 9 \\
10. visiting., travel & 22 \\
11. meetings, disputes & 38 \\
12. miscellaneous village tasks & 123 \\
13. ritual & 1,538 \\
14. sickness, other recreation activities & \\
\hline
\end{tabular}

ment (TABLE 44). These activities occupied some 945 man-days, the remainder being devoted to tasks such as housebuilding and ritual. The figures obtained in this manner were then simply converted into values for the percentage time devoted to each activity during the test period.

Actual rates of energy expenditure for different kinds of activity were obtained by consulting the tables compiled by Hipsley and Kirk (1965: 43), Durnin and Passmore (1967) and Norgan, Ferro-Luzzi and Durnin (1974), in conjunction with field data on body weights. The mean weight of Ruhuwa adult males was calculated at 52.04 kilograms (range: 37.58 62.26 kilograms) for a total population of 43 individuals, that is approximately 18 units of metabolic size. However, in certain cases, since the rates computed by these other workers were not for strictly comparable activities, the resulting rates have in some instances been marginally corrected by intensive time and motion studies in the field for specific activities. The method employed is discussed by Weiner and Lourie (1969: 270, 279) and Durnin and Passmore (1967: 24-9). Data of this description, which include such coded information as periods of rest and expenditure for each stage of the activity and its physical nature, are not explored further here. It is to be admitted that in places the assessment of metabolic cost for a particular activity is inaccurate, but this is less likely 
to be a source of substantial error than the estimation of time, where the field data collected are much more reliable. While it is important not to underestimate the difficulties of making even the most approximate estimations of energy expenditure on the basis of such time and motion data, I have felt the task to be a worthwhile one, if only to avoid some of the problems of using undifferentiated time as an index of input and measure of ecological interaction. Methods must be determined ultimately by the purpose of the study, and therefore any inadequacies must in the last instance be seen in the context of the appropriateness of a more physiologically exacting approach. On the whole, the rates given probably underestimate energy expenditure for a particular activity.

Given the time devoted to each activity and the approximate rate of energy expenditure (in Cals. per minute) it was possible to arrive at a general figure for the total energy expenditure for the activities during the test period, and then convert them to percentages (TABLES 15, 34 and 35). In the ratios used an attempt has been made to allow for the actual activity, rest periods and walking. The latter occupies a significant proportion of the Nuaulu day: about $10 \%$ of the 24 hours. It can be reasonably assumed that the rate of energy expenditure for walking to and from any location for any exploitative purpose is around 4.50 Cals. per minute (Hipsley and Kirk 1965: table 14). For fishing, hunting and trapping and various secondary gathering activities, the amount of energy expended in walking proportional to that expended in actually undertaking the activity is minimal (less than 5 per cent); for copra production it is low to minimal, much of the active work taking place within the village or during extended stays at garden huts; in gardening and in the extraction of cultivated sago, although the time taken in travel may amount to over 10 per cent of the total, the rate of energy expenditure for walking is equal to the average rate for these actual activities combined. Where my figures are more open to error is in relation to the extraction of wild sago, where travel between the village and locality of work may take up to six hours, sometimes 50 per cent of the total time devoted to the activity. In view of the possibility of error on this score I have also included figures for the actual number of man-days involved. 


\section{ORTHOGRAPHY AND GLOSSARY}

For convenience, a simple broad phonemic orthography without any indication of stress has been adopted, based on the symbols of the International Phonetic Association. A provisional analysis of the Nuaulu sound system (which I have used here as a working guide) suggests five vowels ( $i, e, a, o, u)$, four dipthongs (ai, oi, au, eu), two half-consonants ( $\mathrm{j}, \mathrm{w})$ and 15 consonants $(\mathrm{p}, \mathrm{b}, \mathrm{t}, \mathrm{d}, \mathrm{k}, \mathrm{m}, \mathrm{n}, \mathrm{l}, \mathrm{h}, \mathrm{g}, \mathrm{r}$, $s, \mathrm{n}, \mathrm{t}, \mathrm{d})$. In handling linguistic data, I have generally followed Pike's guide to orthographical procedures (1963: 208-31); further information on the structure of Seramese language is to be found in Stresemann (1927). Indonesian words and names are written unitalicized in the revised standard orthography adopted in 1972. Consequently, certain alterations have been made in the spelling of some place names appearing on old Dutch maps.

Below are listed the most common Nuaulu terms used in the text, although those formal categories dealt with in the appendices have been omitted. More detailed explanations are usually given at the point in the text where they first occur.

$\begin{array}{ll}\text { ahue } & \begin{array}{l}\text { secondary growth forest, vegetation covering } \\ \text { abandoned garden } \\ \text { ai }\end{array} \\ \text { trees and woody shrubs, excluding palms } \\ \text { ainatai } \\ \text { airui wasi } & \begin{array}{l}\text { to make a gift of land } \\ \text { ai jana wasi }\end{array} \\ \text { ai jonata } & \begin{array}{l}\text { 'trees of the garden', secondary forest trees on } \\ \text { owned land }\end{array} \\ \text { arena } & \text { 'great trees', the trees of mature forest } \\ \text { barisi } & \text { minor forest and garden paths } \\ & \text { major inter-village and coastal paths }\end{array}$


bosune

bosune nisi

hanakane

hatu nohuwe

heute

hunisone

hunoni tau mansia

ihute

ipan

jai nisi pina

jonate

jonate aia

jonate ipan

jonate Matoke

kakarane

kapitane

kona upua

lante

lowe menstruation hut

temporary menstruation shelter in garden

temporary scaffolding erected around the base of large trees to make felling easier

cavernous rock outcrop, cave

covered timber store for ritual houses

central and most spacious part of house interior 'paying with a person', incorporation of first child of a union into the clan of the wife

wind

clan, patrilineal descent group

marriage by entering into the bride's household; literally, 'to eat the gardens of women'

chief, elder

village headman

clan chief

chief of the clan Matoke; ritual guardian of all land and the sacred suane ritual house; 'Lord of the Land'

elevated platform along interior walls of house or suane

formerly clan war leader; his ritual duties complement those of the clan chief

payment (typically consisting of sago-flour, betel, betel-chewing requisities, Agathis alba resin and cuscus meat) made by the clan of the groom to that of the bride immediately prior to marriage

split bamboo flooring

meeting of adult males 


\begin{tabular}{|c|c|}
\hline matahene & male initiation festival \\
\hline mitanunwe & door; walls along the mountain-sea axis \\
\hline mone & sacred; forbidden \\
\hline monote & weeds \\
\hline nasai nisi & $\begin{array}{l}\text { a small feast held in the garden following } \\
\text { the first fruit ceremony }\end{array}$ \\
\hline nemakai & $\begin{array}{l}\text { mother's brother's daugther - father's sister's } \\
\text { son relationship; preferred marital union }\end{array}$ \\
\hline nenene & boundaries of a wasi \\
\hline nesaneu & $\begin{array}{l}\text { payment made at marriage by the clan of the } \\
\text { sister's husband to that of the groom }\end{array}$ \\
\hline nia monai & the old village \\
\hline niane & village \\
\hline nisi & a cultivated garden plot \\
\hline nisi ahue & $\begin{array}{l}\text { discarded garden covered with secondary } \\
\text { growth }\end{array}$ \\
\hline nisi hatane & sago grove \\
\hline nisi honwe & first year garden \\
\hline nisi kupanahane & clove grove \\
\hline niși monai & old garden \\
\hline nisi niane & village-owned garden \\
\hline nisi nione & coconut grove \\
\hline nisi nione kanai & coconut-betel-palm grove \\
\hline numa & household \\
\hline numa ainatai & small garden shelter \\
\hline numa mone & $\begin{array}{l}\text { clan ritual house: the repository of valuables } \\
\text { and location of ancestral spirits; typically the } \\
\text { house of a clan chief or kapitane }\end{array}$ \\
\hline numa nisi & garden house or hut \\
\hline
\end{tabular}




\begin{tabular}{|c|c|}
\hline numa onate & the numa mone of a clan chief \\
\hline numa tepine & bivouac, or roughly constructed shelter \\
\hline numa wanane & $\begin{array}{l}\text { huts built as halting places for long-distance } \\
\text { treks }\end{array}$ \\
\hline pakelo & bamboo openwork fences \\
\hline pantetane & outside sitting platform of house \\
\hline Patalima & 'Five Division' of Seramese tribes \\
\hline Patasiwa & 'Nine Division' of Seramese tribes \\
\hline pela & blood-brotherhood pacts between villages \\
\hline peni & $\begin{array}{l}\text { category of game animals, composed of pig, } \\
\text { deer and cassowary }\end{array}$ \\
\hline pokuwe & garden rite performed prior to clearing new land \\
\hline pupue & $\begin{array}{l}\text { ridgeland, crests, the higher reaches of valley } \\
\text { walls }\end{array}$ \\
\hline rahue & herbs and shrubby plants \\
\hline rini & shelf or loft in house roof-space \\
\hline rumanai pina & marriage by elopement \\
\hline sanene & valley sides \\
\hline santehune & bamboo water conduit \\
\hline sasi & $\begin{array}{l}\text { prohibition on the harvesting of specified } \\
\text { domesticated and non-domesticated resources }\end{array}$ \\
\hline sasi tuamai & $\begin{array}{l}\text { ritual prohibition on using land for a prescribed } \\
\text { period }\end{array}$ \\
\hline sasau & $\begin{array}{l}\text { payment made at marriage by the clan of the } \\
\text { bride to that of the groom }\end{array}$ \\
\hline seute & first fruits ceremony \\
\hline sine & walls along the east-west axis \\
\hline sioroiki wasi & to make a gift of land to a specified person \\
\hline so mai inai & marriage by negotiation, by proposal \\
\hline
\end{tabular}


sowe

suane

tinete, pupue tinete

tinete reroke

tone

tuamai mone

tuamanai

tuaman tiai

wane

wasi

watane

wesia upua

wesi huje

wesi, wesie a ritual wasi, formerly associated with headhunting ritual

village ritual house

mountains, peaks

exceptionally steep land

garden fence

sacred ground

land, earth, terrain (in opposition to sky)

dance ground

lianas and trailers

land in which rights are held; a social unit of land

flat areas, the coastal margins, valley floors

'the honoured of the forest', ancestral spirits of garden land

'empty forest', unowned mature forest

general term for forest over which no direct land rights are exercised 


\section{LIST OF WORKS CITED}

ADMIRALTY 1944. Netherlands East Indies 1. Naval Intelligence.

ALlAN, W. 1949. Studies in African land use in Northern Rhodesia. (Rhodes Livingstone Papers 15). London: Oxford University Press.

ALTSCHULER, M. 1968. Review of Harris (1968). Curr. Anthrop. 2, 521.

ANDERSON, E.N. 1969. Sacred fish. Man (N.S.) 4, 443-449.

ANDRZEJEWSKI, Stanislaw 1954.' Military organization and society. London: Routledge.

BARRAU, J. 1958. Subsistence agriculture in Melanesia (Bernice P. Bishop Museum Bulletin 219). Honolulu: Bernice P. Bishop Museum.

BARRAU, J. 1959. The sago palms and other food plants of marsh dwellers in the south Pacific Islands. Economic botany 13, 151-162.

BARRAU, J. n.d. An ethnobotanical guide for anthropological research in MalayoOceania (Preliminary Draft). Djakarta: UNESCO science cooperation office for southeast Asia.

BARTH, Fredrik 1956. Ecologic relationships of ethnic groups in Swat, North Pakistan. Am.Anthrop. 58, 1079-89. Reprinted 1969 in Environment and cultural behaviour: ecological studies in cultural anthropology (ed.) Andrew P. Vayda. New York: The Natural History Press.

BARTH, Fredrik 1964. Competition and symbiosis in north-east Baluchistan. Folk, 6, 15-22.

BARTH, Fredrik 1966. Models of social organization (Occ. Pap. R. Anthrop. Inst. 23). London: Royal Anthropological Institute.

BARTH, Fredrik 1969 'Introduction'. In Ethnic groups and boundaries (ed.) Fredrik Barth. London: George Allen and Unwin.

BASTIAN, A. 1884. Die Molukken. In Indonesien oder die Inseln des Malayischen Archipels (1884-94), 5 Vols.

BATES, Marston 1960. 'Ecology and evolution'. In Evolution after Darwin 1 (ed) Sol Tax. Chicago: University of Chicago Press.

BIEBUYCK, D. 1963. 'Introduction'. In African agrarian systems (ed.) D. Biebuyck. London: International African Institute.

BIK, M. J. 1967. 'Structural geomorphology and morphoclimatic zonation in the central highlands, Australian New Guinea', In Landform studies from Australia and New Guinea (eds.) J. N. Jennings and J. A. Mabbutt. Canberra: Australian National University Press.

BOHANNAN, P. 1963 'Land', 'tenure' and 'land-tenure'. In African agrarian systems (ed.) D. Biebuyck. London: International African Institute.

BOSERUP, Ester 1965. The conditions of agricultural growth: the economics of agrarian change under population pressure. London: Allen and Unwin.

BOUMAN, J. C. et al. 1960. The South Moluccas, Rebellious province or occupied state. Leiden: Sythoff.

BOXER, C. R. 1965. 'Some Portuguese sources for Indonesian historiography'. In An introduction to Indonesian historiography (eds.) Soedjatmoko et al. Ithaca, New York: Cornell University Press. 
BROOKFIELD, H. C. 1962. Geography and anthropology. Pacif. Viewp. 3, 11-16.

BROOKFIELD, H. C. 1962a. Local study and comparative method: An example from central New Guinea. Ann. Assoc. Am. Geographers. 52, 242-54.

BROOKFIELD, H.C. 1964. 'The ecology of Highland settlement; some suggestions'. In New Guinea: the central highlands (ed.) James B. Watson. Amer. Anthrop. (Special Publ.) 66, 20-38.

BROOKFIELD, H. C. 1964a. Questions on the human frontiers of geography. Economic Geography 40, 283-303.

BROOKFIELD, H. C. 1968. 'New directions in the study of agricultural systems in tropical areas'. In Evolution and environment: A symposium presented on the occasion of the one hundredth anniversary of the foundation of Peabody Museum of history at Yale University (ed.) Ellen T. Drake. New Haven and London: Yale University Press.

BROOKFIELD, H. C. 1969. On the environment as perceived. Progress in Geography: international review of current research. 1, 51-80.

BROOKFIELD, H. C. and P. Brown 1963. Struggle for land: agriculture and group territories among the Chimbu of the New Guinea Highlands. Melbourne: Oxford University Press.

BROOKFIELD, H. C. with D. Hart 1971. Melanesia: a geographical interpretation of an island world. London: Methuen.

BROWN, P. 1962. Geography and anthropology. Pacif. Viewp. 3, 11-16

BROWN, P. and H. C. Brookfield 1967. Chimbu residence and settlement: A study of cycles, trends and idiosyncracies. Pacif. Viewp. 8, 119-51.

BUCKLEY, Walter 1967. Sociology and modern systems theory. Englewood Cliffs, New Jersey: Prentice-Hall.

BURKILL, I. H. 1935. A dictionary of the economic products of the Malay peninsula. London: Crown agents for the colonies.

BURKILL, I. H. 1951. The rise and decline of the greater yam in the service of man. The Advancement of Science. 7, 443-448.

BURLING, Robbins 1964. Cognition and componential analysis: God's truth or hocus pocus? Amer. Anthrop. 66, 20-28.

BURLING, R. 1969. Linguistics and ethnographic deseription. Am. Anthrop. 71, 817827.

BUTT, Audrey J. 1970. 'Land use and social organization of tropical forest peoples of the Guianas'. In Human ecology in the tropics (eds.) J. P. Garlick and R. W. J. Keay (Symposia of the society for the study of human biology 9). Oxford and London: Pergamon.

CARNEIRO, Robert. L. 1960.'Slash and burn agriculture: a closer look at its implications for settlement patterns'. In Men and cultures: selected papers of the fifth international congress of anthropological and ethnological sciences, 1956 (ed.) A. F. C. Wallace. Philadelphia: University of Pennsylvania Press.

CHATFIELD, C. 1949. Food composition tables for international use. Rome: Food and Agricultural Organization of the United Nations.

CHISHOLM, Michael 1968. Rural settlement and land use. London: Hutchinson University Library.

CLARKE, William C. 1966. From extensive to intensive shifting cultivation: a succession from New Guinea. Ethnology 5, 347-59.

CLARKE, William C. 1971. Place and people: an ecology of a New Guinean community. Berkeley, Los Angeles: University of California Press.

COBLEY, Leslie S. 1956. An introduction to the botany of tropical crops. London: Longmans.

COHEN, Erik 1973. Social ecology - a multidimensional approach. Department of Sociology, University of Singapore: Working papers No.3.

COHEN, Percy 1968. Modern social theory. London: Heinemann. 
CONKLIN, H. C. 1957. Hanunoo agriculture, a report on an integral system of shifting cultivation in the Philippines. (Forestry Development paper No.12) Rome: Food and Agricultural Organization of the United Nations.

CONKLIN, H. C. 1959. Shifting cultivation and the succession to grassland. Proceedings, Ninth Pacific Science Congress (1957). 7, 60-62.

CONKLIN, H. C. 1960 . The cultural significance of land resources among the Hanunoos. Philadelphia Anthropological Society Bulletin, 13. 38-42.

CONKLIN, H. C. 1961. The study of shifting cultivation. Curr. Anthrop. 2, 27-61. Also published 1963. Pan American Union Studies and Monographs No.VI, Washington.

CONKLIN, H. C. 1962. Lexicographical treatment of folk taxonomies. Intern. J. Am. Linguistics 28, 119-141. In Problems in lexicography 4 (eds.) F. W. Householder and S. Saporta (publication 21). Bloomington: Indiana University Research Center in Anthropology, Folklore and Linguistics.

CONKLIN, H. C. 1967. 'Ifugao ethnobotany, 1905-1965; the 1911 Beyer-Merrill report in perspective'. In Studies in Philippine anthropology: in honour of H. Otley Beyer: (ed.) Mario D. Zamora. Quezon city: Alemar-Phoenix. Reprinted 1967 Economic Botany 21, 243-272.

CONKLIN, H. C. 1968. Some aspects of ethnographic research in Ifugao. Trans. N.Y. Acad. Sci. 30, 99-121.

CONKLIN, H. C. 1969. An ethnoecological approach to shifting agriculture. In Environment and cultural behaviour: ecological studies in cultural anthropology (ed.) Andrew P. Vayda. New York: The Natural History Press. First published 1954 Trans. N.Y. Acad. Sci.17, 133-142.. Also reprinted in 1962 Readings in cultural geography (eds.) P. L. Wagner and M. W. Mikesell. Chicago: University of Chicago Press.

CONKLIN, H. C. 1972. Folk classification: a topically arranged bibliography of contemporary and background references through 1971. New Haven: Yale University Department of Anthropology.

COOLEY, Frank L. 1962. Ambonese adat, a general description. (Cultural report series 10). New Haven: University southeast Asia studies.

COOLEY, Frank L. 1971. 'Persentuhan kebudajaan di Maluku Tengah 1475-1675'. In Bunga rampai sedjarah Maluku (ed.) C. P. F. Luhulima. Djarkarta: Lembaga research kebudajaan nasional.

CORNER, E. J. H. 1952. Wayside trees of Malaya. Government Printer.

COURSEY, D. G. 1967. Yams, an account of the nature, origins, cultivation and utilisation of the useful members of the Dioscoreaceae. London: Longmans.

CROCKER, J. Christopher 1969. Reciprocity and hierarchy among the eastern Bororo. $\operatorname{Man}$ (N.S.) 4, 44-58.

CUNNINGHAM, C. E. 1964. Order in the Atoni house. Bijdr. Taal-, Land-, Volkenk. 120, 34-68.

DAVID, N. 1971. The Fulani compound and the archaeologist. World Archaeology 3(2): 111-131.

DEMANGEON, Albert 1962. 'The origin and causes of settlement types'. In Readings in cultural geography (eds.) P. L. Wagner and M. W. Mikesell.Chicago: University of Chicago Press. First published 1927 in La geographie de l'habitat rural.

DOBBY, E. H. G. 1969. Southeast Asia. London: University of London Press.

DOUGLAS, Mary 1972. 'Symbolic orders in the use of domestic space'. In Man, settlement and urbanism. (eds.) Peter J. Ucko, Ruth Tringham and G. W. Dimbleby. London: Duckworth.

DOUGLAS, Mary 1972a. 'Environments at risk'. In Ecology in theory and practice. (ed.) J. Benthall. New York: Viking Press.

DUDAL, R. and F. R. Moormann 1964. Major soils of south east Asia: their characteristics, distribution, use and agricultural potential. The journal of tropical Geography, 54-80. In Studies in the Geography of Southeast Asia (1964 Regional Conference of South-East Asian Geographers). London: George Philip. 
DUMOND, D. E. 1961. Swidden agriculture and the rise of Maya civilization. S. West. J. Anthrop. 17, 301-316.

DURNIN, J. V. G. A. and R. Passmore 1967. Energy, work and leisure. London: Heinemann Educational Books.

DUYVENDAK, J. P. 1926. Het Kakean-genootschap van Seran. Almelo: Hilarius.

DYEN, I. 1965. A lexicostatistical classification of the Austronesian languages. Indiana University Publications in Anthropology and Linguistics, Memoir 19: Supplement to International Journal of American Linguistics Vol 31, No. 1.

ELLEN, Roy F. 1972. The marsupial in Nuaulu ritual behaviour. Man (N.S.) 7, 223-238.

ELLEN, Roy F. 1973. Nuaulu settlement and ecology: the environmental relations of an eastern Indonesian community. Thesis submitted for the degree of Doctor of Philosophy in the University of London: unpublished.

ELLEN, Roy F. 1975. Variable constructs in Nuaulu zoological classification. Soc. Sci. inform. 14(3/4): 201-28.

ELLEN, Roy F. 1975a. Non-domesticated resources in Nuaulu ecological relations. Soc. Sci. inform. 14(5): 127-50.

ELLEN, Roy F. 1977. Resource and commodity: problems in the analysis of the social relations of Nuaulu land use. Journ. Anthrop. Research, Vol 33, No. 1, 50-72.

ESSER, S. J. 1938. 'Talen'. In Atlas van Tropisch Nederland. Het Koninklijk Nederlandsch Aardrijkskundig Genootschap in samenwerking met den Topographischen Dienst in Nederlandsch-Indie. 's-Gravenhage: M. Nijhoff.

FIRTH, Raymond 1951. Elements of social organization. London: Watts.

FIRTH, Raymond 1965. Primitive Polynesian economy. London: Routledge and Kegan Paul.

FISHER, C. A. 1966. South-east Asia: a social, economic and political geography. London: Methuen.

FITZPATRICK, E. A. Doreen Hart and H. C. Brookfield 1966. Rainfall seasonality in the tropical southwest Pacific. Erdkunde 20, 181-94.

FORTES, M. 1949.'Time and social structure; an Ashanti case study'. In Social structure: studies presented to A. R. Radcliffe-Brown (ed.) M. Fortes. Oxford: Clarendon Press.

FORTES, M. 1958. 'Introduction'. In The developmental cycle in domestic groups (ed.) Jack Goody. (Camb. Pap. social Anthrop. 1) Cambridge: Univ. Press.

FOSBERG, F. R. 1962. 'Nature and detection of plant communities resulting from activities of early man'. In Symposium on the impact of man on humid tropics vegetation. Goroka, Territory of Papua and New Guinea, 1960, 251-252. Djakarta: UNESCO Science cooperation office for southeast Asia.

FOSBERG, F. R., Garnier, B. J. and Küchler A. W. 1961. Delimitation of the humid tropics. The Geographical Review 51, 333-347.

FRAKE, C. O. 1956. Malayo-Polynesian land tenure. Amer. Anthrop. 58, 170-173.

FRAKE, C. O. 1962. 'The ethnographic study of cognitive systems'. In Anthropology and human behaviour (eds.) T. Gladwin and W. C. Sturtevant. Washington: The Anthropological Society of Washington.

FRAKE, C. O. 1962a. Cultural ecology and ethnography. Amer.Anthrop. 64, 53-59.

FRAKE, C. O. 1964. 'Notes on queries in ethnography'. In Transcultural studies in cognition (eds.) A. Kimball Romney and Roy Goodwin d'Andrade. Amer. Anthrop. $66,132-145$.

FRASER, D. 1968. Village planning in the primitive world. London: Studio Vista.

FREEMAN, D. 1955. Iban agriculture (Colonial research studies 18) London: Her Majesty's Stationery Office.

FREEMAN, D. 1970. Report on the Iban (London School of Economics Monographs on social anthropology 41). London: Athlone.

FRIED, M. 1952. Land tenure, geography and ecology in the contact of cultures. The American Journal of Economics and Sociology. 11, 391-412. 
GEERTZ, Clifford 1959. Form and variation in Balinese village stucture. Am. Anthrop. 61, 991-1012.

GEERTZ C. 1963. Agricultural involution, the process of ecological change in Indonesia. Berkeley and Los Angeles: University of California Press.

GELLNER, Ernest 1963. Nature and society in social anthropology, Philos. Sci. 30, 236-251.

GERMERAAD, J. H. 1946 'Geology of central Seran'. In Rutten, L. and W. Hotz. (ed.). Geological, petrographical and palaeontological result of explorations, carried out from September 1919 till June 1919 in the island of Ceram. Third Series Geology, No. 2 Amsterdam: J. H. de Bussy.

GLUCKMAN, Max (ed.) 1964. Closed systems and open minds; the limits of naivety in social anthropology. Edinburgh and London: Oliver and Boyd.

GODELIER, Maurice 1972. Rationality and irrationality in economics. London: New Left Review Editions.

GOODENOUGH, W. H. 1955. A problem in Malayo-Polynesian social organization. Amer. Anthrop. 57, 71-83.

GOODENOUGH, W. H. 1956. Componential analysis and the study of meaning. Language. 32, 195-216.

GOODENOUGH, W. H. 1957. 'Cultural anthropology and linguistics'. In Report of the seventh annual round table meeting on linguistics and language study (ed.) P. L. Garvin. Monograph series on language and linguistics No. 9. Washington D.C.: Georgetown University Press.

GOODEY, B. 1971. Perception of the environment: an introduction to the literature (Occasional paper no. 17) Birmingham: University of Birmingham centre for urban and regional studies.

GOODY, J. (ed.) 1958. The developmental cycle in domestic groups (Camb. pap. in Social. Anthrop. 1). Cambridge: Univ. Press.

GOUROU, P. 1961. The Tropical World (Trans. E. D. Laborde) London: Longmans Green.

GREENLAND, D. J. and P. H. Nye 1961. Does straw induce nitrogen deficiency in tropical soils? Transactions of seventh international congress of soil science, 19602 , 478-485.

GROVES, Murray 1963. A review article: the nature of Fijian society. Journal of the Polynesian Society 72, 272-291.

HAGGETT, F. 1969. 'Network models in geography' In Integrated models in geography (eds.) Richard J. Chorley and Peter Haggett. London: Methuen.

HARLAN, Jack R. 1972. 'Crops that extend the range of agricultural settlement'. In Man, settlement and urbanism (eds.) Peter J. Ucko, Ruth Tringham and G. W. Dimbleby. London: Duckworth.

HARRIS, David R. 1969. 'Agricultural systems, ecosystems and the origins of agriculture'. In The domestication and exploitation of plants and animals (eds.) Peter J. Ucko and G. W. Dimbleby. London: Duckworth.

HARRIS, David R. 1972. 'Swidden systems and settlement'. In Man, settlement and urbanism (eds.) Peter J. Ucko, Ruth Tringham and G. W. Dimbleby. London: Duckworth.

HARRIS, M. 1968. The rise of anthropological theory: a history of theories of culture. London: Routledge and Kegan Paul.

HART, J. F. 1954. Central tendency in areal distribution. Economic Geography 30, 48-59.

HARTSHORNE, R. 1959. Perspective on the nature of geography. London: John Murray.

HARVEY, D. 1969. 'Models of the evolution of spatial patterns in human geography'. In Integrated models in geography (eds.) Richard J. Chorley and Peter Haggett. London: Methuen. 
HIPSLEY, E. H. and F. W. Clements 1947. Report of the New Guinea nutrition survey expedition. Canberra: Department of External Territories.

HIPSLEY, E. H. and Nancy Kirk 1965. Studies of dietary intake and expenditure of energy by New Guineans (South Pacific Commission Technical Paper 147). Noumea: South Pacific Commission.

HOLLEMAN, F. D. 1923. Het adat-grondenrecht van Ambon en de Oeliassers. Delft: Molukken Instituut, W. D. Meinema.

IZIKOWITZ, K. G. 1951. Lamet, hill peasants in French Indochina (Etnologiska Studier 17). Göteborg: Etnografiska Museet.

JAMES, A. G. 1949. Village arrangement and social organization among some Amazon Tribes.

JENSEN, A. E. 1948. Die drei Ströme: Züge aus den geistigen und religiösen Leben der Wemale, einem Primitiv-volk in den Molukken (Ergebnisse der Frobenius Expedition 1937-1938 in die Molukken und nach Holländisch Neu-Guinea II). Leipzig: Otto Harrassowitz.

JENSEN, A. E. and H. Niggemeyer 1939. Hainuwele: Volkserzählungen von der Molukken Insel Ceram (Ergebnisse der Frobenius Expedition 1937-1938 in die Molukken und nach Holländisch Neu-Guinea 1). Frankfurt am Main: Klostermann.

JOSSELIN DE JONG, P. E. de 1967. Review of 'The evolution of horticultural systems in native south America' (ed.) Johannes Wilbert. Bijdr. Taal-, Land- en Volkenk. 23, 174-178.

KANTOR Sensus dan Statistik Propinsi Maluku 1972. Sensus Penduduk 1971 Propinsi Maluku. Ambon.

KEESING, Roger M.1972. Paradigms lost: the new ethnography and the new linguistics. Southwestern Journal of Anthropology 28 (4), 299-332.

KELLY, R. C. 1968. Demographic pressure and descent group stucture in the New Guinea Highlands. Oceania 39, 36-63.

KENNEDY, Raymond 1955. Field notes on Indonesia, 1949-1950. (ed.) Harold C. Conklin. New Haven, Connecticut: Human Relations Area Files.

KENNEDY, Raymond 1962. Bibliography of Indonesian peoples and cultures. New Haven, Connecticut: Human Relations Area Files.

KOENTJARANINGRAT 1965. 'Use of anthropological methods in Indonesian historiography. In An introduction to Indonesian historiography (eds.) Soedjatmoko et al. Ithaca, New York: Cornell University Press.

KOENTJARANINGRAT 1967. 'A survey of social studies on rural Indonesia'. In Villages in Indonesia (ed.) Koentjaraningrat. Ithaca, New York: Cornell University Press.

KOENTJARANINGRAT (ed.) 1967a. Villages in Indonesia. Ithaca, New York: Cornell University Press.

KOPPEL, C. van der 1926. Winning van copal in het Gouvernement Celebes en onderhoorigheden, de uitvoer uit Makassar, en eenige details over het gebruik van copal. Tectona, 19, 525-574.

LANGLEY, D. 1947. Part 4, Report of the New Guinea Nutrition Survey Expedition (eds.) E. H. Hipsley and F. W. Clements. Canberra: Department of External Territories.

LANGTON, J. 1973. Potentialities and problems of adopting a systems approach to the study of change in human geography. Progress in Geography: international review of current research 4, 125-79.

LEA, D. A. M. 1964. Abelam Land and Sustenance: swidden horticulture in an area of high population density, Maprik, New Guinea. Thesis submitted for the degree of Doctor of Philosophy in the Australian National University (mimeographed), Canberra.

LEACH, E. R. 1961. Pul Eliya, a village in Ceylon: a study of land tenure and kinship. London: Cambridge University Press.

LEACH, E. R. 1961a. Rethinking anthropology (London School of Economics Monographs on Social Anthropology 22). London: Athlone. 
LÉVI-STRAUSS, C. 1956. Les organisations dualistes existent-elles? Bijdr. Taal-, Landen Volkenk. 112, 99-128.

LÉVI-STRAUSS, C. 1963. Structural anthropology (Trans. Claire Jacobson and Brooke Grundfest Schoepf). New York, London: Basic Books.

MALINOWSKI, B. 1932. The sexual life of savages in north-western Melanesia. London: Routledge.

MARTIN, K, 1894. Reisen in den Molukken. Leiden: Brill.

MASON, L. 1962. Habitat, man and culture. Pacif. Viewp. 3, 3-11

MAYBURY-LEWIS, D. 1967. Structural anthropology and the problem of comparison. VIIIme. Congres International des Sciences Anthropologiques et Ethnologiques, 1964. Vol. 4.

MEGGITT, M. J. 1958. The Enga of the New Guinea Highlands: some preliminary observations. Oceania 28, 252-330.

MEGGITT, M. J. 1965. The lineage system of the Mae Enga of New Guinea. Edinburgh and London: Oliver and Boyd.

MERRILL, E. D. 1954. Plant life of the Pacific world. New York: Macmillan.

MILLAR, J. G. 1965. Living systems; basic concepts. Behavioural Science. 10, 593-237.

NAVAL Staff Intelligence Department 1918. A manual of Netherlands India (Dutch East Indies). Intelligence Department 1209.

NORGAN, N. G., A. Ferro-Luzzi and J. V. G. A. Durnin 1974. The energy and nutrient intake and the energy expenditure of 204 New Guinean adults. Phil. Trans. Royal Soc. Lond. B. 268; 309-348.

NYE, P. H. and D. J. Greenland 1960. The soil under shifting cultivation. (Technical Communication 51) Harpenden: Commonwealth Bureau of Soils.

ONVLEE, L. 1949. Naar aanleiding van de stuwdam in Mangili (Opmerkingen over de sociale structuur van Oost-Soemba) Bijdr. Taal-, Land-en Volkenk. 105, 445-459.

OOMEN, H. A. P. C. and S. M. Malcolm 1958. Nutrition and the Papuan child. (South Pacific Commission Technical Paper 118). Noumea: South Pacific Commission.

ORENSTEIN, M. 1956. 'Irrigation, settlement pattern and social organization'. In Men and cultures (ed.) A. F. C. Wallace. Philadelphia: University of Pennsylvania Press.

OSSENBRUGGEN, F. D. E. van 1918. De oorsprong van het Javaansche begrip montjapat in verband met primitieve classificaties. Verslagen en Mededeelingen der Koninklijke Akademie van Wetenschappen, 3, 6-44.

PASSMORE R. and J. V. G. Durnin 1955. Human energy expenditure. Physiological Reviews (October), pp. 801-840.

PELZER, Karl J. 1941. 'Population and land utilization'. In An economic survey of the Pacific area 1 (ed.) F. V. Field. New York.

PIKE, K. L. 1963. Phonemics: a technique for reducing languages to writing. Ann Arbor: The University of Michigan Press.

PINO, E. and T. Wittermans 1966. Kamus Inggeris. Groningen: Wolters.

PLATT, B. S. 1962 Tables of representative values of foods commonly used in tropical countries. London: Her majesty's stationery office. Medical research council special report series No. 302.

RADCLIFFE-BROWN, A. R. 1952 Structure and function in primitive society. London: Cohen and West.

RAPPAPORT, Roy A. 1963. 'Aspects of man's influence on island ecosystems: alteration and control'. In Man's place in the island ecosystem (ed.) F. R. Fosberg. Honolulu: Bernice P. Bishop Museum.

RAPPAPORT, Roy A. 1967. Ritual regulation of environmental relations among a New Guinea People. Ethnology 6, 17-30.

RAPPAPORT, Roy A. 1968. Pigs for the ancestors: ritual in the ecology of a New Guinea people. New Haven and London: Yale University Press.

RAPPAPORT, Roy A. 1971. The flow of energy in an agricultural society. Scientific American 225, 117-132. 
RICHARDS, P. W. 1952. The tropical rain forest, an ecological study. Cambridge: University Press.

ROBBINS, R. G. 1961. The vegetation of New Guinea. Australian territories, I, 21-32.

RÖDER, J. 1948. Alahatala: Die Religion der Inlandstämme Mittelcerams (Ergebnisse der Frobenius Expedition 1937-1938 in die Molukken und nach Holländisch NeuGuinea III). Bamberg: Bamberger Verlagshaus Meisenbach.

ROUSE, I. 1972. 'Settlement patterns in archaeology'. In Man, settlement and urbanism (eds.) Peter J. Ucko, Ruth Tringham and G. W. Dimbleby. London: Duckworth.

RUXTON, B. P. 1967. 'Slopewash under primary rainforest in northern Papua'. In Landform studies from Australia and New Guinea (eds.) J. N. Jennings and J. A. Mabbutt. Canberra: Australian National University Press.

SACHSE, F. J. P. 1907. Het eiland Seran en zijne bewoners. Leiden: E. J. Brill.

SAHLINS, Marshall D. 1957. Land use and the extended family in Moala, Fiji, Am. Anthrop. 59, 449-62.

SALISBURY, R. F. 1962. From stone to steel. London and New York: Cambridge University Press.

SCHLIPPE P. de 1956. Shifting cultivation in Africa: the Zande system of agriculture. London: Routledge.

SCHMIDT, P. H. and J. H. A. Ferguson 1952. Rainfall types based on wet and dry periods ratios for Indonesia with west New Guinea. Djakarta: Kementerian Perhubungan djawatan meteorologi dan geofisik.

SERAN 1922. Mededeelingen van het bureau voor de bestuurszaken der buitenbezittingen bewerkt door het encyclopaedisch bureau.

SORENSON, E. Richard 1972. Socio-ecological change among the Fore of New Guinea. Curr. Anthrop. 13(3-4), 359-72.

SPENCER, J. E. 1966. Shifting cultivation in southeastern Asia. (University of California publications in geography, Volume 19). Berkeley and Los Angeles: University of California Press.

STANNER, W. E. H. 1967. 'Reflections on Durkheim and aboriginal religion'. in Social organization: Essays presented to Raymond Firth (ed.) Maurice Freedman. London: Cass.

STAUDER, Jack 1971. The Majangir: ecology and society of a southwest Ethiopian people (Cambridge studies in social anthropology 5). Cambridge: University Press.

STEENIS, C. G. van 1935. Maleische vegetatieschetsen. Buitenzorg.

STODDART, D. R. 1965. Geography and the ecological approach; the ecosystem as a geographic principle and method, Geography, 50, 242-51.

STODDART, D. R. 1969. 'Organism and ecosystem as geographical models'. In Integrated models in geography (eds.) Richard J. Chorley and Peter Haggett. London: Methuen.

STRESEMANN, E. 1923. Religiöse Gebrauche auf Seran. Tijdschrift voor Indische Taal-, Land- en Volkenkunde. 62,305-424.

STRESEMANN, E. 1927. Die Lauterscheinungen in den ambonischen Sprachen. Zeitschrift für Eingeborenen-Sprachen 10.

STURTEVANT, W. C. 1964. Studies in ethnoscience. In Transcultural studies in Cognition (eds.) A. Kimball Romney and Roy Goodwin d'Andrade. Am. Anthrop. 66, 99-131.

TAUERN, O. D. 1918. Patasiwa und Patalima. Leipzig.

TER HAAR, B. 1948. Adat law in Indonesia. New York: Institute of Pacific Relations.

TICHELMAN, G. L. 1925. De onderafdeeling Amahei, Seran. Tijdschrift van het Koninklijk Nederlandsch Aardrijkskundig Genootschap, 42, 653-724.

TICHELMAN, G. L. 1960. 'Anthropological aspects'. In Bouman, J. C. et al. The South Moluccas, rebellious province or occupied state. Leiden: Sythoff.

TRIGGER, B. 1968. 'The determinants of settlement patterns'. In Chang, K-C. (ed.) Settlement archaeology. Palo Alto: National Press. 
VAVILOV, N. I. 1951. The origin, variation, immunity and breeding of cultivated plants. Selected writings of N. I. Vavilov translated by K. Starr-Chester. Chronica Botanica 13, 1-366. New York: The Ronald Press Company.

VAYDA, A. P. 1965. 'Anthropologists and ecological problems'. In Man, culture and animals (eds.) Anthony Leeds and Andrew P. Vayda. Washington D. C.: American Association for the Advancement of Science 78.

VAYDA, A. P. 1968. 'Foreword'. In Pigs for the ancestors: ritual in the ecology of a New Guinea people. Roy A. Rappaport. New Haven and London: Yale University Press.

VAYDA, A. P. 1969. An ecological approach in cultural anthropology. Bucknell Review. $17,112-119$.

VAYDA, A. P. 1969a. 'Introduction'. In Environment and cultural behaviour: ecological studies in cultural anthropology (ed.) Andrew P. Vayda. New York: The Natural History Press.

VAYDA, A. P. 1969b. 'Expansion and warfare among swidden agriculturalists'. In Environment and cultural behaviour: ecological studies in cultural anthropology (ed.) Andrew P. Vayda. New York: The Natural History Press. First published 1961.Amer. Anthrop. 63, 346-58.

VAYDA, A. P. and Roy A. Rappaport 1968. 'Ecology, cultural and non-cultural'. In Introduction to cultural anthropology: Essays in the scope and methods of the science of man (ed.) James A. Clifton. Boston. Houghton Mifflin.

VENKATACHALAM, P. S. 1962. A study of the diet, nutrition and health of the people of the Chimbu area. (Monograph 4). Territory of Papua and New Guinea: Department of Public Health.

VOLKER, T. 1925. Het recht van Sasi in de Molukken. Adatrechtbundels. 24, 293-313.

WADDELL, Eric 1972. The mound builders: agricultural practices, environment and society in the central highlands of New Guinea (American ethnological monograph 53). Seattle and London: University of Washington Press.

WARBURG, O. 1893. Vegetationsschilderungen aus Südost Asien. Botanisch Jahrbuch $17,169-176$.

WARD, Barbara 1966. Sociological self-awareness: some uses of the conscious model. Man (N.S.), I, 201-215.

WATSON, J. G. 1928. Malayan plant names. (Malayan forest recofds 5).

WATTERS, R. F. 1960. Some forms of shifting cultivation in the southwest Pacific. Journal of tropical geography 14, 35-50.

WEINER, J. S. and J. A. Lourie 1969. Human biology: a guide to field methods (International Biological Programme Handbook No. 9). Blackwell: Oxford and Edinburgh.

WEULE, Karl 1915. Zur Kartographie der Naturvölker. Petermanns Mitteilungen. 61, 18-21, 59-62.

WIKKRAMATILEKE, R. 1959. Problems of land-use mapping in the tropics, Geography. 44, 79-95.

WOUDEN, F. A. E. van 1968. Types of social structure in eastern Indonesia (Trans. Rodney Needham). The Hague: Martinus Nijhoff. 


\section{NOTES}

\section{CHAPTER I}

1 The use of this old English dialect word for a mode of agriculture focussed on the cultivation of a cleared and burned plot is now too well established in the literature to require explanation of its advantages and disadvantages. Short accounts of the confusion surrounding the use of the term shifting cultivation and of the elaborate debate concerning the adoption of the term swidden are found in Conklin (1957: 1-2, 1961) and Lea (1964: 1), together with the relevant bibliographic material. Here it is used only to define a widespread type of agricultural practice (Harris 1972). Individual plots are referred to as gardens, or by the appropriate Nuaulu terms.

2 Barth himself takes the developmental idea proposed by Fortes (1949: 54-84, 1958: $1-14)$ as some kind of prototype in this respect, and draws certain procedural comparisons between his own work and Leach's topological models (Leach 1961a: 1-27). The former acknowledgement is of particular interest, since the concern of Fortes with the cyclical and developmental nature of the composition of domestic groups is of direct relevance to settlement analysis.

\section{CHAPTER II}

1 Christianity is reported to have been established in south central Seram in 1647 (Seran 1922:31).

2 For a more extensive catalogue of literature see Kennedy's Bibliography (1962).

3 See, however, Tichelman (1925).

4 These and all subsequent census data, apart from those on the Nuaulu themselves (which are based on field materials), or unless otherwise stated, are taken from published figures for the 1971 national census, made available to me through the Biro Pusat Statistik, Jakarta and cited in Kantor Sensus dan Statistik (1972). The reliability of these figures is in places questionable, but for the purpose to which they are put in this monograph the degree of accuracy can be assumed adequate.

5 This designation appears to derive from Stresemann (1923: 374). I was unable to elicit the term in the course of fieldwork, and his inclusion of particular villages (e.g. Huaulu) within the 'Patakai' group is almost certainly erroneous.

6 The apparent ease of transition from the interior highland situation to the rather different habitat of the coast, the apparent lack of serious social and cultural disorganization and the retention of an essentially inland economy is a remarkable contrast to the situation Kennedy has described for transplanted Wemale communities on the south coast of west Seram - Mani and Pokolowoni. He concludes that here the Dutch colonial policy of rust, orde en belasting (peace, order and taxes) aggravated coastal land shortage and resulted in unbeneficial dietary changes (including a short supply of meat and increased consumption of sago, to which they were not used) (1955: 121) and deculturation (122). He talks of the implementation of the policy and how, with the aid of Dutch and Ambonese troops, the Alifuru were driven from their mountain homes to be subject to 'the rule of these coastal puppets' - that is, the coastal rajas (134-5). Kennedy's notes are piecemeal and some of what he says seems unconvincing in the light of my fieldwork, as when he talks of the vegetables on the 
coast and the unimportant role of sago in mountain Alifuru diet. But the pattern of re-settlement obviously varied from one place to another.

7 Seram, therefore, comes broadly within the area of vegetatively propagated cultigens that is the Moluccas eastwards, as opposed to the area of seed propagated cultigens (rice, millet etc.) typical of the Indo-Malaysian region. This is a fact of considerable ethnobotanical and culture-historical importance (Barrau n.d., Burkill 1951). What makes Seram of some additional interest is that dry rice cultivation is important for some communities and quite insignificant for others (including the Nuaulu). Within the zone of vegetatively propagated cultigens, Seram is located in a taro-dominant area, as opposed to the drier yam-dominant areas of parts of New Guinea.

8 The distinction between landforms and vegetational associations is not always as distinct in classificatory schemes as it is among the Nuaulu. Sometimes, as among the Ifugao (Conklin 1968: 105-8), a local categorization of the environment will involve both physical and vegetational criteria.

9 At an early stage in my enquiries into Nuaulu environmental classification, I became worried that it admitted no separate category for the distinctive littoral or shoreline vegetation. It was clearly not wesie and neither was it always wasi. Certainly this zone is botanically distinctive (Warburg 1893) and its characteristic flora and tree-forms are recognised in Malay ethnobotany (Watson 1928). The answer to this problem may lie in a combination of two factors. The first is that Nuaulu environmental classification is still geared to an inland, mountain economy (witness the few shoreline plants listed in Ellen 1973: 450-64). The second factor lies in its liminality as an area of transition between land $(M A L E)$ and sea (FEMALE). Combined with this latter point must be borne in mind Nuaulu attitudes to the sea, which is still widely regarded as polluting (see below p. 246 note 15). Further, for those villages near the shore, the beach has become an area of the same order as the village periphery, where defecation is promiscuous and rubbish is discarded. This merely reinforces any intrinsic polluting qualities it might possess.

\section{CHAPTER III}

1 During the latter phase of re-settlement village location appears to have changed several times, for at least some clans. Sometimes this involved shifting to quite distant localities, as in the case of Nepane-tomoien, which moved as far eastwards as the Werinama administrative district to the village of Kiliwarane, before returning to finally settle in the vicinity of Sepa.

2 Earthquakes may have been an important though rare factor influencing village movement. Seismic disturbances are of frequent occurrence on Seram, which belongs to the older of the two main fold areas of Indonesia. There is a concentration of epicentres particularly in the south-west of the island (Admiralty 1944: 14, 16, 290). Kennedy $(1955: 147,149,150,174)$ reports on the effects of the 1899 earthquake and tidal wave on settlement for a part of the south-west coast, including the entire destruction of the village of Elpaputih, which was responsible for the death of many people and the loss of complete villages. Following this holocaust many of the ritual houses were never replaced. Earthquakes feature in a number of Nuaulu stories and folk beliefs.

3 Thus, the availability of restricted areas of uncleared mature forest between Sepa and Ruhuwa and between Ruhuwa and Tamilau for clearance by the Nuaulu when they first arrived in the area is reflected in the present distribution of wasi in these localities (W5-6, W7-8, W180-182 in MAP 9). However, with the exception of Aihisuru, all present Nuaulu villages are sited on land originally claimed by the raja of Sepa. This considerably strengthened his position with regard to political jurisdiction over them. In general, the people of Sepa regard all land along the coast as traditionally their own, that towards the mountains as the preserve of the Alifuru. 
4 In 1950 the 'Republik Maluku Selatan' (Republic of the South Moluccas) was proclaimed in Ambon in opposition to the new Republic of Indonesia. From this date until well into the last decade the Moluccans waged guerilla warfare against central government forces from bases in the highlands of Seram. Inevitably, the Nuaulu were caught up in the civil unrest and appear to have totally supported the apparently predominantly Christian militia of the R.M.S. As a result of this, for a short but not clearly definable period during this interregnum, the Nuaulu left their coastal villages and returned to the safety of the highlands. It is difficult to assess the affect which these disturbances had on the present pattern of settlement, but in the long-run it appears to have been rather slight. For this reason I have restricted these comments, although important for an understanding of recent Moluccan history, to a short footnote. Had I done otherwise it might have been assumed that in terms of Nuaulu settlement and ecology these events were of more significance than they actually proved to be. For a partisan account of this movement see Bouman et al. (1960).

5 Tichelman, a not entirely reliable and rather casual observer of these events, has written the following: '. . . In his heart of hearts the Ceramese is still the vagrant, the man in search of adventure and good luck.Thus, it was once found that the village of Nuaulu (i.e. Watane-R.F.E.), situated beyond the Mohammedan village of Sepa in south Ceram, served as a 'Potemkin village', with this difference that the houses in Nuaulu were well-built and well-kept. The villagers had two houses, a good one in Nuaulu, which was occupied temporarily when a patrol, the administrative officer or the vaccinator was about, and a badly-built, dirty one beyond the village, which was occupied permanently (i.e. Aihisuru-R.F.E.). There would not have been any objection to people living in an inland settlement, not much more elevated than and close to the seaside village $(. .$.$) , if in the present case it had not been the obvious intention$ to elude periodic inspection. These isolated settlements, neglected, unhygienic and inconvenient (water is lacking!), are strongholds of conservatism and keep alive barbarous, inadmissible customs. The village of Nuaulu was the only Alfurese village in the former district under direct administration whose population persisted in refusing to send the children to school, while it was only with the greatest difficulty that the authorities succeeded in having a small percentage of population vaccinated against the smallpox.' (1960: 188-9).

6 Aihisuru and Hahuwalan are both at a distance of about 500 metres from Watane; 750 and 500 metres respectively from Sepa, measured directly and orthographically. Both lie almost on the 200 metre contour, though Aihisuru is probably marginally higher, and certainly access to it is more difficult. In both cases paths are poor and subject to constant erosion by the rains and through continual use. Coastal Muslims and other outsiders rarely visit these villages, while Watane, Bunara and Ruhuwa are frequently subject to intrusions (much to the annoyance of their occupants), the latter two being situated on important coastal paths and being thoroughfares to gardens belonging to Muslim clans from Sepa.

7 For instance, Ekano, a small settlement of Manusela peoples in Tehoru administrative district, just south and inland of Saunulu (MAP 2).

8 This case offers an interesting illustration of the dynamics of change in ritual law. The practice of polygamy, the existence of which has already been alluded to for former times, appears to have almost entirely ceased by the time the Nuaulu arrived in their present habitat. It had even come to be regarded by many as contrary to present Nuaulu custom. Thus, when Nauhua contracted his second marriage to Sukue (now living in the household of her son Numapena in Ruhuwa - MAP 5, no.3), two factions arose: those who regarded the union as a breach of established custom (including the all-important clan Matoke), and a minority faction which justified the marriage by recourse to former practice, and which formed the nucleus of the present village of Ruhuwa. 
9 During the course of the past few years the Nuaulu area has been designated by the Indonesian Department of Social Services ('Departemen Sosial'), rather inflatedly, as a 'Projekt Sosial', which has meant that it has been in receipt of occasional gifts of implements and of advice/assistance in house construction and public hygiene. In 1971 Bunara had been the only village affected.

10 The vital statistics of the major Nuaulu conduits are as follows:

\begin{tabular}{lrc}
\hline Locality & Length in metres & $\begin{array}{c}\text { Number of bamboo } \\
\text { sections }\end{array}$ \\
\hline Ruhuwa: river Ruhuwa & 396 & 53 \\
Watane: river Joni & 999 & 135 \\
Bunara: river Iseh & 1356 & 184 \\
$\quad$ river Bunara & 236 & 32 \\
\hline
\end{tabular}

11 Since the primary concern here is with horizontal space relationships of settlement, no attention has been paid to symbolically important questions of the vertical organization of village space. On the importance of the symbolic ordering of domestic space in general see, for example, Douglas (1972: 513-22).

12 This is the Nuaulu term for the structure commonly known throughout Seram and Ambon-Lease (Haruku, Saparua and Nusalaut) as the 'baileu'. Cooley discusses the etymology of this central Moluccan term in his treatment of the subject in relation to Ambonese villages (Cooley 1962: 8-13).

13 The basic dimensions of the suane in Ruhuwa are as follows: height at apex 660 centimetres, length 1330 centimetres and width 1260 centimetres. The height of the floor above ground-level is 150 centimetres.

14 Walls of any structure are terminologically distinguished according to which one of these axes they are oriented. Thus, walls on the mountain-sea axis are termed mitanunwe, a term also used for entrances, since, with only very specific exceptions, the position of the two coincide. Walls along the east-west, sunrise-sunset, axis are termed sine. In the correct ritual sense the sine of a suane (in contrast to ordinary dwellings) facing the rising sun is regarded as the front and it is the entrance on this face that marks the ritual point of departure in its construction.

15 While it is generally true to say that the arrangement of clans within the village is not based on ideological concepts, the fact that the clans Sonawe-ainakahata and Matoke are forbidden by tradition from dwelling near the sea or contaminating themselves by having any connection with it, has meant that the households of these clans are usually distributed towards the mountain side of villages. In cases where members of these clans feel that excessive sickness is attributable to an inefficacious location, households will be moved further inland. In one instance, that of Tapone Sonawe-ainakahata in Ruhuwa, it was suggested that his entire household should be relocated quite outside the village in the headwaters of the river Ruhuwa.

16 The one exception, which - as it were - proves the rule, is with the clan Sonaweaipura, where houses are oriented in the opposite direction, with the ridge aligned along the mountain-sea axis. Behaviour with respect to order within the house is accordingly adapted to the orientation of the house, except for sleeping postures, which remain east to west. Nuaulu believe they will die if they sleep along the mountain-sea axis. The origin of this exception, which lies in antiquity, was not known and neither did there appear to be much speculation on the matter.

17 There is some variation in the size of such houses. In practice it was found that numa mone in Ruhuwa varied in width (gable end) from 600 to 1030 centimetres and in length from 760 to 950 centimetres.

18 Menstruation huts are uniformly small structures, about 300 centimetres in width. 400 
centimetres long and 225 centimetres in height at the apex, built from a little timber, but principally bamboo and sago-palm thatch. As with houses the ridge runs east-west, but in contrast, in common with the suane, the doors open along the same axis. Thus the special qualities of these structures in Nuaulu thought separate them off from the normal dwelling house: both SACRED and PROFANE appear to contrast with the MUNDANE. Simply in terms of the relationship between numa and bosune, the critical oppositions become MALE: FEMALE and PURE: POLLUTED. Sometimes menstruation huts are located in the gardens.

19 Old and dilapidated houses and menstruation huts are usually, though in practice not consistently, destroyed by burning, usually at night (since this reduces fire hazard) and after serviceable wood and other items have been salvaged. Not only does this provide an eminently practical means of disposing of the stucture, it is also regarded as neutralising the polluting qualities harboured by human habitation as well as destroying any ill-willed house spirits.

20 Compare this and further attributes of Nuaulu village structure with Malinowski's description and suggestions concerning the Trobriand village of Omarakana (1932: 7-14) together with the reinterpretation of Lévi-Strauss (1956). Whereas in the Trobriands the only person allowed to reside in the central and sacred portion of the village is the chief, among the Nuaulu no humans permanently dwell there, it being the location of the suane and the ancestral guardian-spirits of the Matoke clan.

21 There is one feature in MAP 5 which apparently blatantly contradicts all that has been said here, but for no obvious sociological or environmental reason. But in doing so it appears to provide another instance of an exception which proves a Nuaulu rule. This is the location of household 1 . The reason for the location of this household quite outside the village area is simply that Teliam (Paulus) and his wife and children are Chistian converts and no longer Nuaulu in the strict sense. Normally converts would be obliged to move right away from the village. In this particular case a compromise had to be made between the desire of the Protestant pastor in Amahai to form a bridgehead for further proselytization in the area and the wishes of the ancestors. This may represent a step in the decline of the importance the Nuaulu attach to the symbolism of village layout.

22 Changes in village-plan due to physical changes in its component structures, beginning with deterioration leading to desertion, dereliction and finally destruction of old houses, and the construction of new houses at new sites and the repair and improvement of old structures, should not be ignored, since their implications for the overall plan may be considerable.

23 Clifford Geertz (1959: 991-1012) has justly criticized the Dutch structural approach for its failure to recognize the importance of local adaptation in village structure.

24 Jai nisi pina is frequently the stated response to the inability of the husband's clan to pay the bridewealth requested by that of the bride. This, in effect, means that the 'debt' (in the restricted sense of non-payment of bridewealth) of the bride-takers to the bride-givers is perpetuated for the life of the union, whereas in marriage by proposal the payment of bridewealth is regarded as a once-and-for-all affair.

25 This situation, known generally in the Malayo-Indonesian region as 'ambil anak' (taking a child), has been recorded by Ter Haar (1948: 175-6) for several Indonesian societies. In the central Moluccas it is called 'tolong dati', Ambonese Malay for 'land helper', and suggesting the principal value of the arrangement in this part of the archipelago (Cooley 1962: 25). In very rare instances, the first child of a Nuaulu union may be incorporated into the clan of its mother, following the recognition that bridewealth will not be paid.

26 However, in the present circumstances, it is becoming increasingly difficult to judge whether this situation is derived from a genuine conscious sense of corporate identification, or simply the product of ties of filiation, affection and friendship. 
27 Further details on these particular aspects of change, together with systematic information on changes in composition and household dispersal patterns, were collected in both 1969-71 and 1973. I hope that this material will form part of a study of village change.

28 From the point of view of diminishing land available for cultivation, this is less of a hardship than might at first appear, as land adjacent to villages is rarely used to plant annuals or sub-annuals. But this land, in common with almost the entire village area, possesses (as has already been shown) a high concentration of individually and clanowned fruit trees.

\section{CHAPTER IV}

1 This Chapter is an expanded and slightly modified version of Ellen (1975). I am indebted to the Director and Editor of Social Science Information for permission to reproduce 'Non-domesticated resources in Nuaulu ecological relations' $(1975,14(5)$, 127-50) which appears (in a modified form) as Chapter IV of this monograph.

2 For a discussion of some aspects of the ethnographic significance of mapping, the interpretation of culturally-structured landscapes and the importance of setting socioecological problems in a regional sphere of reference, see Conklin (1968: 111-120).

3 For many communities this distinction between village area and exploited area will be something of an abstraction. Unfortunately it is an abstraction which is commonly perpetuated and reflected in the ethnographic literature, largely due to the neglect of one or other of these parts. For example, although there exists an impressive collection of details on the village-plans of some Amazon tribes (e.g. James 1949, Lévi-Strauss 1956), there are precious little data on the arrangement of their cultivation and their relation to the village. Needless to say, a settlement pattern constitutes the sum total of such arrangements.

4 The terms domesticated and non-domesticated are adopted from the usage of Rappaport (1968). As far as I am aware, this particular terminology has not been used widely elsewhere, but it does have clear advantages. It should be borne in mind, however, that sometimes the distinction between the two is difficult to draw; as in the occasional planting of sago suckers in areas nominally designated as 'wild', or in the gathering of fruit trees in the area of old highland village sites.

5 In alluvial areas there is a tendency for this arrangement to be replaced by five distinguishable vegetation layers and a generally higher diversity index.

6 Sasi almost always relate only to crops, though in traditional Nuaulu territories they could apparently be imposed with respect to fishing rights in certain rivers. Another, rather exceptional, example was given to me of a sasi imposed by the Dutch in the thirties on the hunting of deer for two years, as shrinkage in their numbers had apparently given rise to some concern to the disirict authority. This was the only case informants could give of a sasi relating to game.

7 It has not been possible to enter the proportion of food given away to other households. The figures given here relate to the actual consumption as recorded in daily dietary records and not to the total yields of food for each household. It is estimated that for meats in the peni category the weight consumed by a single household rarely exceeds 50 per cent by weight of the original edible carcase. For other meat the amount redistributed tends to be negligible. This is also true for other foods from nondomesticated sources, with the exception of sago, where the amount retained by the households is frequently below 60 per cent of that originally worked.

8 This reflects Nuaulu attitudes in general to the association between the oppositions OFF THE GROUND: ON THE GROUND, HIGH: LOW, SUPERIOR: INFERIOR. See Ellen (1972).

9 Most of the fruit trees within this inner zone are owned, and consequently accessibility is generally restricted by specific rules. 
10 The importance of the distinction between naturally reproducing and cultivated sago palms in Nuaulu economy is reflected in their thought, for it demonstrates a single but nevertheless striking instance of the dichotomy between the natural and the cultural, and the implications of this in terms of cognition and behaviour (Ellen 1973: 159-60). The same phenotypic varieties, of which some ten are recognized (ibid, table 15), appear in both cultivated and wild types, being genetically indistinguishable and interchangeable, suckers from the wild palm often being collected for planting. This, however, does not appear to lessen the cognitive importance attached to the distinction. It was generally agreed though that the spinous varieties were more typical of the wild type, while smooth varieties were more frequently planted. This is despite the fact that informants were perfectly aware of the fact that spineless varieties can give rise to spinous ones and vice versa, and that several gradations of spinosity are distinguished taxonomically, tending to support the proposition that spinescence is of little or no value as a diagnostic characteristic (Barrau 1959: 153, 1958: 37, Lea 1964: 120).

11 Although I have only presented data here on carbohydrate and protein, it is clear that in terms of fat intake also non-domesticated resources are of paramount importance. Pandanus, Canarium, large and small game alike, all have a high fat content, while root tubers, fruits, greens and other characteristic cultivated foods are notably low in fat, with the exception of the groundnut.

\section{CHAPTER V}

1 Parts of this chapter have appeared in a slightly different form elsewhere (Ellen 1977), where an attempt is made to present an analysis of some features of Nuaulu social relations of land use.

2 Each wasi, irrespective of type (that is each identifiably separate segment of owned land), has been accorded a serial number indicative of its location, as shown in MAP 8. Some brief notes on the techniques used in the field to obtain the standard information recorded for each wasi are given in Appendix C.

3 The extent of land under cultivation by Sepa during the period when the Nuaulu were arriving on the coast is not easy to calculate. Certainly it was somewhat less than it is now. Estimates based on the present spatial distribution of land, approximations and demographic data elicited from administrators and village officials, examination of earlier maps of the area and physical investigation of the village area itself suggest that the population increase has been of the order of $50 \%$. The 1971 figure given for the Sepa census district (including the Nuaulu area and several other Christian and Muslim villages) is 2667 . This would suggest that the figure for the village of Sepa is certainly not less than 1500. An official figure (Seran 1922) for the village of Sepa some thirty years earlier gives 1039, representing an increase of some 500 souls. See above p. 243 note 4.

4 As Spencer has pointed out (1966: 39), genuinely 'virgin forest', that is forest which has never been altered by human interference, is cut only extremely rarely. It is difficult to conceive of any forest which has not been in some way altered by human cultural practices before it is finally slashed for cultivation.

5 Sometimes claims are made on such land by the planting of manioc or other tubers outside the garden proper, in areas free of undergrowth and where there is sufficient light. Such land can be claimed without planting (before it is cleared), usually in the name of the clan. This represents a further 'anomaly' in the system of land tenure and inevitably complicates wasi measurement.

6 This situation is therefore not consistent with the argument of Vayda (1969b: 202-16) that in many instances swidden cultivators actually prefer conflict to clearing primary forest. See also the penultimate section of this chapter. 
7 Buttressing is a common phenomenon with almost all tree species in Seram, the greatest proportion being for trees over 30 metres in height. There is then a correlation between tree height and the production of buttresses (Richards 1952: 62, 66), though theories as to its cause are numerous. Of some significance is an apparent relationship between its occurrence and the nature of the soil. Since the wood of buttresses is often harder than that of the trunk, erection of platforms also has the function of giving access to wood that is more manageable for a limited technology of lumbering.

8 In some contexts the term sipate is used, derived from the Indonesian word 'sipat' from the verb 'menjipat', to measure (Pino and Wittermans 1966: 152). 'Sipat' is used in the central Moluccas as a term for boundaries. Under normal circumstances, the Nuaulu restrict the use of the word sipate to outside-imposed boundaries, such as between the areas of jurisdiction of the Muslim villages of Sepa and Tamilau.

9 In a rejoinder to Goodenough (1955), Frake (1956: 171) has interpreted the evidence for some groups of swidden agriculturalists in this part of Malayo-Polynesia as indicating that rights in crops and not land are emphasized. While the Nuaulu data suggests that something like this may have operated in the past (partly by virtue of a heavy reliance upon hunting and gathering), the present situation represents a mixture of rights in crops and rights in land, partly related to the level at which access to the resource is denied. The recognition of wasi as a unit (separate from nisi) is interesting in this respect.

10 Valuables, however, must always remain within the numa mone and consequently are in the custodianship of the offices of clan headman and kapitane, succession to which is by male primogeniture. This aspect of inheritance may thus be phrased conveniently in another way, by saying that all male siblings receive the same wealth except the eldest, who receives twice as much, including the house and any valuables and hereditary titles.

11 In making gifts of land to affines and others no fixed proportion is given, though it would be a serious matter if a person gave what was considered as too much, or too little, when he could be accused of being niggardly.

12 In a very real sense a man's income and wealth can be said to be considerably dependent on this customary obligation for the wife's father to give him land, but commonly, a fact which is related to the prestigiousness of the type of marriage entered into (see Chapter III), a man will work on the gardens of his father-in-law. If his wife dies or is divorced before bearing children the land is returned to her paternal clan. In this sense it might be said that land is inherited from the clan of one's mother.

13 As well as alienation of wasi to affinal or adoptive kin, it is also possible for an individual to grant rights of harvest for a specified period from fruit trees, commonly in clove.

14 The sale of rights of harvest in coconut or clove groves for specified periods is also known and is probably, though there are no statistics to support this, more common than the permanent alienation of land by sale.

15 See Holleman (1923) and Cooley (1962: 57-9). During the period covered by my own fieldwork I heard several reports from reliable authorities of serious inter-village feuding on Saparua and Haruku, involving the firing of groves, hand-to-hand combat and the use of firearms as well as long bows and spears. Casualties were reported as being high. 


\section{CHAPTER VI}

1 Principal watercourses in the vicinity of Ruhuwa:

\begin{tabular}{rr}
$\begin{array}{c}\text { Approx. } \\
\text { length }\end{array}$ & $\begin{array}{c}\text { Height } \\
\text { of source }\end{array}$ \\
\hline 500 & $100-150$ \\
900 & $100-150$ \\
1550 & $100-150$ \\
2750 & $150-200$ \\
1550 & $300-450$ \\
1450 & $200-300$ \\
225 & 50 \\
1100 & $200-250$ \\
850 & $150-200$ \\
800 & $100-200$ \\
675 & $100-125$
\end{tabular}

1. Makoihiru

2. Usa

3. Waka Kau

$100-150$

4. Mon

$150-200$

5. Lihuru

$200-300$

6. Awao

7. Namtukune

$200-250$

8. Samna'ukuna

$100-200$

10. Kamna'ukuna-Santapinuna

$100-125$

(All measurements in metres.)

2 Slope failure occurs even less under forest than on denuded slopes (Bik 1967: 39), and within the forest such movements are usually increased or initiated in many cases by treefall (Ruxton 1967: 92). In general, there was no great evidence for Ruhuwa of mass movements as an erosional hazard in cultivated areas, and what anti-erosion features exist, such as well-anchored cultigens, free-standing trees and unburned felled boles, appear to check soil creep on well-drained slopes.

3 Within the category sanene, certain areas are regarded as better than others, though at times the Nuaulu reasoning involved in demonstrating this involves a rather tortuous and cyclical logic. Thus, Soiile Sonawe maintained that the Awao-Lihuru area (MAP 9) provided the best horticultural land on account of the number of wasi that had been cut there, and that this was one of few extensive areas of topographically suitable terrain. Indeed, these two valley systems do supply the most extensive single area of sanene, over 40 per cent of that depicted in MAP 10. Even so, the land chosen often has an irregular surface, commonly of great dips and steep gullies.

4 High soil temperatures (around 20-30 degrees centigrade), which are typical of the region, however, tend to increase the speed of chemical reactions and organic metabolism, while high rainfall, such that precipitation exceeds evaporation, leads to almost continual leaching of soluble silicates and bases, except in those limited areas where water-logging prevents the process (Brookfield with Hart 1971: 38; Geertz 1963: 20). But in most soils under tropical forest high soil temperatures have the positive effect of counteracting leaching by transforming dead organic material before leaching can take place. See Appendix B.

5 Large and distinctive trees are also named and used as markers and reference points, on which account they must be left untampered with. Frequently, these are of the resinous conifer Agathis alba Foxw., which as well as being economically important can reach a girth of up to 70 metres (Van der Koppel 1926: 529).

6 It is said that at the time Ruhuwa was first settled all clans cultivated plots near the village, and this appears to be indicated by the present ownership of plots within 0.5 kilometres of the village (MAP 11 and FIGURE 7). FIGURE 7 also reflects, to some extent, the order of arrival of clans in terms of the degree to which they were able to minimize the distance between their gardens and the village: first Sonawe and finally Nepane.

7 Even those households with more than one clan present appear not to recognize ownership of more land than those consisting of a single clan, though it is possible that their area of choice in site-selection is that much greater. 
8 Although I am unable to demonstrate the fact from the data and possess no statements from informants to suggest it, it seems quite probable that it is these same isolated wasi received as gifts which form the most suitable reserve of land (in terms of minimizing material loss) to be channeled out of the clan when this becomes necessary.

9 These latter paths are of two recognized types: arena remnai, narrow paths with the grass on either side growing towards each other, and arena kanjie, wide paths with the grass on either side some distance apart.

10 There are impressive examples of large communities with complex cultures and patterns of settlement having been based on most elemental methods of transportation (see, for example, Dumond 1961). Nevertheless, efficient communication can in some cases increase dramatically the amount of land available for cultivation. This is demonstrably the case for the Kuikuro of the upper Xingu region of central Brazil (Carneiro 1960: 232), whose possession of the canoe and a suitable system of waterways permits access to some 13,350 hectares of cultivable land.

11 Analysis of this kind suggests the applicability of network models as an expression of connectivity of elements, settlement shapes, accessibility and intensity of exploitation. However, this would have required extensive discussion of the question of adaptation and interference of other variables, quite unwarranted by the terms of reference of this study (Haggett 1969: 609-68).

12 The term pheric distance appears to have been introduced into the literature by Andrzejewski (1954: 191). It has subsequently been used by some writers discussing swidden agriculture (Harris 1972: 249; Vayda 1969b (1961): 210).

13 The use of direct horizontal distance can lead to quite substantial inaccuracies. Although for short distances an examination of the Nuaulu data reveals a consistently high correlation between orthographic and direct horizontal measures, exceptional single instances illustrate the dangers inherent in relying too heavily on this more straightforward index.

14 For a discussion of the relativity of distance and its various implications as a continuous variable see Harvey (1969: 559-61).

15

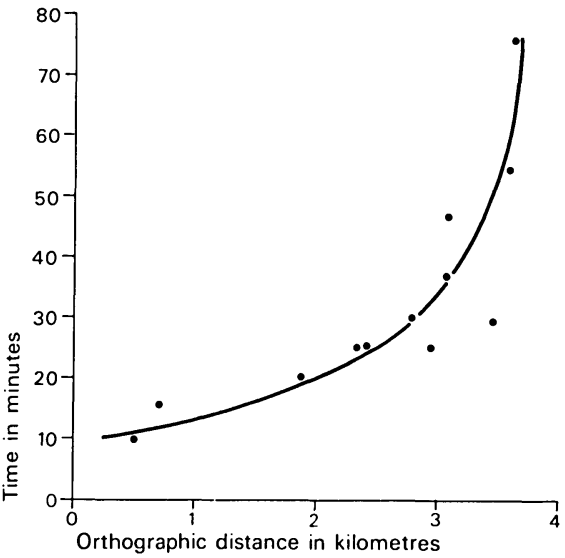

Linear distances as measured in the field can be corrected to their horizontal equivalents and horizontal distances converted to their linear equivalents by the formula $h=I \cos a$, where $h$ is the horizontal equivalent, $l$ is the linear distance and $a$ is the angle of slope.

16 The classic example of the support capability of a system of swidden agriculture is provided by the case of the lowland Maya (Dumond 1961). In terms of rotational systems the hilltop settlements typical of south Italy, Sicily and Sardinia provide an 
interesting case of the increase in tolerable distance in order to benefit from the advantages of nucleation (Chisholm 1968: 55).

17 It was more than once put to me by male informants that good land existed inland in the mountains but that difficulty of access for women made it impossible to utilize.

18 While many Nuaulu festivals are prepared many days (and even months) in advance, some ceremonial is held at improbably short notice. On one occasion an individual had to be recalled from the gardens in order to participate in the marriage ceremony of his younger sister.

19 See Brookfield (1969: 70). Chisholm has pointed out (1968: 167) that the relationship between soil and capacity and population density 'operates only through the costs of separation, which are too great to be tolerated'. He continues, however, to remark that it is evident that in fact any analysis of the distribution of population in subsistence-type economies is an exercise in location concerned with the effects of the cost of overcoming distance. While his emphasis on tolerable distance serves as a timely reminder to ethnographers as to its significance, to place sole emphasis on distance minimization is to equally neglect important cultural and environmental factors. The situation is rather more complex than he suggests.

20 This is both in terms of the horticultural and economic reasons mentioned, and also because the clustering of wasi - together with its corollary, the lessening of fragmentation - has advantages in terms of inheritance and the management of land tenure arrangements.

21 The saving can be expressed in terms of the function $s=2\left(d^{\prime}+d^{\prime \prime}\right) t-2\left(d^{\prime}+d^{\prime \prime} t\right)$, where $d^{\prime}$ is the distance between the nearest garden hut and the village, $d^{\prime \prime}$ is the distance from the hut to the focal wasi, and t represents the time period involved. In the case of W22, for example, the saving was calculated as being of over 50 kilometres for a 10 day period.

22 It is difficult to calculate precisely how much garden land each household requires and 'cultivates' each year. The average amount of land held by each household is 4.08 hectares. Since nisi ahue cannot, by any stretch of the imagination, be regarded as being under cultivation, and since its productivity is relatively low, it can be ignored for this purpose. This leaves some 3.13 hectares under cultivation. I would estimate that actual annual subsistence requirements would be served by about 1.80 hectares, that is by ignoring the area devoted to coconut and clove groves.

23 It frequently happens that if the garden hut itself is distant from a first-year garden some species normally found in first or second year gardens are planted in small patches directly adjacent to the hut. Species commonly planted in this way include tobacco, chillies, papayas, bananas and plantains. If located in an area with no easily accessible manioc, this will be planted also, though it is so widespread and grows so easily that this is seldom necessary.

24 The coastal Muslims emphasize the importance of fences, and their widespread use of them reinforces opinion. It is common for the traditionally coastal peoples to enclose not just one garden, but a series of adjacent ones, such as those belonging to persons related by kinship ties. In such cases of multiple enclosures fences are erected jointly and the participants recognize not only the value of the fencing, but the time saved and the other advantages of grouping gardens together in this way. This is alien to the horticultural repertoire of the Nuaulu. I might add that this practice results in practical difficulties for the fieldworker in calculating garden areas.

25 For example, among the Waina-Sowanda peoples of the upper Sepik in New Guinea (Alfred Gell, personal communication).

26 The Nuaulu regard the weeding of gardens as an unnecessary burden, although the undergrowth of groves, containing coconut and sago palms and fruit trees, is periodically cut back. Further, where seedlings of these stands occur in nisi honwe or young nisi monai they are carefully weeded around. Apart from this very little weeding is 
undertaken in the gardens, as opposed to keeping the village area and principal paths cleared.

27 Some attention is paid to the requirements of individual species. Cloves are only planted in shaded areas of gardens. Shallots and garlic are commonly grown in small artificial banks of earth retained on the downhill side by log debris from firing.

28 As well as containing food plants, gardens frequently contain useful non-edible species, such as tobacco and areca palms. Some of these might easily be mistaken for intrusive weeds, for example okar (?Homalomena sp.) and sina (Laportea decumana Wedd.) used medicinally on account of their irritant qualities.

\section{CHAPTER VII}

1 Had percentage area of each plant type been the index used to estimate the relative proportions of each species the picture would have undoubtedly been somewhat different. However, this method would have proved a poor indicator of the actual biomass involved for several reasons. There is a tendency for different species to occupy different amounts of land, irrespective of their relative masses. Some species grow in a more concentrated fashion than others. Futhermore, it is almost impossible to compute the percentage area devoted to each plant type in gardens where both the species diversity index is very high and plants are rarely separated into single species patches. Although there are undoubtedly some problems involved in the method adopted whereby individual plants are counted (such as the status of clones), it does allow for subsequent computation of approximate yields, given the average weight of the edible part of each plant.

2 Very occasionally nisi honwe, as well as nisi monai, may be purposely devoted entirely to manioc, as was observed for some Hahuwalan gardens on the river Upa. In such cases it was stated that such land, though advantageous in being immediately adjacent to a garden hut and the river, was generally of poor quality, stony and suitable for little else.

3 In harvesting taros a single tuber may be replanted in the same spot, allowing for two crops (the second being invariably much inferior) in a single horticultural season.

4 W142 (apart from that consumed at the seute) yielded 94.35 kilograms of weni, stored in 8.5 baskets (each of approximately 39 tubers) and apportioned as follows: 3 kept for planting, 1.5 gifts for kinsmen and affines, 4 consumed within the household. This was considered a below average yield, blamed on unusually high temperatures, but the pattern of distribution was apparently unaffected. The degree to which dry conditions and high temperatures can really be considered as significant factors in affecting yields is difficult to decide. Normally, the yam is considered as having a high temperature tolerance, but the amount of rainfall and length of the rainy season are important. However, it is equally likely that the practice of intercropping and the absence of sophisticated horticultural techniques are responsible for some of the variation in yields (Coursey 1967: 70-2, 92-7).

5 The list excludes relishes such as chillis and limes and garden snacks such as sugar-cane and young coconut (appendix D). Furthermore no attempt has been made to distinguish between recognized varieties of a single taxon, the criteria of distinction of which may often involve relative yield, shape, size and number of tubers from a single plant. It may be that such variation is quite significant. For example, the average weight for tubers from the two terminal yam taxa weni ai'arine and w. tumata are 18.500 and 560 grams respectively, a difference of 17,940 grams. However, since yams constitute such a relatively small proportion of the total weight of tubers consumed a consistent preference pattern proved difficult to establish (c.f. Lea 1964: 101-7).

6 The average daily intake, irrespective of age, in those households for which consumption was measured comes to 2,314 Cals., compared with the 3,085 Cals., estimated daily adult intake (Appendix D). Both these values are high when compared 
with the figures for some recent nutritional studies of similarly organized communities in New Guinea (c.f. Waddell 1972: 127):
1. Chimbu
Venkatchalam: 1962
1,930
2. Tsembaga
Rappaport 1968: 283
2,015
3. Pari
* 4. Bomagai-Angoiang
Hipsley and Kirk 1965
$2,360 \pm 185$
* 5. Siane
Clarke 1971: 178
2,650
6. Raiapu-Enga
Salisbury 1962: 80-81
2,927
Waddell 1972: 125
2,390

* adult males only

Earlier work, such as that undertaken by Hipsley and Clements (1947), appears to have rather underestimated the actual per capita consumption (Rappaport 1968: 283-4).

7 This would place the Nuaulu between type 1 and type 2 of Watters' classification of swidden agriculturalists (1960: 63); that is, they are almost equally dependent on hunter/gathering and gardening. But to talk of 'dependence' in this way might be misleading, since what evidence I have been able to provide suggests that it would not be impossible for the Nuaulu to subsist entirely on non-domesticated resources.

8 In the case of a durian sasi the owners of each tree must, when the sasi has been lifted, present the village headman with twenty of the fruits, who in turn distributes two of them to each clan chief, the remaining ten being presented to the Lord of the Land. If the crop is a poor one then only five fruits need be given, one for each clan chief. This kind of redistribution is seen as a symbolic statement of the interdependence of the villagers as producers and consumers.

9 It is common at this stage to intercrop small numbers of other kinds of fruit tree, such as pala (Myristica fragrans L., nutmeg), tahene (Artocarpus champeden Spreng.), iane (Canarium commune L.), nasate (Lansium domesticum Jack.), tunene (Durio zibethinus L.; durian) and kanai (Areca catechu L.; areca-palm).

10 The evidence for this lies partly in Nuaulu assurances that some of the inland sago areas were originally planted by their mountain ancestors, and partly (and more convincingly) in the current practice of highlanders in the interior of west Seram. Here coconut and clove cash-cropping has, as yet, failed to establish itself as a viable source of income.

11 Details of yields of individual palms in different localities are not dealt with here. In the field I was obliged to pay considerable attention to the whole question of the economics of sago-exploitation and intend to fully examine the data in a future research report.

12 Forty-three local terminal taxa were recorded in the field as being persistent weeds and classified as such. However, little importance should be attached to this precise figure. Of those recorded, only eleven were habitually prefixed by mono (from monote: 'weed'). This illustrates the divergence between a taxon grouped together by common lexical indicators and the actual number of members of a taxon. The term monote is used by the Nuaulu specifically to refer to spontaneously-occurring plants of no practical utility found in nisi honwe, nisi monai and nisi ahue of the first phase of vegetative regeneration. For a list of these taxa see Ellen (1973: 391-2).

13 Coastal Muslims appear to have a much more clearly defined fallowing policy, geared to a much more intensive form of horticulture. Unless land is selected for coconut or sago groves it is generally cultivated for two or three years and left fallow for five, that is, usually until the garden is exhausted. Partial reclearance during the three year period and cultivation of small plots within coconut groves is also a feature here, where pressure on land is that much greater.

14 Trees left standing within the garden area as a result of inçomplete clearance also serve this purpose, and to more effect. Some plants and bushes, in particular sakaputi (Malaleuca leucadendron L.), possess such a degree of fire resistance (Burkill 1935: 1433) that complete eradication is impossible under normal circumstances. 
15 Given $\mathrm{P}$ and $\mathrm{T}$ it is possible to calculate the following three indices of population density:

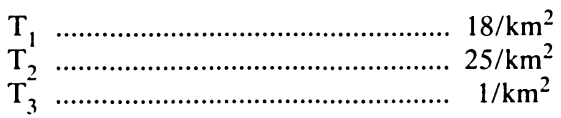

In comparative southeast Asian terms all three indices are low. $T_{1}$, the most easily and commonly computed index, is somewhat lower than the figure given by Conklin (1957) for the Hanunoo $\left(30 / \mathrm{km}^{2}\right)$ and that given by Rappaport (1968) for the Tsembaga $\left(42.43 / \mathrm{km}^{2}\right)$. Here again it appears that the Nuaulu figure may be seen as a concomitant of relatively low horticultural productivity and reliance on non-domesticated resources. $T_{3}$ is exceptionally low, although Izikowitz (1951) records a population/ total area index for the Lamet of 2.9. The Nuaulu figure, however, does tend to reflect the overall situation on Seram (TABLE 1).

\section{CHAPTER VIII}

1 The terms interpretative and cognitive as applied to environmental models are adapted from Rappaport's usage (1963: 159, 1967: 22, 1968: 237). These particular terms have - I think - advantages over operational and cognized, used to draw the same distinction (see Bates 1960: 554; Rappaport 1963: 159). Brookfield's use of the term perceived environment (1969) is synonymous with my use of the term cognitive environment.

2 The importance of studying systems of environmental classification in general has been recognized for a long time. See, for instance, Conklin's re-assessment of the 1911 Beyer-Merrill report on Ifugao ethnobotany (1967: 207) and De Schlippe (1956: xvi). The literature on folk-taxonomies is large and expanding rapidly in all directions (Conklin 1972), but two sources usefully consulted on some of the main problems and topics are Conklin (1962: 119-41) and Sturtevant (1964).

3 See Conklin (1968) for an extensive discussion of land-form classification in relation to the Ifugao system of wet-rice cultivation.

4 After most of this book had been completed I read the short but interesting essay by Audrey Butt (1970) on settlement patterns among forest peoples of the Guianas. Here, not only is the form of the settlement pattern the principal subject under investigation, but the analysis consciously attempts to incorporate all relevant factors, both environmental and from a variety of different kinds of social activity. It is significant that such an integrative approach was adopted in a symposium mainly concerned with population biology and environmental aspects of human ecology in the tropics.

5 It could be argued that this kind of categorization of rules is somewhat artificial, since it is in danger of bringing together what is perceived as separate and separating what is perceived as together. With respect to the purpose of this analysis, the simple distinction of three classes seemed appropriate. Erik Cohen (1973: 6-9), however, has attempted a more detailed classification of 'orientations' to the perceived environment. Some of the problems these procedures raise are dealt with below.

6 Further discussion in support of this statement is to be found in Brookfield (1962; 1964a), Brown (1962) and Mason (1962).

7 I think it is important to exercise some caution with respect to the adoption of certain geographical techniques, since there is a danger that the mechanics involved in establishing a particular index are not worth the effort of their computation. In terms of the present analysis, for example, the value of calculating to a high degree of accuracy the central point of settlement, as refelected in the minimum point of aggregate travel, is rather dubious (see above p. 28 Hart 1954 and Brookfield 1968). The index in itself is rather meaningless. Its significance lies rather in isolating the various pressures which 
result in the deviation of the central point from the nuclear cluster of dwellings. It is this balance which I have tried to achieve. There is little merit in using techniques merely because they are fashionable, or to simply increase the sum total of information on man-environment relations. Utility should be assessed with respect to calculated analytical productivity.

8 Brookfield has recently noted (1969: 70) that in his earlier fieldwork among the Chimbu of the New Guinea highlands (Brookfield and Brown 1963) he failed to realize that land evaluation depends on the proximity of site and political conditions as much as it does on terrain characteristics. Had his approach been within a more comprehensive generative framework it is arguable that these significant factors would not have been neglected in the way they were.

9 'If we excluded physical nature and the difficulties and imperatives it imposes, functional accounts which merely related purely social features to each other would get rather close to logical vacuousness' (Gellner 1963: 239; see also 248-51). This view should be seen in relation to the counter argument of writers such as Devons and Gluckman (Gluckman 1964: 17).

10 Generative models '.. are not designed to be homologous with observed social regularities; instead they are designed so that they, by specified operations, can generate such regularities or forms. They should be constituted of a limited number of clearly abstracted parts, the magnitude or constellation of which can be varied, so that one model can be made to produce a number of different forms. Thus by a series of logical operations, forms can be generated; these forms may be compared to empirical forms of social systems, and where there is correspondence in formal features between the two, the empirical form may then be characterized as a particular constellation of the variables of the model' (Barth 1966: v).

APPENDIX D

1 The unit 'man-day' refers to the normal waking day - about 14 hours. Thus, if gardening occupied 5 hours one day and 9 the next, this would be considered a total contribution of one man-day. 


\section{INDEX}

Accessibility, more than geographical proximity, 28

ADMIRALTY, 244

Adoption and incorporation, 49

Agathis, 5, 68, 251;

resin of, 50, 67, 75, 85

Alifuru, 10, 11, 12, 22, 23, 81, 121, $243,244,245$

ALLAN, W., 181

ALTSCHULER, M., 193

Amahai, 11, 12, 19, 20, 44, 212, 213, 214,247

Ambon, 5, 21, 105, 245, 246

Ambonese, 10, 23, 51, 57, 171, 247

ANDERSON, E. N., 191

ANDRZEJEWSKI, S., 252

Animals:

collection of miscellaneous foods,

68-69, 71;

domestication of, 17,46 ;

as game, 17, 66, 69;

local categories for, 77 ;

non-food products of, 72 ;

as protein, $69,70,80$

Augury, 25

Bamboo, 75-76, 117

Bananas and plantains, 17, 44, 153, 164, $166,167,171,172,223,225,253$

BARRAU, J., 68, 171, 249

BARTH, F., 2, 18, 77, 105, 194, 195, 203, 204, 205, 207, 211, 243, 257

BASTIAN, A., 4

BATES, M., 256

BIEBUYCK, D., 93, 107

BIK, M. J., 251

BOHANNAN, P., 103

Bomagai-Angoiang, 255

BOSERUP, E., 68

BOUMAN, J. C., 245

BOXER, C. R., 4

Bride service, 50

Bridewealth, 51-52, 53, 247

See also Marriage, transactions surrounding

BROOKFIELD, H. C., 2, 5, 28, 93 , $107,136,175,181,187,192,194$,

$200,206,209,214,251,253,256,257$

BROWN, P., 181, 194, 256, 257

BRUNSDEN, D., 215

BUCKLEY, W., 2

BURKILL, I. H., 178, 255

BURLING, R., 193

BUTT, A., 256

Buttressing in trees, 250

Canarium nuts, $17,66,68,72,73$, $96,175,225,249,255$

CARNEIRO, R. L., 181, 182, 183, 252

Carrying-capacity, 180-184

Cash, use of, 104, 179; cash crops and cash cropping, 95, 103, $104,107,183-184,255$

See also Coconut and Clove

Cassowary, 17, 38, 66, 69, 225

Cemeteries, 111, 118, 119-120, 196

Central points (and central place theory), 28, 208, 256

CHATFIELD, C., 224

Chimbu, 255, 257

CHISHOLM, M., 136, 139, 141, 209, 253

CHOMSKY, N., 193

Christian settlements, 12, 17, 18, 22, $44,81,249$

Clans:

distribution prior to resettlement, 11,14 ;

dual divisions, 14, 15, 16, 57;

headman, 14, 15, 56, 230, 250;

kapitane, 14, 230, 250;

present distribution of by village,

13,14 ;

ritual houses, 14-16, 37, 46, 47,

$56,231,246,250$;

segmentation, 15-17, 94;

structure, 11, 13-17, 22, 49, 51, 100

CLARKE, W. C., 184, 187, 209, 255 
Classification:

of ethnic groups, 10 ;

folk (local), 190-193, 198, 206,

207, 208, 256;

of Nuaulu, 22-23, 191

See also Animals, Soil, Topography and Vegetation

CLEMENTS, F. W., 255

Climate (including cloud cover, relative humidity and temperature), 212-214, 254;

and plant growth, 214

See also Rainfall

Cloves:

groves and cultivation of, 38,91 , $103,110,165,170,171,172,173$, 175-177, 231, 250, 254, 255;

trade in, 4

COBLEY, L. S., 177

Coconut, groves and cultivation of, $38,59,91,100,103,114,165,167$, $168,170,171,172,173,174-175$, $223,225,228,231,250,253,254,255$

COHEN, E., 196, 199, 256

COHEN, P., 1, 199

Concentrism, as a form of classification, 23,40

CONKLIN, H. C., 2, 5, 25, 45, 65, 84, $117,150,158,180,191,194,203$, $207,217,243,244,248,255,256$

Consumption, measurement of, 222-225, 248, 249, 254

Conversion to Christianity and Islam, $12,21,22,243,247$

COOLEY, F. L., 4, 23, 41, 51, 171, 247,250

Correlative analysis, 211

COURSEY, D. G., 111, 164, 165, 254

CROCKER, J. C., 42

Cultivated land:

alienation of, 52, 100-104, 124, 126,250 ;

changes in social relations of,

94-95, 249-250;

collection of data on, 220-221;

as commodity, 98, 102, 103, 104;

disputes concerning, 104-106, 250;

distance from settlement, 124; distribution according to clan, 123, 125;

distribution according to household, 126; and exchange relations, 97-98; exchange of and vegetative cover, 98 ;

flexibility in relations regarding,

93, 104, 106-107, 187;

fragmentation of, 102, 124, 253;

gifts of, 97, 100, 250;

history of land ownership, 81-83;

individualistic ideology and,

92, 104, 187;

inheritance of, 97, 98-100, 253;

mode of acquisition, 97, 98, 100-101;

movement between clans,

$127,128,250$;

obtaining rights of access to, 84, 92-97;

sale of, 97, 102-104, 250;

sources and social organization,

81-107, 249-250;

transfer of as means of compensatory

adjustment, 123-130

shortage of, 105, 171, 243;

See also Gardens and Wasi

Cultivation:

environmental limitations on,

108-118;

labour arrangements for, 154-156;

procedures in, 149-154, 210 ;

ritual limitations on, 118-120;

role of children in, 156;

sexual division of labour and,

155-156;

social limitations on, 118-123;

tenurial limitations on, 121-130;

See also Gardens

CUNNINGHAM, C. E., 39

Cuscus (Phalanger), 17, 69, 70, 77,225

Dancing ground, 37

Dati system, 105

DAVID, N., 56

Decision-making, indigenous, 2, 22, 158-159, 188-193, 195-207, 208,

209, 210;

and different phases of future action, 203

Deer, 17, 38, 69, 77, 225, 248

DEMANGEON, A., 194

Distance:

considered in ethnographic analysis, 208-209, 252, 253;

and cost-benefit analysis, 209, 253;

time and, 133-135, 253;

travelled by Nuaulu from Ruhuwa, 
19-21;

tolerable, 133, 253;

types of measurement, 133-135, 252

Divorce, 57

DOBBY, E. H. G., 5, 214, 219

Domestic groups:

developmental cycle of, 188, 194, 201, 243;

disputes in, 57

Domestic mode of production, 92

Domesticated environment: calorific and protein contribution of, 168 ;

compared with non-domesticated environment, $65,78,169,197$, 200, 248;

contribution of plant resources, 167; effort involved in appropriation of resources, 168-169;

input-output relations, 166-169, 200;

in time and space, 184-189

See also Non-domesticated

environment

DOUGLAS, M., 191, 246

Drainage, 110

Dualism, as a form of classification, $23,40,41$

DUDAL, R., 114

DUMOND, D. E., 252

DURNIN, J. V. G. A., 78, 79, 168, 227

Dutch colonial government, influence in resettlement, 32-33, 243

DUYVENDAK, J. P., 4, 10, 23

DYEN, I., 11

Earthquakes, 244

Ecological succession, 161-166, 171-172, 177-178, 187-189, 203

Ecosystem, concept of, 1, 2, 61

ELLEN, R. F., 17, 36, 45, 66, 67, 68, 71, $72,85,86,88,100,101,102,103$, $105,154,165,187,193,224,244$, 248, 249, 255

Energy expenditure, computation of, 79, 226-228

Environment:

as interpreted, 2, 190-193, 256;

direct and indirect factors, 202;

as perceived (classified, cognized), 2, 22-26, 190-193, 198, 256; understanding of by anthropologists, 207-208
Erosion, 212

ESSER, S.J., 11

Ethno-ecological (cognitive) categories and approach, 2, 188, 191, 207, 208, 210

Ethnoscience, 190-193

Exploitative environment: ecological variation, 64 ; of Ruhuwa, 20, 26, 61, 64-65, 77,215

Fallow and soil conversation, 110, 171, $178-180,182,186,218-219,255$

Fencing, 43-44, 91, 148-149, 169, 232, 233, 253

FERGUSON, J. H. A., 212

FERRO-LUZZI, A., 78, 79, 168, 227

Firewood, 75

FIRTH, R., 203

FISHER, C. A., 212

Fish and fishing, 68, 71, 77, 80, 225, 228,248

Flooding, 43, 110, 212

Forest:

clearance, 87-89, 249; depleted, 76, 85, 91, 249;

distribution, structure and composition of, 67-68; mature, 65-67, 81-83, 87, 229,

244, 249;

montane, 67;

non-edible products of, $69,75-76$; problem of defining 'primary' forest, 83-84;

rain forest, 5, 67, 83, 219;

secondary, 5, 96

See also Secondary growth

FORTES, M., 194, 243

FOSBERG, F. R., 5, 85

FRAKE, C. O., 2, 27, 190, 194, 197, 199, 205, 209, 250

FRASER, D., 58, 60

FREEMAN, J. D., 5, 84, 85, 145, 150

FRIED, M., 95

Frobenius expedition, 4

Fruit trees and their ownership, 45, $96-97,164,165,166,167,171,173$, $175,248,250,253,255$

Functionalism, 195 
Gardens: abandonment and regeneration of cleared sites, 156-157, 172, 182; affects of first year crop pattern, 161-165;

boundaries, 91, 231, 250; characteristics of new garden, 161-165, 253, 254; cleared each year by one household, 108-109;

clustering, 141, 145, 253; and communications, 131-133; composition, 161-166; concept of nisi, 89-92, 231; crop inventory, 161, 163; development of, 161-189; differentiated and undifferentiated old gardens (nisi monai), 100, 171-177, 186, 231, 253, 254;

distance between, 140-141, 197;

distribution related to altitude, 139-140;

drying, 152;

and ecological succession, 161-189, 203;

economic factors in selection of sites, 130-149;

firing, 87, 152-153, 214, 254;

diversity index, 254;

garden complex, 141-147, 203;

harvesting, 165-166, 254;

huts, 69, 86, 140, 141-144, 201, 231, 253;

integration of factors affecting

distribution, 157-160;

intercropping, 154, 165, 166, 254, 255;

planting, 87, 153-154;

preparation, 108-160;

productivity, 182, 254;

proportion cut from mature forest,

83-86, 99;

protection, 148-149;

relation to household, 27, 136-139,

204;

rituals associated with, $88,157,165$,

169-171;

ritual delays on harvesting, 169-171;

selection of sites, $87,108-160$, 158, 201;

shape and size, 147-148, 185;

technology associated with, 88 ;

types of defined and compared, 24,
184-188;

village-owned, 95 ;

weeding, 153, 169, 180, 253, 254

See also Cultivated land, Groves and silviculture and Wasi

GARNIER, B. J., 5

GEERTZ, C., 1, 5, 153, 186, 247, 251

GELL, A., 253

GELLNER, E., 194, 211, 257

Generative (and processual) analysis, models and processes, 1, 2, 108,190, 192, 194-207, 208, 210-211, 243, 257;

diagrammatic representation of processes, 206;

viewed as the interaction of rules, 195-207, 257

Geography, economic, 26; and the analysis of settlement, 207-210;

and anthropology, 207-210

GERMERAAD, J. H., 215, 217

GLUCKMAN, M., 257

GODELIER, M., 103, 104, 193, 202

GOODENOUGH, W. H., 2, 129, 250

GOODEY, B., 209

GOODY, J., 194

GOUROU, P., 153

Grasslands, succession to, 5, 9, 110

See also Imperata

GREENLAND, D. J., 217

Groups, relation between formal and local, 28,94

GROVES, M., 208

Groves and silviculture, 171-177, 203, 218, 250

See also Clove, Coconut, Gardens and Sago

HAGGETT, F., 28, 251

Hanunoo, 5, 84, 256

HARRIS, D., 1, 186, 195, 243, 252

HARRIS, M., 191, 193

HART, D., 5, 175, 187, 192, 206, 209, $214,251,256$

HARTSHORNE, R., 207

Haruku, 5, 105, 246, 250

HARVEY, D., 252

Head-hunting, 30, 120, 233

HIPSLEY, E. H., 79, 227, 228, 255

HOLLEMAN, F. D., 250 
Horticultural cycle, stages of, 150-154, 184, 188, 201, 203

See also Cultivation

Houses:

building materials, 76 ;

structure and symbolism of, 38-39, $43,44,65,246$

Household, 16, 38, 46-49, 56, 231; composition of, 47-48;

property of, 47 ;

relation to garden, $27,136-139$

Hunting, 68, 69, 78, 80, 228

HUWAE, O., 213

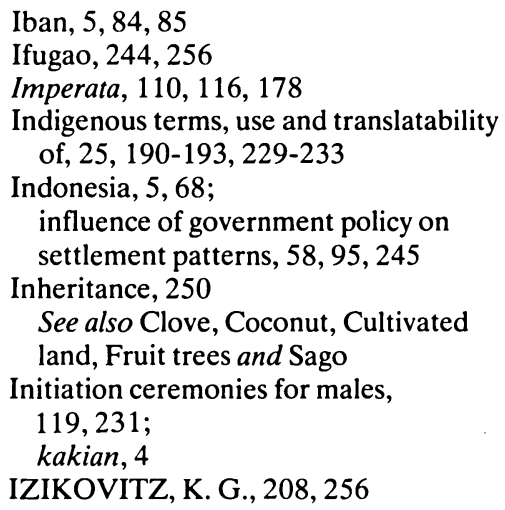

JAMES, A. G., 248

JENSEN, A. E., 4

JOSSELIN DE JONG, P. E. DE, 181, 182,183

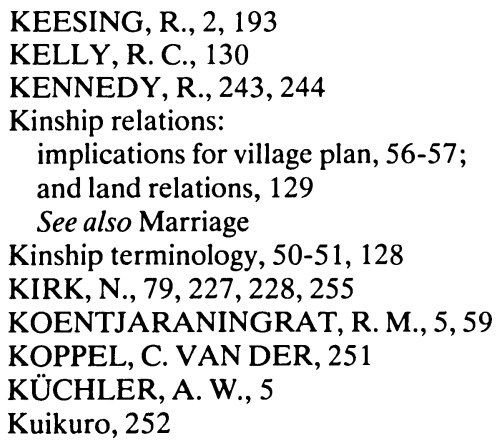

\author{
Lamet, 256 \\ LANGLEY, D., 223 \\ LANGTON, J., 1, 2, 202 \\ LEA, D. A. M., 75, 181, 208, 209, \\ $210,243,249,254$ \\ LEACH, E. R., 194, 195, 198, 209, 243 \\ LÉVI-STRAUSS, C., 40, 42, 194, \\ 247,248 \\ Limiting factors, 197-198 \\ Linguistic analogies, 2, 200, 204 \\ Locational analysis, 208, 253 \\ 'Lord of the Land', 15, 31, 32, 69, 86-87, \\ $106,118,120,170,230,255$ \\ LOURIE, J. A., 226, 227
}

Magic, 66; manipulation of environment with, 25

MALCOLM, S. M., 75

MALINOWSKI, B., 247

Manioc, 17, 45, 116, 153, 154, 161, $163,164,165,166,167,172$, 249, 253, 254

Manusela, 4, 11, 245

Mapping, 207-208, 220-221, 248

Marriage, 47, 100-101, 127, 129, 253; with bilateral cross-cousins, 16-17, 50-51, 54, 100, 128; circulating connubium, 54 ; monogamous, 49; with outsiders, 21; polygamous, 245; and residence pattern, 49-55, 56, 57; transactions surrounding, 53, 54, 230, 231, 232;

types of, 51-53, 230, 232, 247, 250

MARTIN, K., 4

MASON, L., 256

Massenerhebung affect, 67

Maya, 252

MAYBURY-LEWIS, D., 193

Measurement, Nuaulu units of, 134

MEGGITT, M.J., 129

Menstruation huts, 39, 119, 137, 156, 230, 247

MERRILL, E. D., 5, 85, 117, 178

Middens, 39

MILLAR, J. G., 202

Mindanao, 27

Mindoro, 84

Minerals, Nuaulu classification of, 215-216 
Models, cognitive and interpretative, 195, 207, 209, 256; of interrelated processes, 199

Moluccas, central, 5

Monsoon winds, 111

MOORMAN, F. R., 114

Muslim settlements, 12, 17, 18, 22, 31, $44,59,77,78,81,91,97,103,105$, $114,120,122,146,147,148,164$, $170,245,249,250,253,255$

Myth, 4, 66, 153

\section{NAVAL STAFF INTELLIGENCE DEPARTMENT, 12}

Network models, 208, 252

New Guinea, 68, 84, 156, 178, 253 , 255,257

NIGGEMEYER, H., 4

Non-domesticated environment, 61-80, 197; appropriation for food, 68-75; appropriation inverse to distance from settlement, 72;

calorific and protein contribution of, 77 ;

contribution of plant matter, 72,73 ; differential appropriation by locality, 63-64, 78-80; effort expended in appropriation, 77-79;

input-output aspects of, 76-80, 200; productivity, 79 ;

significance of, 68, 80, 183, 255

See also Domesticated environment

NORGAN, N. G., 78, 79, 168, 227

Nuaulu:

defined, 1, 11;

external relationships of, 18-22;

language, 229-233;

outline of social organization, 11-17; outline of subsistence, 17

Nusalaut, 5, 105, 246

Nutritional surveys, 79, 222, 223, 226

NYE, P. H., 217

ONVLEE, L., 196

OOMEN, H. A. P. C., 75

ORENSTEIN, M., 194

OSSENBRUGGEN, F. D. E. VAN, 36
Pari, 254

PASSMORE, R., 227

Patakai, 11, 21, 22, 243

Patasiwa and patalima, 4, 22-23, 232; political significance of, 30

Pathways, 66-67, 131-133, 136, 154, 212, 229, 245, 252

Pela alliances, 19, 21, 232

PELZER, K. J., 98

Pig, 38, 69, 77, 225

PIKE, K. L., 229

PLATT, B. S., 224

Population:

of Christian and Muslim

settlements, 9;

density, 5, 7, 31, 169, 253, 256;

depopulation of highlands, 10 ;

ecological, 26;

increase, $31,45,59,84,183,249$;

Nuaulu villages, 12;

Seram, 9-10, 243;

sex and age structure, 223-224

Processual models and analysis, see Generative analysis

Property, fallacy of unitary concept of, 103-104

Quantitative data, use of, 208-210

Raiapu-Enga, 255

Rainfall, 87, 131-132, 212-214, 251,254 ;

in relation to garden activity, 132

RAPPAPORT, R., 1, 26, 84, 150, 170, $173,180,181,191,209,217,223$, $224,248,255,256$

Rationality, intentional and unintentional, 195

Rattan, 75, 85

Republik Maluku Selatan, 33, 245

Re-settlement, 11, 17, 29-33, 81, 94, 244,249

Residence patterns, 47, 56; changes in, 55;

and marriage, 49-55;

uxorilocal, 52-53, 129

RICHARDS, P. W., 67, 83, 85, 177, 250

ROBBINS, R. G., 68

RÖDER, J., 4

Ruhuwa, origin of, 32, 245

RUXTON, B. P., 251 
SACHSE, F. J. P., 11, 30

Sacred land, 118-120

Sacred plants, 37, 41

Sacred natural objects, 120

Sago palms (Metroxylon):

cultivated, $45,114,165,167,168$, $170,171,172,173-174,175,200$, 228, 231, 249, 253, 255;

distribution and appropriation of naturally propagated palms, $9-10,68$, $69,72-75,77,80,96,168,200,228$, 249,255 ;

extraction of flour, 75 ;

flour, 50, 222, 225;

non-food uses, 76, 229

SAHLINS, M. D., 155

SALISBURY, R. F., 103, 254

Saparua, 5, 105, 246, 250

Sarawak Dyak, 84

Sasi, ritual prohibitions on appropriation, 69, 87, 118, 169-171, $196,232,248,255$

SCHLIPPE, P. DE, 256

SCHMIDT, P. H., 212

Secondary growth, $83,88,117$, 177-178, 202, 229, 231; clearing, 150

Sepa:

Muslim settlement of, 11, 12, 18, 20, $30,32,59,74,78,103,120,121,122$, $146,148,155,170,244,245$, 249, 250;

Nuaulu relations with, $19,21,31,32$, $77,105,122,245$; raja of, 13, 32, 131, 244

Seram:

climate, 5, 212-214;

distribution of settlement and traditional ethnic groupings, 8-9; environment and population, 5-11; ethnographic study of, 4;

fauna, 5 ; geology, 215-217;

languages, 10-11;

north, 11, 22, 67, 212, 214;

topography, 9 ;

vegetation, 5

SERAN, 12, 59, 111, 214, 243, 249

Settlement, parameters of, 61-64

Settlement pattern:

defined, 26;

differentiation of factors affecting, 195-200; geographical techniques in the analysis of, 207-210, 256;

integrating the generative elements of, 200-207;

morphology of, 65 ;

summary of generative factors involved, 195-207;

as unit of analysis, 194-195

Siane, 255

Soa, administrative unit of, 12-13,33, 60

Soil:

condition, 110, 114-115, 180, 215-219, 250, 251, 253;

erosion, $43,111,245,251$;

leaching, 214, 218, 251;

moisture, 110, 214;

Nuaulu classification of, 114-116, 169, 215;

preparation, 169

Sorcery accusations, 57

SORENSON, E. R., 187, 194

SPENCER, J. E., 83, 169, 249

Spirits, 25, 39, 65, 157, 165, 233

STANNER, W. E. H., 41

STAUDER, J., 25, 144

STEENIS, C. G. VAN, 67

STRESEMANN, E., 10, 229, 243

Structuralism, Dutch, 247

STURTEVANT, W. C., 256

Subanan, 27

Subclans, 15,16

See also Clans

Sumba, 196

Surface conditions, limiting, 110-111

Sweet potato, 116, 153, 164, 165, 166, 167,225

Swidden cultivation, $68,83,117,136$, $168,186,187,197,203,243,249$, 250, 252, 255;

and indigenous terminologies, 25 ;

in Indonesia, 5;

in Melanesia, 150;

in Southeast Asia, 5, 150, 217

Synchrony, relation to diachrony, 202

Systems:

approach, 1, 202, 209;

duality of, 1 ;

relation of physical to social, 194 , 210-211, 257 
Taboo signs, 25,118

Taro, 110, 116, 153, 163, 164, 166, 167, 244,254

TAUERN, O. D., 4, 13, 15

TER HAAR, B., 15, 247

TICHELMAN, G. L., 11, 12, 95, 243, 245

Time:

and the expenditure of energy,

227-228;

and motion studies, 227-228;

Nuaulu units of, 134, 198

Topography:

exposed, 110 ;

limiting, 110, 114;

Nuaulu classification of, 114-115, 140, 206, 244, 256;

of Seram, 9

Trade objects, 21-22, 74, 97

Transportation and size of nucleated settlements, 252

Trapping, 71, 80, 228

Trobriand Islands, 247

Tsembaga Maring, 84, 255, 256

Valuables, 22, 38-39, 46, 250

VAVILOV, N. I., 5

VAYDA, A. P., 1, 3, 209, 249, 252

Vegetables, 68, 72-73, 163, 164, 165, $166,167,243-244$

Vegetation:

limiting, 110, 116-117;

Nuaulu classification of, 23-25, 66, 89, $176,188,206,248,254,255,256$

VENKATCHALAM, P. S., 255

Villages:

developmental cycle of, 42 ,

58-59, 247;

distribution and location, 11,18 ,

31-33, 244, 245;

environmental determinants of

location, 33-34;

environmental factors and layout,

43-45;

as a fixed point and given, 60 ;

genealogical organization, 45-57;

headmen, 13, 255;

historical origins of distribution, 30-31; ideological (symbolic) factors in structure of, 36-43, 196, 244, 245 , 247, 248;

integration of factors affecting plan, 59-60;

location and structure, 27-60, 197;

names, 12 ;

non-kinship organizational factors

and, 57-58;

prior to resettlement, 29-30;

ritual house (suane), 14, 36-37, 42, 65, 120, 233, 246, 247;

symbolism of village plan

summarized, 40-41;

warfare between, 105;

washing ceremony, 41

VOLKER, T., 171

WADDELL, E., 209, 255

Waina-Sowanda, 253

WARBURG, O., 244

WARD, B., 23

Wasi:

concept of described, 89-92, 92-93, 95, 233;

contrasted with non-owned forest, 65 ; polysemous character defined, 23-24

See also Cultivated land and Gardens

Water conduits, 36, 232, 245

Watercourses, 61, 110, 251

WATSON, J. G., 244

WATTERS, R. F., 255

Weeds and weed growth, 157, 163, 177-178, 179, 180, 197, 231, 255

WEINER, J. S., 226, 227

Wemale, 4, 243

WEULE, K., 192

WIKKRAMATILEKE, R., 197, 207, 220

Work groups, 87

Work patterns, $61,63,64$

WOUDEN, F. A. E. VAN, 40

Xanthosoma, 153, 225

Yams, 110, 111, 116, 153, 163, 164, $165,166,167,225,244,254$ 